\title{
Magia e Superstição no Mediterrâneo Antigo
}

Maria do Céu Fialho, Maria Regina Candido, Nuno Simões Rodrigues (Coords.) 


\section{HVMANITAS SVPPLEMENTVM • ESTUDOS MONOGRÁFICOS}

ISSN: $2182-8814$

Apresentação: esta série destina-se a publicar estudos de fundo sobre um leque variado de temas e perspetivas de abordagem (literatura, cultura, história antiga, arqueologia, história da arte, filosofia, língua e linguística), mantendo embora como denominador comum os Estudos Clássicos e sua projeção na Idade Média, Renascimento e receção na atualidade.

Breve nota curricular sobre a Coordenação do volume

Maria do Céu Fialho é Professora Catedrática da Universidade de Coimbra tendo como Áreas de Investigação os seguintes temas: Estudos Literários-Línguas e Literaturas Clássicas; Línguas e Literaturas Clássicas e sua Receção; Poéticas; Filosofia Antiga. Foi Coordenadora Científica do Centro de Estudos Clássicos e Humanísticos (2000-2013). Foi Diretora do Curso de Doutoramento em Estudos Clássicos-Poética e Hermenêutica.

Maria Regina Candido é Professora Associada da Universidade do Estado do Rio de Janeiro/UERJ, coordenadora do Núcleo de Estudos da Antiguidade/NEA/UERJ (P.710/SR-3) e coordenadora do Curso de Especialização de História Antiga e Medieval da UERJ (Lato Sensu). Atua junto ao programa de Pós-Graduação da História Comparada/UFRJ e da Pós-Graduação de História da UERJ. Tem experiência na área de História, Filosofia, Antropologia e Arqueologia com ênfase em sociedades antigas grega e romana. Interage com a área de Teoria e Metodologia na construção do conhecimento em História aplicadas principalmente nos temas como: rituais, práticas mágicas, análise do discurso, práticas sociais, política e na recepção dos estudos clássicos.

Nuno Simões Rodrigues é Professor Associado da Universidade de Lisboa. Doutor em Letras (História da Antiguidade Clássica), é investigador dos Centros de História e de Estudos Clássicos da ULisboa e de Estudos Clássicos e Humanísticos da Universidade de Coimbra. Tem dedicado a sua investigação à História Cultural da Grécia Antiga (mito, religião, teatro e historiografia), à História Social e Política da Roma Antiga (finais da República e inícios do Principado) e à Receção da Antiguidade Clássica no cinema e na banda desenhada. Atualmente, é o Diretor do curso de Licenciatura em História da ULisboa. 
Série Humanitas Supplementum

Estudos Monográficos 


\section{Estruturas Editoriais \\ Série Humanitas Supplementum \\ Estudos Monográficos}

ISSN: 2182-8814

Diretor Principal

Main Editor

Delfim Leão

Universidade de Coimbra

\section{Assistentes Editoriais}

Editorial Assistants

Nelson Ferreira

Universidade de Coimbra

\section{Comissão Científica}

EDITORIAL BOARD

Ana Iriarte Goñi

Universidad del País Vasco

Renata Senna Garraffoni

Universidade Federal do Paraná

Carmen Gallardo

Universidad Autonoma de Madrid

Aurelio Pérez Jiménez

Universidad de Málaga

Gilberto da Silva Francisco

Universidade Federal de Sáo Paulo
Elina Miranda Cancela

Universidad de la Habana

Álvaro Alfredo Bragança Jr Universidade Federal do Rio do Rio de Janeiro

\section{Carmen Soares}

Universidade de Coimbra

Emilio Suárez de la Torre Universidad Pompeu Fabra 


\section{Magia e Superstição no Mediterrâneo Antigo}

\section{Maria do Céu Fialho, Maria Regina Candido, Nuno Simões Rodrigues (Coords.)}


Título Title

Magia e Superstição no Mediterrâneo Antigo

Magic and Superstition in the Ancient Mediterranean

CoORds. EDS.

Maria do Céu Fialho, Maria Regina Candido, Nuno Simóes Rodrigues

Editores Publishers

Imprensa da Universidade de Coimbra

Coimbra University Press

www.uc.pt/imprensa_uc
Contacto Contact

imprensa@uc.pt

Vendas online Online Sales

http://livrariadaimprensa.uc.pt

Coordenação Editorial Editorial Coordination

Imprensa da Universidade de Coimbra

Conceção Gráfica Graphics

Rodolfo Lopes, Nelson Ferreira

Infografia Infographics

Nelson Ferreira

Preparação de originais

Manuela Ribeiro Barbosa

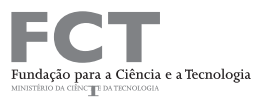

POCI/2010

Projeto UID/ELT/00196/2019 -

Centro de Estudos Clássicos e Humanísticos da Universidade de Coimbra

Impressão e Acabamento Printed by

KDP

ISSN

2182-8814

ISBN

978-989-26-1551-6

ISBN Digital

978-989-26-1552-3

DOI

(C) Dezembro 2021

Imprensa da Universidade de Coimbra

Classica Digitalia Vniversitatis Conimbrigensis

http://classicadigitalia.uc.pt

Centro de Estudos Clássicos e Humanísticos

da Universidade de Coimbra

https://doi.org/10.14195/978-989-26-1552-3

A ortografia dos textos é da inteira responsabilidade dos autores.

Trabalho publicado ao abrigo da Licença This work is licensed under

Creative Commons CC-BY (http://creativecommons.org/licenses/by/3.0/pt/legalcode) 


\section{Magia e Superstição no Mediterrâneo Antigo \\ Magic and Superstition in the Ancient Mediterranean}

Coords. Eds.

Maria do Céu Fialho, Maria Regina Candido, Nuno Simóes Rodrigues

Filiação Afeilitation

Universidade de Coimbra, Universidade do Estado do Rio de Janeiro, Universidade de Lisboa

\section{Resumo}

Este volume nos permitiu reunir especialistas brasileiros, espanhóis, franceses, gregos, italianos e portugueses que pesquisam sobre Magia e Superstição no Mediterrâneo Antigo. O tema circulou em torno da relaçáo entre magia, religiăo e superstição em diferentes sociedades antigas e com uma acentuada bibliografia atualizada que nos leva a refletir sobre a relaçáo entre os homens e os deuses e as suas diferentes manifestaçôes mágico-religiosas.

Palavras-Chave

Magia, religião, superstição e ritual

Abstract

This volume allowed us to gather Brazilian, Spanish, French, Greek, Italian and Portuguese specialists who search about magic and superstition in the Ancient Mediterranean. The theme circled around the relationship between magic, religion and superstition in different ancient societies and with a sharp updated bibliography which leads us to reflect on the relationship between men and the gods and their different magical religious manifestations.

KEYWORDS

Magic, religion, superstition, and ritual 
CoOrd.

Maria do Céu Fialho é Professora Catedrática da Universidade de Coimbra tendo como Áreas de Investigação os seguintes temas: Estudos Literários-Línguas e Literaturas Clássicas; Línguas e Literaturas Clássicas e sua Receção; Poéticas; Filosofia Antiga. Foi Coordenadora Científica do Centro de Estudos Clássicos e Humanísticos (2000-2013). Foi Diretora do Curso de Doutoramento em Estudos Clássicos-Poética e Hermenêutica.

orcid.org/0000-0003-2115-9638

Maria Regina Candido é Professora Associada da Universidade do Estado do Rio de Janeiro/UERJ, coordenadora do Núcleo de Estudos da Antiguidade/NEA/ UERJ (P.710/SR-3) e coordenadora do Curso de Especialização de História Antiga e Medieval da UERJ (Lato Sensu). Atua junto ao programa de Pós-Graduação da História Comparada/UFRJ e da Pós-Graduação de História da UERJ. Tem experiência na área de História, Filosofia, Antropologia e Arqueologia com ênfase em sociedades antigas grega e romana. Interage com a área de Teoria e Metodologia na construção do conhecimento em História aplicada principalmente nos temas sobre: rituais, práticas mágicas, análise do discurso, práticas sociais, políticas e na recepção dos estudos clássicos.

orcid.org/0000-0002-1278-838X

Nuno Simões Rodrigues é Professor Associado da Universidade de Lisboa. Doutor em Letras (História da Antiguidade Clássica), é investigador dos Centros de História e de Estudos Clássicos da ULisboa e de Estudos Clássicos e Humanísticos da Universidade de Coimbra. Tem dedicado a sua investigação à História Cultural da Grécia Antiga (mito, religião, teatro e historiografia), à História Social e Política da Roma Antiga (finais da República e inícios do Principado) e à Receção da Antiguidade Clássica no cinema e na banda desenhada. Atualmente, é o Diretor do curso de Licenciatura em História da ULisboa.

orcid.org/0000-0001-6109-4096 
EDs.

Maria do Céu Fialho is a Full Professor at the University of Coimbra, having as Research Areas the following subjects: Literary Studies-Languages and Classical Poetic Literatures; Ancient Philosophy; Classical Languages and Literature and its Reception. She was Scientific Coordinator of the Center for Classical and Humanistic Studies (2000-2013). She was the Director of the PhD Course in Classical-Poetic and Hermeneutic Studies.

orcid.org/0000-0003-2115-9638

Maria Regina Candido is an Associate Professor at the University of the State of Rio de Janeiro / UERJ, coordinator of the Núcleo de Estudos de Antiguidade / NEA / UERJ (P.710 / SR-3) and coordinator of the Specialization Course on Ancient and Medieval History of UERJ (Lato Sensu). She works in conjunction with the Graduate Program in Comparative History / UFRJ and UERJ's History Graduate Program. Has experience in History, Philosophy, Anthropology and Archeology with emphasis on ancient Greek and Roman societies. Interactive with the area of Theory and Methodology in the construction of knowledge in History applied mainly in the subjects on: rituals, magical practices, analysis of speeches, social practices, politics and in the reception of the classic.

orcid.org/0000-0002-1278-838X

Nuno Simões Rodrigues is an Associate Professor at the University of Lisbon. Has a PhD in Letters (History of Classical Antiquity), he is a researcher at the Centres for History and Classical Studies at the University of Lisbon and for Classical and Humanistic Studies at the University of Coimbra. He has dedicated his research to the Cultural History of Ancient Greece (myth, religion, theatre and historiography), the Social and Political History of Ancient Rome (late Republic and early Principate), and the reception of Classical Antiquity in cinema and comics. He is currently the Director of the History degree course at the University of Lisbon.

orcid.org/0000-0001-6109-4096 
(Página deixada propositadamente em branco) 


\section{SuMÁRIO}

INTRODUÇÃo

Daniel Ogden

A mística dos homens divinos (eEIOI AnAPes)

NA DOCUMENTAÇÃO TEXTUAL E MATERIAL:

NOTAS SOBRE UM CONCEITO HEURÍSTICO E INTOLERÂNCIA RELIGIOSA

(The mystique of divine men ( $\theta \varepsilon \tilde{\imath} 0 l$ ŏ $v \delta \rho \varepsilon \varsigma)$ in textual and material documentation: notes on a heuristic concept and religious intolerance)

André Leonardo Chevitarese, Daniel Brasil Justi

Artémis de Thasos, entre religion et magie

(Artemis of Thasos: between magic and religion)

Clarisse Prêtre

EVIDÊNCIAS LITERÁRIAS DA PRÁTICA DAS AGOGAI ANTES DA ÉPOCA ROMANA

(Literary evidence of the practice of agogai before roman era)

Cláudia Cravo

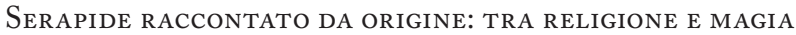

(Serapis told from origin: between religion and magic)

Ennio Sanzi

A luta pelo monopólio do sagrado em Antioquia:

JoÃo Crisóstomo e o Ataque À magia e seus agentes (sÉc. IV D.c.)

(The struggle for the sacred monopoly in Antioch:

John Chrysostom and the attack to magic and its agents (4th c. AD))

Gilvan Ventura da Silva, Érica Cristhyane Morais da Silva

Mania, magia y sophia. Los avatares de la Alianza

(Mania, magic and sophia. The avatars of the alliance)

María Cecilia Colombani

A magia actuante da palavra em Ésquilo, Sete contra Tebas

(The actuant magic of the word in Aeschylus' Seven against Thebes)

Maria do Céu Fialho

A PRÁTICA DA MAGIA AMOROSA NO PERÍODO HELENístico

(The practice of love magic in the helenistic period)

Maria Regina Candido

Uma cena de necromancia em Flávio Josefo

(A scene of necromancy in Flavius Josephus)

Nuno Simões Rodrigues 
O SAgrado coração: identidade E magia no Antigo Egipto

(The sacred heart: identity and magic in Ancient Egypt)

Rogério Sousa

Deisidaimonia y teChNAI en los diálogos de Platón

(Deisidaimonia and Technai in Plato's Dialogues)

Víctor Hugo Méndez Aguirre

Enchanted Wine in the ODYSSEY

179

J. C. B. Petropoulos

INDEX LOCORVM

ÍNDICE DE NOMES PRÓPRIOS 


\title{
INTRODUCTION
}

\author{
Daniel Ogden \\ University of Exeter \\ (d.ogden@exeter.ac.uk)
}

The essays in this volume consider a series of magical topics that span the full range of Classical antiquity from Homer to Late Antiquity (and even beyond, with a glance backwards also at Egypt), and take in the evidence of both texts and objects.

Two of the papers contribute to the debate as to how far back in time the history of Greek magic may be taken, and cause considerable difficulties for those that continue to insist that the concept of magic was only developed ca. $500 \mathrm{BC}$, this on the basis of some supposed revolution in Greek thought at that point (though such an argument might be more successfully founded on the apparent fact that that was the point at which the term magos was imported from the Persian: Heraclitus DK 12b F14; cf. Aeschylus Persians 318). So it is that J. C. B. Petropoulos investigates further traces of magic in Homer's (ca. 700 BC?) Odyssey (Chapter 12), going beyond the familiar loci of Helen's pair of good and evil drugs in Book 4, Circe's animal-transformation potion (etc.) in Book 10 and the wound-healing incantation of the sons of Autolycus in Book 19. He finds these traces in the wine of Maron, the priest of Apollo, the 'divine drink' with which Odysseus puts the Cyclops to sleep in Book 9. Homer's initial description of the wine (205-11) shares two seemingly magical features with the dipinto on Nestor's cup, one of the very earliest Greek texts to survive to us. The comparison between the two texts is intriguing. In the first place both are jangling and alliterative (Homer deploys runs of deltas; Nestor's cup the phrases eupoton potèrion and himeros hairēei). In the second place both employ a general-condition formula reminiscent of an incantation (Homer, 'whenever they drank the honey-sweet red wine...; Nestor's cup, 'whoever drinks from this cup...;). Furthermore, Homer's narrative aligns with more modern folktales of the 'Blinding of the Ogre' type in which a drink of avowedly magical nature is employed to put a giant to sleep.

Cláudia Cravo (Chapter 3) is concerned to locate evidence for love spells of attraction or agogai prior to the Imperial age, when they came to flourish in the Greek Magical Papyri. She does so by finding refractions of them in Sappho's F1 (ca. 600 BC), Pindar's Pythians 4 and Theocritus Idylls 2, the Simaetha poem. Indeed the Pindar text, which describes Jason's seduction of Medea by means of a iynx tool, a wheel with a wryneck-bird bound to it, rather helps to prove that the tradition of such spells is far older even than Sappho, for the wheel the poet describes is emphatically prefigured in a fine geometric terracotta of 750-700 
BC from Attica, perhaps originally from Phalerum more specifically, and now housed in Boston's Museum of Fine Arts (accession no. 28.49). One can debate whether this compelling artefact, a wheel with with eleven wrynecks attached to it (the bird's natural colouring and patterning lending themselves perfectly to the palette and stylisation of geometric ceramics) should be considered to have bee a tool for practical use in itself, fragile though it must always have been, or rather a model (an idealised one?) of such a tool. A model iynx made for votive purposes is referred to in a Hellenistic epigram, a golden one inset with amethyst, no less (Hellenistic Epigrams Anon. 35 Gow and Page).

Maria Regina Candido also looks at Theocritus' Simaetha, in one of a pair of papers focusing on witches or witchlike figures (Chapter 8). The second of the Idylls is one of our most distinctive literary sources for the practice of - or the imagination of - magic in antiquity, with Simaetha's monologue guiding the reader through the elaborate rituals she is undertaking in order to recover the love of Delphis. Prof. Candido compares the rites expounded with the some of the love spells prescribed in the greatest of the grimoires amongst the Greek Magical Papyri, PGM IV. Simaetha does indeed remain an enigma. Is she an experienced and competent witch? The great number and the great complexity of the procedures she describes herself as performing might suggest so, as might the confidence with which she issues directions to her assistant Thestylis. On the other hand, she refers to herself as having consulted seemingly greater magical professionals than herself: she had turned to old women with knowledge of incantations, and she has learned of the powers of drugs from an Assyrian stranger. And so the very number of her magical rites may give rise rather to the impression that she is rather an amateur desperately throwing every procedure she can at Delphis in the hope that one of them at least will have an effect: nowhere else in the literary tradition of ancient magic or in the documentary evidence provided by the expansive Greek magical papyri do we find such an extended concatenation of rites of love-magic.

Nuno Simões Rodrigues looks at the reception of the Hebrew Bible's necromantic Witch of Endor episode (1 Samuel 28) in Classical literature (Chapter 9). His most striking claim relates to Callimachus' Hecale. This epyllion survives to us only in miserable fragments, our best access to the poem's plot being provided by the Diegesis' summary of it and Philochorus FGrH/BNJ 328 F109 (= Plutarch Theseus 14), which Callimachus is thought to have read. He contends that Callimachus' handling of the tale of Theseus and Hecale was shaped by the Biblical Endor episode, to which the poet gained access through his patron Ptolemy Philadelphus' parallel commissioning of the translation of the Hebrew Bible into Greek, as the Septuagint. He further contends that the Hecale then in turn exerted its own reciprocal influence on the Endor tradition, specifically upon Josephus' handling of the tale (Jewish Antiquities 6.327-50). It must be conceded that there is not very much necromancy in the fragments of 
the Hecale, but they do share with both the Bible and Josephus' Endor tale the themes of a poor woman's generous hospitality towards the king or prince she hosts, and her preparedness to kill an animal for him.

Turning away from the women, a further pair of papers looks at male practitioners of magic, or something akin thereto. In a somewhat philosophical discussion, María Cecilia Colombani investigates, inter alia, the so-called Greek shamans, those devotees of (Hyperborean) Apollo who, like the god's own Pythia, gained special access to hidden and privileged forms of knowledge (Chapter 6). A number of figures in the Pythagorean tradition could be classified in this way, including Pythagoras himself: also, Orpheus, Trophonius, Aristeas of Proconnesus, Hermotimus of Clazomenae, Epimenides of Cnossus, Abaris the Hyperborean, Zalmoxis of the Thracian Getae and Empedocles of Acragas. Herodotus has much to tell of Aristeas' ability to project his soul and send it into never-never lands on voyages of discovery (4.13-16). In later texts at any rate, these figures were assimilated to mages and sorcerers. Strabo refers to Aristeas as the sorcerer (goès) par excellence (C589 F16), whilst associating Orpheus, Trophonius and Zalmoxis with Chaldaeans, mages and necromancers (C762); in his famous history of magic, Pliny associates one of his mysterious Zoroasters with Aristeas' own Proconnesus (Natural History 30.9); Apuleius associates Zalmoxis with Zoroaster (Apology 26), whilst noting that Epimenides, Pythagoras and Empedocles were commonly regarded as mages (27); Diogenes Laertius knows that Pythagoras associated with mages and Chaldaeans (8.3); and Hierocles compares Aristeas to Apollonius of Tyana, himself commonly referred to as a mage and a sorcerer (apud Eusebius Against Hierocles 2). Prof. Colombani regards the Greek shamans as theoi andres avant la lettre.

It is indeed to the paradigm of the itinerant, miracle-working 'divine man' (theios anerr) that André Leonardo Chevitarese and Daniel Brasil Justi turn (Chapter 1).They provide useful reviews of the doxography on this intriguing but murky notion and of the sundry attempts to give precise definition to it (the undepinning phrase theios anèr is by no means frequent in Classical sources: one example is to be found at Philostratus Life of Apollonius 2.40, where it is applied to the great man himself). The fundamental problem in relation to the paradigm is the question whether it originated within early Christianity, and expanded out from there to colonise pagan thought, or whether it was already a more widespread Hellenistic paradigm to which the figures of early Christianity were themselves assimilated. Chevitarese and Justi come down in favour of the latter. Let us note, finally here, that although the theios aneer paradigm was indeed normally applied to males, there could also be female examples: in his earlier-fourth-century AD Lives of the Philosophers and Sophists Eunapius imparts fascinating details of a female counterpart to Apollonius and his fellows, a theia gyne, one might say, one Sosipatra of Ephesus, an initiate 
into Chaldaean mysteries, a remote-seeing prophet, a theurgist, a Neo-Platonist and, like Apollonius, a Neo-Pythagorean (6.5-11).

Three of the papers investigate questions of demonology. Víctor Hugo Méndez Aguirre contemplates the subject of deisidaimonia ('superstition', more literally 'daemon-fear') and the technai ('arts') in the works of Plato (Chapter 11). He contends that Plato admitted the existence of an 'intellectualist deisidaimonia' insofar as he considered certain forms of magic and divination to constitute technai, and insofar as his Socrates openly depended upon the promptings of his daimonion ('daemon-let').

Ennio Sanzi looks at Origen's reconfiguration of the tale of Ptolemy's foundation of the cult of Sarapis some 500 years before him (Chapter 4). Origen represents the foundation not merely in abusive terms but actually in terms of the demonology familiar to him in his own age. Ptolemy, we now learn, had Sarapis created not only with the aid of sculptors of divine images, but also with that of mages (magoi) and sorcerers (pharmakeis) and the demons that they enchant with their incantations, these being invoked by trickeries (manganeiai) and profane rites.

Gilvan Ventura da Silva and Érica Cristhyane Morais da Silva discuss John Chrysostom's attempt to secure a 'monopoly of the sacred' for his Christian faith in his fair colonnaded city of Antioch at the end of the fourth century AD (Chapter 5). This he did by launching tirades against magic, divination, the evil demons that lay behind them and the human exponents of these activities. In this they find Chrysostom struggling against 'an integrated system of knowledge' in open competition with the precepts of Christianity, one that required the Fathers of the Church to be continuously vigilant in the effort to eradicate it. So it is that he campaigned against the use by the Christians themselves of amulets and talismans to protect their newborns against envy and the evil eye (a battle yet to be won in that part of the world!) and attempted to establish the crucifix as a suitable and supreme replacement for such things. The extent to which Chrysostom was in actual fact in battle with an opposing integrated system of knowledge might remain moot: was it rather Chrysostom and his fellow Christians that were constructing and fashioning their enemy in this way, all the better to enhance and animate the supposed threat he offered?

This last paper treats of amulets and talismanic objects. Three other papers focus more directly upon such things. Maria do Céu Fialho discusses the shields of the Seven Against Thebes in Aeschylus' tragedy of that name, in which they are reported to Eteocles by the messenger (375-676; Chapter 7). She regards the threatening images of their blazons as carrying a magical force that works in support of their bearers as they attack the city, whilst the inscriptions that some of the shields also carry should, she holds, be considered as akin to curses (Eteocles does indeed wonder whether the letters themselves on Polynices' shield, worked in gold, will be able to restore him to his home, 660). Eteocles' response 
to each of these blazons and inscriptions as they are described to him is designed to neutralise the magic or to turn it back against the shield's bearer. So it is that the he averts the power of Tydeus' blazon, the full moon in a starry night sky, the 'eye of the night', by declaring that it portends the night, i.e. the death, that is about to descend upon Tydeus' eyes. Hippomedon's blazon is an image of the fire-breathing Typhon belching black smoke from his mouth; Eteocles counters this by declaring that he will station against him the warrior Hyperbius, whose own shield blazon appropriately consists of Typhon's nemesis: Zeus hurling the thunderbolt.

Clarisse Prêtre looks at objects dedicated in the cult Artemis at Thasos (Chapter 2). An intriguing feature of the world of ancient Greek magic is the identification between Hecate, the dread goddess of the night and the patron of witches, and Artemis, the more innocent patron of virgin girls and childbirth. The identification is fully achieved in the prayers of Theocritus' Simaetha and in the magical hymns extracted and reconstructed by Preisendanz from the Greek Magical Papyri (where in both cases Selene too is absorbed into the mix). On occasion Artemis herself can be portrayed as a goddess of destructive magic, even without any explicit acknowledgement of her Hecatean affinities. We think, for example, of the curious, partly rationalising narrative of Medea's career that Diodorus derives from the third-century BC Dionysius Scytobrachion: here Medea fills a hollow statue of Artemis with her drugs in order to inflict a common madness on the people of Iolcus, and more specifically to induce the daughters of Pelias to kill him (4.51-2 = FGrH/BNJ 32 F14). Prof. Prêtre's study of Artemis at Thasos reveals that the goddess here was fundamentally concerned with the protection of girls, in the usual way, but that her Hecatean affinities were nonetheless acknowledged not only in inscriptions that referred to her as 'Artemis Hecate' but also in the dedication to her of objects of magical and divinatory interest, cymbal-pendents, amulets and knuckle-bones. But Prêtre insists that the goddess, whilst duly thanked for licensing some magical activities of an unthreatening variety, was not herself exploited directly for magical ends. Frazer's familiar distinction between religion, in which one displays a supplicative attitude towards the gods, and magic, in which one attempts to subject them to one's own will, is allowed to survive intact, in this regard at any rate.

Turning away from Graeco-Roman culture, Rogério Sousa discusses the heart amulets frequently found in ancient Egyptian burials (Chapter 10). He elucidates their functions in line with the wider symbolism of the heart in Egyptian culture. The amulets' magical power was founded in the fact that they identified the heart of their wearers with life-giving power of Horus himself. They served as symbols of protection both in the earthly life and in the afterlife alike. From a different perspective, he also traces the democratization of the amulet over time, as its adoption expanded beyond the elite groups with which it had originated. 
(Página deixada propositadamente em branco) 


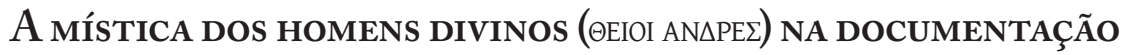 TEXTUAL E MATERIAL: \\ NOTAS SOBRE UM CONCEITO HEURÍSTICO E INTOLERÂNCIA RELIGIOSA (The mystique of divine men $\left(\theta \varepsilon \tilde{\varepsilon} o l \ddot{\alpha}^{\prime} \nu \delta \rho \varsigma\right)$ in textual and material documentation: notes on a heuristic concept and religious intolerance)
}

\author{
André Leonardo Chevitarese ${ }^{1}$ \\ IH/UFRJ \\ (andrechevitarese@yahoo.com.br) \\ Daniel Brasil Justi ${ }^{2}$ \\ PPGHC - IH/UFRJ
}

\begin{abstract}
Resumo - O presente texto tem por objetivo apresentar o ambiente mediterrânico antigo em sua pluralidade de experiências religiosas (místicas) e cotidianas, além de propor um modelo teórico-metodológico para analisar, contextualizar e compreender personagens que atuavam nesse ambiente. As atuações dessas personagens podem ser entendidas com conceitos modernos aplicados as suas respectivas vivencias e atuações. Aqui, será proposto um desses conceitos ou modelos: homem divino. Como núcleo decisivo para realização dessa proposta será tomada a longa história da interpretação do conceito de homem divino, bem como sua origem e desdobramentos posteriores. Por fim, será enunciado que, embora relativamente "abandonado", o conceito de homem divino como o aqui formulado é tese fundamental para se analisar, contextualizar e compreender determinadas personagens do ambiente místico antigo mediterrânico.

Palavras-chave: Homens divinos, mística mediterrânica antiga, pluralidade religiosa, conceitos e documentação histórica.
\end{abstract}

Aвstract - This article aims to present the ancient Mediterranean environment in its plurality of religious (mystical) and everyday experiences, in addition to proposing a theoretical-methodological pattern to analyze, contextualize and understand characters that acted in this environment. The performances of these characters can be understood within modern concepts applied to their respective experiences and performances. Here, one of these concepts or patterns will be proposed: divine man. As a decisive nucleus for the realization of this proposal will be taken the long history

${ }^{1}$ Professor Titular do Instituto de História da Universidade Federal do Rio de Janeiro. Coordenador do Laboratório de História das Experiências Religiosas do Instituto de História da Universidade Federal do Rio de Janeiro - LHER - IH/UFRJ.

${ }^{2}$ Bolsista de pós-doutorado em História no Programa de Pós-Graduação em História Comparada - PPGHC-IH/UFRJ. Coordenador do Laboratório de História das Experiências Religiosas do Instituto de História da Universidade Federal do Rio de Janeiro - LHER - IH/ UFRJ. Coordenador e Professor da Pós-Graduação Latu Senso em História do Cristianismo do Centro Universitário Augusto Motta - PGHC/Unisuam. 
of the interpretation of the concept of divine man, as well as its origin and later bibliographical discussion. Finally, it will be assumed that, although relatively "abandoned", the concept of divine man as formulated here is a fundamental thesis to analyze, contextualize and understand certain characters of the ancient Mediterranean mystic environment.

Keywords: Divine man, ancient Mediterranean mystic, religious plurality, concepts and historical documentation.

\section{A. Breve introdução}

Não é incomum, muito pelo contrário, encontrar na documentação antiga mediterrânica, em diferentes épocas cronológicas, relatos e episódios de personagens que curam ou são curados, realizam feitos extraordinários ou os presenciam, organizações "estatais" lançando mão de artifícios sobrenaturais nas suas composições cotidianas, tensões e conflitos mediados pelos poderes supra-humanos, experiências e agentes históricos, em suma, vivenciando um ambiente místico ${ }^{3}$ altamente complexo e amplamente disseminado. A, assim conhecida, Bacia Mediterrânica indubitavelmente, era Um Mundo Repleto de Deuses ( $A$ World Full of Gods).

O livro imediatamente acima, de Keith Hopkins (1999), talvez tenha sido mais profícuo na ideia expressa em seu título do que pelo seu conteúdo propriamente dito. $\mathrm{O}$ tom romanceado da narrativa, de caráter experimental, que já fora anunciado por seu autor como uma possível problemática para sua assunção nas conclusões que postula, se consolidou, de fato, muito mais por expressar uma realidade cotidiana absolutamente inserida e permeada por figuras divinas do que por analisá-las, contextualizá-las ou compreendê-las. As possibilidades para se dar conta desse ambiente são variadíssimas. Inclusive, as variedades de possibilidades incontáveis nesse estudo, certamente, são tão múltiplas quanto a própria pluralidade das experiências místicas em si.

\section{B. Apresentação de testemunhos contextuais da documentação}

Alguns testemunhos documentais, em diferentes suportes materiais, testemunham feitos extraordinários de determinadas personagens mediterrânicas. Esses atos constituem-se valiosos indícios (Ginzburg, 2007:143-179) de uma pluralidade de experiências místicas que importam ser analisadas aqui. No que

${ }^{3}$ Em outros lugares já definimos o termo mística e o porquê de seu emprego quando se trata de experiências religiosas que envolvam religião, mito e magia e suas respectivas articulações. Ver: Justi (2015:23-24; 106-144); Chevitarese e Penna (2004:9-24). 


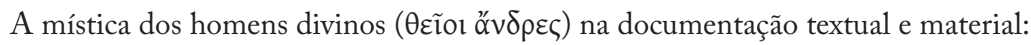
notas sobre um conceito heurístico e intolerância religiosa

diz respeito a curas, por exemplo, a Asclépio é atribuído o restabelecimento de uma mulher com hidropsia:

. Arata, uma mulher com hidropsia é curada à distância (Inscriptiones Graecae 4. 1. 121-122: Estela 2. 21 - século IV a.e.c.):

"Arata, uma mulher de Lacedônia, hidrópica. Para ela, enquanto ela permanece em Lacedônia, sua mãe dorme no templo e sonha. Parecia-lhe que o deus cortou a cabeça de sua filha e desligou seu corpo de tal forma que sua garganta estava virada para baixo. Para fora dele veio uma enorme quantidade de fluido. Então ele tirou o corpo e montou a cabeça de volta no pescoço. Depois que ela viu esse sonho, voltou para Lacedônia, onde encontrou sua filha em boa saúde; ela tinha visto o mesmo sonho."

Também com hidropsia, para o caso de Jesus, existe um testemunho para cura: . Um homem com hidropsia é curado (Lc 14, 1-6):

${ }^{~ "}{ }^{C}$ erto sábado, ele entrou na casa de um dos chefes dos fariseus para tomar uma refeição, e eles o espiavam. ${ }^{2}$ Eis que um hidrópico estava ali, diante dele. ${ }^{3}$ Tomando a palavra, Jesus disse aos legistas e aos fariseus: "É lícito ou não curar no sábado?" "Eles, porém, ficaram calados. Tomou-o então, curou-o e despediu-o. ${ }^{5}$ Depois perguntou-lhes: "Qual de vós, se seu filho ou seu boi cai num poço, não o retira imediatamente em dia de sábado?" 'Diante disso, nada lhe puderam replicar."

Sobre a capacidade de realizar curas, Asclépio, Jesus e Hércules, em diferentes tempos e espaços são assumidos como capazes e poderosos para realizarem tais feitos:

. Jesus Mt 15, 29-31 (// Mc 7, 31-37):

${ }^{229}$ Jesus, partindo dali, foi para as cercanias do mar da Galiléia e, subindo a uma montanha, sentou-se. ${ }^{30}$ Logo vieram até ele numerosas multidões trazendo coxos, cegos, aleijados, mudos e muitos outros, e os puseram aos seus pés e ele os curou, ${ }^{31} \mathrm{de}$ sorte que as multidões ficaram espantadas ao ver os mudos falando, os aleijados sãos, os coxos andando e os cegos a ver. E renderam glória ao Deus de Israel."

- Asclépio:

. Alcetas, o homem cego (Inscriptiones Graecae 4. 1. 121-122: Estela 1.18 - século IV a.e.c.):

"Alcetas de Halieis. O homem cego viu um sonho. Pareceu-o que o deus veio até ele e com seus dedos abriu seus olhos, e que sua primeira visão foram as árvores do santuário. Ao amanhecer ele saiu sadio." 
. Valerius Aper, o soldado cego (Inscriptiones Graecae 14. 966 - século II e.c.):

"Para Valerius Aper, um soldado cego, o deus revelou que ele deveria ir e dar o sangue de um galo branco, junto com mel, e fazer um colírio e por três dias deveria aplicá-lo aos olhos. E ele poderia ver de novo e foi e publicamente ofereceu graças ao deus."

. Cura de um menino mudo (Inscriptiones Graecae 4. 1. 121-122: Estela 1. 5 - século IV a.e.c.):

"Um menino sem voz . Ele veio para o Templo como um suplicante em favor de sua voz. Quando ele tinha realizado os sacrifícios preliminares e cumprido os ritos habituais, o servo do templo, que traz o fogo para o deus, olhando para o pai do menino, exigiu que, se ele tiver obtido a cura pela qual ele tivera vindo, ele deveria prometer trazer, dentro de um ano, a oferta de agradecimento para a cura. Porém, o menino de repente disse: "Eu prometo." Seu pai ficou assustado com isso e pediu-lhe para repetir. $\mathrm{O}$ menino repetiu as palavras e depois ficou bem."

. Hércules:

. Aristides (século II e.c.), em Heracles, testemunha que Hércules cura todas as doenças:

"Mas, porque deveríamos falar de história antiga. Para a atividade do deus ainda é agora manifesto. Por um lado, como ouvimos, ele faz maravilhas em Gadira e acredita-se ser o segundo de todos os deuses. E, por outro lado, em Messene na Sicília ele liberta os homens de todas as doenças, e aqueles que escaparam do perigo no mar atribuem o beneficiamento igualmente a Poseidon e Hércules. Poderíamos listar muitos outros lugares sagrados ao deus e outras manifestações de seu poder. "(Aristides, Heracles, $40,12)$.

Para além dos testemunhos textuais, também na imagética antiga, outros episódios atestam o poder de determinadas personagens em realizar atos sobrenaturais, principalmente quando elas têm em suas mãos "varinhas mágicas". Ver, por exemplo:

\footnotetext{
${ }^{4}$ Para um aprofundamento do tema de varinhas mágicas, ver: Chevitarese, 2016:67-88.
} 


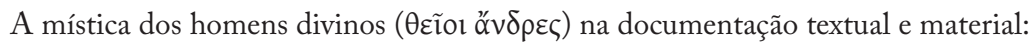
notas sobre um conceito heurístico e intolerância religiosa

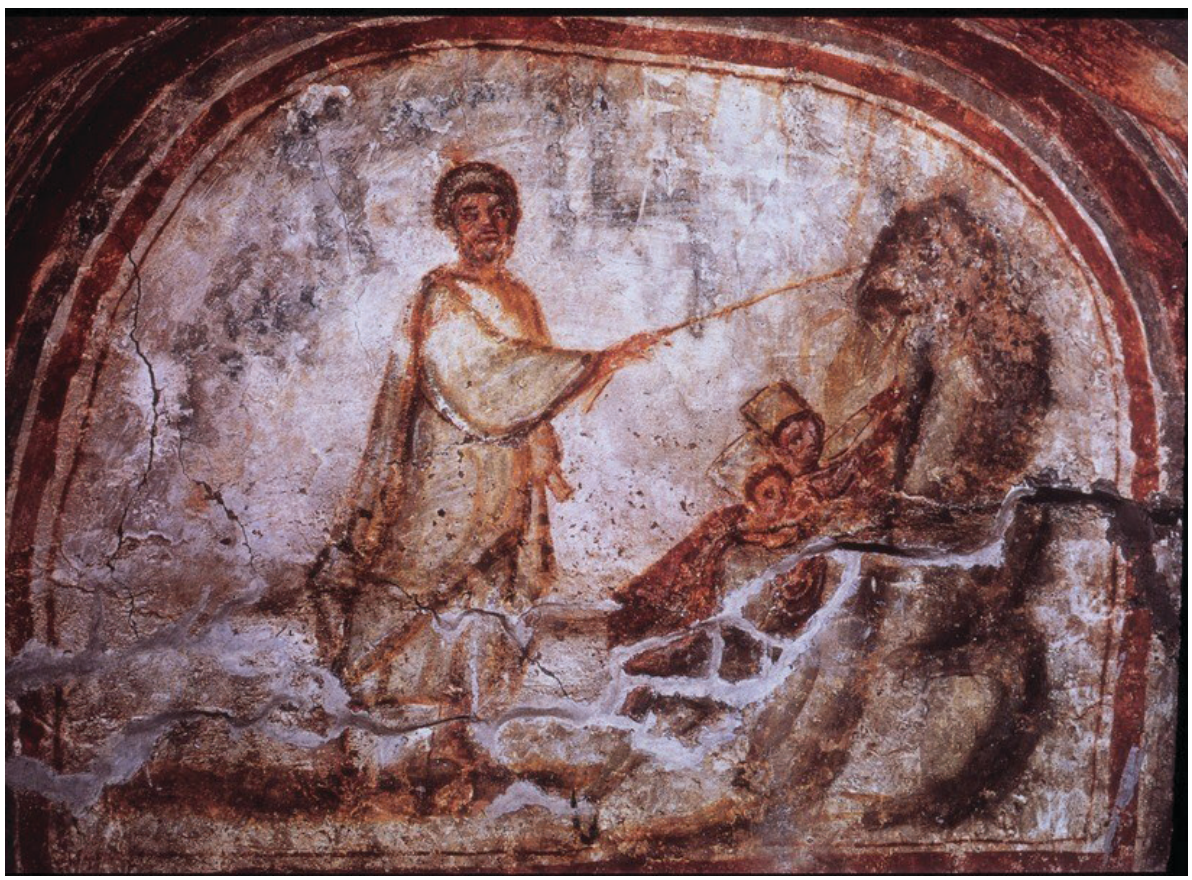

Afresco. À esquerda, Moisés batendo com a vara na rocha. Cubiculum N5. Catacumba de Commodilla. Datação: século IV. Disponível na base de dados Alinari: http://www.alinariarchives.it/en/search?isPostBack=1\&query=\%22Ca. Acessado em 03 de Abril de 2017

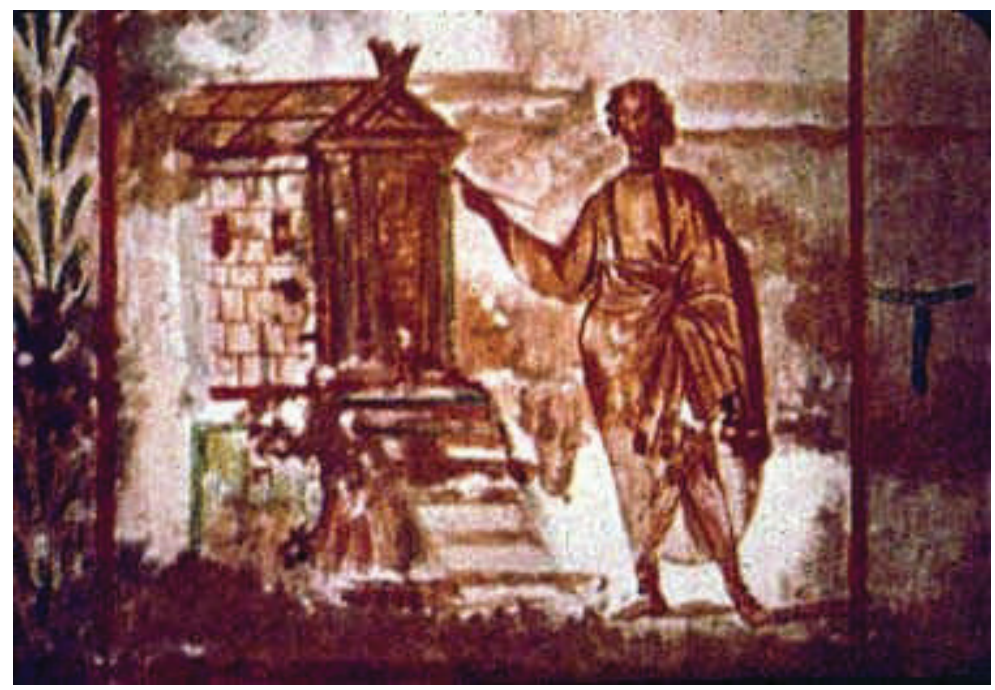

Afresco. Jesus e a Ressurreição de Lázaro. Catacumba de São Marcelino e São Pedro, Roma. Datação: início do século IV. Disponível na base de dados Alamy: http:/www.alamy. com/stock-photo-lazarus-catacomb-136505590.html. Acessado em: 03 de Abril de 2017 


\section{BALANÇO CRÍTICO E COMPARATIVO DA BIBLIOGRAFIA ESPECIALIZADA NA FORMAÇÃO E CONSOLIDAÇÃO DO CONCEITO THEIOS ANER ( $\Theta E I O \Sigma$ 'ANHP) E A PROPOSTA DE UM NOVO MODELO}

A pergunta fundamental, no entanto, diante dos testemunhos documentais antigos imediatamente acima expostos passa a ser: como é possível entender todos esses relatos? Decorrente dessa questão central: eles dialogam entre si? É possível analisá-los sob uma mesma perspectiva heurística? O que essas similitudes revelam sobre as experiências místicas antigas? A proposta, aqui, que segue como encaminhamento é justamente unificar essas experiências sob o conceito

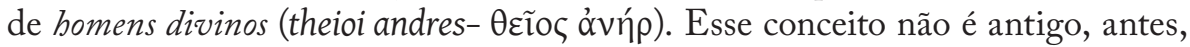
trata-se de uma definição moderna para dar conta de questões documentais antigas.

As obras cotejadas para esse estudo não esgotam o tema - não é a pretensão aqui, muito menos se pensa ser possível tal feito -, mas, seguramente, no que diz

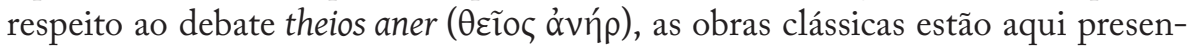
tes. Por "obras clássicas", bem entendido, quer-se referir àquelas que (i) foram fundantes para o debate; (ii) a partir delas, tantas outras surgiram; e, finalmente, (iii) foram consolidadas, por parte dos estudiosos do tema, como referência nas discussões centrais sobre o conceito/compreensão dos homens divinos assim como a temas corolários ${ }^{5}$.

Gail Corrington (1986:2-4) estava correta em afirmar que o debate estava longe de ter um fim. Essa idéia pode ser sustentada ainda nos dias de hoje. Inclusive, deve-se concordar com ela que esse debate carece de mais definições

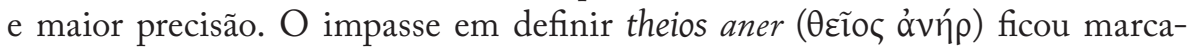
do, fundamentalmente por vincular a figura de Jesus, em Marcos, aos demais homens divinos da antiguidade. Inclusive, foi precisamente essa operação que desenrolou tamanha polêmica e disputa em vincular ou não Jesus a esse "título".

A singularidade de Jesus como um messias ou salvador da humanidade começou a ser questionada no bojo da reação que a religionsgeschichtliche Schule (escola de história das religiões) alemã marcou em seus debates com obras da escola mitológica. Em 1913, Bousset (1970), adotando o título de kyrios (senhor) a Jesus terminou por demonstrar a irreversível "helenização" do nazareno e aproximou-o das religiões de mistério helenísticas. De forma decisiva, foi Reitzenstein, em 1908, que primeiramente deu voz à forma como se entende a figura do homem divino na antiguidade:

"[uma] concepção geral de homem divino..., segundo a qual um homem tão

${ }^{5}$ Uma extensa e profunda revisão bibliográfica pode ser encontrada em Justi, 2015:31-105. Os dados são longamente expostos e discutidos tendo por base a problemática de definição do conceito de homem divino que abrange materiais desde a antiguidade até o tempo presente. 
divino combina dentro de si mesmo, com base em uma natureza grandiosa e santidade pessoal, o conhecimento mais profundo, a visão e o poder para operar milagres." (Reitzenstein, 1978:26).

A definição primeva do intelectual alemão ao postular que esse homem divino helenístico era alguém portador de (i) natureza humana grandiosa e santa; (ii) conhecimento vasto e profundo; e, (iii) visão e poder para operar milagres; estabeleceu as bases para se organizar em quais características uma personagem histórica deveria ser enquadrada para dialogar com o modelo recentemente formulado.

Esse primeiro e inédito passo rumo à definição do que viria a se tornar

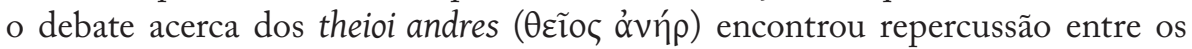
estudiosos bíblicos a partir das contribuições de Dibelius, em 1919 e Bultmann, em 1921. Dessa forma, ambos também inseriram, nos mesmos estudos, a idéia de que uma aretologia deveria estar por trás de personagens potencialmente classificados como homens divinos. Embora não o fizessem, no caso de Jesus, por exemplo, de forma definitiva consolidaram a categoria nos trabalhos de "crítica e história das formas" (Formgeschichte) de textos do Novo Testamento.

Anos mais tarde, em 1935, será por meio de Bieler que o modelo theios aner conhecerá sua mais extensa, controversa e duradoura definição. Convém destacar a lista a partir da qual o autor alemão entende o modelo theios aner

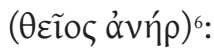

(i) sua relação com um deus é especial seja por testemunhar aquele deus, ser inspirado por ele ou receber conhecimento secreto da parte dele;

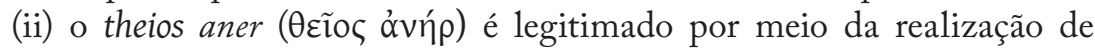
milagres, eles provam que o homem divino possui a virtude divina (göttliche Kraft);

(iii) seu nascimento e morte são acompanhados, legitimados ou evidenciados por prodígios e maravilhas;

(iv) a vida do homem divino é errante, acompanhado de poucos discípulos leais, os quais mantêm sua memória viva após sua morte;

(v) sua morte é quase sempre o resultado de um martírio com seu próprio consentimento e é acompanhado, legitimado ou evidenciado por meio de prodígios e maravilhas;

(vi) após sua morte, freqüentemente, o então homem divino se torna deus. Ressurreição e aparições corpóreas são características de sua vida após a morte.

${ }^{6}$ Lista extraída da excelente sistematização de Corrington (1986:23) a partir da obra de Bieler (1967:31-47;140-143). 
Foi a essa lista, ou conjunto de características, que, dos anos 30 até a atualidade, diferentes intelectuais, das mais variadas vertentes buscaram objetar, analisar,

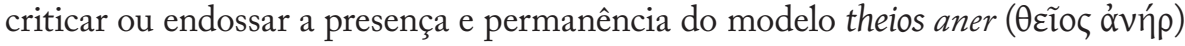
na antiguidade como um paradigma científico moderno para o estudo e entendimento dessas figuras extraordinárias. Até aqui, Corrington (1988:24-26) chama a atenção para duas distintas gerações que "buscaram" o entendimento dessas figuras de homens divinos: a (primeira) situada entre fins do século XIX até os anos 30 do século XX e aquela (segunda) entre os anos 60-80 também do século XX.

As pesquisas posteriores - leia-se, entre os anos 60 e 80 - reacenderam a polêmica. Os quase 30 anos que motivaram esse silêncio poder-se-ia ser entendido por conta de alguns fatores: (i) dificuldade na contestação do modelo proposto por Bieler; (ii) um longo tempo até que se digerisse a proposta do autor alemão e, no retorno às fontes primárias, novas análises para construção de um debate qualificado a partir da tese de Bieler; ou, ainda, (iii) por conta do interregno nas pesquisas causado pela II Guerra Mundial.

É mais razoável, ao que parece, considerar a terceira opção. Dada a polêmica que esse estudo provocou e as implicações drásticas que atingiam aspectos centrais da fé cristã - singularidade de Jesus e seus discípulos e/ou apóstolos - o contexto de guerra e pós-guerra pode ter sido decisivo em tão longo espaço de tempo nas pesquisas. Ora, em um cenário de Europa devastada pela guerra, os projetos intelectuais de civilização plenamente contestados pelo conflito mundial e o devastador ambiente de desilusão frente ao que se seguiu antes, durante e depois do conflito já era, por si só, suficientemente polêmico para que se seguisse com contestações centrais à fé de muitos naquele momento.

Em fins dos anos 50 Rudolf Bultmann em sua monumental Teologia do Novo Testamento refuta a tese de theios aner ao discutir a noção do que hoje se conhece por "Espirito Santo" (pneuma - $\pi v \varepsilon \tilde{u} \mu \alpha)$. O que é central para a discussão aqui desenvolvida e que possibilitou este trabalho desenvolver o próprio conceito

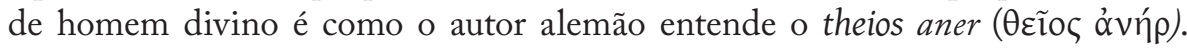
Trata-se de um indivíduo de natureza mais elevada que os mortais comuns e detentor de uma misteriosa potência divina que o faz capaz de conhecimento e ações prodigiosas. Além disso, complementa Bultmann, essa potência que está no homem divino é o poder (dynamis), não o Espírito (pneuma - $\pi v \varepsilon \tilde{u} \mu \alpha)$ que está no cristianismo primitivo (Bultmann, 1984:156).

Dessa maneira, o autor alemão reconhece a figura poderosa (dynamis) do homem divino, muito embora o distinga dos discípulos e apóstolos seguidores de Jesus, estes, portadores do Espírito (pneuma $-\pi v \varepsilon \tilde{v} \mu \alpha$ ). Aliás, não é incomum esse comportamento de Bultmann. É notória em suas obras a piedade confessional cristã que o pastor luterano opera nos seus tratados em (i) singularizar a experiência religiosa cristã em meio ao existencialismo "galopante" europeu; e, (ii) por meio de argumentos científicos pós-metafísicos "desmitologizar" (título de um de seus livros) as narrativas neotestamentárias. 
A finalidade última, então, de um lado, é ganhar a audiência da racionalidade moderna europeia e, por outro, manter como original e singular o kerygma cristológico para sua audiência eclesiástica. Contudo, talvez sem esperar o resultado que se viu posteriormente, é justamente o poder (dynamis) desses homens divinos que unificará experiências religiosas mediterrânicas e os paleocristianismos em estudos sobre os theioi andres ( $\theta \varepsilon i ̃ o \varsigma \alpha ̉ v \eta ́ p)$. Trata-se, fundamentalmente, do trabalho de Corrington e, modestamente, o presente texto.

Quando o tema é retomado, na figura de Betz (especialmente 1961 e 1968, mas, posteriormente, 1983) a tese geral e fundamental é que a ocorrência da expressão theios aner ( $\theta \varepsilon \tilde{\imath} o \zeta \grave{\alpha} v \eta ́ \rho)$ não pode ser decisiva para a questão da existência do conceito, pois o conceito pode ser expresso através de variadas formas (Betz, 1961:102; 1968:117). Partindo de Luciano de Samósata - detrator de figuras popularescas ( $(\mathrm{ic})$, isto é, personagens “mágicas” em contexto de piedade popular - e as críticas do autor do II século e.c., Betz demonstra como seus enunciados acabam por conformar topoi ou termini technici ao satirizá-los rumo à percepção de que se poderia identificar como homens divinos (Betz, 1961:6-9; 114-115).

Quase que contemporaneamente a Betz (1961), Smith e Hadas (1965), em 1963, lançaram uma ideia que, para muitos, consolidou-se como central na discussão sobre homens divinos: a aretologia. Segundo os autores (1965:63) esse gênero biográfico de exaltação teve como modelo inicial o Sócrates de Platão que acabou por converter-se em "fonte para todas subseqüentes aretologias, pagãs e cristãs". Assim definiram aretologia (Smith; Hadas, 1965:3):

"Nós podemos definir isso como uma descrição formal da carreira notável de um impressionante mestre que foi usada como base para instrução moral. Os dons sobrenaturais do mestre freqüentemente incluem o poder de realizar maravilhas; freqüentemente seu ensino trouxe a ele a hostilidade de um tirano, contra o qual ele confrontou com coragem e pelas mãos de quem sofreu o martírio. Freqüentemente as circunstâncias de seu nascimento envolvem milagres."

Essa definição de Smith e Hadas, no entanto, não é tácita e, muito menos, trata-se de um consenso científico entender aretologias como um gênero literário. Mas, a identificação dessa aretologia em documentações, a partir daqui, passou a ser mais identificada como um documento base para que se conheça um homem divino na antiguidade. Assim entende Cornelli (2000:87-92) quando declara que "falar de aretologia é então falar de homem divino." (2000:89). Não será por meio dessa conclusão do autor ítalo-brasileiro que este trabalho abordará a figura de um theios aner (Өعĩos ảvńp).

Assim como mencionado anteriormente, para Smith, as coleções de milagres advindas da antiguidade são poucas (1971:177, nota 27) e mais, não parecem ser, como coleções, muito similares literariamente aos evangelhos 
canônicos (1971:178-79). Nesse sentido, o historiador reabilita Justino para identificar, nos textos bíblicos, um modelo diferente: herói. Esse modelo distinto às aretologias também dão conta de homens divinos, mas não negam a existência das aretologias, apenas limitam os exemplos que ele encontra para homens divinos (1971:179).

As discussões detalhadas de três autores parecem posicionar o debate sobre as aretologias de forma mais adequada. Koester (1971:216-219) assume que a teologia theios aner está, indubitavelmente, por trás de uma das quatro formas de aceitar e acreditar em Jesus nas bases formativas dos cristianismos antigos. Segundo ele, as histórias de milagres presentes nos evangelhos canônicos são o resultado de uma leitura de Jesus como homem divino anteriores a um dos materiais que serviram de base para a composição dos evangelhos. De igual forma, Achtemeier (1970 e 1972) percebe esse primeiro estágio sobre a crença

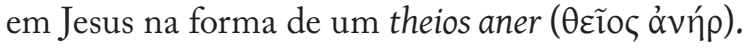

Por fim, Tiede (1972), através de análise diacrônica, postula que é possível demonstrar a existência de dois critérios para classificar um homem divino, não através de um exclusivo gênero, ou seja, a aretologia: (1) virtude moral e sabedoria; (2) feitos ou eventos miraculosos. Existiriam, portanto, esses dois tipos de thêîŏi ándrĕs que devem ser percebidos distintamente: (1) tipo filosófico, recuperado desde Sócrates; (2) operador de milagres divinos.

Desse núcleo de discussões acerca da aretologia, duas posições contrárias ao modelo theios aner ( $\theta \varepsilon \tilde{\imath} о \varsigma$ àv

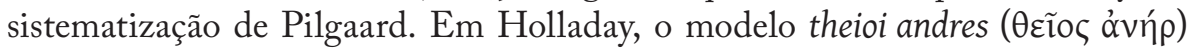
não é frontalmente analisado. As discussões que desenvolve no centro de suas reflexões dizem muito mais respeito ao grau de helenização da Palestina - justamente para tentar refutar o modelo theios aner ( $\theta \varepsilon \tilde{o} о \varsigma$ ơ $v$ ń $\rho)$ como presente naquela cultura (Holladay, 1977:6.15-17.237-38) - do que um estudo sobre o impacto que tal fenômeno tenha causado. A contundente crítica que faz está em negar que em autores específicos (Artapano e Josefo) exista o gênero aretologia e, por conseqüência, o modelo theios aner ( $\theta \varepsilon \tilde{\imath} о \varsigma \grave{\alpha} v \eta ́ p)$.

Pilgaard, por sua vez, sistematizando de que forma o modelo foi construído ao longo da história da interpretação, acaba por enunciar dados parciais, incompletos ou intencionalmente selecionados, pois negligencia - nesse resumo, não no artigo como um todo - uma série de elementos problematizados ao longo dos estudos como aqueles aqui já apresentados. Segundo ele, o modelo theios aner

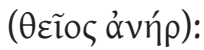

“designa um conceito bem claro personificado em muitas figuras históricas do período Romano-Helenístico. O que é substancial no conceito é que o homem pode participar na divindade e, essa qualidade divina, é demonstrada primariamente através de poderes miraculosos e sabedoria extraordinária. Sociologicamente, homens, classificados sob o conceito, eram pregadores itinerantes 
de salvação (ou eram assim pregados por meio de seus aderentes), um status que era enfatizado pelo apelo (primeiramente) aos seus poderes miraculosos. Os feitos miraculosos do homem divino eram comunicados através de um gênero específico, a aretologia. $\mathrm{O}$ conceito, bem como a atividade missionária foi tomado pelo Judaísmo Helenístico da Diáspora para defender e promover a religião judaica. Assim, o judaísmo helenístico funcionou como meio de transferência do conceito para o Cristianismo Judaico Helenístico". (Pilgaard, 1997:102).

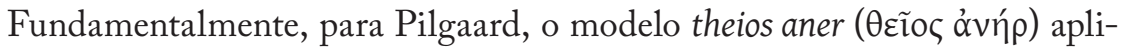
cado a Jesus, segundo o evangelho de Marcos, nada mais é do que a correção (sic) da theologia gloriae (milagres e feitos extraordinários) em termos da theologia crucis (Pilgaard, 1997:102). Essa posição do autor norueguês se justifica na medida em que a vida do Jesus Histórico, marcada que foi pela crucificação, gerava uma contradição em relação ao projeto de instauração do Reino de Deus. O projeto estava derrotado na cruz. A imagem que ficara era de mais um "milagreiro" itinerante que tivera seu caminho interrompido pela morte.

O contraditório fora, então, superado pela morte, agora, redentiva de

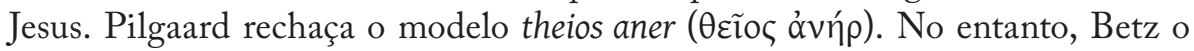
adota, mas identifica que as cristologias neotestamentárias oscilam entre duas percepções: aderir e seguir Jesus é (i) estar, já, além da morte e participando do "Reino de Deus" como realização histórica do plano de salvação universal idealizado e cumprido por Deus agindo como theoi anthropoi (humanos divinos

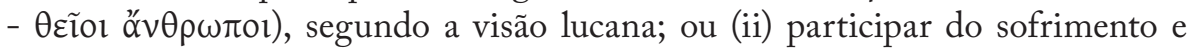
morte de Jesus, como entendem Marcos, Mateus, João e a idéia paulina de imitar Jesus. (Betz, 1968:130).

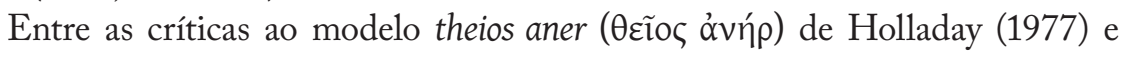
Pilgaard (1997), nos anos 80, há uma análise que parece ser a mais consistente já proposta na história da formação e consolidação do conceito de homem divino. Trata-se do modelo proposto por Gail Corrington (1986). De imediato, a autora norte-americana retoma Betz (1961:102; 1968:117) concordando que a ocorrência do termo em fontes antigas não é decisiva para a existência/validade do conceito e, indo adiante, enuncia que a audiência para quem os thě̂̌ói ándrĕs ( $\theta \varepsilon \tilde{o} о \varsigma$ ảvń $\rho)$ se dirigiam é absolutamente decisiva para compreensão do fenômeno. Preliminarmente, formula a autora norte-americana (Corrington, 1986:43):

"O que coletamos [da revisão bibliográfica feita até este ponto] é que o termo theios anēr, mesmo não ocorrendo muito freqüentemente como um termo na literatura antiga, é uma forma de categorizar ou classificar olhares por parte de certa audiência, especificamente uma audiência missionária, e conseqüentemente, lidar com a resposta daquela audiência a certas características da propaganda missionária, com mais ou menos resultados definitivos baseados nos pressupostos daquela mesma audiência." 
O que há de inédito (talvez), mas certamente, do ponto de vista conceitual, interessante é agregar a ideia de uma recepção do homem divino à análise e/ou

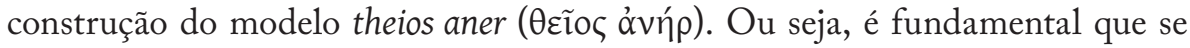
trate de uma definição conceitual do objeto de estudo, mas, fundamentalmente, que se considere também a recepção que a formulação do conceito conheceu no(s) momento(s) de sua(s) experiência(s) histórica(s). Ora, se um dos aspectos decisivos da formulação do conceito e compreensão da existência e atuação dos homens divinos é a demonstração de seus poderes (sejam eles quais forem) e, por conseguinte, aderência de seguidores, nada mais oportuno do que perceber de que forma a audiência desses homens divinos o compreendia.

Outro fator preponderante na análise e/ou construção do conceito, segundo Corrington, é a comparação dos modelos, obviamente, após a formulação desse "tipo ideal", "padrão" ou, conforme este trabalho vem adotando a terminologia, "modelo":

"No entanto, o que já foi tentado na pesquisa sobre theios anēr parece apontar para a construção de um 'tipo' ideal, um padrão de pensamento ou de uma trajetória para a qual se conforme o discreto fenômeno, mas que não precise ser manifestada em sua totalidade por todos os fenômenos que pertencem a ela. Este 'tipo' pode, então, servir de base para comparação com outros 'tipos' ou trajetórias." (Corrington, 1986:43-44).

A armadilha que decorre dessa tentativa de formulação de um "tipo ideal" ou "modelo", segundo Corrington, é que muitos dados terminam por ser coletados que, ao fim, o modelo então se expande demais para encaixar todos esses dados. Esse, ao que parece, foi o caso de Bieler e Wendland.

Esse enunciado da autora norte-americana também passou a ser usado como crítica à análise de Holladay, pois o referido autor falhou em dois aspectos: (i) o fato de que palavras empregadas no tempo moderno foram usadas para entender figuras da antiguidade não implica na inexistência do conceito em épocas antigas; e, (ii) ele falhou em reconhecer que, para compreensão de homens divinos antigos, um modelo ou "tipificação ideal" foi utilizada de forma geral, não em casos muito específicos como o estudo de Holladay quis enfatizar (Corrington, 1986:44).

De forma resumida, Corrington (1986:45) entende que todas as ocorrências do modelo ("tipo ideal") devem ser vistas como pontos ao longo da mesma trajetória. Esse é um enunciado bastante semelhante ao que Cornelli (2000) proporá em sua tese quando advoga a "equivocidade" na recepção dos homens divinos Jesus de Nazaré e Apolônio de Tiana7. O que está em jogo para o autor

\footnotetext{
${ }^{7}$ Cornelli (2000:31, nota 45) deixa claro que o uso que faz da palavra está em oposição a "univocidade", e não que ela esteja ligada ao campo semântico do "equívoco". Esclarecimento bastante pertinente especialmente se o que se tem em vista é a celeuma que a construção e análise do modelo de homem divino causaram na bibliografia especializada.
} 
ítalo-brasileiro é a fluidez e mobilidade do conceito de homem divino a figuras extraordinárias na antiguidade (Cornelli, 2000:41-46). A convergência dessas idéias torna-se ainda mais interessante quando se observa que Cornelli não teve acesso ao material de Corrington!

Tendo no horizonte essa perspectiva de "tipo ideal" ou modelo, Bryan Wilson é convidado por Corrington para sustentar a discussão. O sociólogo da religião aponta dois elementos decisivos que apóiam a construção do conceito de homem divino: (i) na "tipificação ideal" há a possibilidade de divergências dentro da estrutura do fenômeno, não diretamente do "tipo" propriamente dito (Wilson, 1973:21); (ii) o "construto tipológico" deve estar relacionado ao milieu onde ocorre (Wilson, 1973:135).

Para a primeira afirmação, observa-se uma resposta direta ao que Holladay propôs em seu trabalho de análise particular que, conforme já mencionado, Corring ton objeta ${ }^{8}$. Para a segunda afirmação, que relaciona o modelo ao milieu em que ocorre, implica dizer que a resposta com que determinada audiência enxerga e percebe o mundo, determina como um fenômeno tal qual theios aner ( $\theta \varepsilon \tilde{\imath} о \varsigma$ ảvń $\rho)$ ocorre e é percebido. Assim, por exemplo, um grupo com cosmovisão taumatúrgica vive dentro de um horizonte no qual são necessários feitos extraordinários de poder personalistas e realizações mágicas para que se crie a expectativa de um messias operador de milagres (Wilson, 1973:135).

Nesse contexto, um grupo que aguarda um Jesus escatológico, o "senhor do futuro" será mal interpretado por aqueles que aguardam um mediador de salvação como uma fonte presente e atual de obtenção de empoderamento para as questões de seu tempo presente (Corrington,1986:45). Essa dinâmica pode ser observada no período pós-iluminista, de igual forma, quando as diferentes denominações cristãs, mediada em suas experiências pela razão, passaram a aceitar uma experiência religiosa muito mais guiada pela "pregação da Palavra" do que pela realização de feitos extraordinários.

${ }^{8}$ Partido dos argumentos de Wilson, Corrington objeta Holladay. Para além dessa resposta da autora norte-americana, pode-se também construir uma crítica a Holladay a partir de três elementos: (i) ele falha ao exigir que um modelo geral atenda a todo e qualquer caso particular mencionado no interior desse mesmo modelo. Do ponto de vista da ciência moderna, o procedimento de Holladay tem valor, no entanto, os dois outros aspectos seguintes explicam melhor o porquê de ter adotado tal procedimento; (ii) Holladay é bastante zeloso para com a fé cristã ortodoxa, por assim dizer. A assunção do conceito de homem divino, em alguma medida, destitui Jesus e demais líderes dos movimentos paleocristãos de suas posições unívocas e singulares. Tal como já mencionado, essa postura de "teólogo em missão" pretende muito mais inviabilizar a investigação heurística do que submeter o modelo theios aner à investigação criteriosa dos diferentes modelos epistemológicos da ciência moderna.

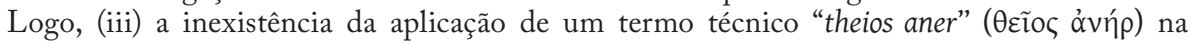
documentação antiga mais o tensionamento do conceito e limites do que seja a helenização do judaísmo perfazem o arcabouço teórico-metodológico que o levam a refutar o conceito de homem divino quando aplicado a Josefo, Artapano e Fílon. 
Por meio dessa operação, as lideranças das auto-proclamadas ortodoxias cristãs encontraram meios e subterfúgios para não perderem seus aderentes para "qualquer pregador carismático" que aparecesse. É claro que o fenômeno é bastante mais complexo, uma vez que a próprio catolicismo apostólico romano se valeu (e funciona até hoje!) das figuras dos (homens) santos como referenciais de virtude e veneração.

Alternativamente, mas de alguma maneira complementar ao quadro geral, Corrington lembra a noção de “trajetória”, presente em Koester/Robinson como uma forma de entender a interação entre os documentos neotestamentários com o mundo à volta deles. Consoante Robinson (1971:10), na noção de trajetória um fenômeno particular pode ser visto como "expoente de movimentos inteligíveis" oferecendo um meio a partir do qual a fluidez do conceito pode ser percebida enquanto que a mesma atenção é prestada ao seu desenvolvimento cronológico e horizonte ou horizontes em que o fenômeno ocorre.

Disso decorre que a dinâmica cultural em que o fenômeno theios aner ( $\theta \varepsilon \tilde{o}$ ک ảvńp) conhece seu desenvolvimento deve ser esquematizada a fim de perceber de que forma os diferentes fenômenos podem ser reunidos sob a categoria/termo/

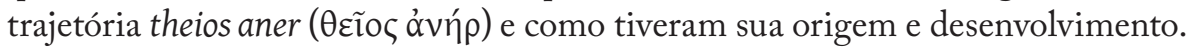
Nesse mister, Corrington (1986:46) entende que deve ser demonstrado como o conceito de homem divino se desenvolveu no mundo helenístico como uma

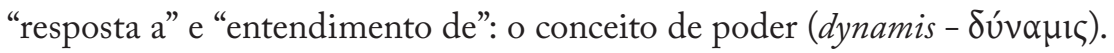

Após estabelecer a noção que está por trás do homem divino como um modelo, a autora norte-americana define propriamente o que entende por theios

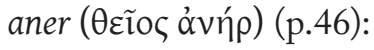

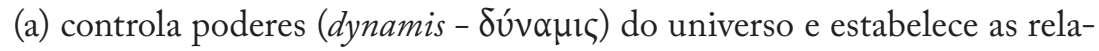
ções a partir das quais os demais seres humanos têm com esse poder - essa é uma atribuição de um ser divinizado;

(b) as descrições de poderes e atributos da divindade a qual se relaciona o homem divino - descritas em aretologias e dynameis - paulatinamente vão sendo designadas a quem possui o mesmo controle e habilidade de manipulação desses poderes;

(c) o taumaturgo é tido como uma epifania ou revelação do deus a quem representa. Àqueles que são capazes de demonstrar tais feitos - portanto, homens divinos - podem ser: filósofos dotados de sabedorias (sophoi -

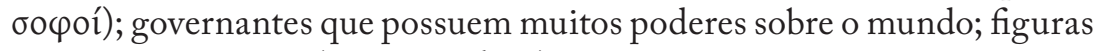

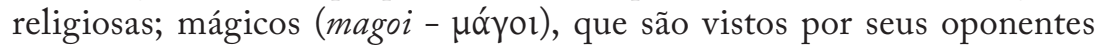

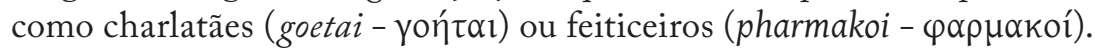

Do ponto de vista da documentação, Corrington (1986:46-49) entende que o milieu próprio para se buscar as figuras de homens divinos sejam aqueles de origem mais "popular", de cunho menos rebuscado e com intenções 
de atingir as massas menos privilegiadas de instrução: uma "audiência menos qualificada" (p.46). A categoria "popular" para a autora norte-americana está diretamente ligada à baixa instrução e menor poder econômico. Esse seria, então, o alvo preferencial em que se poderiam encontrar mais informações sobre homens divinos.

Inclusive, os evangelhos canônicos e Atos dos Apóstolos seriam textos direcionados àquela audiência menos qualificada e, portanto, por excelência documentos "populares" (p.47). O que definiria o conteúdo desses materiais como "populares" e os qualificaria como destinados a audiências menos sofisticadas seriam as refutações e sátiras que receberam de outros autores contemporâneos ou imediatamente posteriores a eles, defende Corrington (pp.47-48).

Para essa audiência, os apologistas - esses, sim, intelectualizados e mais sofisticados, Josefo, Fílon, dentre outros - empenhavam-se em demonstrar as

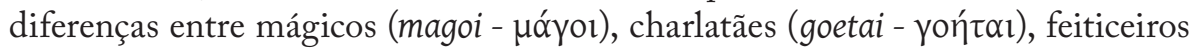

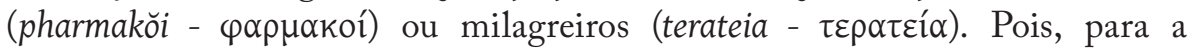
leitura "popular", os atos, procedimentos e métodos de realização de feitos extraordinários, embora realizados a partir de meios ou naturezas diferentes, tinham o mesmo efeito, portanto, arrebanhavam aderentes com base em suas "enganações". (pp.47-48).

Essa dicotomia entre "audiência menos sofisticada" ou "popular" - a quem, por exemplo, foram direcionados evangelhos canônicos - e "apologistas" ou "círculos mais refinados ou sofisticados" apresenta-se como uma categorização quanto à natureza dos documentos por demais artificial, preconceituosa e imaginária. Corrington não se mostra diferente da literatura corrente em fins do século XIX e no XX que criou essas falsas dicotomias?.

É certo que em contexto mediterrânico, os níveis de alfabetização eram baixíssimos, ${ }^{10}$ mas ela parece ignorar o fato de que textos produzidos nessa bacia mediterrânica dificilmente circulavam para serem lidos ou reproduzidos amplamente para distribuição e leitura indiscriminada. ${ }^{11}$ Tanto a redação de tais textos, quanto sua circulação, em sua maioria, estavam restritas a grupos muito

${ }^{9}$ Esse tema foi mais bem explorado em Justi, 2015:130-149.

${ }^{10}$ Discussões e evidências deste fato são tratadas de forma mais aprofundada em Crossan (2004), Faria (2009 e 2011), Gamble (1995), Kloppenborg (2000), e Young (1998 e 1998a).

${ }^{11} \mathrm{O}$ mesmo pode ser observado no que está na nota 55. Para do que já foi dito, uma perspectiva mais recente, ou seja, a "escola" da performance (o movimento não iniciou como uma "escola", mas acabou por se consolidar e tomar forma de um grupo específico nessa abordagem - www.biblicalperformancecriticism.org) busca reconstruir as narrativas antigas, no geral, e bíblicas, no particular, sob o ponto de vista da maneira com a qual esses textos eram "desempenhados" em leituras ou recitações públicas. Essa performance ou desempenho constitui-se no esforço em reconstruir um cenário no qual textos que não foram produzidos para leitura - dada a altíssima taxa de não letrados na bacia mediterrânica -, mas para ritualização coletiva. 
pequenos de elites letradas. E, quando se tornavam de conhecimento mais amplo, eram lidos com boa dose de representação e "performance" por parte dos leitores.

Ao proceder tal classificação dos documentos e definir, socialmente, que grupos tinham acesso a qual tipo de leitura da realidade, a autora norte-americana falha em reconhecer as dinâmicas a partir das quais as culturas mediterrânicas eram informadas cotidianamente. Sobretudo pelas imagens, modelos arquitetônicos, numismática, monumentos públicos ou representações imagéticas em espaços públicos ou privados de pinturas, por exemplo. ${ }^{12}$

Torna-se muito difícil julgar a que tipos de materiais ou pesquisas sobre culturas mediterrânicas a autora teve acesso e, proporcionalmente, mais cômodo, desde o tempo presente, estabelecer falhas ou críticas ao trabalho dela, por essa razão é que o tema não se alongará aqui. O fato é que, para concluir, certamente o trabalho da autora norte-americana, que é valioso em múltiplos aspectos, ganharia bastante com um olhar transdisciplinar para as culturas mediterrânicas.

O modelo mais recente que analisa os homens divinos no mediterrâneo é aquele já mencionado de Cornelli (2000). Por meio da comparação entre as personagens Jesus de Nazaré - presente nos evangelhos canônicos - e Apolônio de Tiana - de Filostrato - o autor ítalo-brasileiro constrói o conceito de equivocidade na recepção de homens divinos antigos sustentado por uma arguta

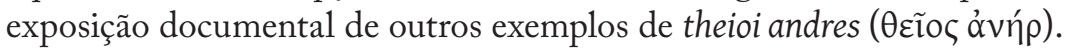

De forma inédita e com muito valor heurístico, Cornelli traz inovação em seu trabalho, bem como qualidade científica em contexto brasileiro que até então teve os assuntos relacionados a estudos de paleocristianismos como monopólio quase exclusivo de estudiosos religiosos confessionais. Embora tenha produzido sua tese em um programa de pós-graduação em Ciências da Religião de uma universidade Metodista, o conteúdo de sua análise revela um padrão e abordagem digna de mesmo status de relevância internacional em

${ }^{12}$ Dois excelentes referenciais para sustentar essa realidade em culturas mediterrânicas são Bonner (1950) e Balch (2003). Bonner elaborou um sistemático catálogo de amuletos, moedas, entre outros artefatos de cultura material que testemunham a ampla disseminação de elementos mágicos presentes nos mais diferentes espaços cotidianos - casas e cemitérios, por exemplo, para o espaço público e amuletos de uso pessoal (espaço privado, mas também de exposição pública) - que perfazem um conjunto significativo de elementos "informativos" que impossibilitam a classificação social de seus portadores na dicotomia entre o que é de acesso por parte de uma audiência mais ou menos "sofisticada". Balch também expõe um espectro de afrescos no interior de casas e templos em Pompéia que dão conta do amplo uso da iconografia material como elementos informativos da audiência mediterrânica, de igual modo, impossíveis de determinar sua procedência quanto a uma classificação social no que diz respeito ao acesso de uns em detrimento de outros. Trata-se de evidências incontestes de que o acesso a temas mágicos vão muito além de textos. Torna-se, assim, impossível afirmar que textos ou imagens têm alvos específicos, especialmente se o que se leva em conta é a condição social ou de letramento de grupos sociais na plêiade de experiências culturais cotidianas mediterrânicas. 
círculos não religiosos.

Uma vez percorrida a trajetória de formação e consolidação do conceito

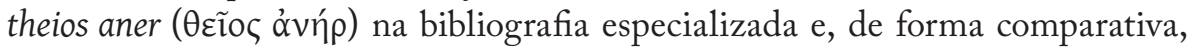
levado em conta os temas centrais e corolários da definição de um tema polêmico como esse, convém, agora, traçar um modelo a partir do qual este trabalho entende a figura dos homens divinos mediterrânicos antigos. É, sem dúvida, um trabalho árduo para um historiador definir um modelo geral para enquadrar determinadas figuras históricas em uma categoria de análise.

\section{Estabelecimento de um modelo teórico-Metodológico com EXPLICAÇÃO DOS PASSOS COERENTES NECESSÁRIOS}

Assumindo a história como a ciência do particular, que opera na investigação da ação do homem no tempo e no espaço, é cada vez mais difícil sistematizar dados conceituais para aplicar a diferentes agentes históricos em distintos tempos e espaços a fim de que um modelo sirva como ponto de partida para investigações científicas. Mas, é justamente ciente dessa dificuldade que o modelo parece ganhar validade enquanto indicativo para início de análise comparativa.

É óbvio, em se tratando de estudos históricos, que especificidades locais e temporais devem ser levadas em conta, desde que isso não imobilize uma formulação mais ampla que permita um olhar comparativo de fenômenos humanos sob perspectiva histórica. Formular, então, um modelo próprio para o estudo dos homens divinos é uma tarefa dupla:

(i) comparar diferentes personagens em seus respectivos tempos e espaços e buscar extrair elementos gerais de suas ações e recepções rumo a uma sistematização mais ampla;

(ii) tendo no horizonte essas características gerais de personagens ao longo da história, analisar se, especificamente ou na particularidade de suas existências, os mais amplos espectros possíveis de características particulares tornam possíveis sua leitura (ou enquadramento) naquele modelo geral.

O passo mais primordial nesse mister é, de imediato, aceitar o pressuposto de Betz $(1961: 102 ; 1968: 117)$ de que a ocorrência do termo ou expressão theios aner ( $\theta \varepsilon \tilde{\imath} o \zeta$ $\alpha$ v́p) na documentação antiga não é decisiva para a percepção do modelo. Não é, em hipótese alguma, embaraçoso admitir que theios aner ( $\theta \varepsilon \tilde{\imath} о \varsigma$ óví $\rho$ ) raramente tenha sido usado como um título na documentação antiga, mas se trata de um construto científico moderno para o estudo daquelas personagens antigas que atendam a este ou aquele modelo. O que se faz central é a coerência interna e clareza nas opções na construção de tal modelo. 
A advertência de Corrington (1986:43-44) sobre os modelos de Bieler e Wendland parece muito pertinente nesse sentido, pois ampliar por demais as características básicas do que venha a ser um homem divino acaba por fazer com que o modelo se deforme para abarcar todos os dados. Não são os dados que devem moldar o modelo, mas a observação deles, enquanto modelos gerais nos diferentes casos comparados, é que devem construir um modelo epistemológico consistente a partir de um conceito bem delimitado.

A necessidade de um modelo epistemológico deve obedecer a um criterioso método de conceituação e verificação empírica, na documentação, para seu estabelecimento. Caso contrário, o critério de classificação se assemelharia a um mero procedimento burocrático como comprar um automóvel, uma casa ou emitir um documento legal: reúne-se uma lista de documentos exigidos e submete-os ao escrutínio de um burocrata que conferirá item a item para observar se todos os elementos exigidos foram anexados a um formulário. Não deve ser esse o caso.

O que se observou em boa parte das discussões em torno do modelo theios aner foi precisamente esse procedimento. Expandiu-se demais um conjunto de características necessárias ao cumprimento de um "padrão" que, obviamente, levou à imobilização do objetivo final. Em alguns casos (Blackburn, por exemplo), essa operação não passou de uma intenção programática de anular a validade de um modelo epistemológico em que equalizasse Jesus e demais seguidores com tantas outras personagens religiosas mediterrânicas. Em outros casos (Holladay, por exemplo), o rigorosíssimo exame das particularidades mínimas acabou por criar fissuras em um "tipo ideal”.

Elaborar, portanto, um modelo coerente para classificar homens divinos demanda, primeiramente, a assunção de um conceito-chave a partir do qual essas personagens serão entendidas. Nesse sentido, Corrington parece correta em adotar o poder (dynamis) como eixo central para agrupar essas diferentes experiências místicas. É o poder de controlar ou manipular forças divinas, por parte de um ser humano, que primeiramente o qualifica com uma natureza superior aos demais seres vivos.

A partir desse núcleo fundamental, a expectativa (demanda) da audiência pela realização histórica e concreta, material, portanto, desse poder que motivará a personagem na realização de algum feito admirável, maravilhoso, fantástico. O homem divino deverá exercer esse poder como prova visível de que o conhece e tem meios para manipulá-lo. Trata-se da performance, demonstração ou manifestação do poder propriamente dito.

Por conseguinte, o último e imprescindível passo para a consolidação do modelo será a reação da audiência. $\mathrm{O}$ ato de poder realizado pelo homem divino pode gerar seguidores ou detratores. Mas, o fim último da ação desses homens divinos é gerar credulidade e aderência por parte daquela audiência. Eis o modelo graficamente representado:

A - Audiência

B - Expectativa, demanda, intervenção voluntária 
C Agente de poder (candidato ou o homem divino propriamente dito)

B' - Performance, demonstração, manifestação material

A' - Aderentes ou detratores

A hierarquia social desses candidatos a seres divinizados será dada a partir dessa dinâmica específica. Ou seja, sua credibilidade em realizar feitos

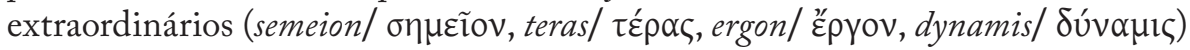
é que fará com que seguidores ou detratores os qualifiquem, positiva ou negativamente, como praticantes de magia (mageia - $\mu \alpha \gamma \varepsilon i ́ \alpha)$, charlatanismo

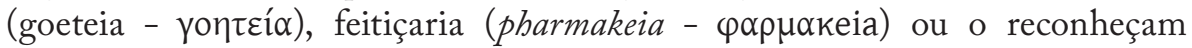

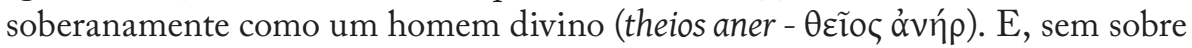
de dúvidas, somente aqueles que forem capazes de "vencer" essas disputas é que receberão o título de homens divinos.

As demandas e lógicas culturais em que está inserida cada personagem ou candidato à divinização atribuirão os títulos respectivos a essas figuras divinas. Isso explica o porquê das múltiplas titulações e divergências de rótulos conferidos a cada personagem. Esse aspecto está relacionado à particularidade do tempo, espaço e, por conseguinte, cultura que acolhe esses homens (divinos ou não). É precisamente nesse aspecto que o modelo teórico theios aner (theios aner - $\theta \varepsilon \tilde{\imath}$ ○

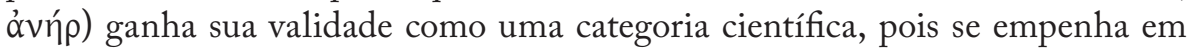
agrupar tanto quanto possível essas experiências místicas, classificá-las e, de igual forma, entendê-las em suas mesmas especificidades culturais.

\section{E. Breves Conclusões}

À primeira vista, o tema dos homens divinos parece estar confinado a discussões ambientadas nos paleocristianismos. No entanto, é somente por meio do estudo comparativo das diferentes culturas mediterrânicas e suas experiências místicas é que o conceito veio a existir, primeiramente, e, somente depois, as personagens paleocristãs foram observadas em termos de validade ou não nessa categorização. É justamente nessa amplitude e diversidade conceitual e discursiva - mediada por elementos documentais palpáveis - que a análise das personagens antigas ganha destaque.

Esse procedimento quer, fundamentalmente, enfatizar a pluralidade de experiências místicas da Bacia Mediterrânica e asseverar o caráter plural, especial, mas não exclusivamente, dos paleocristianismos que, mesmo em sua origem, nunca foram singulares. Assim, as pretensas e auto-proclamadas ortodoxias cristãs de diferentes tempos e espaços que, de uma forma ou outra, estão nas bases da intolerância religiosa perdem sentido e fundamento. 
André Leonardo Chevitarese, Daniel Brasil Justi

\section{Documentação}

Bíblia Sagrada. Versão de João Ferreira de Almeida, Revista e Atualizada, 2a Edição. Rio de Janeiro: Sociedade Bíblica do Brasil, 1993.

Henderson, Jeffrey (Ed.). (2014). Digital Loeb Classical Libary. Disponível em: < http://www.hup.harvard.edu/catalog.php?isbn=9780674425088>. Cambridge: Harvard University Press.

Inscriptiones Graecae e Corpus Inscriptionum Graecarum. Disponíveis em < http:// epigraphy.packhum.org/inscriptions>. The Packard Humanities Institute. Cornell University e Ohio State University. 


\section{Bibliografia}

Achtemeier, Paul J. (1970). Toward the Isolation of Pre-Markan Miracle Catenae. In: Journal of Biblical Literature. Vol. 89, No 3 (Setembro de 1970). pp.265-91.

Achtemeier, Paul J. (1972). The Origin and Function of the Pre-Marcan Miracle Catenae. In: Journal of Biblical Literature. Vol. 91, No 2 (Junho de 1972). pp.198-221.

Almeida, Maria Aparecida de Andrade. (2008). O Poder de Jesus na Cura do Cego de Nascença (Jo 9). In: Candido, Maria Regina e Gomes, José Roberto de Paiva (Ed.) NEARCO - Revista Eletrônica de Antiguidade. No 1, Vol. 1 .

Anderson, Graham (1994). Sage, Saint and Sophist. Holy Men and their Associates in the Early Roman Empire. New York, London: Routledge.

Balch, David L. (2003). The Suffering of Isis/Io and Paul's Portrait of Christ Crucified (Gal. 3:1): Frescoes in Pompeian and Roman Houses and in the Temple of Isis in Pompeii. In: The Journal of Religion, Vol. 83, No. 1 (Jan., 2003), pp. 24-55. Chicago: University of Chicago Press. pp.24-55.

Baur, Ferdinand Christian. (1832). Apollonius Von Tyana und Christus: Oder das Verhaltniss des Pythagoreismus Zum Christenthum. Tübingen. Reprinted from Tübinger Zeitschrift für Theologie.

Betz, Hans Dieter. (1968). "Jesus as Divine Man”. In: Trotter, F. Thomas (ed.). Jesus and the Historian. Philadelphia: Westminster Press, pp. 114-33. (1961). Lukian von Samosata und das Neue Testament. Religionsgeschichtliche und paränetische Parallelen. Texte und Unttersuchungen der altchristlichen Literatur, vol. 76. Berlin: Akademie-Verlag.

Bieler, Ludwig. (1967). QEIOS ANHR. Das Bild des "göttlichen Menschen" in Spätantike und Frühchristentum. 2 Vol. Viena: Wissenschaftliche Buchgesellschaft.

Blackurn, Barry L. (1991). Theios Anèr and the Markan Miracle Traditions. A Critique of the Theios Aner Concept as an Interpretative Background of the Miracle Traditions Used by Mark. Wissenschafliche Untersuchungen zum Neuen Testament, 2. Reihe 40. Tubingen.

Bultmann, Rudolf. (2000). Historia de la Tradicion Sinoptica. Salamanca, España: Ediciones Sigueme.

(1984). Teologia del Nuovo Testamento. Brescia: Editrice Queriniana.

Chevitarese, A. L. e Penn, F. A. (2004). Magia e Religião no Festival das Antestérias. In: História Revista (UFG), Goias, v. 6, n.2, p. 9-24.

(2016). Cristianismos. Questões e Debates Metodológicos. Edição Revista e Ampliada. Rio de Janeiro: Klínē Editora. 
Cotter, Wendy. (1999). Miracles in Greco-Roman Antiquity: a sourcebook. London: Routledge.

Cornelli, Gabriele. (2001). Sábios, Filósofos, Profetas ou Magos? Equivocidade na recepção das figuras de qeiloi a;ndrej na literatura belenistica: a magia incômoda de Apolônio de Tiana e Jesus de Nazaré. Tese de Doutorado. São Bernardo do Campo.

Corrington, Gail. Peterson. (1986). The "Divine Man" His Origin and Function in Hellenistic Popular Religion. American University Studies VII, Theology and religion 17. New York/Bern/Frankfurt am Main: Peter Lang.

Crossan, John Dominic. (1994). O Jesus Histórico. A Vida de um Camponês Judeu do Mediterrâneo. Rio de Janeiro: Imago.

Crossan, J. D. (2004). O Nascimento do Cristianismo. São Paulo: Paulinas.

Dibelius, Martin. (1984). La Historia de las Formas Evangelicas. España, Valencia: Edicep.

Faria, Lair Amaro dos Santos. (2011). "Quem vos ouve, ouve a mim": Oralidade e Memória nos Cristianismos Originários. Rio de Janeiro: Klínē Editora.

Ginzburg, Carlo. (2007). Mitos, Emblemas, Sinais: Morfologia e História. São Paulo: Companhia das Letras.

Holladay, Carl R. (1977). Theios Aner in Hellenistic Judaism. Society of Biblical Literature. Dissertation Series. 40; Missoula, Montana: Scholars Press.

Hopkins, Keith. (1999). A World full of Gods. Pagans, Jerws and Christians in the Roman Empire. Great Britain: The Guernsey Press Co. Ltd.

Jefferson, Lee. M. (2014). Christ the Miracle Worker in Early Christian Art. Philadelfia: Fortress Press.

Jones, Maurice. (1924). The New Testament in the Twentieth Century. London: Macmillan.

Justi, Daniel Brasil. (2015). A construção de Paulo de Tarso como homem divino (theios aner) em Atos dos Apóstolos: as culturas mediterrânicas e paleocristãs em perspectiva comparada. Rio de Janeiro, 259p. Tese de Doutorado - Instituto de História, Programa de Pós-Graduação em História Comparada da Universidade Federal do Rio de Janeiro.

Kloppenborg, J. S. (2000). Excavating Q: the history and setting of the Sayings Gospel. Minneapolis: Fortress Press.

Koester, Helmut. (1971). The Structure and Criteria of Early Christian Beliefs. In: Koester, Helmut e Robinson, James M. (1971). Trajectories through Early Christianity. Philadelphia: Fortress Press.

Luck, Georg. (2006). Arcana Mundi. Magic and the Occult in the Greek and Roman Worlds. A Collection of Ancient Texts. Baltmore: The Johns Hopkins University Press. 
Pilgaard, Aage (1997). The Hellenistic Theios Aner - A Model for Early Christian Christology? In: Borgen, Peder. \& Giversen, Søren (Ed.) The New Testament and Hellenistic Judaism. Peabody, Massachusetts: Hendrickson Publisher.

Reitzenstein, Richard August. (1978). Hellenistic Mystery-Religions: Their Basic Ideas and Significance. Pittsburg Theological Monograph Series, Book 15. Pittsburg: Pickwick Press.

(1963). Hellenistiche Wundererzäblungen. Stuttgart: Teubner.

Smith, Morton; Hadas, Moses. (1965). Heroes and Gods, Spiritual Biographies in Antiquity. New York: Harper \& Row.

(1971). Prolegomena to a Discussion of Aretalogies, Divine Man, the Gospels and Jesus. In: Journal of Biblical Literature, Vol. 90, № 2 (Jun. 1971). pp. 174-99.

(1978). On the History of the Divine Man. In: Festschrift, Marcel Simon. Paganisme, Judaisme, Christianisme. Paris: de Boccard. pp.335345 .

(1996). On the History of the Divine Man. In: Cohen, Shaye J. D. Morton Smith. Studies in the Cult of Yahweh. Vol 2: New Testament, Early Christianity e Magic. Netherlands: E. J. Brill.

Talbert, Charles H.. (1975). The Concept of Immortals in Mediterranean Antiquity. In: Journal of Biblical Literature. Vol. 94 № 3 (Sep., 1975). pp. 419-36.

Tiede, David. L. (1972). The Charismatic Figure as Miracle Worker. Missoula, Montana: Scholars Press.

Wendland, Paul. (1904). Swth,r. In: Preuschen, Erwin (Org.). Zeitschrift für die Neutestamentliche Wissenschaft und die Kunde der Älteren Kirche. Volume 5. Issue 1. Gieszen, J. Ricker'sche Verlasgabuchhandlung. 
(Página deixada propositadamente em branco) 


\title{
Artémis de thasos, entre religion et magie (Artemis of Thasos: between magic and religion)
}

\author{
Clarisse Prêtre \\ Universite Paris-Quest \\ (clarisse.pretre@mae.u-paris10.fr)
}

\begin{abstract}
Aвstrait - De l'époque archaïque à la fin de l'époque hellénistique, le sanctuaire d'Artémis à Thasos a livré une grande quantité d'offrandes. Si certaines catégories (figurines, céramiques) ne présentent pas de spécialité locale et peut être analysées dans un contexte dédicatoire plus grand concernant les sanctuaires du monde grec, le spécificité thasienne de quelques autres offrandes permet de dégager de nouvelles fonctions d'Artémis, qui abandon le rôle simple positif de kourotrophe pour réviser une dimension plus sombre, caractéristique d'Hécate. Certains petits objets votifs (astragals en ambre, jetons en verre, clochettes apotropaïques, amulettes prophylactiques) nous obligent à réinterpréter les pratiques rituelles des femmes qui se complètent pour l'Artémision et à la reconsidération sous l'angle de la divination et de la magie , suscité par l'ambivalence divine entre Artemis et Hécate.
\end{abstract}

Mots CLÉs: religion grecque; Artemis; Hécate; la magie; apotropatique

Aвstract - De l'époque archaïque à la fin de l'époque hellénistique, le sanctuaire d'Artémis à Thasos a livré une grande quantité d'offrandes. Si certaines catégories (figurines, céramiques) ne présentent pas de particularisme local et peuvent être analysées dans un contexte dédicatoire plus large concernant tous les sanctuaires $d u$ monde grec, la spécificité thasienne de quelques autres offrandes permet de dégager de nouvelles fonctions d'Artémis, qui abandonne le simple rôle positif de kourotrophe pour revêtir une dimension plus sombre, caractéristique d'Hécate. Certains petits objets votifs (astragales en ambre, jetons en cristal, clochettes apotropaïques, amulettes prophylactiques) nous obligent à réinterpréter les pratiques rituelles des femmes qui se rendaient à l'Artémision et à les reconsidérer sous l'angle de la divination et de la magie, suscitées par l'ambivalence divine entre Artémis et Hécate.

Keywords: Greek religion; Artemis; Hecate; Magic; apotropatique

Associer magie et religion dans l'Antiquité grecque, c'est supposer d'emblée le chevauchement des deux domaines ${ }^{1}$. A première vue, la distinction est en effet ambiguë, puisque les procédés auxquels on fait appel sont parfois les mêmes: l'Hippolyte d'Euripide est à cet égard un exemple de la dualité de certaines pratiques. Ainsi, avec les incantations et les prières, on bascule régulièrement du

${ }^{1}$ A condition de savoir ce qu'on désigne par le terme de religion, ainsi que le soulignait déjà Frazer, 1922: 3 "hence a writer may reasonably be expected to define his conception of religion before he proceeds to investigate its relation to magic". 
divin au magique. Les servantes expliquent le mal de Phèdre par une possession divine, inspirée par Pan ou Hécate, mais la nourrice suggère le recours à des incantations à double tranchant: susciter le désir d'Hippolyte et apaiser la torture

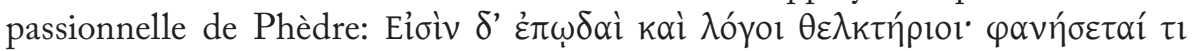

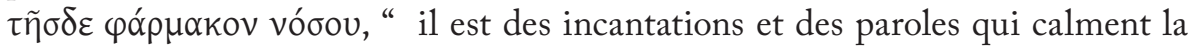
peine d'amour: on trouvera un remède pour ton mal ". Le pharmakon évoqué ici, renvoie à un autre type de procédé commun à la magie et la religion, puisque dans les deux cas, la confection de breuvages peut amener une guérison ou la mort, selon la personne qui le fabrique: le traité Sur la maladie sacrée du corpus hippocratique condamne fortement les traitements des mages contre l'épilepsie, ainsi que tout ce qui ressemble de près ou de loin à des remèdes magiques. Cependant, il n'est pas rare de trouver les mêmes ingrédients en composition de philtres maléfiques comme de potions thérapeutiques: Ulysse enduit ses pointes de flèches de poison à base d'hellébore, Démèter protège le fils de Métaneire grâce à "un remède plus puissant que toutes les herbes coupées dans les forêts" Les sacrifices ou encore les pratiques divinatoires procèdent également d'une ambivalence éprouvée durant toute l'Antiquité: à côté des rituels religieux, les mentions de sacrifices d'oiseaux à usage magique sont ainsi bien connues ${ }^{4}$.

Force est également de reconnaitre que si la plupart des termes des sources textuelles désignant les acteurs de la magie s'appliquent davantage à des hommes

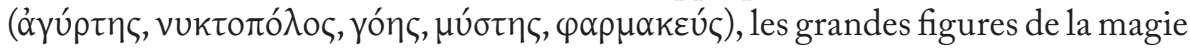
dans la mythologie sont Circé, Médée ou encore Calypso, c'est-à-dire autant de femmes auxquelles répondent le plus souvent des divinités féminines également. Dans un système polythéiste, aucun domaine n'est en général la propriété exclusive d'une figure divine: toutes les divinités peuvent donc susciter cette dualité entre pratiques religieuses et magiques, mais certaines sont plus propices que d'autres à une orientation aux confins de la magie, ou pour atténuer la portée négative contenue dans le terme " magie", leurs attributs, leurs épiclèses parfois, portent à des rites superstitieux sortant du cadre strict de la religion ${ }^{5}$. Qu'on se souvienne des efforts de Simaitha, dans les Magiciennes de Théocrite, pour reconquérir l'amant perdu. Les rituels qu'elle met en scène au fur et à mesure de la cérémonie, sont ceux qui sont habituellement employés par les hommes pour conquérir les femmes. Les gestes sont souvent brutaux, voire violents comme ceux d'un homme en pareil cas: "Je veux écraser une salamandre (...) Je pétris les os de Delphis ”. A côté des litanies magiques, l'orge qu'elle brûle est habituellement utilisé dans les sacrifices, à côté du breuvage magique, elle accomplit des libations religieuses, et surtout, à côté de sa malédiction invoquant

\footnotetext{
${ }^{2}$ Hip.: 477.

${ }^{3}$ Hymne à Déméter: 229.

${ }^{4}$ Zografou, 2008: 187-203.

${ }^{5}$ Pour une mise en garde à propos des mots religio et superstitio, voir Sachot, 1991:355-394.
} 
Hadès, son incantation liminaire est destinée à Sélénè, Aphrodite, et ArtémisHécate: “Mais toi, Séléné, brille d'un bel éclat ; car c'est à toi que je vais adresser à voix basse mes incantations, déesse, et à la souterraine Hécate, devant qui tremblent les chiens eux-mêmes, quand elle vient à travers les monuments des morts et le sang noir (...) Comme ce disque d'airain tourne éperdument sous l'action d'Aphrodite, ainsi puisse-t-il tourner éperdument à ma porte (...) Artémis, toi qui serais capable de remuer et l'acier des Enfers et ce qu'il peut y avoir encore d'inébranlable... Thestylis, les chiens, tu les entends, aboient à travers la ville ; la déesse est dans les carrefours ; vite, fais résonner l'airain"'.

Artémis est une figure divine emblématique de cette oscillation entre prières religieuses et incantations magiques et les offrandes qu'on lui adresse dans certains sanctuaires peuvent être envisagées comme de simples objets votifs, mais également parfois comme les instruments de pratiques superstitieuses ou divinatoires.

Ainsi, l'Artémis célébrée à Thasos dès l'époque archaïque n'a longtemps été considérée que la protectrice des jeunes gens ${ }^{7}$ via la chasse et le banquet, et de la femme aux différentes étapes de sa vie. Il est évidemment possible de faire coïncider de grands types d'offrandes avec ces fonctions bien connues. Certaines études de la dernière décennie, fondées sur une partie du matériel — figurines de terre cuite ou vases à boire - confirmaient donc des attributions bien attestées dans d'autres sanctuaires de la déesse ${ }^{8}$, sans parvenir à dégager une spécificité votive pour cet Artémision: la majeure partie des objets déposés ne présentait guère de particularité, en suivant ainsi le principe d'interchangeabilité des dédicaces dans les sanctuaires, indistinctement de la divinité: on pouvait aussi bien offrir une figurine de terre cuite à Héra qu'à Artémis dans l'ensemble du monde grec, et en outre, pour un même type de sanctuaire (comme un Thesmophorion par exemple), les offrandes présentaient de fortes similitudes, que ce soit pour celui de Thasos, celui de Pergame ou encore celui du Pirée. La plupart des petits objets votifs recensés dans le sanctuaire thasien entrent donc parfaitement dans ces champs d'action attendus pour Artémis9.

C'est par l'étude d'un autre type de mobilier votif ne relevant pas de l'artisanat de masse qu'il est possible de discerner l'ambivalence évoquée de

${ }^{6}$ Théocrite, Idylles, $2.10-16$ et 2.30 sqq.

${ }^{7}$ Avec une méthodologie douteuse, on invoque parfois une épiclèse d'Artémis Pôlô attestée au IIème s. av. J.-C. pour justifier une protectrice des jeunes gens à l'époque archaïque. Maffre, Tichit, 2011: 137-164. Pour un commentaire sur les dangers de la surinterprétation des objets trouvés dans un sanctuaire, voir Prêtre, 2011: 227-237.

${ }^{8}$ Notamment Huysecom-Haxhi, 2009. L'étude menée actuellement sur les vases à boire de l'Artémision par A. Tichit reprend le sempiternel motif du rite de passage des jeunes gens utilisant des coupes lors de banquets. On peine néanmoins à justifier pourtant l'absence d'amphores et de cratères dans ce contexte.

${ }^{9}$ Pour une synthèse sur ces offrandes non spécifiques de l'Artémis thasienne, voir Prêtre, C. 2015: 143-144 notamment. 
certaines pratiques aux confins entre la religion, la magie et la superstition; par ce biais, on comprend alors comment se manifeste le lien avéré qui unit Artémis à Hécate à Thasos.

L'association d'Artémis à Hécate est en effet connue grâce à deux inscriptions de la première moitié du Ve s. av. J.-C. Dans un règlement de police et de voirie des années $460^{10}$, une amende est exigée en cas d'infraction au code et elle devra être

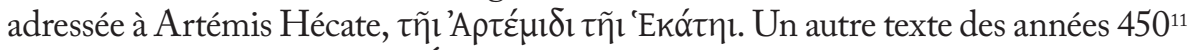
porte une dédicace à Artémis Épauliè Hécate. Plus que d'entités distinctes, il s'agit ici d'une assimilation totale entre les divinités, qui renforce le rôle dédié à Artémis lors des épousailles des femmes le lendemain des noces. La mention d'Artémis-Hécate ne doit pas surprendre quand on sait qu'outre son aspect chthonien, elle présidait elle aussi à certaines phases de la vie des femmes et notamment à l'accouchement. Par cette triple dénomination, on a là les trois étapes féminines importantes: la jeune fille protégée par Artémis, l'épousée protégée par Artémis Épauliè, la mère dans l'enfantement protégée par Artémis Épauliè Hécate.

Néanmoins, les quelques petits objets qui seront étudiés ici tendent à prouver qu'Hécate entraîne Artémis vers un côté plus sombre, suscitant des pratiques magiques, et cette autre dimension d'Artémis nous autorise à remettre en perspective l'emplacement de son sanctuaire, auquel on n'avait guère attaché d'importance jusqu'à présent.

\section{— Les objets votifs: entre divination et magie.}

- Les pendeloques à clochettes (Fig. 1)

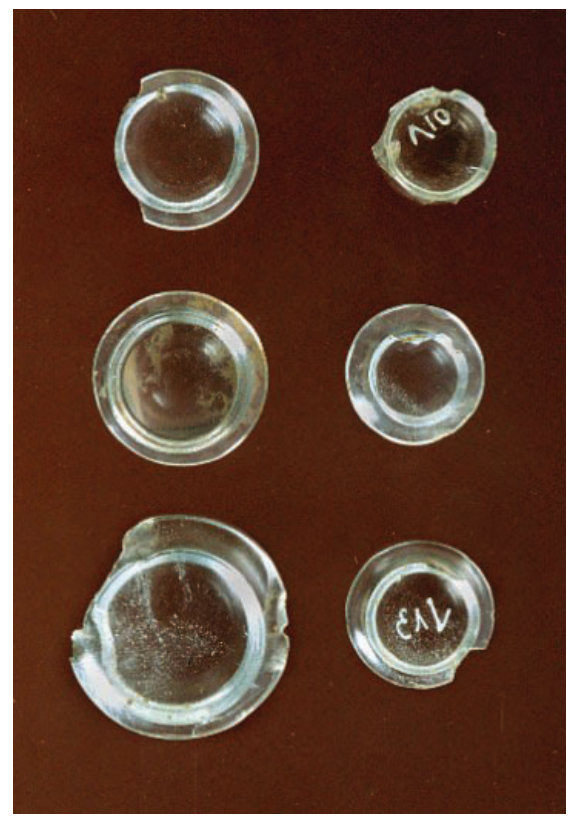

\footnotetext{
${ }^{10}$ Duchêne, H. 1992: 1. 49 du texte.

${ }^{11}$ IG XII 8. 359.
} 
Sept exemplaires d'un genre particulier de pendeloques ont été trouvés dans l'Artémision de Thasos. Toutes relèvent d'un type macédonien en vogue dans les débuts du sanctuaire thasien, soit avant 650 av. J.-C. En Grèce continentale, on les recense dès l'époque mycénienne ${ }^{12}$. Il est important de souligner que la majorité de ces offrandes se trouvaient dans des tombes de femmes nubiles, et non dans des lieux de culte: leur position au niveau des hanches a permis de comprendre qu'elles étaient accrochées à la ceinture ${ }^{13}$. Jusqu'à présent, on expliquait ce passage d'un contexte funéraire à un contexte votif par la venue à Thasos de femmes de bergers de Chalcidique qui auraient adopté les mœurs du Sud. Mais ces bijoux originaux, lourds et riches ne correspondent pas à des offrandes banales et il est difficile d'imaginer qu'une telle démarche votive était pratique courante pour les Macédoniennes.

Par ailleurs, dans certaines tombes, les squelettes auxquels étaient associées ces pendeloques ont été découverts avec des restes de foetus ou de nourrisson: qui étaient réellement ces femmes qu’on enterrait avec ces bijoux et leurs enfants morts-nés? Mortes en couches, elles étaient ensevelies avec une parure qui symbolisait leur vie d'épouse voire de mère. A l'Artémision de Thasos, on ne sait si ces parures étaient acquises spécialement au moment d'un accouchement ou au moment du mariage, mais il est certain qu'elles n'appartenaient pas à des jeunes filles. La déesse semble d'ailleurs avoir été davantage tournée vers la protection des femmes mariées que des jeunes filles, à l'époque archaïque et classique tout du moins: les parallèles thasiens trouvés en contexte votif renvoient donc une fois encore à un statut de femme à une étape très précise de sa vie, que ce soit l'hymen ou l'enfantement. C'est Artémis-Hécate qui est au cœur de cette pratique dédicatoire et cet aspect sera renforcé à l'époque romaine par le culte à Artémis-Eileithyia, connu par le décret pour Épiè où il est dit que cette dernière a rendu hommage à la divinité ${ }^{14}$. Artémis, dont les nombreuses épiclèses comme Eulochia ou Sôodina la désigne comme une déesse qui assiste souvent les accouchements, se confond souvent avec la déesse fonctionnelle de la délivrance, Eileithyia. Mais Artémis-Hécate préside également à l'enfantement comme le rappelle Eschyle dans les Suppliantes lorsque le chœur la prie " de veiller aux couches des femmes ${ }^{{ }_{15}}$.

Certes, l'origine macédonienne de ces pendeloques justifie peut-être qu'on les trouve en offrandes dans un sanctuaire en face de la côte, mais même en laissant la question du profil des donatrices, leur dépôt dans l'Artémision thasien doit être vu comme une marque originale, associant dans une même divinité plusieurs attributs qui se recoupent. En outre, il n'est pas anodin de constater que

\footnotetext{
${ }^{12}$ Kilian-Dirlmeier I. 1979: pl. 23 et 24 avec modèles composites.

${ }^{13}$ Pour une étude détaillée du type, Dunant, Rolley, 1987: 55-61.

${ }^{14}$ Salviat, 1959: 363.

${ }^{15}$ V. 685 .
} 
les seules pendeloques à avoir été en contexte votif comme à Thasos se trouvaient dans un sanctuaire d'Artémis Énodia à Pherai et d'Athéna Itonia à Philia ${ }^{16}$. Les liens entre ces deux divinités à épiclèses et le monde chthonien sont évidents, puisque Énodia “l'une dans la rue “était aussi une épiclèse d'Hécate et qu’Athéna Itonia était en connexion avec les divinités chthoniennes. D'une manière plus générale, Artémis régit aussi la mort des femmes hors accouchements; qu'on songe à Niobè et ses douze enfants, qui osa se moquer de Létô: ses six filles furent transpercées par une flèche d'Artémis.

A Thasos donc, la dédicace à Artémis-Hécate de pendeloques de ceinture dépasse le simple cadre votif pour prendre une fonction apotropaïque et détourner ainsi la douleur cruelle de l'accouchement, souvent activée par Artémis en souvenir de la souffrance de sa mère Létô. On glisse insensiblement de la religion à la "superstition " selon le sens déterminé par E. Benveniste, c'està-dire un amalgame populaire de normes religieuses et de pratiques divinatoires à la limite du magique.

D'autres offrandes thasiennes viennent confirmer cette évolution du rite.

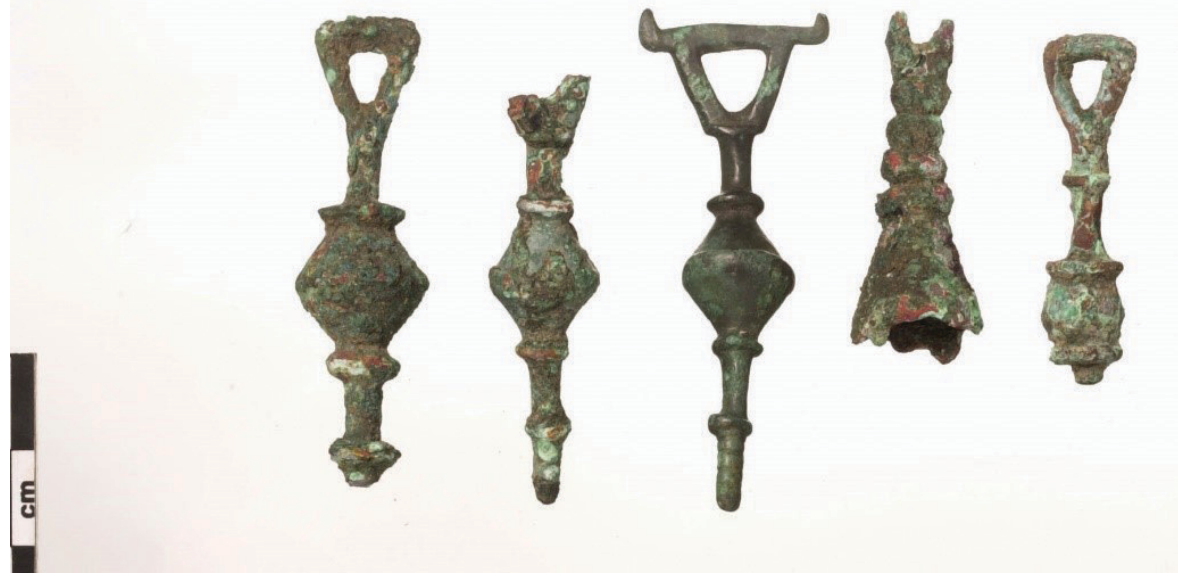

- Les jetons en cristal de roche (fig. 2)

C'est le cas d'objets en cristal de roche découverts en grand nombre dans l'Artémision de Thasos. Affectant une forme de "bobine " très polie qui a pu longtemps les faire confondre avec des loupes ou des éléments de métiers à tisser, ces disques circulaires épais sont resserrés en leur centre et possédent un diamètre différent sur chacune des deux bases. La surface de la grande base est toujours concave, la surface de la petite base est plane ou convexe, plus rarement

${ }^{16}$ Kilian-Dirlmeier, I. (1979): pl. 23 et 24 avec les origines indiquées dans le catalogue. Pour les liens d'Athéna Itonia avec le monde chthonien, voir en dernier lieu Papachatzis (1992): 321-325. 
concave. Aucun disque ne présente de perforation centrale ni de trace de tour: tous semblent avoir été finis à la main après taille du cristal.

Ils ont suscité de nombreuses conjectures sur leur usage propre. On en recense dans d'autres sites, en contexte votif et funéraire, à Éphèse, Paros, Camiros ou encore $\mathrm{Samos}^{17}$. En laissant de côté les nombreuses hypothèses plus ou moins valables à propos de ces objets précieux, l'interprétation la plus plausible dans le contexte d'Artémis thasienne est celle d'une reproduction précieuse de pièces de jeu ou de divination. Le jeu de l'astragale et autres loisirs apparentés étaient fort pratiqués par les femmes, comme en attestent diverses statues et reproductions sur vases, et la divination par ailleurs pouvait se pratiquer au moyen de jetons de même type. En outre, la ressemblance formelle des pièces de cristal avec les vertèbres de thon fréquemment utilisées comme jetons ne manque pas de frapper. Ces éléments portent à croire qu'on pourrait avoir affaire à Thasos à des pièces spécialement fabriquées pour la déesse, afin de rappeler deux pratiques courantes chez les femmes, le jeu des osselets mais aussi la divination liée aux étapes de leur vie. Les épigrammes votives soulignent souvent le lien entre jeunes filles en passe de se marier et leurs jeux avec les osselets: la fille de Lycomedeides prend un congé temporaire d'Artémis pour se marier, alors qu'elle était encore à l'âge

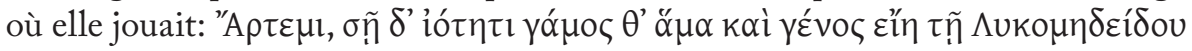
$\pi \alpha 1 \delta i \lambda_{\imath} \pi \alpha \sigma \tau \rho \alpha \gamma \alpha \dot{\alpha} \lambda \eta ̣$, "O Artémis, que par ta grâce il soit accordé un mari et des enfants à la fille de Lycomedeides, qui a renoncé aux astragales du jeune âge "18.

\section{- Les amulettes en cristal de roche}

En outre, la matière choisie pour réinterpréter de façon votive ces pions divinatoires est loin d'être anodine tant on prête au cristal de roche des vertus occultes. Un autre type d'objet dédié à l'Artémision confirme ce caractère magique. Deux tiges hexagonales en cristal biseauté ont été retrouvées parmi les offrandes à Artémis; à Kythnos ou Phaistos, des parallèles plus anciens se trouvaient enchâssées dans une extrémité d'or se terminant par un anneau. Diodore de Sicile résume bien les propriétés quasi magiques que le cristal possédait dans l'Antiquité: “ tels sont les cristaux; ils se composent d'eau pure congelée, non par le froid, mais par l'action d'un feu divin qui les rend

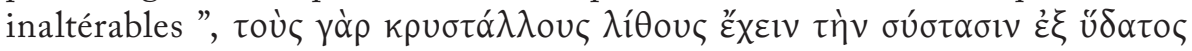

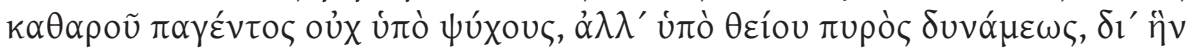

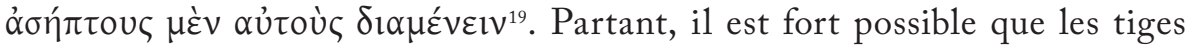
hexagonales de Thasos aient été consacrées à Artémis-Hécate dans un but prophylactique.

\footnotetext{
${ }^{17}$ Pour le détail et une historiographie de l'objet, voir Prêtre, 2015: 29-30.

${ }^{18}$ Anth. Pal. 6.276.

${ }^{19}$ Diodore de Sicile, 2. 52.
} 
En choisissant de dédier une offrande en cristal de roche, on confirmait ainsi l'ambivalence d'Artémis-Hécate à Thasos, en suscitant son côté sombre pour se protéger des peurs, pour conjurer des sorts, des dangers divers. $\mathrm{Ce}$ pouvait être évidemment lié à des moments-clés de la vie des femmes par exemple, et après avoir consacré une amulette en cristal de roche, on pouvait espérer ne rien risquer au moment des noces ou de l'accouchement: la magie divinatoire n'est là pas très loin des pratiques votives plus traditionnelles ${ }^{20}$.

\section{- Les astragales divinatoires}

Les pratiques supersitieuses à l'Artémision semblent être d'autant plus assurées qu'on a retrouvé plusieurs vertèbres de thon utilisées comme jetons de divination ${ }^{21}$, mais surtout, un grand nombre d'astragales de caprins transformés en palets par aplanissement des faces. Il s'agit d'une exploitation de tous les éléments des rites sacrificiels à la déesse: après avoir partagé les parts de la chèvre dédiée, on extrayait alors les astragales réinvestis ensuite d'une fonction divinatoire afin d'être déposés en dédicace dans le temple. Ces coutumes à mi-chemin entre le jeu et la magie sont corroborées par la présence d'astragales votifs en ambre, verre teinté et bronze, peut-être offerts par les femmes une fois qu'elles avaient interrogé leur avenir.

La divination était couramment pratiquée par les femmes dans leur maison mais aussi dans les sanctuaires, où après avoir posé une question à la divinité, elles lançaient les jetons ou les astragales afin d'obtenir une réponse satisfaisante et claire. Certes les astragales thasiens ne sont pas inscrits comme certains de l'Antre corycien par exemple ${ }^{22}$, mais tous n'étaient pas destinés au jeu et n'étaient pas sciés en palets: les exemplaires en verre ou en ambre sont sans doute strictement votifs en raison de leur fragilité et sont une réminiscence d'une réponse obtenue à la suite d'un vœu. L'astragalomancie ne constitue pas forcément une divination institutionnalisée, comme celle qui se pratique à travers les oracles, les sacrifices, la lecture des entrailles, etc. Lancer les osselets pour connaître son avenir est une forme courante de divination individuelle, qui n'a pas besoin d'un devin pour être interprétée comme l'explique Pausanias à propos de l'oracle de Boura, en Achaïe: devant la statue d'Héraklès se trouve la table divisée en compartiments sur lesquels on jette des dés oblongs nommés astragales; “ en

${ }^{20}$ On observe d'ailleurs une résurgence de la puissance magique du cristal de roche bien après l'époque classique: Livie consacre au Capitole un bloc brut de près de $50 \mathrm{~kg}$ et Cléopâtre écrit des lettres d'amour à Antoine sur des tablettes de cristal: Pline, HN37. 27, Plutarque, Ant. 58.11.

${ }^{21}$ Dès l'époque archaïque, dans un Héraion par exemple: Payne, 1940: 444, nos 332-333 et pl. 188 .

${ }^{22}$ Certains exemplaires de l'antre corycien portaient des traces de dorure, d'autres les noms des divinités. Amandry, 1984: 363. 
descendant de Bura vers la mer, vous trouvez le fleuve Buraïcus et une caverne où il $\mathrm{y}$ a une petite statue d'Hercule qui est aussi surnommé Buraïcus. Il y a dans cette caverne un oracle qui fait connaître l'avenir par le moyen d'un tableau et de dés. Celui qui veut le consulter, adresse d'abord des prières à la statue, il prend ensuite des dés, qui sont toujours en très grand nombre devant cette statue, il en jette quatre sur la table, et va chercher l'explication du coup sur le tableau, où tous les différents coups de dés sont représentés, avec l'explication de ce qu'ils prédisent" ${ }^{23}$. Sans imaginer un tel fonctionnement à Thasos, il est évident que les femmes pratiquaient seules l'astragalomancie. On imagine facilement quelles étaient leurs interrogations, à la veille de leur mariage ou d'un accouchement quand elles apportaient des astragales-amulettes censés les protéger ${ }^{24}$. Selon le même principe, les tiges de cristal protégeaient contre une maladie ou un problème au cours d'un enfantement: l'épisode de Létô peinant à accoucher d'Artémis à Délos était présent dans les esprits des femmes à l'heure de la "délivrance". On le lit dans l'Hymne à Apollon: "Alors pendant neuf jours et pendant neuf nuits, Létô fut déchirée par les cruelles douleurs de l'enfantement (...) Létô était en proie aux plus vives douleurs". On le lit dans les offrandes dédiées à Artémis après des accouchements douloureux, comme celui-ci: "Des sandales, un riche bandeau, une boucle parfumée détachée de beaux cheveux, une ceinture, le tissu léger d'un vêtement de dessous, de belles bandelettes pour soutenir le sein, voilà ce qu'Ambrosia après ses couches, ayant échappé aux périls de la grossesse, offre dans son temple à Artémis, sa bienfaitrice "25. Dans un monde où la mortalité des enfants et des femmes à l'accouchement est pléthore, cette étape de la vie est végue comme une lutte pour la survie et non comme un moment heureux.

Associée à la puissance divine, l'amulette aux pouvoirs magiques doit alors donner des forces et préserver de la douleur, accompagnée parfois d'incantations des sages-femmes ; une fois l'enfant né, on la dédie en offrande gratulatoire.

Les amulettes peuvent également être offertes de façon plus discrète après les noces qui selon les lieux et les croyances, n'étaient pas forcément considérées comme un élément positif: au contraire, la défloration pouvait être représenter une veritable terreur pour les jeunes filles, comme le rapporte une épigramme de l'Anthologie Palatine et certaines fêtes à Artémis se terminaient d'ailleurs par des viols simulés ou des parodies de violence ${ }^{26}$. On est loin ici de la figure de la chasseresse protectrice des animaux, de la vierge faisant grandir les jeunes gens et jeunes filles: on se doit de l'honorer pour être heureuse en mariage ou ne pas souffrir lors de son accouchement ; ce sont là deux étapes positives de la vie d'une femme que n'ont connues ni Artémis ni sa mère. "Malheur à ceux que

\footnotetext{
${ }^{23}$ Paus. VII, 25, 10.

${ }^{24}$ Sur la qualité d'amulette des astragales, Amandry, 1984: 377.

${ }_{25}$ Anth. Pal. 6, 201. Voir l'article de Brulé, 1996: 11-32.

${ }^{26}$ Ellinger, 2009: 97-100.
} 
poursuit ta colère! ", dit Callimaque, " les femmes, frappées de mort aux jours de l'enfantement ou n'accouchant que dans les horreurs de la guerre, n'élèvent jamais leurs enfants “.

Cette crainte atavique de la douleur est combattue par des pratiques rituelles renforcées par une dimension supertistieuse contenue dans certains objets votifs, en raison de leur fonction même ou de leur matière. Les offrandes ne s'adressent pas à Artémis mais à Artémis-Hécate, en reproduisant par leur caractère double, l'ambivalence des fonctions de la divinité.

\section{- La topographie du sanctuaire: pour une déesse sombre et sauvage.}

Ce balancement équivoque entre bonté et menace divines est renforcé par la position géographique du sanctuaire par rapport à la cité de Thasos.

La plupart des inscriptions de Thasos mentionnant Hécate et/ou Artémis ont été trouvées à la porte maritime, aux abords de la porte du Silène ou encore à la porte d'Hermès ; déjà avant l'époque romaine, on peut y retrouver une allusion à une Hécate protectrice des passages, des portes et par extension des enceintes sacrées. Cette identification d'un des aspects de la divinité honorée à l'Artémision contribue à conforter la prééminence d'Artémis, en surveillant les portes du sanctuaire comme le font d'ailleurs les chœurs de jeunes filles dans certaines pratiques cultuelles ${ }^{27}$. Ainsi, les donateurs se rendant à l'Artémision avaient à leur disposition toute une série de codes pour les aider dans leur interprétation des attributs d'Artémis: Artémis pour les jeunes filles et les jeunes gens amateurs de chasse et évoluant vers l'âge adulte, sans doute, Artémis pour les femmes mariées, assurément, mais aussi Artémis endossant les rôles sombres d'Hécate pour asseoir sa toute-puissance sur tous les chemins menant à l'Artémision. La triple dimension d'Artémis-Hécate se révélait de façon subliminale à quiconque empruntait le passage des théores pour se rendre à l'Artémision voisin ; sur une des niches du passage, figuraient en effet trois jeunes filles, souvent assimilées aux Charites ${ }^{28}$. La triple vision, le passage, les jeunes filles étaient autant d'éléments annonciateurs de la divinité qu'on allait honorer, un écho de la triple Hécate. Cette procession des trois jeunes filles menées par Hermès pouvait être une résurgence du culte d'Artémis à Paros - même si rien ne prouve que les trois aient été liés à l'origine lors de leur arrivée à Thasos: un relief archaïque parien représente face à face Hermès et Artémis ${ }^{29}$ et on peut encore tisser là un lien subtil en jouant sur les triades.

La tradition littéraire souligne que le dieu est connu pour soustraire les

${ }^{27}$ Zografou, 2010: 237-239.

${ }^{28}$ Le passage des théores a d'ailleurs succédé à une porte de la ville à la fin de l'époque archaïque: Blondé, Muller, Mulliez, 2000: 885-907.

${ }^{29}$ Rösch, 1914: pl. III, 1. 
jeunes filles au chœur d'Artémis: dans l'hymne homérique, le mensonge monté par Aphrodite pour séduire Anchise est révélateur de la brutalité à laquelle peuvent être confrontées les jeunes filles dans les Artémisia: "Hermès à la baguette d'or vient de m'enlever à un chœur que conduisait Artémis armée de flèches et qui se plaît au tumulte de la chasse. Nous étions là plusieurs nymphes et plusieurs vierges aux riches dots: nous jouions ensemble en formant un grand cercle. C'est là que m'a saisie le meurtrier d'Argos: il m'a conduite à travers les champs cultivés par les mains des hommes à travers les terres incultes et désertes qu'habitent les bêtes sauvages au sein des vallées ténébreuses: mes pieds semblaient ne pas toucher la terre. Il m'a dit que j'étais destinée à partager la couche d'Anchise, que je serai son épouse fidèle, et que je lui donnerai de beaux enfants " 30 .

Ce faisceau de signes convergeant vers un aspect "sauvage " de l'Artémis thasienne est conforté par la place du sanctuaire par rapport à la cité archaïque; comme dans l'hymne de Callimaque, ce n'est pas le champ d'action d'une déesse " civilisée " qui se dégage des offrandes à l'Artémis thasienne; son sanctuaire adossé à la colline et proche d'une zone inhabitée et insalubre à l'époque archaïque $^{31}$ renvoie à sa supplique à Zeus: "Cède-moi les montagnes. Je ne demande qu'une ville à ton choix. Artémis descendra rarement dans les villes. J'habiterai les monts, et n'approcherai des cités qu'aux moments où les femmes, travaillées des douleurs aiguës de l'enfantement, m'appelleront à leur aide " ${ }_{32}$.

En confrontant ces données topographiques aux offrandes propres à l'Artémis thasienne, on dresse ainsi le portrait d'une divinité que les femmes vénèrent pour bénéficier de sa protection mais avec des pratiques votives et rituelles relevant de domaines proches de la magie et de la superstition. Ce pouvoir multiple ne transparaît ni dans les offrandes de figurines de terre cuite, ni dans la céramique qui lui est dédiée. Artémis n'est pas seulement une déesse bienfaitrice présidant aux destinées de l'épouse et de la mère de famille, car elle concilie ses attributions bénéfiques avec un côté sombre imposé par la figure d'Hécate. Il y a une superposition de fonctions qu'on observe dans d'autres Artémisia, comme à Mounychia par exemple ${ }^{33}$. C'est la déesse des dangers, ceux du mariage parfois liés à la brutalité sexuelle, ceux de l'enfantement ravivant la douleur originelle de Létô -, c'est aussi la déesse des marges, soulignée par la trimorphie d'Hécate qui pose ses jalons sur les passages menant aux portes de l'Artémision, et enfin

${ }^{30}$ Hymne à Aphrodite. La réalité du culte est évidemment tout autre mais l'image d'Artémis s'est aussi construite autour du mythe de la brutalité.

${ }^{31}$ Avant la construction du rempart au Vème s., la partie basse de l'acropole jusqu'à l'emplacement de la future agora était traversée de multiples ruisseaux et constituait le réceptacle naturel des eaux venant de l'acropole. Le rempart a modifié le cours des ruisseaux et a contribué à assainir l'endroit insalubre et marécageux jusqu'alors.

${ }^{32}$ Hymne à Artémis, v. 19 sqq.

${ }^{33}$ Artémis Eupôria et Liménoskopos y préside les rites de passage des Ourses et les triérarques lui font des sacrifices avant les expéditions navales. 
c'est la déesse sauvage des transitions régnant sur un sanctuaire aux limites de la montagne et d'un marécage à l'époque archaïque ; en dégageant cette entité inquiétante, on comprend mieux que les femmes tentent de se concilier ses faveurs par de nombreux moyens, alliant pratiques religieuses et superstitieuses à des objets magiques.

\section{Dans ce culte à Artémis, peut-on alors réellement parler de magie?}

La distinction faite entre la magie pure et les pratiques magiques doit être soulignée ici: les femmes, en s'adressant à Artémis-Hécate, ne le font pas dans une intention négative: point de tablettes de defixio, point de traces de liens de malédiction, par exemple. La différence est là et elle est fondamentale: les femmes qui viennent au sanctuaire thasien cherchent à se concilier la déesse et non à la forcer comme un magicien le ferait avec des esprits. Leurs offrandes propitiatoires sont là pour attirer sa bienveillance et les objets qui ont pu servir à la divination sont les témoins de leurs frayeurs personnelles et non d'un désir de nuire. Artémis-Hécate suscite la superstition, réveille les peurs des femmes aux différents stades de leur vie mais ne les entraîne pas sur les chemins des maléfices. Les procédés pour connaître leur avenir ont une apparence magique, leurs dédicaces sont souvent ambiguës mais on observe la séparation habituelle entre religion et magie, telle que l'avait définie Frazer: "L'homme a essayé de plier la nature à ses volontés par la simple force de ses charmes et de ses enchantements, avant de tâcher d'amadouer et d'apaiser une divinité farouche, capricieuse ou irascible par la douce insinuation de la prière et du sacrifice ${ }^{{ }_{34}}$.

\footnotetext{
${ }^{34}$ Frazer, 1922: 10: " man essayed to bend nature to his wishes by the sheer force of spells and enchantments before he strove to coax and mollify a coy, capricious, or irascible deity by the soft insinuation of prayer and sacrifice”.
} 


\section{Bibliographie}

Amandry, P. (1904), L'antre corycien II, Paris. Blondé Fr., Muller A., Mulliez D., (2000) "Le Passage des Théores à Thasos: une "énigme" résolue? Questions de topographie et d'urbanisme à l'époque archaïque ", CRAI 144: 885-907.

Brulé, P. (1996), "Des osselets et des tambourins pour Artémis", Clio. Histoire, femmes et sociétés 4:11-32.

Duchêne, H. (1992), La stèle du port: recherches sur une nouvelle inscription thasienne, Paris.

Dunant, Chr., Rolley, C. (1987), "Bronzes macédoniens à l'Artémision de Thasos", BCH 111: 55-61

Ellinger, P. (2009), Artémis, déesse de tous les dangers, Paris.

Frazer, J. G. (1911), The Golden Bough, Oxford.

Huysecom-Haxhi, S. (2009), Les figurines en terre cuite archaïques de l'Artémision de Thasos: artisanat et piété populaire à l'époque de l'archaïsme mûr et récent, Paris.

Kilian-Dirlmeier, I. (1979), Anhänger in Griechenland von der mykenischen bis zur spätgeometrischen Zeit, München.

Maffre, J.-J., Tichit, A. (2011), “ Quelles offrandes faisait-on à Artémis dans son sanctuaire de Thasos?”, Kernos 24: 137-164.

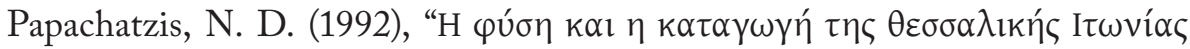

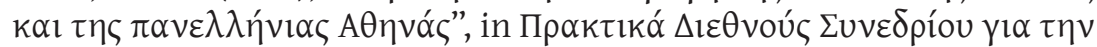

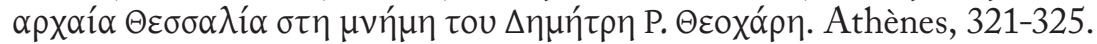

Payne, H. (1940), Perachora. The Sanctuaries of Hera Akraia and Limenia, I. Architecture, Bronzes, Terracottas, Athènes.

Prêtre, C. (2015), La fibule et le clou. Paris.

Prêtre, C. (2011), "Offrandes et dédicants dans les sanctuaires de Thasos ", Revue des Etudes Grecques 124: 227-237.

Rösch, G. (1914), Altertümliche Marmorwerke von Paros I, Köln.

Sachot, M. (1991), " Religio/superstitio. Historique d'une subversion et d'un retournement ", Revue de l'histoire des religions, 208-4: 355-394.

Salviat, Fr. (1959), "Décrets pour Épié, fille de Dionysios: déesses et sanctuaires thasiens", BCH 83: 363.

Zografou, A. (2008), “Prescriptions sacrificielles dans les papyri magiques ”, in V. Mehl, P. Brulé (ed.), Le sacrifice antique: Vestiges, procédures et stratégies. Rennes, 187-203.

Zografou, A. (2010), Chemins d'Hécate. Portes, routes, carrefours et autres figures de l'entre-deux, Liège. 
(Página deixada propositadamente em branco) 


\title{
EvidêNCIAS LITERÁRIAS DA PRÁTICA DAS $A G O G A I$ ANTES DA ÉPOCA ROMANA (Literary evidence of the practice of agogai before roman era)
}

\author{
Cláudia Cravo \\ $\mathrm{CECH}$ - Faculdade de Letras da Universidade de Coimbra \\ (claudiacravo80@gmail.com)
}

\begin{abstract}
Resumo - Com base nos Papiros Mágicos Gregos, não é possível provarmos a existência de encantamentos gregos de atracção (conhecidos como agogai) em tempos mais recuados. A falta de documentos reais anteriores à Época Romana é, felizmente, colmatada pela literatura grega, que nos deixou indícios suficientes da existência de práticas de magia erótica (em geral, e das agogai em particular) em épocas muito antigas. Deter-nos-emos nos três textos literários que consideramos mais significativos a este respeito e que nos deixam a garantia de que as agogai, tão famosas no mundo grego, têm de facto uma extraordinária e longa história.
\end{abstract}

Palavras-chave: Papiros mágicos; magia erótica, Roma; Safo; discurso amoroso

Aвstract - Based on the Greek Magyar Papyri, it is not possible to prove the existence of Greek enchanting spells (known as agogai) in earlier times. The lack of real documents prior to the Roman Epoch is fortunately clogged up by Greek literature, which left us sufficient evidence of the existence of erotic magic practices (in general, and agogai in particular) in very ancient times. We shall dwell on the three literary texts which we regard as most significant in this respect, and which give us the assurance that the Agogai, so famous in the Greek world, indeed have an extraordinary and long history.

KeYwords: Magic papyrus; erotic magic, Rome; Sappho; love speech

Uma agoge é, como o próprio nome indica, um encantamento "que conduz/

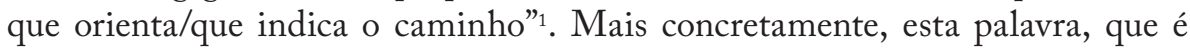
rubrica frequente dos manuais de magia, designa um encantamento erótico de atracção que, através da violência e da tortura, tem como objectivo fazer com que uma pessoa (normalmente uma mulher) conceba uma paixão irremediável por outra pessoa (normalmente um homem), ao ponto de se sentir forçada a abandonar a sua própria casa para ir ao seu encontro.

Aqui deixamos, desde logo, um exemplo ilustrativo deste tipo de práticas. $\mathrm{O}$ conjuro amoroso que passamos a citar é do séc. IV ou $\mathrm{V}$ d. C. e encontra-se em Papyri Graecae Magicae (PGM) 19a. É um encantamento, dirigido, como tantos outros, a uma entidade designada apenas por daimon, usado por um homem chamado Apalos, na tentativa de levar uma mulher, de nome Carosa, a vir ter

${ }^{1}$ Palavra formada a partir do verbo grego agein. Estudo desenvolvido no âmbito do projeto UID/ELT/00196/2013, financiado pela FCT - Fundação para a Ciência e Tecnologia. 
com ele perdida de paixão:

Sim (...), trá-la, fá-la arder, destrói-a, queima-a, fá-la perder os sentidos enquanto é queimada e se inflama. Atravessa com um aguilhão a sua alma torturada (...) até que saia e venha para junto de Apalos, filho de Teonila, por paixão e por amor, agora mesmo, já, já, depressa, depressa! (...) Não deixes que ela, Carosa, filha de Teló, pense no seu marido nem no seu filho, nem na bebida, nem na comida, mas que venha derretida pela paixão, pelo amor e pela vontade de sexo, desejando mais do que tudo a companhia de Apalos, filho de Teonila. Agora, neste exacto momento! Já, já, depressa, depressa!

Dentro da magia erótica grega, as agogai são, de longe, o género mais popular, mais bem documentado. Muito embora existam oitenta e uma agogai publicadas, não podemos, no entanto, a partir dos Papiros Mágicos Gregos, atestar a presença destes encantamentos de atracção em tempos mais recuados, uma vez que não existem testemunhos anteriores à Época Romana ${ }^{2}$. Este vazio é, felizmente, colmatado pela literatura grega, que nos deixou indícios suficientes da existência de práticas de magia erótica (em geral, e das agogai em particular) em épocas muito antigas.

Podíamos mencionar várias passagens literárias que reflectem, de forma mais ou menos óbvia, a existência de encantamentos de atracção desde os períodos mais recuados. Optámos, no entanto, por nos focar apenas nos três textos que consideramos mais significativos a este respeito e que nos deixam a garantia de que as agogai, largamente conhecidas no mundo grego, têm de facto uma extraordinária e longa história.

\section{Safo, Hino a Afrodite (Fr. i Lobel-Page)}

Safo deixou-nos uma composição poética que, não contendo propriamente alusões à prática de magia erótica, é frequentemente (e bem!) associada às agogai que os papiros mágicos nos deram a conhecer, na medida em que reflecte a forma, o conteúdo e a intenção desses encantamentos amorosos reais ${ }^{3}$. Refiro-me ao Hino a Afrodite, um poema repleto de ardente e angustiada paixão, em que Safo invoca Afrodite e suplica a sua intervenção naquele momento em que sofre por um desejo insaciado. A poetisa recorda imagens das aparições anteriores da deusa em ocasiões idênticas e, subitamente, é a própria Afrodite que começa a falar (vv. 18-24):

${ }^{2}$ Como é sabido, os papiros mágicos são os documentos mais importantes para o estudo da magia grega. Ora, convém lembrar que o papiro mágico mais antigo conservado é do séc. I a. C.e não é de teor erótico. Do séc. I d. C. há apenas um feitiço de cariz amoroso, mas a grande maioria dos papiros gregos de magia pertencem aos séculos III e IV d. C., sobretudo a este último.

${ }^{3}$ Sobre esta questão, vide Cameron (1939), Segal (1974), Burnett 1983: 254-256, Faraone (1992) e Petropoulos (1993). 
$\tau i ́ v \alpha \delta \eta \tilde{\tau} \tau \varepsilon \pi \varepsilon i ́ \theta \omega$

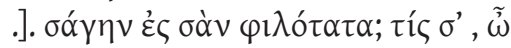

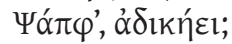

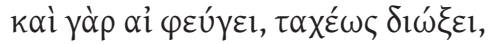

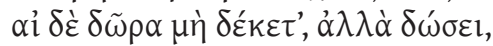

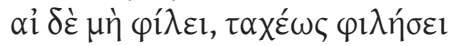

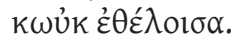

Quem de novo devo

convencer a voltar ao teu amor? Quem,

ó Safo, te faz mal?

Pois se foge, rapidamente perseguirá;

se não aceita os presentes, em vez disso os dará;

se não ama, rapidamente amará, mesmo que

ela o não queira.

(Tradução de Lourenço, 2006: 35)

A deusa pergunta amavelmente a Safo quem é o actual objecto do seu desejo e promete-lhe que, tal como das outras vezes, também agora haverá de dar cumprimento aos seus propósitos e fazer com que o seu amor não correspondido passe imediatamente a merecer retribuição.

Se atentarmos, com algum cuidado, nos versos acabados de citar, facilmente encontramos vários ingredientes que justificam a frequente associação desta composição poética aos encantamentos eróticos de atracção tradicionais, ou seja, às agogai. Desde logo, o facto de Afrodite querer saber quem deve convencer, daquela vez, a amar a poetisa, implica que as preces que esta normalmente lhe dirige tenham sempre uma única finalidade: atrair a si o ente amado. Além disso, quando prediz a mudança da situação amorosa de Safo, nos vv. 21-24, a deusa utiliza uma formulação sintáctica que nos reporta, de imediato, para a linguagem dos textos mágicos reais. De facto, as várias proposições condicionais pronunciadas sob a forma de repetição antitética ('se ..., então ...') assemelham-se a certas enunciações mágicas, como àquela que encontramos, por exemplo, em PGM 4. 1510-1520:

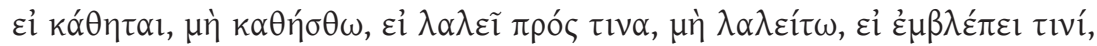

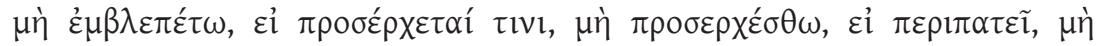

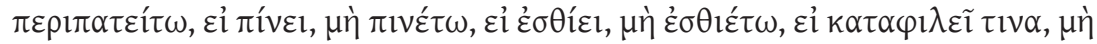

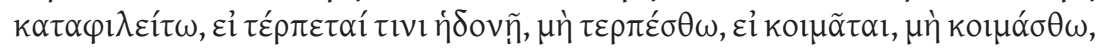

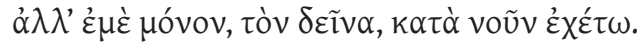

Se se senta, que não se sente; se fala com alguém, que não fale; se olha para alguém, que não olhe; se se aproxima de alguém, que não se aproxime; se passeia, que não passeie; se bebe, que não beba; se come, que não coma; se beija 
alguém, que não o beije; se se alegra com algum prazer, que não se alegre; se se deita, que não se deite; mas que só em mim, fulano, tenha o seu pensamento.

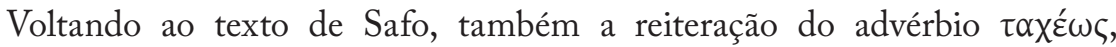
nos vv. 21 e 23, nos remete para o mundo da magia e, em particular, para os

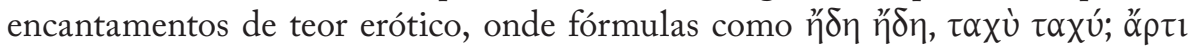

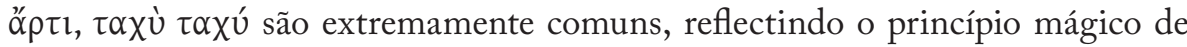
que a intervenção da divindade se deseja imediata.

No v. 24, Afrodite reafirma a sua pretensão de forçar a amada de Safo a amá-

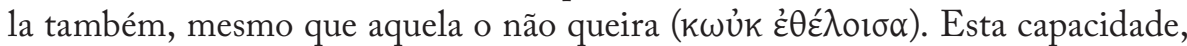
demonstrada por Afrodite, de induzir uma pessoa a amar outra mesmo contra a sua vontade, figura também num hino à deusa, que aparece encaixado nos $P G M$ (em 4. 2934: oủk $\dot{\varepsilon} \theta \dot{\varepsilon} \lambda o v \tau \alpha$ ), num encantamento amoroso muito elaborado.

A orientação homossexual do poema de Safo é explícita. E é curioso notar que o amor entre pessoas do mesmo sexo também encontra expressão (embora em pequena escala) nos encantamentos de atracção que chegaram até nós. Segundo pudemos verificar, das oitenta e uma agogai publicadas, há três que são de índole homoerótica (SM 42, PGM 32 e PGM 32a).

Voltamos a ouvir a poetisa nos últimos versos da composição (25-28):

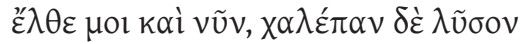

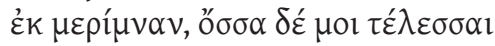

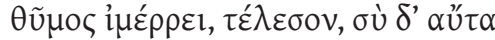

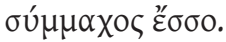

Vem até mim, agora também! Salva-me da aflitiva ansiedade; e para mim faz cumprir tudo o que meu coração deseja ver cumprido; e tu própria combate ao meu lado!

(Tradução de Lourenço, 2006: 35)

Também aqui é possível descobrirmos paralelos com a tradição grega de magia amorosa. O verbo $\tau \varepsilon \lambda \varepsilon \tilde{\imath} v$, usado por Safo nos vv. 26 e 27, aparece com muita frequência no final dos encantamentos eróticos de atracção. Faraone (1992) chamou a atenção para este facto e foi mais longe, ao interpretar o

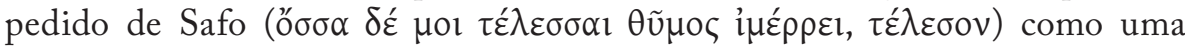

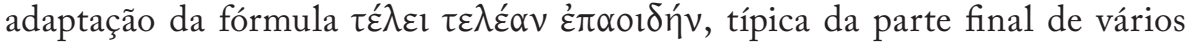
sortilégios eróticos reais, alguns dos quais dirigidos a Afrodite, como é o caso de $P G M$ 4. $2939^{4}$.

\footnotetext{
${ }^{4}$ Este assunto foi largamente explorado por Faraone, no artigo citado. A propósito, vide ainda, Faraone 1999: 136-137.
} 
Há alguns estudiosos que defendem a ideia de que as palavras de Safo pressupõem o acompanhamento de um acto mágico efectivo ${ }^{5}$. Não conhecemos as circunstâncias externas que rodeiam o Hino a Afrodite e, como tal, não podemos ir tão longe na argumentação. As evidências de que dispomos permitem-nos tão-somente concluir que as muitas afinidades sintácticas encontradas entre o poema em causa e o discurso de magia não serão, com toda a certeza, mera obra do acaso, ou seja, existirá uma base comum entre as palavras de Safo e uma longa tradição de encantamentos eróticos dirigidos a Afrodite.

\section{Píndaro, Pítica 4}

Mas a mais importante prova da antiguidade da prática das agogai encontramo-la em Píndaro, na sua Pítica 4. O poeta oferece-nos a primeira descrição detalhada de um rito de magia erótica. Conta-nos como, para ajudar Jasão a seduzir Medeia, Afrodite amarrou a uma roda 'o torcicolo de plumagem

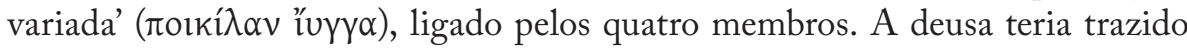

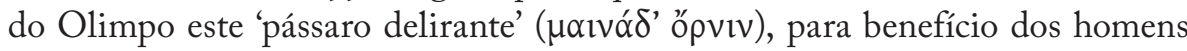
e teria assim inventado um poderoso instrumento de magia erótica, com o qual Jasão poderia inflamar de desejo o coração de Medeia e convencê-la a segui-lo até à Grécia. Valerá a pena recordar o passo em questão (vv. 213-219):

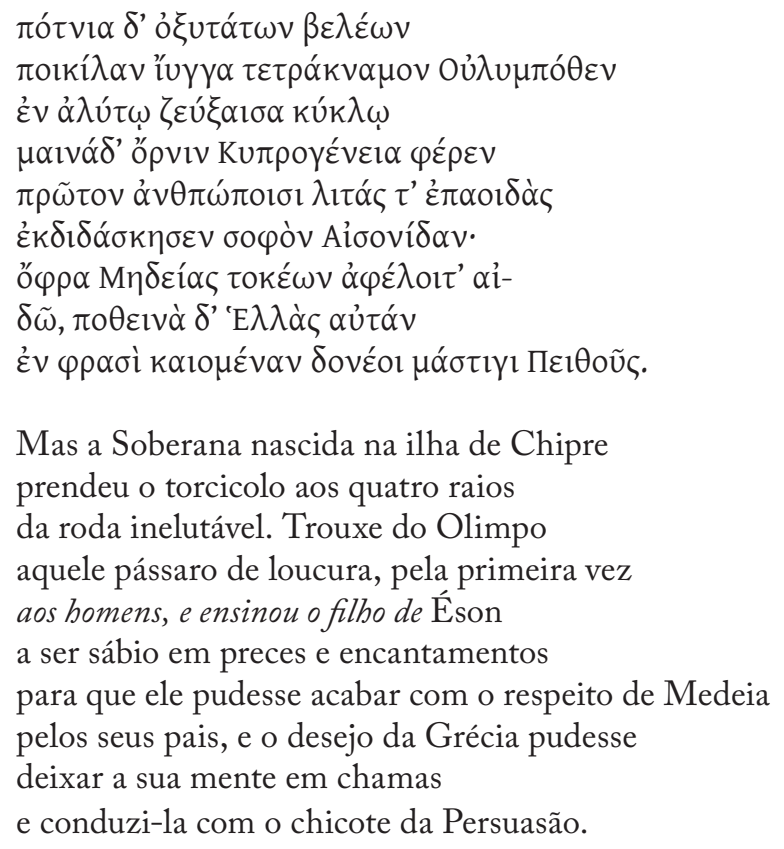

${ }^{5}$ Vide, e. g., Petropoulos 1993: 54. 
Muitas são as afinidades existentes entre esta descrição do rito de magia erótica feita por Píndaro e as agogai preservadas nos documentos mágicos reais. Há excelentes estudos publicados sobre esta questão $0^{6}$, que será aqui resumida em breves tópicos, aqueles que, obviamente, consideramos mais pertinentes:

Desde logo, interessa salientar que o procedimento mágico descrito por Píndaro alia a praxis ao logos, como é costume acontecer nos rituais de magia reais: quando falamos em praxis referimo-nos ao acto de amarrar o pássaro à roda e à manipulação da própria roda; quanto ao logos, é dito claramente que

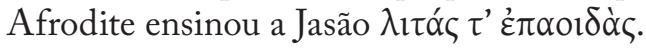

Estes versos constituem a primeira menção ao bizarro expediente mágico conhecido por iunx que encontraremos depois, repetidas vezes, nos ritos de magia erótica de atracção.

Uma outra correspondência entre os versos de Píndaro e as agogai posteriores é a ideia de insanidade. $\mathrm{O}$ desejo sexual causado pelos encantamentos de atracção é comummente descrito como um louco frenesim. Píndaro descreve o pássaro iunx como 'louco' e dá ênfase ao adjectivo, recorrendo à técnica do encavalgamento ou transposição do verso. É também curioso notar que usa um adjectivo feminino ( $\mu \alpha \imath v \alpha$ q́ $\zeta$ ), detalhe que sugere a transferência da loucura para Medeia, a quem o encantamento fará enlouquecer de desejo.

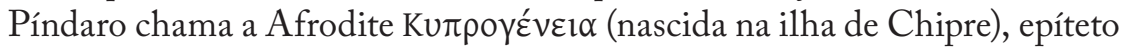
pelo qual a deusa é frequentemente invocada nas agogai tardias.

Ao descrever os efeitos do encantamento de Jasão, Píndaro diz que Medeia será atacada com o 'chicote da (deusa) Persuasão'. Instrumentos de tortura como chicotes, aguilhões e outros, aparecem com frequência em encantamentos de atracção reais. Há muitos exemplos destas imagens de tortura. Deixamo-vos apenas um, mas bastante sugestivo. $\mathrm{O}$ trecho que passamos a citar encontra-se em $P G M$ 17a e contém um conjuro dirigido ao deus Anúbis:

Anúbis, deus da terra e subterrâneo e celeste, cão, cão, cão, reúne todo o teu poder e toda a tua força contra Tigeró, nascida de Sofia. Põe fim à sua arrogância, ao seu entendimento e ao seu pudor. Traz-ma derretida pelo desejo amoroso a todas as horas do dia e da noite. Que sempre pense em mim, comendo, bebendo, trabalhando, falando, dormindo e sonhando; até que, aguilhoada por ti, venha desejando-me com as mãos cheias, com o seu bem dotado sexo, e oferecendo-se a si mesma (...) servindo o meu apetite e o seu, sem hesitação e sem pudor, músculo com músculo, ventre com ventre, e unindo a sua negrura com a minha, que é o maior prazer. Sim, Senhor, traz até mim a filha de Sofia, até mim, Hermeias, filho de Hermíone, já, já, depressa, depressa, impelida pelo teu aguilhão.

\footnotetext{
${ }^{6}$ Vide, sobretudo, Faraone (1993) e Johnston (1995).
} 
Mais correspondências encontraríamos entre a descrição de Píndaro e os feitiços reais conhecidos. Cremos, no entanto, estar provada a enorme importância destes versos da Pítica 4 enquanto eco da existência de uma tradição muito antiga de agogai.

Estas breves linhas de Píndaro são extremamente valiosas para a história da magia de teor erótico, na medida em que atestam, pela primeira vez, um encantamento amoroso de atracção (agoge), mas temos de esperar pela Época Helenística para nos ser concedida a oportunidade de assistir a uma minuciosa descrição literária das operações típicas desta categoria de magia.

\section{Teócrito, IDÍlio 2}

Referimo-nos, obviamente, a Teócrito e ao seu Idílio 2, obra de peso excepcional na história da magia erótica em geral e na história das agogai, em particular.

A meio da noite, Simeta e a sua escrava Téstilis executam uma série de práticas mágicas com o objectivo de reconquistar o amor de Délfis, um jovem atleta que, durante algum tempo, fora amante de Simeta mas que entretanto a trocara por um novo amor. Todo o ritual mágico de atracção é relatado em pormenor, o que demonstra claramente que Teócrito estava familiarizado com as operações de magia usadas para atrair a pessoa amada, ou seja, com os procedimentos que envolviam as famosas agogai.

São, de facto, muitos (e de vária ordem) os paralelismos existentes entre o sortilégio erótico de Simeta e os encantamentos de atracção reais que encontramos nos papiros mágicos e nas defixiones.

Teócrito deixa claro, logo a partir do v. 10 (ao escolher a palavra Өúos), que a protagonista do seu idílio vai levar a cabo um encantamento de atracção no qual utilizará fogo, como é habitual acontecer nas agogai reais. Simeta diz:

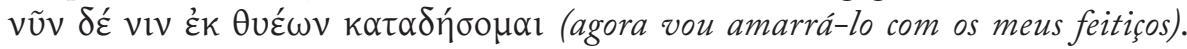
A palavra $\theta$ úo implica sempre uso do fogo, tanto em rituais mágicos como religiosos. Neste caso, refere-se, objectivamente, ao encantamento de teor amoroso que vai ter lugar momentos depois (vv. 17 sqq.), onde a jovem irá queimar substâncias tão diversas como farinha, louro, cera e uma franja do manto de Délfis, entre outras. A própria forma verbal aqui utilizada

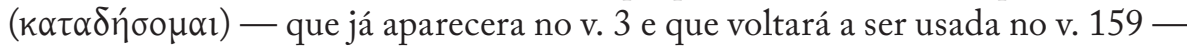
reflecte a linguagem dos sortilégios amorosos reais. O verbo $\kappa \alpha \tau \alpha \delta \varepsilon ́ \omega$ é uma presença constante em encantamentos amorosos cuja intenção é, tal como no Idilio 2, prender a pessoa amada ${ }^{7}$.

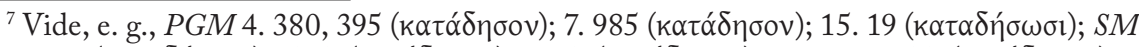

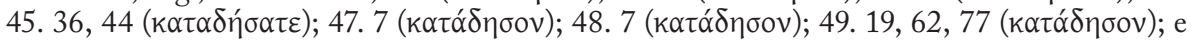
ainda $D T 49$, onde a palavra $\kappa \alpha \tau \alpha \delta \tilde{\omega}$ é repetida nove vezes. 


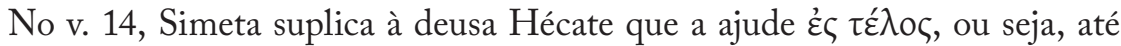
que se cumpra o propósito do encantamento mágico. Esta petição não é mais do que o refinamento literário de um conceito que, nas agogai reais, é expresso com o imperativo $\tau \varepsilon ́ \lambda \varepsilon \sigma o v$. De facto, quando alguém, nos papiros mágicos, pede a uma divindade que realize determinada acção sobrenatural, como acontece aqui, utiliza habitualmente o verbo $\tau \varepsilon \lambda \varepsilon^{\prime} \omega^{8}$.

Ao longo da série de estrofes que compõem a cena de encantamento, que ocupa os vv. 17-63, Simeta vai desenvolver todo um ritual de agoge, na tentativa de atrair Délfis até sua casa. A jovem mulher recorre, com insistência, a um tipo comum de fórmula mágica (a que é vulgar chamar-se similia similibus) em que aquele que executa o feitiço procura transferir uma determinada acção ou um estado de uma substância que tem em seu poder para uma outra substância ou, mais frequentemente, para uma pessoa.

Recordemos alguns momentos do dito ritual, que é intercalado regularmente por um verso-refrão, em que Simeta reitera a sua intenção: Roda mágica, atrai à

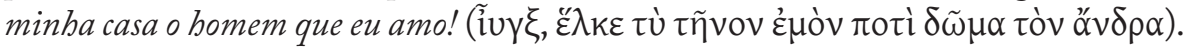
Facilmente conseguimos idealizar uma jovem louca de paixão, empenhada em fazer girar, em intervalos regulares, uma pequena roda que - acreditava ela teria o poder de atrair o homem amado. E a iunx não é o único instrumento de atracção que Simeta vai usar na tentativa de recuperar o amante perdido. Mais à frente, no v. 30, ela faz girar um rombo de bronze, ao mesmo tempo que exprime o desejo de que o homem amado descreva um movimento semelhante até sua casa.

A primeira acção ritual (vv. 18-21) consiste em lançar ao fogo farinha de cevada ( $\alpha \lambda(\varphi \imath \tau \alpha)$, ingrediente que funciona aqui como símbolo dos ossos do amado infiel. As ordens de Simeta são muito claras: ao mesmo tempo que faz arder a cevada, a sua escrava Téstilis deve proferir as seguintes palavras

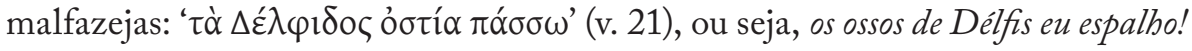

Levado a efeito pela própria Simeta, o segundo rito (vv. 23-26) é uma expansão do primeiro. O louro que é queimado representa a carne de Délfis, que a jovem quer ver consumir-se no fogo, tão rapidamente como a planta: $E$ assim como o louro crepita no fogo vivamente e nele, de repente, se consome, sem que vejamos sequer a sua cinza, assim também a carne de Délfis nas chamas se desfaça!

Nos vv. 28-31, a jovem feiticeira faz derreter cera para que, analogicamente, Délfis se derreta de amor por ela. A questão que aqui se levanta é saber se a cera mencionada pela jovem feiticeira se encontra ou não modelada em figurinha. $\mathrm{O}$ texto não contém nenhuma indicação que nos permita esclarecer esta dúvida,

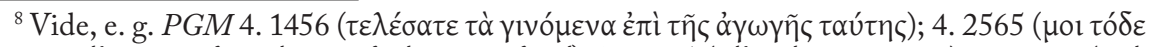

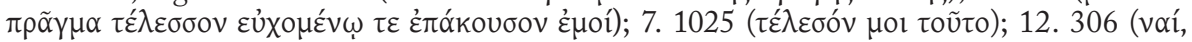

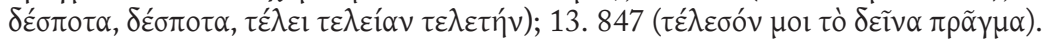


mas a maioria da crítica defende que o mais provável é mesmo que Simeta seja detentora de uma imagem de cera representativa do amante infiel. Como se sabe, o uso de estatuetas (de chumbo, bronze, barro, cera, etc.) em contextos mágicos foi, desde sempre, um fenómeno muito comum, em particular na magia erótica de atracção'.

Nos vv. 43-46, Simeta dirige-se a Hécate nestes termos: Três vezes faço uma libação e três vezes, Soberana, pronuncio estas palavras: quer seja mulher, quer seja homem que com ele dorme agora, que um tão grande esquecimento invada Délfis como aquele que - ao que dizem - fez Teseu esquecer, em Dia, Ariadne de belas tranças.

O número três tem um valor mágico inegável, normalmente justificado pelo facto de ser o primeiro número ímpar (se exceptuarmos, como é óbvio, a unidade) e de às forças sobrenaturais agradarem estes números, que são indivisíveis por dois e, como tal, dotados de um grande poder. É impossível ignorar a presença insistente do número três ao longo dos mais diversos documentos que atestam práticas mágicas. De acordo com variadíssimas prescrições dos papiros, determinadas acções e fórmulas rituais devem ser repetidas três vezes ou reproduzidas segundo um número múltiplo de três: e. g. PGM 12. 307 (e quando terminares esta fórmula, di-la três vezes cada dia, na hora terceira, sexta e nona) ou 13. 237 (para uma 'agoge', dirige ao sol três vezes estas palavras...).

A jovem feiticeira expressa o seu desejo de que um grande esquecimento se apodere do homem que ama. Délfis deverá apagar da memória a sua actual companhia e voltar a bater à sua porta. A acção da magia sobre a memória é um motivo muito explorado desde os tempos mais antigos e há-de vir a aparecer, com frequência, em textos ligados a rituais de magia erótica de atracção. Uma defixio ática, datada do séc. IV a. C., estabelece que um certo Cárias venha a esquecer a sua amada Teodora, bem como o filho desta ${ }^{10}$. Vários papiros mágicos repetem um tipo característico de feitiços amorosos que têm como objectivo provocar o esquecimento de antigos relacionamentos, tal como acontece neste passo de Teócrito. A fórmula normalmente utilizada assenta no que podemos designar por 'amnésia selectiva': a "vítima” deve esquecer a sua família, amigos e/ ou amantes e ter na mente apenas o indivíduo (homem ou mulher) que executa o encantamento. Recordemos, a título de exemplo, PGM 61. 29-30: que se esqueça de seu pai e de sua mãe e de seus irmãos e de seu marido e de seu amigo; excepto de mim, que se esqueça destes todos. E não podemos deixar de citar PGM 4. 2740-2744, onde

${ }^{9}$ Destas figurinhas, que normalmente simbolizavam (e ainda hoje simbolizam!) a "vítima", ou seja, o inimigo pessoal ou aquele que é objecto do desejo de quem pratica o ritual de encantamento amoroso, chegaram até aos nossos dias variadíssimos exemplares, alguns deles muito antigos, oriundos dos mais diversos locais espalhados pelo mundo grego e romano. Num longo estudo que dedicou ao uso de figurinhas na Grécia antiga, Faraone (1991) apresenta, em apêndice, o catálogo de todas as "private voodoo dolls" gregas, etruscas e romanas que sobreviveram até aos nossos dias.

${ }^{10}$ DT 68. As circunstâncias que envolvem esta defixio são desconhecidas. 
encontramos uma prece muito semelhante à de Simeta, mas aqui articulada por uma voz masculina: se está deitada no regaço de outro, que o rejeite e me coloque a mim no seu coração e, quando o deixe, que imediatamente se apresente às portas da minha casa, dominada pelo desejo do meu amor e do meu leito.

O ritual mágico continua, com Simeta a exprimir, nos vv. 48-51, o desejo de que Délfis chegue a sua casa completamente louco de amor, assim como ficam as éguas por acção do hipómanes ${ }^{11}$. Em seguida, queima uma franja do manto do amado (vv. 53-54): Do seu manto, Délfis perdeu esta franja, que eu agora, fio a fio, lanço no fogo voraz. A intenção desta prática é evidente e decorre da crença generalizada de que um objecto (ou parte de um objecto) que tenha estado em contacto com o corpo de um indivíduo permite exercer uma acção sobre ele. Desta forma se explica que a utilização de roupa (ou de fragmentos de roupa) da pessoa amada seja muito frequente em contextos de magia erótica de atracção.

E a cerimónia mágica vai terminar com um toque de malvadez e de tortura, tão ao jeito das agogai reais que chegaram até nós. São estas as palavras de Simeta na última estrofe do sortilégio amoroso (vv. 58-62): Vou esmagar um lagarto e levar-lhe amanhã uma poção maligna. Mas agora, Téstilis, toma tu estas ervas mágicas e amassa-as, às escondidas, sobre a soleira da sua casa, enquanto ainda é de noite, escarra e diz depois: «eu amasso os ossos de Délfis».

Concluiremos a enumeração dos paralelismos existentes entre o sortilégio erótico de Simeta e os encantamentos de atracção reais, chamando a atenção para um pormenor curioso, que, ao que nos parece, tem passado despercebido aos estudiosos deste poema.

O ritual de agoge protagonizado por Simeta é precedido por uma invocação inesperada. Após declarar que os seus encantamentos serão dirigidos a Selene e a Hécate infernal, Simeta solicita a ajuda desta última, da seguinte forma (vv. 14-16): Salve, ó Hécate terrivel! Assiste-me até ao fim para que estas drogas sejam tão fortes como as de Circe, ou de Medeia ou da loura Perimede.

Esta é a primeira vez que testemunhamos a ligação de um encantamento erótico de atracção a uma divindade habitante no submundo. E Simeta invoca Hécate na sua vertente mais assustadora, tal como é comum acontecer nas agogai da Época Romana. Ela é a Hécate infernal, diante da qual até os cães tremem, quando passa por entre os túmulos dos mortos... (v. 12).

Inúmeros são os exemplos de agogai tardias que invocam ou mencionam divindades do reino das sombras, sobretudo Hécate, Perséfone e Hermes. No Período Romano, Selene encontra-se assimilada a Hécate, na sua forma ctónica de superintendente dos mortos, e é também invocada em vários sortilégios de teor erótico. Não sabemos exactamente quando se terá dado esta assimilação,

\footnotetext{
${ }^{11}$ Sobre esta curiosa substância afrodisíaca, vide Cravo (2014).
} 
mas a verdade é que as duas divindades já aparecem lado a lado, naturalmente associadas, no Idílio 2 de Teócrito.

Em suma, e em jeito de conclusão, cabe-nos dizer que os inúmeros pontos de contacto entre o texto teocritiano e os documentos de magia erótica posteriores deixam claro que o poeta fez uso de material pertencente a uma tradição antiga de encantamentos de atracção, uma tradição muitíssimo anterior ao seu tempo, que, embora não possa ser provada por testemunhos reais, já se encontra reflectida no Hino a Afrodite de Safo e, dois séculos mais tarde, é claramente atestada por Píndaro na sua Pítica 4. 


\section{Bibliografia}

Audollent, A. (ed.) 1904. Defixionum Tabellae. Paris. (DT)

Burnett, A. P. 1983. Three Archaic Poets. Archilochus, Alcaeus, Sappho. London.

Cameron, A. 1939. «Sappho's prayer to Aphrodite», HThR 32: 1-17.

Cravo, C. 2014. «Hipómanes: um lugar-comum da magia erótica literária», in A. Martínez Fernández, B. Ortega Villaro, H. Velasco López, H. Zamora Salamanca (eds.), Ágalma. Homenaje a Manuel García Teijeiro. Valladolid, 993-1000.

Daniel, R. W. - Maltomini, F. 1990-1992. Supplementum Magicum. Papyrologica Coloniensia XVI. 1 and 2. Opladen. 2 vols. (SM)

Faraone, C. A. 1991. «Binding and burying the forces of evil: The defensive use of "voodoo dolls" in Ancient Greece», ClAnt 10: 165-205.

Faraone, C. A. 1992. "Aristophanes, Amphiaraus, Fr. 29 (Kassel-Austin): oracular response or erotic incantation? ", $C Q$ 42: 320-327.

Faraone, C. A. 1993. «The wheel, the whip and other implements of torture: erotic magic in Pindar Pythian 4. 213-19», CJ 89: 1-19.

Johnston, S. I. 1995. "The song of the Iynx: magic and rhetoric in Pythian 4», TAPhA 125: 177-206

Lobel, E.- Page, D. L. 1963. Poetarum Lesbiorum Fragmenta. Oxford.

Lourenço. F. 2006. Poesia Grega. De Álcman a Teócrito. Lisboa.

Petropoulos, J. C. B. 1993. «Sappho sorceress: another look at frag.1 (L-P)», ZPE 97: 43-56.

Preisendanz, K. (ed.) 1973. Papyri Graecae Magicae. Vol.I. Stuttgart. [1ª ed. 1928, Leipzig \& Berlin] (PGM)

Preisendanz, K. (ed.) 1974. Papyri Graecae Magicae. Vol.II. Stuttgart. [1ª ed. 1931, Leipzig \& Berlin] (PGM)

Race, W. H. 1997. Pindar. Olympian Odes. Pythian Odes. Cambridge, Mass.

Segal, C. 1974. «Eros and incantation: Sappho and oral poetry», Arethusa 7. 2: 139-160. 


\title{
Serapide raccontato da origine: Tra religione e Magia (Serapis told from origin: between religion and magic)
}

\author{
EnNio SANZI \\ Seconda Università di NAPOLI \\ (enniosanzi@libero.it)
}

\begin{abstract}
Riassunto - Oltre ad avere determinato la sopravvivenza di un trattato apologetico delle religioni tradizionali a danno del cristianesimo, il Contra Celsum di Origene si rivela una fonte preziosa per ricostruire dal punto di vista storico-religioso la querelle che tra il II e il III sec. d.C. vede impegnati su fronti contrapposti uomini di fede diversa ma di analoga formazione culturale. In questo contributo si analizza il passaggio nel quale il teologo alessandrino, nel rievocare la fondazione del culto di Serapide avvenuta circa 500 anni prima ad opera di Tolomeo francamente accusato di aver fatto ricorso a delle manganeiai, offre uno spaccato della dialettica Weltanschauung contemporanea circa un mondo nel quale dietro all'incontro con maghi e sacerdoti si cela sempre la pervicace e tralignante azione dei dèmoni.

Parole chiave: Origene; il culto di Serapide; formula magica; dammatio memoriae; religione
\end{abstract}

Aвstract - In addition to determining the survival of an apologetic treatise of traditional religions to the detriment of Christianity, Contra Celsum of Origen is a precious source for reconstructing from the historical and religious point of view the quarrels between the $2 \mathrm{nd}$ and $3 \mathrm{rd}$ centuries. A.D. sees engaged on opposing faces of different faiths but of similar cultural formation. In this contribution, we analyze the passage in which the theologian alessandrino, in recalling the foundation of the cult of Serapide, about 500 years before by Ptolemy frankly accused of having resorted to manganese, offers a split of contemporary Weltanschauung dialectics about a world in which, behind the encounter with magicians and priests, always lies the pervading and languishing action of the demons

Keywords: Origene; the cult of Serapide; Magic; dammatio memoriae; religion

Nel novero dei Padri della chiesa che con i loro scritti si rivelano fonti imprescindibili per la ricostruzione della querelle che intercore tra pagani e cristiani nei primi secoli della nostra èra un ruolo di primaria importanza deve essere riconosciuto a Origene e al suo Contra Celsum (Crouzel 1971, Crouzel 1982; Crouzel 1996; Le Boullec 1998). La nota opera apologetica, infatti, oltre ad aver permesso la sopravvivenza di un esplicito $j$ 'accuse altrimenti perduto, offre allo storico delle religioni la possibilità di penetrare in uno spaccato variegato $\mathrm{e}$ vissuto della sensibilità religiosa pagana e cristiana per come essa si attesta tra la seconda metà del II e la prima metà del III secolo d.C.; c'è da dire che tale possibilità si rivela così ampia che anche quei loci che potremmo definire "minori" 
meritano di essere analizzati alla luce della sapiente portata argomentativa che connota l'intero trattato. Ascoltiamo, dunque, cosa riferisce Origene a proposito di un dio "recente": "Il racconto su Serapide è lungo e incoerente, comparso poco fa grazie a certe manganeiai di Tolomeo che voleva mostrar(lo) agli Alessandrini come un dio epiphanes. E abbiamo letto in Numenio il pitagorico sulla costituzione di quello (i.e. Serapide), come dunque (egli) partecipi dell'essenza di tutti gli animali e di tutte le piante governate dalla natura, cosicché sembra essere stato istituito quale dio grazie ai riti (iniziatici?) vani e alle manganeiai che invocano i dèmoni non soltanto per opera degli scultori ma anche per intervento dei maghi, degli stregoni e dei dèmoni che sono chiamati dalle loro formule incantatorie" (Cels. 5. 38)1.

Si può immediatamente constatare come il termine tecnico manganeia (ad. es. Plato $L g$. 9. 933a) costituisca il quid medium che lega le parole di Origene a quelle di Numenio da lui stesso ricordate. Già da una tale constatazione è possibile dedurre quanta ragguardevole importanza venga riconosciuta alla magia nel passo riportato. Altra parola di rilievo è la qualifica di Serapide quale dio epiphanes.

Merita di essere preso in considerazione se e come tale titolatura sia attestata nell'epigrafia serapiaca. Ad es. un altare circolare proveniente dal serapeo C di Delo e datato tra il 122 e il 121 a.C. risulta essere stato posto in onore di Serapide epiphanes per ordine del dio stesso (Bricault 2005, n. 202/0263), mentre in un'epigrafe incisa su di una base di marmo situata a sinistra dell'entrata del serapeo di Leptis Magna e datata al II secolo d.C. il dio, che ha salvato il dedicante da una grave malattia, è addirittura avvertito come epiphanestatos (Bricault 2005, n. 702/0107). Queste epigrafi evidenziano bene due tra le caratteristiche "costitutive" della nostra divinità: siamo di fronte a un dio del quale viene enfatizzata l'autorevolezza e la capacità di proporre vie percorribili per scampare tanto dai pericoli della vita quotidiana quanto da quelli legati a un cattivo stato di salute (AA.VV. 2006); è da mettere in rilievo anche il fatto che nella due iscrizioni venga sublimata la dimensione epifanica del dio, la stessa qualità ironicamente ricordata da Origene.

Una rapida collazione di altro materiale epigrafico "in sintonia" con le testimonianze riportate ci aiuterà a comprendere meglio le modalità secondo le quali la salutare potestas del dio operi e si manifesti; si terrà particolarmente conto delle formule ek megales nosou diasotheis e kata prostagma. Su di una base in marmo iscritta proveniente da Anchialos, in Grecia, e datata tra il II e il I sec a.C., si legge che un tal Pasisseno ha lasciato la sua offerta a Serapide e a Iside

\footnotetext{
${ }^{1}$ Per una prima presentazione di Serapide e del culto a lui dedicato cfr. Turcan 2004, pp. 78 ss.e passim; per una messa a punto della questione relativa all'introduzione del dio ad Alessandria cfr. Borgeaud - Volokhine 2000; a entrambi i contributisi rinvia per delle notizie bibliografiche.
} 
dai quali è stato guarito (Bricault 2005, n. 114/1301); un'altra base di marmo iscritta, proveniente dal territorio di Camiros, un'isola del Dodecanneso, e datata anch'essa tra il II e il I secolo a.C., ci fa sapere di un ex voto offerto a Ecate e a Serapide dal momento che il dedicante è stato salvato da grandi pericoli (Bricault 2005, n. 204/0218); ancora una base di marmo iscritta proveniente dal Serapeo C di Delo e datata intorno al 150 a.C. testimonia che un ex voto è stato posto in onore di Serapide, Iside, Anubi, Apollo e gli dèi synnaoi da un fedele salvato da molti e grandi pericoli (Bricault 2005, n. 202/0230); una colonna in marmo proveniente da Roma datata tra il II e il III secolo d.C. e destinata a sorreggere una statua del tipo di Serapide da Canopo ci ricorda di un neocoro che, salvato più e più volte da grandi pericoli, rivolge il proprio ex voto a Zeus Helios megas Serapide (Bricault 2005, n. 501/0145); un'iscrizione ancora in situ nel bouleuterion di Stratonica in Caria e datata tra il II e il III secolo d.C. è stata posta come ex voto in onore di Zeus Panemerios e di Helios Zeus Serapide da quattro soldati che hanno avuto salva la vita durante pericolose battaglie per terra e per mare (Bricault 2005, n. 305/0503).

Oltre a essere attestato dall'epigrafe di Leptis Magna sopra riportata, il fatto che tra questi pericoli da scampare spesso genericamente rubricati sia contemplata proprio la malattia ci è ribadito, per così dire, almeno da altre due iscrizioni. La prima, posta su di una base in marmo ritrovata tra le rovine della chiesa di san Simeone sull'isola di Lesbo e datata approssimativamente al II secolo d.C., ricorda che un tal Isidoro, di provenienza alessandrina, ha pregato e posto un ex voto a Zeus Helios megas Serapide e a Iside signora dal momento che è stato salvato dalla malattia (Bricault 2005, n. 205/0304); la seconda, ancora più significativa, è incisa su di una colonnetta di marmo proveniente dall'asclepieio di Lebena a Creta, datata tra il III e il IV secolo d.C. e offerta a Zeus Serapide Asclepio iatros (Bricault 2005, n. 203/0301).

La portata taumaturgica dell'azione guaritrice del dio è ben presente anche nelle testimonianze letterarie. Oltre a Demetrio Falereo che compone dei peana in onore di Serapide per ringraziare il dio di avergli reso la vista (Diog. Laert. Vit. phil. 5. 76) e a Claudio Eliano che rievoca delle guarigioni operate dalla medesima divinità finanche sugli animali (Ael. NA 11. 31), sarà sufficiente ricordare Strabone quando riferisce che nel serapeo di Canopo si potevano trovare dei resoconti delle terapie e dei buoni servizi degli oracoli formulati in loco (Str. Geogr. 17. 1, 17).

Tra le varie iscrizioni che riportano la formula kata prostagma alcune non possono passare sotto silenzio. La prima, incisa su una base in marmo proveniente da Atene (probabilmente dal serapeo) e datata tra il 116-115 e il 95-94 a.C. ricorda un dono offerto a Iside, Serapide, Anubi, Arpocrate, per ordine degli stessi dèi e fa menzione di un onirocrita tra il personale cultuale elencato (Bricault 2005, n. 101/0206); un ceppo di marmo originario del serapeo C di Delo e datato tra il 98 e il 97 a.C. è posto in onore di Serapide, Iside e Anubi per rispondere a 
un ordine interpretato da un oniricrita (Bricault 2005, n. 202/0340); ancora dal medesimo serapeo si conservano una base di marmo sulla quale si legge una dedica a Zeus soter Serapide, Iside e Anubi che risponde a un ordine ricevuto (Bricault 2005, n. 202/0362), e una placca di marmo datata anteriormente al 166 a.C. dove si ricorda l'offerta di un sindonoforo ad Anubi hegemon, Serapide soter e Iside soteira per rispondere a un ordine impartito dal dio (Bricault 2005, n. 202/0170). Un'epigrafe di assoluta rilevanza (e dal greco incerto) è quella relativa all'atto di fondazione del serapeo A di Delo incisa su di una colonna in marmo e datata alla fine del III secolo a.C. commissionata da un sacerdote per ordine del dio manifestatoglisi in sogno (Bricault 2005, n. 202/0101).

Oltre all'epigrafia, anche la la papirologia restituisce alcune fra le più immediate espressioni della devozione quotidiana di fedeli minuti nei confronti della grande divinità alessandrina. Per esempio, nell'epistolografia privata conservataci dai papiri di Ossirinco è facile trovare testimonianze di devoti di Serapide appellato megas (ad es. POxy. XLIII 3094) o kyrios (ad es. POxy. LIX 3992) che per la sicurezza del destinatario di turno dichiarano di compiere ogni giorno un atto di venerazione, e cioè il proskynema, nei riguardi di questa divinità; ripetuti sono gli inviti a banchetto in onore di Serapide signore (ad es. POxy. XII 1484; LXII 4339) in occasione di ricorrenze speciali quali genetliaci et similia che si celebrano spesso nello stesso serapeo (POxy. XXXI 2592; LII 3693; LXVI 4540; cfr. Bricault 2013) e che possono fregiarsi di avere il dio come "padrone di casa" (ad es. P. Col. $255=$ Koenen 1967, p. 122) $)^{2}$.

Accanto a questo tipo di testimonianze papiracee che a più riprese ricorrono nella documentazione in nostro possesso, altre meno comuni meritano di essere ricordate in quanto ancor più vicine alla devota spontaneità dei fedeli del dio. Quale pars pro toto riportiamo un papiro mutilo di II secolo d.C.: "Disse: «Grazie a te, accorderò l'acqua agli abitanti di Faro». Così, dopo averlo salutato, navigando tornò indietro e dà l'acqua agli abitanti di Faro e riceve da quelli come ricompensa cento dracme d'argento. L'atto di grazia è registrato nelle biblioteche di Mercurio. Voi che vi trovate lì pronunciate: «Heis Zeus Sarapis» [lacuna] Atto di grazia di Zeus Helios Serapide nei confronti di Surione il timoniere" (POxy. XI 1382). È da sottolineare la formula attestante la portata enoteistica del dio alessandrino che si è chiamati a pronunciare. Si tratta di un Serapide "affiancato" dal massimo degli dèi del pantheon classico e avvertito in maniera così rilevante da finire con l'essere invocato come unico. Naturalmente non è possibile parlare di monoteismo in casi di tal genere; la riconosciuta unicità deve essere intesa

${ }^{2}$ A fianco di testimonianze di tal genere, ancora in ambito papiraceo, vanno ricordati i cosiddetti "biglietti oracolari", veri e propri foglietti di papiro sui quali venivano scritti dubbi da sciogliere e desideri da realizzare (tutti di ambito intra-mondano) affidati a Zeus Helios "megas" (ad. es. POxy. 8. 1149; POxy. IX 1213) "kyrios" (ad es. POxy. 8.1148) Serapide il quale manifestava la propria filantropica benevolenza attraverso l'estrazione o meno del biglietto stesso. 
come la superiorità del dio all'interno di un pantheon che non arriva mai a essere negato (Mitchell - van Nuffelen 2010a; Mitchell - van Nuffelen 2010b).

Quale sia la teologia che legittimi affermazioni come queste ci è bene indicata dalle fonti letterarie. Giuliano detto "l'apostata", nel redarguire gli abitanti di Alessandria per essersi macchiati dell'omicidio del vescovo Giorgio di Cappadocia considerato colpevole di avere dileggiato i culti pagani e profanato i misteri di Mithra, li rimprovera di non aver rispettato Serapide dio megas e hagiotatos, quel dio che, primo fra tutti gli dèi, ha posto proprio Giuliano a guida dell'ecumene (Iul. Ep. 60.378c). È ancora l'imperatore che nella sua orazione in onore di Helios re in un'evidente prospettiva enoteistica neoplatonica riporta un oracolo di Apollo che recita: "Heis Zeus, heis Aides, heis Helios esti Sarapis" (Iul. imp. Or. in Hel. reg. 136a). In maniera meno speculativa rispetto all'orazione di cui si è fatto cenno, ma con eguale se non ancora più immediata e autentica sensibilità religiosa, il pio Elio Aristide, nel ricordare come Serapide apparsogli mentre era sul punto di fare naufragio lo abbia salvato (Ael Ar. Or. in Sar. 33), non si stanca di glorificare il dio di cui esalta la filantropica disposizione e sottolinea l'assoluta superiorità esprimendosi fideisticamente secondo "modalità" del tutto vicine a quelle del Numenio citato da Origene: "Queste sono le opere di Serapide, attraverso le quali il genere umano è guidato, e giammai noi sfuggiamo al suo potere, e, piuttosto, siamo salvi e lo saremo anche in futuro in forza della sua provvidenza. $\mathrm{Fu}$ preposto, inoltre, alla nascita e al nutrimento di tutti gli esseri viventi” (Ael. Aristid. Or. in Sar. 32).

È evidente come un dio capace di sussumere su di sé il cosmo intero venga avvertito quale heis theos. Proprio tale tipo di formula è attestata a più riprese dall'epigrafia. È notissimo il cippo marmoreo iscritto rinvenuto nel pronao del c.d. Mitreo delle Terme di Caracalla a Roma. Sulla parte anteriore si legge: "Heis Zeus Sarapis (postmodum in Mitras [sic] mutatum) Helios kosmokrator aneiketos"; su quella posteriore: "Dii Helioi megaloi Sarapidi soteri ploutodotei epekoi euergetei aneiketoi Mithrai charisterion (Bricault 2005, n. 501/0126). Il fatto che nelle due iscrizioni il nome di Serapide una volta sia stato sostituito da quello di Mithra e una volta mantenuto torna a riproporre quell'attenzione enoteistica tipica del secondo ellenismo: non una damnatio memoriae di Serapide a vantaggio di Mithra ma una sostituzione dell'uno con l'altro proprio perché entrambi avvertiti, anche se in milieux religiosi diversi ma non antinomici, come dèi sommi, ai quali ben si attagliano, tanto all'uno quanto all'altro, le epiclesi heis theos e kosmokrator. Proprio facendo riferimento alla prima delle due epigrafi appena ricordate, il Bianchi (Bianchi 1975, pp. 246 ss.) fa notare come chiamare Serapide con il nome del signore dell'Olimpo significhi ribadirne la portata di divinità somma, universale e capace di reggere l'intero cosmo sul quale esercita un dominio retto, incontrastato e incontrastabile; in più, il dio alessandrino è anche chiamato Helios, una figura sulla quale nella sensibilità ellenistico-romana si era venuta a concentrare l'essenza della divinità. Il fatto che tale cippo sia stato ritrovato 
in un ambiente sacro non lascia dubbi sul significato precipuamente religioso della dedica. A riprova si può ricordare un'iscrizione posta su di un piede colossale (tipico dono votivo sarapiaco) trascritta da Ciriaco d'Ancona a Eraclea Pontica in Bitinia e datata ipoteticamente tra il II e il III secolo d.C.; l'ex voto è rivolto a Zeus Helios Mithra Serapide (Bricault 2005, n. 308/0801). E con gli stessi nomi, ai quali si aggiungono l'epiclesi aniketos e i nomi di Meliouchos, Melicherta e Meligenetor, megas Serapide viene invocato in un papiro magico dove sono prescritte le modalità rituali da seguire al fine di ottenere un oracolo per "intercessione" di Serapide (PGM V 4-53).

A proposito di religione e magia è da riportare un'iscrizione lasciata su un muro di un'antica casa di Roma dove è possibile leggere un'invocazione apotropaica nei confronti di ogni invidioso ammaliatore: "Heis Zeus Sarapis baskanos lakeseto (Bricault 2005, n. 501/0216). Con il termine baskanos/baskania si può intendere tanto colui che getta il malocchio quanto il vero e proprio mago e, di conseguenza, la relativa e specifica capacità di ammaliare; qui, pur mantenendo un basso profilo, si dovrà leggere una manifestazione "religiosa" che, per quanto legata alla cosiddetta "religiosità popolare", sconfina nel territorio della fascinatio (Luck 1997, pp. XXX ss.). D’altronde, proprio baskania qualificata come ctonia compare personificata in un incantesimo erotico assieme ad altre divinità tra la quali Ermete ed Ecate (PGM IV 1444-1453). E ancora a tale milieu può rinviare un bassorilievo rinvenuto a Quintanilla de Somoza nei pressi di Astorga, nella Hispania Tarraconensis, e datato tra il III e il IV secolo d.C. dove una dextra elata è raffigurata all'interno di un tempio il cui frontone è affiancato da due dischi; nel timpano si legge: "Heis Zeus soter(?) Serapis"; sul palmo della mano: "Iao", cioè il nome del dio dei Giudei (Bricault 2005, n. 603/0901). Anche se tale tipo di associazione, per quanto ne sappiamo, costituisce un unicum nell'epigrafia sarapiaca, non sarà da sottovalutare una lettura del reperto che tenga conto dei formulari incantatori così come della glittica magica dove Iao compare con una frequenza pressoché "sistematica". In particolare, in un papiro magico che riporta un incantesimo volto a ottenere successo, all'interno della formula da rivolgere al signore degli dèi Zeus Iao Adonai, tra le altre divinità nominate ci sono proprio Iao e Serapide (PGM V 486). Sempre i cosiddetti "papiri magici greci" attestano la preparazione di amuleti e la recitazione di incantesimi dove Serapide è qualificato dagli stessi titoli che gli riconosce l'epigrafia devozionale. Gli epiteti kyrios, hagios, kosmokrator, megistos come attributi di Serapide compaiono nel noto "libro segreto di Mose" (PGM XIII 618-620), e il complesso incantesimo volto all'evocazione di un dio capace di garantire successo e prosperità si chiude con la seguente richiesta: "Proteggimi da ogni mio specifico destino astrale, liberami dal cattivo destino, distribuisci beni a me e alla mia progenie, rendi prospera la mia vita con molti beni, poiché io sono il tuo servo e supplice e ho cantato in un inno il tuo autentico e santo nome, signore, glorioso, reggitore del cosmo, dai mille nomi, grandissimo, nutritore, distributore, Serapide" (PGM 
XIII 633-640). Un incantesimo indirizzato a Helios e volto alla consacrazione di un anello (o di un filatterio) capace di garantire qualsiasi successo si chiude con la già ricordata formula: "Heis Zeus Sarapis" (PGM IV 1708-1715). Ancora un papiro magico rilegge magico more una delle prerogative del dio, e cioè la capacità di manifestarsi filantropicamente durante il sonno: "Su un'agata simile al diaspro incidi Serapide seduto... sul retro della pietra il nome e mettilo al sicuro... dopo aver messo l'anello nel dito indice della tua mano sinistra con la pietra rivolta all'interno e dopo averlo attaccato al tuo orecchio sinistro mettiti a dormire senza farne parola (con nessuno)" (PGM V 447-458).

Specificamente da quest'ultimo documento possiamo dedurre due elementi di particolare rilievo: il nome del dio da tenere nascosto che permette di cogliere la portata magica dell'amuleto e il fatto che, anche se in ambito magico, a Serapide si richiedono delle epifanie di natura onirica in occasione delle quali proprio lui si mostrerà propizio al suo fedele grazie all'anello magico da questi indossato. Come si evince da tali testimonianze, all'immagine andava associato un nome atto ad accrescerne e garantirne l'efficacia (Sfameni Gasparro 2009, pp. 315 ss.). La glittica magica fornisce delle attestazioni che costituiscono la prova inconfutabile della diffusione di questo genere di amuleti. Nella collezione del British Museum sono conservate alcune gemme magiche che meritano di essere menzionate. Nella prima, sul recto, si vede il busto di Serapide e, sul verso, si legge proprio la formula "Heis Zeus Sarapis" (Michel 2001 I, n. 25); la seconda mostra, sul recto, il busto di Serapide circondato dall'espressione "mega to onoma tou Sarapis (sic)" (Michel $2001 \mathrm{I}, \mathrm{n} .27$ ) che può avere una portata magica (ad es. PGM 1. 226-227), proprio come in una terza gemma riportata dal Bonner dove ricorre la medesima espressione e il dio è definito kyrios (Bonner 1950, n. 398 = Mastrocinque 2014, n. 601); una quinta presenta sul recto una figura imberbe o francamente femminile con scettro e modio, sul verso si legge: "nikai ho Serapis ton phthonon" (Michel 2001 I, n. 37), un'invocazione che richiama la maledizione contro il baskanos nel nome di Serapide di cui si è già detto e che ribadisce la forza della parola nella dimensione della magia dal momento che non sembrerebbero esserci legami tra il recto e il verso dell'intaglio ${ }^{3}$.

Si ricorderà che Origene parlava di azioni francamente magiche alle quali avrebbe fatto ricorso Tolomeo per introdurre il culto di Serapide ad Alessandria d'Egitto. C'è da chiedersi in che cosa sia consistita l'azione del sovrano per essere rubricata come magica. Da Tacito sappiamo che a più riprese il dio si manifesta in sogno a Tolomeo per incitarlo affinché sia trasportato dal Ponto e gli venga istituito il culto che merita nella città fondata da Alessandro Magno, pena la

\footnotetext{
${ }^{3}$ Per una raccolta pressoché completa delle gemme devozionali e/o magiche che rappresentano Serapide o che ne riportano il nome cfr. Veymiers 2009, il catalogo è regolarmente aggiornato nei volumi di "Bibliotheca Isiaca".
} 
fine dello stesso diadoco nonché del suo regno. Grazie a degli emissari che per tre anni e con offerte sempre maggiori incalzano il re del Ponto Scidrotemide (e la sua sensibilità ai doni) il dio, dopo un viaggio tanto breve da essere considerato miracoloso, è accolto ad Alessandria dove gli viene riservato un tempio di straordinaria grandezza ed eccezionale bellezza (Tac. Hist. 4. 83-84). Si tratta del meraviglioso serapeo nella cui cella era ospitata la titanica e mirabile statua di Serapide (McKenzie - Gibson - Reyes 2004; Sabottka 2008), intesa quale epifania tutelare della città e dell'intero cosmo come bene ci fa sapere, ancorché per negationem, Rufino di Aquileia quando ne rievoca la distruzione avvenuta sotto il militante patriarcato di Teofilo (Ruf. Aquil. Hist. eccl. 2. 23). $\grave{E}$ evidente che tale visione apocalittica può trovare giustificazione nella visione teologica di un Serapide inteso come dio sommo, della cui portata cosmica circa due secoli prima dell'assalto al serapeo alessandrino si era ottimamente fatto portavoce Elio Aristide nella sua Oratio in Sarapidem dove ben si dichiarava in chiave rigorosamente enoteistica: "Gli abitanti della grande città presso l'Egitto (i.e. Alessandria) invocano come Zeus anche questo heis, poiché non è stato sopravanzato per la straordianaria potestas, ma giunge attraverso tutte le cose e ha riempito il tutto. Mentre, infatti, negli altri dèi le potestates e gli onori sono stati divisi, e gli uomini invocano diversi (dèi) per diverse cose, lui, come fosse un corifeo, possiede il principio e la fine di tutte le cose. Egli solo, inoltre, è pronto a compiere ciò per chi ha bisogno di una qualunque cosa... Per il fatto di possedere le potestates di tutti (gli dèi), alcuni lo venerano al posto di tutti (gli altri), alcuni lo onorano oltre agli (dèi) nei quali credono, come essere straordinario, dal momento che è comune a tutta la terra" (Ael. Aristid. Or. in Sar. 21-23). C'è da pensare che un Serapide di tal tipo sia stato al centro della'attività "missionaria" di Tolomeo; saremmo allora davanti a un dio "optimus maximus" e kosmokrator che specificamente a Tolomeo e, per di più, a livello onirico avrebbe ingiunto la propria translatio. Tutto questo doveva essere ben noto all'alessandrino Origene.

È risaputo come i cristiani dell'epoca non abbiano negato l'efficacia della divinazione così come quella dei sogni rivelatori ma le abbiano attribuite ai dèmoni i quali vi avrebbero fatto ricorso per attirare gli uomini nelle loro trame diaboliche. Ad esempio Giustino Martire non esita ad asserire: "Infatti, si sforzano (i.e. i dèmoni) di avervi quali schiavi e servitori e a volte tramite delle epifanie attraverso sogni, altre volte attraverso raggiri magici riducono in loro potere tutti quelli che non lottano per la propria salvezza" (Iustin. I Apol. 14. 1). A lui sembra fare quasi eco Tertulliano quando afferma: "Infatti, abbiamo detto che nella maggior parte dei casi i sogni sono imposti dai dèmoni, e benché talvolta (appaiano) veridici e benefici, tuttavia... (si rivelano) illusori e capaci di sedurre e ancor di più vani, illusori, torbidi, pieni di ludibrio e immondi" (Tert. De anim. 47. 1). D'altronde, già nel Pentateuco la magia e la divinazione in senso lato erano state condannate a più riprese (Ex 22, 17; Lv 19, 26 e 31), fino al dettagliato divieto del Deuteronomio (Dt 18, 10-12). L'accusa di magia costituiva 
il comune terreno di scontro nel quale cristiani e pagani si criminalizzavano vicendovolmente per il fatto di ricorrere a incantesimi e sortilegi al fine di operare azioni taumaturgiche; è noto, infatti, che la stessa attività esorcistica di Gesù di Nazareth, lungi dall'essere negata dagli avversari della nuova religione, veniva utilizzata proprio per ricondurre il Cristo al fenomeno della goeteia (Smith 1978; Clark Kee 1993).

Né i cristiani negavano il potere taumaturgico e divinatorio del quale si servivano gli angeli decaduti e i loro figli, cioè i dèmoni e gli dèi del paganesimo, per corroborare la propria natura malvagia e la loro pervicace attività tralignante nei confronti dell'uomo, creatura di un Dio buono a tal punto da essersi adoperato per la redenzione e la salvezza del genere umano inviando il Cristo-Logos destinato alla crocifissione e alla resurrezione dai morti. Ancora, sia i pagani che i cristiani erano assolutamente convinti della forza dell'invocazione magica che, se pronunciata nella lingua originale, godeva di indubitabile efficacia (ad es. Corp. Herm. 16. 2; Iamb. Myst. 7. 4-5). Ancor prima delle testimonianze di Giustino Martire e di Tertulliano sopra riportate, già nell'Epistola di Barnaba non c'è nessun'esitazione nel rubricare il veneficio e la magia tra i comportamenti assolutamente negativi (Barn. ep. 20. 1), e nella Didaché XII apostolorum si invita espressamente il fedele a non ricorrere alla magia così come ai venefici, nonché gli si intima di non diventare un augure, un mago, un astrologo, un superstizioso, tutti atteggiamenti che conducono alla dannazione dell'anima (Did. 2. 2). Anche Ignazio di Antiochia fa suo il tema dell'astrologia connesso alla magia e alla divinazione quando nell'Epistula ad Ephesios contrappone il potere di Cristo e della sua venuta al potere demoniaco che si esercita sul cosmo attraverso gli angeli decaduti secondo la tradizione ebraica e giudeo-cristiana: la venuta del figlio di Dio in forma di uomo coincide con la dissoluzione di ogni magia e la distruzione di ogni legame insito nella malvagità (Ign. Anth. Ep. ad Eph. 19. 3). Se Quadrato nel rivendicare la legittimità delle guarigioni e delle resurrezioni operate da Gesù tramite il ricordo di testimoni ancora vivi ai suoi tempi (ap. Eus. Hist. eccl. 4. 3. 2) sembra volere difendere il nascente cristianesimo dall'accusa di magia rivolta al fondatore tanto dai Giudei che dai pagani, l'ateniese Aristide, oltre a vituperare gli stessi Giudei per la loro disconoscenza del Figlio del Dio e lodare l'esemplarità etica della vita dei cristiani (Arist. Ath. Apol. 14. 2; 15. 3-8), quando taccia di assurdità la fede dei Caldei, dei pagani e degli Egiziani non esita ad accusare Ermete di essere un dio mago e Asclepio un dio guaritore incapace di salvare se stesso (Arist. Ath. Apol. 10. 2-3).

Della reciproca accusa di magia si è già fatto cenno, il problema che continua a essere avvertito dai cristiani è quello di giustificare l'efficacia del loro modus operandi senza che questo fnisca con l'essere equiparato agli esorcismi dei maghi comunque efficaci perché pronunciati nel nome di Dio e di Gesù. La risposta fornita dai Padri della chiesa è unanime: gli dèi sono i dèmoni; siano 
quest'ultimi il risultato dell'unione degli angeli ribelli con le donne, secondo quanto sostengono ad es. Giustino (Iustin. II Apol. 5. 3), Atenagora (Athenag. Leg. 24. 3-25. 1) e Tertulliano (Tert. Apol. 22. 3), oppure siano gli angeli ribelli tout court, secondo l'interpretazione di Taziano (Tatian. Orat. ad Greac. 7. 4-5) e di Minucio Felice (Min. Fel. Oct. 26. 8-27. 1). In forza della loro natura angelica, ancorché degradata, essi possiedono poteri superiori a quelli dell'uomo; in forza della loro volontà traviata sono malvagi e dacché erano stati posti al di sopra degli uomini per sostenerli, ora sono disposti a qualsiasi nefandezza pur di arrivare a traviarne l'anima (Monaci Castagno 1996) ${ }^{4}$. Questi dèmoni, che abitano presso - se non dentro - i simulacri degli dèi e si nutrono degli effluvi dei sacrifici cruenti, si servono di visioni e incantesimi per portare a termine il loro piano esiziale. La veridicità delle prime è giustificata dai Padri della chiesa tanto con gli studi filosofici relativi alla psicologia, secondo la quale i sogni possono essere veritieri, quanto con il fatto che i dèmoni, oltre a essere più potenti dell'uomo, si compongono di natura aerea e pertanto possono sfruttare la loro velocità costitutiva per sapere in anticipo quanto accade altrove e quindi riferirlo secondo le modalità della divinazione ufficiale e/o personale. Com'è noto, pur non negando a priori la portata profetica dei sogni (basti pensare ai sogni interpretati da Giuseppe nel libro della Genesi [Gn 40. 9-19; 41. 17-32] e all'importanza dei sogni ricevuti da san Giuseppe [Mt 1. 20-24; 2. 13-14]), la forma di divinazione per antonomasia ammessa dai cristiani è quella dei profeti che, come dice Giustino, ispirati dallo Spirito Santo hanno compiuto dei prodigi al fine di glorificare Dio e annunciare la venuta del Figlio; a loro vengono contrapposti tutti quei falsi profeti che compiono falsi prodigi per strabiliare gli uomini e farli cadere nelle reti tese dai dèmoni (Iustin. Dial. cum Tryph. 7. 3).

L'efficacia della magia, invece, trova giustificazione specialmente nella certa convinzione che alcune parole abbiano un valore proprio il quale, indipendentemente da chi le reciti, non viene mai meno a patto che esse siano pronunciate nella lingua originale. $\grave{E}$ ancora Giustino a far presente che chiunque pronunci il nome del Dio di Abramo, di Isacco e di Giacobbe otterrà potere sul dèmone da esorcizzare (Iustin. Dial. cum Tryph. 85. 3), noché a ribadire che solo i cristiani, esorcizzando nel nome di Gesù Cristo, hanno avuto successo proprio laddove nessun altro esorcista o propolatore di farmaci aveva potuto avere la meglio sul dèmone che si era impossessato del corpo del malcapitato (Iustin.

\footnotetext{
${ }^{4}$ Accanto all'identificazione dèi-dèmoni si afferma anche la riproposizione delle teorie evemeristiche; ad es. Athen. Leg. 30. 3; Tert. Apol. 12. 1; Tert. Ad nat. 2. 7. 14; Theoph. Ad Aut. 1. 9. Secondo tale interpretazione Serapide non sarebbe altri che 1'“egizianizzazione" del greco Sarra pais, con riferimento al noto Giuseppe del libro della Genesi che salvò l'Egitto da una terribile carestia, così in Tert. Ad nat. 2. 8. 10-17; Firm. Mat. Err. prof. rel. 13. 1-2; Paul. Nol. Carm. 19. 98-106.
} 
II Apol. 6. 6). Anche Atenagora non esita a riconoscere la validità dei prodigi operati dagli dèi pagani giustificandola con la pervicace azione mistificatrice dei dèmoni: gli dèi venerati dai vari popoli, così come i miracoli a essi attribuiti, sono la conseguenza dell'azione antagonistica delle potenze che agiscono sulla materia - e cioè gli angeli caduti dal cielo e i giganti -, e per mezzo di essa, lo spirito che è sulla materia, proprio come gli angeli, benché sia stato creato da Dio, si oppone al suo creatore; così questi dèmoni che vivono presso le statue degli idoli ivi trascinano gli uomini al fine di poter godere dei sacrifici colà celebrati e di potersi vedere attribuite tutte quelle forme di preveggenza naturale proprie dell'anima razionale (Athenag. Leg. 27. 1-2). Nell'Oratio ad Graecos di Taziano è ben presente la tematica dell'identificazione tra dèi e dèmoni malvagi: sono loro ad avere introdotto la magia, le pratiche medicali (a essa assimilate) e la divinazione; si riprende il tema degli angeli caduti a seguito di una scelta volontaristica alla quale fa seguito anche il peccato dei protoplasti; gli uomini così traviati, vittime della propria apostasia, hanno iniziato ad attribuire un potere fatale agli astri poiché incapaci di accogliere nella propria anima quello spirito che sarebbe capace di indirizzarli verso Dio (Tatian. Orat. 8. 1-9. 1). I dèmoni, più forti degli uomini, possono mostrarsi a loro per imbonirli o danneggiarli e possono anche entrare nei loro corpi fino a quando la parola di Dio non li abbia allontanati. La stessa magia è intesa quale autentico agguato del demonio, e a essa si affidano non solo i malati e gli innamorati ma anche coloro che cadono preda dell'odio e della vendetta (Tatian. Orat. 17. 3-4); in forza del fatto che la magia non lesini l'uso di elementi animali e vegetali per la realizzazione degli incantesimi proprio come la medicina per la cura delle patologie, anche la medicina e le malattie finiscono con l'essere ricondotte al medesimo alveo demoniaco dall'apologeta, specialmente quel tipo di malattia che chiameremmo psichica e contro la quale i pagani contemporanei non esitavano a ricorre a culti iatromantici: "I dèmoni non guariscono ma grazie alla (loro) abilità rendono schiavi gli uomini... entrando nelle membra di alcuni... quando tutti guardano... balzati fuori da coloro che sono sofferenti, eliminando la malattia che causarono, ristabiliscono gli uomini nella condizione precedente" (Tatian. Orat. 18., 5-6).

Da qui sarà consequenziale sostenere che anche la divinazione è un prodotto della volontà dei dèmoni sempre occupati a spingere l'uomo nel fondo dell'abisso della perdizione. Gli scritti dei già ricordati Clemente Alessandrino e Tertulliano, così come l'Octavius di Minucio Felice, ci aiutano nella ricostruzione del quadro teologico cristiano più o meno contemporaneo alla redazione dell'opera di Celso 5 . Il primo negli Stromata arriva a dire: "I dialetti primitivi e specifici da una parte sono barbari, dall'altra hanno nomi secondo natura, per questo gli

\footnotetext{
${ }^{5}$ Si pensa che il Discorso vero sia da datarsi intorno al 178.
} 
uomini sono concordi nell'ammettere che le preghiere sono più potenti una volta pronunciate in lingua barbara" (Clem. A1. Strom. 1. 21. 143). È evidente che proprio la certezza nel potere della parola tipica della cultura contemporanea (dotta come popolare) è alla base della convinzione dell'assoluta efficacia delle formule magiche - convinzione che sarà anche di Origene - e corrobora non solo quanti, dando credito ai ciarlatani si fanno scudo degli amuleti da loro prodotti consacrati magico more e dei loro incantesimi, ma addirittura i maghi stessi che possono vantarsi di avere al loro servizio dei dèmoni servitori ridotti in schiavitù grazie alla potenza dell'incantesimo recitato; contro entrambi Clemente si schiera nel Protrepticus (Clem. Al. Protr. 58. 3; 115, 2).

A più riprese Tertulliano si scaglia contro i dèmoni che, assunte le sembianze degli dèi pagani, spingono l'uomo alla dannazione facendo leva sulla divinazione, la taumaturgia e la magia, oltre a far ricadere sui cristiani e sulla loro conversione i momenti di difficoltà nei quali le popolazioni possono venirsi a trovare. Questi dèmoni-dèi, in forza della loro natura e della loro prava disposizione a traviare l'anima dell'uomo naturalmente incline a credere al Dio unico, non esitano a rivelarsi latori di benefici, specialmente nel campo della salus dal momento che sono proprio loro, dopo aver recato danno agli uomini diabolicamente, a dare l'illusione di guarirli quando in realtà non fanno altro che rimuovere la causa del male della quale erano diretti responsabili" (Tert. Apol. 22. 11). È noto che i rimedi per una guarigione miracolosa venivano ricevuti dai devoti debilitati soprattutto durante il sonno o comunque in uno stato di coscienza alterato. $\mathrm{Nel}$ De anima, Tertulliano, dopo avere delegittimato l'intero patrimonio onirologico e iatromantico in quanto opera demoniaca, finisce anche col fornire una prova della pervasività di tali fenomeni quando rivela che "questo potere non è certamente delimitato né rimane circoscritto nei confini dei santuari; invero, esso è vagante e dotato di estrema mobilità e nondimeno libero" (Tert. De anim. 46. 13-47. 1).

Seppur per linee oltremodo generali, quanto appena presentato è il pensiero dei Padri della chiesa in relazione alla divinazione e alla magia più o meno contemporaneo al clima culturale pagano nel quale viene a essere redatto il Discorso vero di Celso. Anche Origene, per confutare le tesi poste a fondamento dell'opera anti-cristiana, non esita a riproporre la critica dei Padri della chiesa nei confronti degli dèi, dell'efficacia che pure doveva essere riconosciuta alla loro costitutiva potestas e, almeno in alcuni casi, della benevolenza filantropica da questi mostrata nei confronti dei propri fedeli avviluppati nei difficili legacci dell'esistenza. Analizzeremo unicamente il Contra Celsusm, l'opera dalla quale è stata tratta la citazione con cui si apre questo contributo; tale citazione è contenuta nel libro V. Sarà interessante notare che proprio all'inizio di questo libro, nel rispondere a Celso che, alla luce della presunta impossibilità della discesa sulla terra di un Dio o di un Figlio di Dio, aveva finito con l'identificare gli angeli con i dèmoni della tradizione pagana, l'alessandrino, nell'arrivare a negare, per consequentiam, ogni manifestazione degli 
dèi, ricorda proprio Apollo Pitico e Asclepio, ovverosia quegli dèi specificamente legati alla mantica e alla guarigione (Orig. Cels. 5. 2).

Alla luce dell'argomentazione di Celso, infatti, Origene arriva a sostenere che essi, giacché si manifestano, non possono essere dèi e pertanto saranno da considerarsi dèmoni. Ancora nel medesimo libro, per difendere, ancorché pro domo sua, i Giudei dall'accusa di essere stati irretiti da Mosé considerato un mago dal polemista pagano, il dotto teologo ed esegeta non solo ne fa presente l'assoluta superiorità etica nei confronti degli altri popoli ma non esita a rivendicare che essi, rifiutando qualsiasi forma di divinazione perché considerata di matrice demoniaca, si sono affidati alle anime di coloro che avevano ricevuto lo Spirito di Dio (Orig. Cels. 5. 42). E ancora, appare degno di rilievo il passaggio successivo con il quale Origene, nel confutare Celso per avere dichiarato l'assoluta indifferenza nel chiamare Zeus l'Altissimo, Zen, Adonai, Sabaoth, Ammone, Papeo, contribuisce a presentarci meglio il quadro della magia contemporanea; qui, in contrapposizione alle tesi aristoteliche, ribadisce che le lingue degli uomini non hanno la loro origine dagli uomini stessi e che quei nomi che per natura hanno potere nella lingua originale lo perdono una volta tradotti (Orig. Cels. 5. 45). In questo passo, a dimostrazione di una sistematica volontà compositiva, è lo stesso Origene a richiamarsi a quanto da lui stesso argomentato nel corso dell'opera. Infatti, fin dai primi capitoli del I libro, nel controbattere all'accusa secondo la quale non solo i poteri dei cristiani sono dovuti al pronunciare i nomi di alcuni dèmoni e alla recitazione di incantesimi ma anche lo stesso Salvatore servendosi della magia avrebbe potuto operare i miracoli a lui attribuiti, si mette bene in evidenza come i cristiani abbiano tale potere unicamente perché pronunciano il nome di Gesù assieme ad altre parole tramandate dalle Sacre Scritture senza nessun bisogno di ricorrere a incantesimi (Orig. Cels. 1. 6). Pochi paragrafi dopo si apre una lunga digressione sul potere dei nomi, nonché sulla conseguente efficacia della magia intesa quale sistema coerente e caratterizzato da principi esoterici: "E così, mentre i nomi dei dèmonidèi egizi, persiani o di qualsiasi altra popolazione sono in grado di piegare alla volontà del mago solo gli dèi dei singoli popoli, la sequenza Sabaoth Adonai se pronunciata in lingua originale ha valore su tutti i dèmoni-dèi dal momento che si riferisce al Dio sommo di gran lunga più potente del più potente fra i dèmoni. Non sarà quindi la volontà di Dio a dare valenza all'incantesimo ma la forza evocatrice propria del suo nome e valida in quanto tale, indipendentemente dalla volontà di chiunque sia a pronunciarla" (Orig. Cels. 1. 24-25). Accanto all'accusa di magia rivolta da Celso ai cristiani per giustificare l'efficacia dei miracoli, il polemista affianca anche quella della recenziorità del Cristo nei confronti degli dèi pagani: il Cristo non sarebbe altri che un uomo di bassa estrazione che si sarebbe servito della magia appresa presso gli Egiziani per la sua attività taumaturgica al fine di proclamarsi Dio col risultato di essere crocifisso (Orig. Cels. 1. 28). Contro questa opinione, Origene, oltre a rilevare la mancanza di tradizione che accompagna alcuni dèi pagani tra i quali proprio Serapide (Orig. Cels. 5. 34; 5. 
37), a più riprese fa notare come la venuta di Cristo fosse stata preannunciata ampiamente dai profeti (Orig. Cels. passim).

$\mathrm{E}$ di fronte all'accusa di goeteia, in forza della quale così spesso Celso denigra Gesù associandolo ai ciarlatani, è già alla fine del I libro che Origene afferma che il Cristo si differenzia totalmente da maghi e ciarlatani per avere utilizzato la propria attività taumaturgica al fine di condurre sulla via della salvezza gli uomini e finendo così per proporsi come modello di vita eccellente, cosa del tutto aliena anche al principe dei maghi (Orig. Cels. 1. 68). Si tratta di uno degli argomenti fondamentali con i quali Origene nel corso dell'intera opera rivendica la differenza assoluta tra i miracoli operati da Gesù e le azioni dei maghi: i primi sono volti a convertire gli uomini al fine di salvarne l'anima, le seconde vengono messe in opera con l'aiuto dei dèmoni-dèi e sono indirizzate alla dannazione di coloro che rifiutano di accogliere la "Buona Novella". Sarà sufficiente analizzare il penultimo capitolo del VII e i loci specifici dell'VIII e ultimo libro del Contra Celsum. A chiusura del VII libro Origene pone un passo che presenta forti assonanze con quello da cui abbiamo preso le mosse: "Quale sia la natura dei dèmoni è manifestato anche da quelli che invocano $i$ dèmoni per $i$ cosiddetti «filtri», per i malefici, per impedimenti di azioni o per infinite cose del genere. Queste cose compiono quelli che hanno appreso a invocare i dèmoni attraverso formule e incantesimi e a obbligarli a compiere ciò che essi desiderano. Perciò il culto di tutti i dèmoni è estraneo a noi, che veneriamo il Dio al di sopra di tutte le cose. E il culto dei cosiddetti «dèi» è un culto di dèmoni, poiché «tutti gli dèi delle nazioni sono dèmoni» (= Ps 95.5).

Questo è manifestato anche dal fatto che pure per quelli che sembrano essere $\mathrm{i}$ più potenti fra i cosiddetti «santuari» si pronunciano insolite invocazioni, così come all'inizio della realizzazione di queste statue e templi, le quali invocazioni sono fatte da quelli che si dedicano al culto dei dèmoni attraverso incantesimi. Perciò noi abbiamo deciso di fuggire come una rovina il culto dei dèmoni e affermiamo che è un culto rivolto ai dèmoni ogni pretesa adorazione di dèi, a opera dei Greci, (che ha luogo) presso altari, statue e templi” (Orig. Cels. 7. 69). Tale lettura ritorna già nelle prime pagine del libro successivo laddove si ribadisce, da una parte, la differenza assoluta tra i miracoli di Gesù e il potere dei maghi, dall'altra, l'impossibilità per i cristiani di venerare gli dèi in quanto essi, lungi dall'essere divinità, sono dèmoni che si aggirano intorno alle statue sacre innalzate dai pagani (Orig. Cels. 8. 11); di conseguenza i cristiani non frequenteranno i templi degli dèi (Orig. Cels. 8. 20) né le feste che proprio i pagani celebrano in loro onore (Orig. Cels. 8. 24) senza che questo possa determinare una revanche da parte dei dèmoni una volta vistisi trascurati (Orig. Cels. 8. 36). Non manca neanche un'ampia distinzione tra gli angeli inviati da Dio per proteggere dall'azione malvagia dei dèmoni chi ne è degno e i dèmoni stessi, all'interno della quale si ribadisce la necessità per i cristiani di astenersi dai sacrifici celebrati per la venerazione dei dèmoni-dèi (Orig. Cels. 8. 25-27). Ancora una volta si torna a controbattere Celso che ha appena ribadito che $\mathrm{i}$ cristiani riescono 
a compiere prodigi in quanto ricorrono a parole di potenza pronunciate in "lingua originale" e che Cristo altri non sia se non un ciarlatano (Orig. Cels. 8. 37; Cels. 8. 41). Segue una ripetuta difesa della capacità dei cristiani di allontanare i dèmoni che albergano nelle statue degli dèi, ancora una volta considerati da Celso come benevoli, manifesti e prodighi nei confronti dell'uomo soprattutto nella dimensione oracolare (Orig. Cels. 8. 45); ai presunti miracoli da questi operati si contrappongono gli "autentici" miracoli ricordati nelle Sacre Scritture: i miracoli degli dèi sono un prodotto dei dèmoni e della loro costituiva potestas, quelli delle Sacre Scritture sono opera di Dio e di Cristo (Orig. Cels. 8. 47). Si procede, quindi, con Celso che non esita ad affermare che non solo i cristiani ma anche, e soprattutto, i pagani credono alle punizioni eterne, specialmente gli interpreti dei misteri sacri, gli iniziatori e i mistagoghi (Orig. Cels. 8. 48), al punto che anche per Celso diventa accettabile la posizione dei cristiani circa la beatitudine dei giusti nel post mortem a patto che essi non insultino i dèmoni di quaggiù (Orig. Cels. 8. 49). Dopo una digressione sulla melothesia (Orig. Cels. 8. 58), inizia una vera e propria Spannung che attraverso il continuo riproporre la dialettica Cristo vs. maghi e dèmoni-dèi arriva a sciogliersi nell'ipotizzare che lo stesso Celso sia rimasto vittima dell'azione tralignante di queste potenze malvagie (Orig. Cels. 8. 63).

Alla luce di quanto fin qui presentato, allora, quali potranno essere state le manganeiai messe in atto da Tolomeo? Sarà legittimo distinguere tra un momento passivo e uno attivo nell'atteggiamento del monarca nei confronti di Serapide. All'inizio, infatti, egli riceve in sogno un'epifania del dio nella quale gli si ingiunge di portarne la statua dal Ponto ad Alessandria. Nel seguito della vicenda il sovrano e i suoi discendenti saranno i grandi propalatori del culto di Serapide grazie alla costruzione del meraviglioso serapeo alessandrino con la mirabile statua del dio ivi ospitata. Abbiamo visto quante volte Origene non abbia esitato a individuare nella dimensione onirica uno dei terreni di elezione utilizzati dai dèmoni-dèi per manifestarsi agli uomini e abbia tacciato i dèmoni di assieparsi intorno alle statue delle divinità per nutrirsi dei fumi dei sacrifici cruenti. Ed è proprio il Serapide di Alessandria, dio benevolo e guaritore che partecipa dell'essenza di quel cosmo che lui stesso regola, che al tempo di Origene gode non solo della devozione di pagani che a lui chiedono miracoli ma anche della "fiducia" dei maghi che arrivano ad invocarlo nei loro incantesimi come "Serapide kyrios, colui che nutre l'ecumene intera, vince ogni cosa" (PCol. 1982 = Daniel - Maltomini 1990-1992 I, n. 7). Allora, alla luce dell'enorme successo raggiunto dal dio sia nell'ambito lecito e manifesto della religione pubblica e privata che in quello clandestino e periglioso della magia, dietro al breve passaggio del Contra Celsum riportato si deve cogliere per intero la querelle senza esclusione di colpi che vede impegnati i cristiani da un parte e i pagani dall'altra nel rimpallarsi l'accusa di magia a giustificazione di visibili e altrimenti irrealizzabili thaumata. 


\section{Abbreviazioni e bibliografia}

AA.VV. (2006), Pagani e Cristiani alla ricerca della salvezza (secoli I-III), XXXIV Incontro di studiosi dell'antichità cristiana, Roma.

Bianchi, U. (1975), La religione greca, Torino.

Bonner, C. (1950), Studies in Magical Amulets Chiefly Graeco-Egyptian, Ann Arbor - London 1950.

Borgeaud, Ph. Volokhine, Y. (2000), "La formation de la légende de Sarapis. Une approche transculturelle", ARG 2:37-76.

Bricault, L. (2013), "Sarapis au banquet: lectisternes d'Alexandrie et d'Égypte”, RN 170: 101-134

Clark Kee, H. (1993), Medicina, miracolo e magia nei tempi del Nuovo Testamento, Brescia (ed. or. Cambridge 1990²).

CoptEnc: A.S. Atiya (ed.), The Coptic Encyclopedia, 8 voll., New York - Toronto - Oxford et al. 1991.

Crouzel, H. (1971), H. Crouzel, Bibliographie critique d'Origène, Steenbrugis Hagae Comitis.

Crouzel, H. (1982), Bibliographie critique d'Origène. Supplément I, Steenbrugis Hagae Comitis.

Crouzel, H. (1996), Bibliographie critique d'Origène. Supplément II, Steenbrugis - Turnhout.

Daniel, R.W. Maltomini, F. (1990-1992), (edd.), Supplementum magicum, 2 voll., Opladen.

Koenen, L. (1967), "Eine Einladung zur Kline des Sarapis”, ZPE 1: 121-126.

Le Boullec, A. (1998). Vingt ans de recherche sur le Contre Celse: état des lieux, in L. Perrone (ed.), Discorsi di verità. Paganesimo, giudaismo e cristianesimo a confronto nel Contro Celso di Origene. Atti del II convegno del Gruppo Italiano di Ricerca su "Origene e la Tradizione Alessandrina", Roma, 9-28.

Luck, G. (1997), (ed.), Arcana mundi. Magia e occulto nel mondo greco e romano. I: Magia, Miracoli, Demonologia, Milano.

Mastrocinque, A. (2014), (ed.), Les intailles magiques du Département des Monnaies, Médailles et Antiques, Paris.

Mckenzie, J. Gibson, S. Reyes, A.T. (2004), "Reconstructing the Serapeum in Alexandria from the Archeological evidence", JRS 94: 73-121.

Michel, S. (2001), (ed.), Die magischen Gemmen im Britischen Museum, 2 voll., London.

Mitchell, S. van Nuffelen, P. (2010a), (edd.), Monotheism between Pagans and Christians in Late Antiquity, Leuven - Walpole [MA]. 
Mitchell, S. van Nuffelen, P. (2010b), (edd.), One God: Pagan Monotheism in the Roman Empire, Cambridge - New York - Melbourne et al.

Monaci Castagno, A. (1996), (ed.), Il diavolo e i suoi angeli. Testi e tradizioni (secoli I-III), Fiesole.

P. Col.: Papyri Colonienses.

Pgm: K. Preisendanz (ed.), Papyri Magicae Graecae, Leipzig 1972-1974³.

P. Oxy.: Papyri Oxyrhinchitae.

Bricault, L. (2005), (ed.), Recueil des Inscriptions Concernant les Cultes Isiaques, 3 voll., Paris.

Sabottka, M. (2008), Das Serapeum in Alexandria. Untersuchungen zur Architektur und Baugeschichte des Heiligtums von der frühen ptolemäischen Zeit bis zur Zerstörung 391 n. Chr., Le Caire.

Sfameni Gasparro, G. (2009), Problemi di religione greca ed ellenistica, Cosenza.

Smith, M. (1978), Jesus the Magician, New York - Hagerstown [MD] - San Francisco et al.

Turcan, R. (2004), Les cultes orientaux dans le monde romain, Paris ${ }^{3}$.

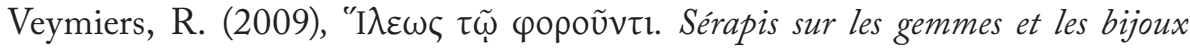
antiques, Bruxelles. 
(Página deixada propositadamente em branco) 


\title{
A luta pelo monopólio do Sagrado em antioquia: joão CRISÓSTOMO E O ATAQUE À MAGIA E SEUS AGENTES (sÉc. IV D.c.) [The struggle for the sacred monopoly in Antioch: John Chrysostom and the attack to magic and its agents (4th c. AD)]
}

\author{
Gilvan Ventura da Silva ${ }^{1}$ \\ Érica Cristhyane Morais da Silva ${ }^{2}$ \\ Universidade Federal do Espírito Santo \\ (gil-ventura@uol.com.br; dephis.ufes@hotmail.com)
}

Resumo - Nosso propósito, neste capítulo, é discutir a maneira pela qual, na Antiguidade Tardia, momento em que a cristianização do Império Romano adquire um vigoroso impulso, as práticas de magia e adivinhação, bem como a crença em forças demoníacas, eram acontecimentos constituintes da própria vida cotidiana, integrando um sistema de saberes em franca concorrência com os preceitos cristãos, o que exigiu dos Padres da Igreja um esforço contínuo visando a erradicá-las, embora sem sucesso. Para tanto, tomamos como estudo de caso a atuação de João Crisóstomo que, entre 386 e 397, na condição de presbítero da congregação de Antioquia, desenvolveu uma extensa pregação voltada para a reforma espiritual da pólis e para a fixação de um modus vivendi genuinamente cristão, o que o levou a se pronunciar, em diversas ocasiões, acerca da capacidade malfazeja dos demônios e da crença em ritos mágicos como sérios obstáculos ao processo de cristianização, ao mesmo tempo em que reafirmava as prerrogativas dos sacerdotes cristãos como únicos porta-vozes autorizados do sagrado.

Palavras-chave: Antiguidade Tardia. Magia. Sagrado. Antioquia. João Crisóstomo.

Aвstract - In this chapter, we intend to discuss how in Late Antiquity, a time span when the Christianization of the Roman Empire evolved quickly, the magical and divinatory practices as well as the belief in demoniacal powers were ordinary facts, taking part of a system of thought in direct opposition to the Christian precepts. Because of that, the Fathers of the Church strove continuously to eradicate such system, although unsuccessfully. In order to cast some light on such process, we chose as case study the work of John Chrysostom, who between 386 and 397 A.D., as presbyter of the Antiochene congregation, devoted himself to the spiritual reform of the polis and to the institution of a genuine Christian way of life through his homilies and treatises. This effort led him to emphasize, in several occasions, the interference of demons in the world and to criticize the belief in magical rites, a major hindrance to the Christianization of the Roman society. In doing so, the preacher also strengthened the prerogatives of the Christian priests as exclusive representatives of divine.

Keywords: Late Antiquity. Magic. Divine. Antioch. John Chrysostom.

\footnotetext{
${ }^{1}$ Professor Titular de História Antiga da Universidade Federal do Espírito Santo (Ufes).

${ }^{2}$ Professora Adjunta de História Antiga da Universidade Federal do Espírito Santo (Ufes).
} 
Gilvan Ventura da Silva

Érica Cristhyane Morais da Silva

\section{Palavras iniciais}

Nas sociedades ocidentais contemporâneas, marcadas por séculos de estrito treinamento filosófico e pelo seu corolário direto, o conhecimento científico, parece haver cada vez menos espaço para as reflexões em torno daquilo que costumamos qualificar como magia, um amplo conjunto de crenças e práticas amiúde relegadas ao domínio do senso comum, da experiência vulgar, apanágio de pessoas rudes e ignorantes que, na ausência de instrução suficiente para compreender que todo e qualquer fenômeno natural possui, ele próprio, causas naturais e plenamente compreensíveis de um ponto de vista lógico, racional, tenderiam a buscar explicações para os acontecimentos numa suposta capacidade inata ou adquirida de alguns indivíduos - os magos, bruxos e feiticeiros de todas as cepas - para produzir alterações sensíveis na realidade, não raro com a intenção de causar dano a outrem. Para tanto, tais indivíduos recorreriam amiúde a forças sobrenaturais ou, como propõe Philsooph (1971), numa definição lapidar, a agentes espirituais conscientes, dentre os quais os mais solicitados seriam, sem dúvida, os demônios, que, integrando as falanges de Satanás, estariam sempre prontos a disseminar a ruína e o infortúnio, na condição de principais inimigos do gênero humano, como costuma alardear, no Brasil e alhures, uma pletora de igrejas cujos líderes, na disputa pela atenção dos fiéis, lançam mão de todos os meios disponíveis, a ponto de elegerem os demônios como parceiros privilegiados da missão evangelizadora, a despeito do paradoxo evidente. A bem da verdade, a presença resiliente, na sociedade brasileira, de um discurso sobre as origens do mal calcado em preceitos judaico-cristãos ancestrais, discurso este que se situa na contracorrente daquilo que denominamos, ao menos a partir da Revolução Francesa, como processo de secularização, ou seja, como a separação entre os domínios laico e religioso (Floristán Samanes; Tamayo-Acosta, 1999: 767), nos induz a concluir que, ao contrário do esperado, a crença na eficácia da magia e na existência de potências demoníacas não pode de modo algum ser tomada como mero substrato de concepções arcaicas que tenderiam ao desaparecimento à medida que avança o nosso conhecimento positivo, científico, sobre os seres e as coisas. Pelo contrário, o que temos observado com surpreendente nitidez ao longo dos últimos anos é a instauração de um amplo movimento de reconfiguração religiosa, não apenas da política, mas de todos os setores da vida em sociedade, pois, como salienta Geertz (2001: 155), hoje, mais do que nunca, os sociólogos e antropólogos parecem ter consciência de que "o mundo não funciona apenas com crenças. Mas dificilmente consegue funcionar sem elas".

Desde pelo menos as duas últimas décadas do século XX temos assistido à proliferação de visões de mundo e de experiências religiosas que, assentadas na recuperação dos textos sagrados e dos seus ensinamentos sobre o sentido da vida e da morte, recolocam na ordem do dia opiniões que, no passado, não tardariam a ser descartadas como fruto de mera especulação, a exemplo da crença na 
influência nefasta dos demônios e na capacidade intercessora dos anjos e santos, como comprova a renovação carismática católica, movimento de raiz neopentecostal saturado de misticismo e de certa dose de fanatismo que investe na recuperação dos charismata, ou seja, dos dons do Espírito, a exemplo da glossolalia, a capacidade de falar línguas estrangeiras sem aprendizado (Cross; Livingstone, 2005: 324). Diante de um cenário como este, no qual os fenômenos mágicos e as intervenções sobrenaturais na realidade, quer para o bem quer para o mal, são manejados como autênticas categorias explicativas, como respostas plausíveis a determinado problema ou impasse, os estudos que tenham por objetivo analisar as funções da magia e o lugar ocupado pelos seus agentes humanos e espirituais sob uma perspectiva histórica, antropológica, sociológica, teológica, psicológica ou qualquer outra adquirem um novo e relevante papel, pois não se trata, em absoluto, de investigar um assunto potencialmente significativo apenas para as bruxas da Idade Média, para as tribos de África ou para os aborígenes do Novo Mundo, mas de lançar alguma luz sobre experiências que se encontram enraizadas no nosso próprio mundo e no nosso próprio tempo, dos quais o mágico, o maravilhoso, o misterioso e o sobrenatural nunca foram, de fato, banidos.

Tendo em vista estas considerações iniciais, nosso propósito, neste texto, é discutir a maneira pela qual, na Antiguidade Tardia, momento em que a cristianização do Império Romano adquire um vigoroso impulso, as práticas de magia e adivinhação, bem como a crença em forças demoníacas, eram acontecimentos constituintes da própria vida cotidiana, integrando um sistema de saberes em franca concorrência com os preceitos cristãos, o que exigiu dos Padres da Igreja um esforço contínuo visando a erradicá-las, embora sem sucesso. Para tanto, tomamos como estudo de caso a atuação de João Crisóstomo que, entre 386 e 397, na condição de presbítero da congregação de Antioquia, desenvolveu uma extensa pregação voltada para a reforma espiritual da pólis e para a fixação de um modus vivendi genuinamente cristão, o que o levou a se pronunciar, em diversas ocasióes, acerca da capacidade malfazeja dos demônios e da crença em ritos mágicos como sérios obstáculos ao processo de cristianização, ao mesmo tempo em que reafirmava as prerrogativas dos sacerdotes cristãos como únicos porta-vozes autorizados do sagrado. Antes, porém, de prosseguirmos faz-se necessário aclarar, ainda que brevemente, o conteúdo do conceito de magia que empregamos.

\section{A magia como Sistema simbólico}

Em termos teóricos, a investigação em torno do exercício da magia nas suas distintas manifestações foi, por muito tempo, dependente de um modelo interpretativo do qual James Frazer é o principal expoente. Com a publicação, em 1890, de O ramo de ouro, Frazer lançava os fundamentos de um influente paradigma antropológico segundo o qual a magia representaria uma tentativa falsa 
e ilusória de se alterar a ordem do mundo, um recurso empregado pelo homem "primitivo", que pouco conhecia das leis da Física, da Química e da Biologia e que, portanto, se quedaria impotente diante das forças da natureza. A magia era então compreendida como uma falsa ciência, ou seja, como uma tentativa de intervenção física sobre a realidade mediante a fixação de relações causais arbitrárias entre os seres e as coisas, o que, evidentemente, comprometeria de modo irremediável sua validade. A principal dúvida subjacente ao paradigma antropológico clássico de interpretação dos fenômenos mágicos era descobrir se os "primitivos" que recorriam à magia como forma de manipulação do mundo seriam portadores do assim denominado "pensamento racional", na medida em que, à época, se supunha que os aborígenes, indígenas, silvícolas e similares se distinguissem dos europeus por um pensamento de tipo "selvagem" e, portanto, pré-científico ou mesmo a-científico. O approach teórico de Frazer e sucessores continha um substrato evolucionista de difícil comprovação, uma vez que a magia era concebida como uma modalidade de intercâmbio com o sobrenatural anterior à religião e, portanto, menos complexa, dentro de uma escala que conduziria, no futuro, à superação da própria religião pela ciência, modalidade de conhecimento bastante cara aos eruditos do século XIX envolvidos na construção das assim denominadas Ciências Humanas.

Por esse approach, estabeleceu-se uma clivagem primária entre magia e religião que condicionou por décadas a literatura sobre o assunto, pressupondo-se que a magia era distinta da religião devido a uma série de fatores. Em primeiro lugar, pelo fato de a magia lidar com forças imanentes, tectônicas, ao passo que a religião se reportaria a forças transcendentes, celestiais e, por isso mesmo, superiores ao homem. Em segundo lugar, pela atuação individual, arrogante e egoísta do mago, um especialista na execução de rituais que, visando a atender os seus caprichos, não hesitava em coagir os elementos. Em terceiro lugar, pelo caráter francamente dissociativo da magia, voltada à produção de malefícios em oposição à religião, comprometida com a coesão do grupo ou, dito em outros termos, com a salvaguarda do bem comum. Por outro lado, ao se constatar a ineficácia dos ritos mágicos, o homem tomaria aos poucos consciência da sua fragilidade, passando a adotar então uma atitude religiosa - vale dizer, reverente - diante da natureza e dos deuses, à semelhança do adolescente que, ao se tornar adulto, passa a reconhecer a autoridade investida nos pais e professores, um importante sinal de maturidade.

Todo esse conjunto de pressupostos clássicos de interpretação da magia mais ou menos compartilhados pelos estudiosos do final do século XIX cedo experimentou um processo de erosão intelectual, sendo pouco a pouco superado à medida que avançavam as pesquisas de campo. Na opinião de um autor como Lévy-Bruhl, por exemplo, a oposição imanência mágica versus transcendência religiosa não passaria de um equívoco, uma vez que os povos ditos "primitivos" não distinguiam, a princípio, as realidades sensíveis das sobrenaturais, que se 
confundiam e interpenetravam, como podemos constatar por intermédio das narrativas mitológicas de inúmeros povos (Montero, 1990: 36 e ss.). Já para Marcel Mauss (2003), um dos expoentes no estudo dos vínculos entre magia e religião, as práticas mágicas, mesmo quando executadas solitariamente, não são uma criação absoluta do sujeito, encontrando-se fundadas em crenças e expectativas coletivas, de maneira que é sempre a sociedade que age por intermédio do mago ou do feiticeiro. Isso nos fornece uma explicação bastante satisfatória para a permanência da crença na magia mesmo diante de um eventual fracasso, atribuído à imperícia do oficiante e não à ineficácia do rito em si mesmo. Cumpre observar, no entanto, que, segundo Mauss, a magia era uma experiência alheia aos cultos institucionalizados e públicos, razão pela qual tenderia ao malefício, o que reforçava a posição teórica de Durkheim, para quem a religião seria uma fonte de coesão social e a magia de anomia, de desestabilização dos laços comunitários, pois o mago, ao exercer um ofício solitário, romperia a solidariedade grupal. Para ambos os autores, a magia seria assim uma das categorias possíveis de desvio social, o que reclamava a intervenção dos poderes públicos no sentido de coibi-la (Montero, 1990: 15).

A despeito de algumas considerações hoje não mais aceitas, devemos reconhecer que Durkheim e Mauss foram responsáveis por inaugurar uma corrente de interpretação da magia interessada menos na identificação dos seus princípios cognitivos do que na compreensão dos sentidos culturais por ela assumidos em diferentes tempos e sociedades. Assim, Durkheim e Mauss se preocuparam muito mais em apreender o significado e o impacto das práticas mágicas no cotidiano dos agrupamentos sociais do que em discernir os contornos do chamado "pensamento mágico". A contribuição desses autores foi decisiva para que se começasse a analisar a magia, não nos termos de um recurso simplório diante da ausência de uma explicação lógica sobre como o universo, o planeta e o meio ambiente se comportavam, mas como uma prática e um saber capazes de contribuir, de algum modo, para o desempenho de uma organização/instituição social. Nesse sentido, os ritos mágicos devem ser compreendidos, não como experiências culturais fadadas ao desaparecimento à medida que a humanidade "progride", mas como sistemas simbólicos por excelência, ou seja, sistemas responsáveis por conferir determinada ordem ao mundo, permitindo ao homem produzir conhecimento sobre a realidade. Decerto, não o conhecimento positivo, científico, mas um conhecimento de outra ordem, voltado para a decodificação de realidades suprasensíveis e para a explicação de liames aparentemente insondáveis entre corpo e espírito, céu e terra, vida e morte, relegados quase sempre a uma posição secundária pelos cientistas. De importância capital para essa mudança de perspectiva acerca da magia foi a contribuição de Lévi-Strauss (1975). Em franco desacordo com a escola clássica de interpretação, que julgava a magia obsoleta e inútil, e tendo como inspiração argumentos antecipados por Marcel Mauss, o autor defendeu de modo convincente a eficácia simbólica da 
magia, argumentando que a crença nos atos e símbolos mágicos era capaz, em determinadas circunstâncias, de intervir sobre o real, modificando-o.

Cumpre assinalar, no entanto, a impropriedade de se continuar tratando magia e religião como realidades distintas e até mesmo opostas, abordagem ainda vigente em determinados círculos acadêmicos. A magia, ao contrário do que se supunha, não age pela manipulação (embora equivocada) de relações mecânicas entre os elementos, mas faz sempre apelo a entidades sobrenaturais, a agentes espirituais conscientes, do mesmo modo que a religião. A fim de superar a dicotomia absolutamente estéril que se criou entre ambas, talvez a melhor estratégia intelectual seja considerar a magia um subsistema do sistema religioso cuja finalidade específica é produzir alterações na realidade sensível e romper com o encadeamento presente/passado/futuro mediante a intervenção de uma entidade qualquer, seja ela um daimon, um deus ou mesmo o espírito de um morto (Silva, 2003: 165-6). Desse ponto de vista, toda e qualquer religião, mesmo as monoteístas, comportaria, em maior ou menor grau, a execução de ritos proféticos, taumatúrgicos ou miraculosos, um componente indispensável para a retroalimentação da crença do devoto na divindade ou divindades que venera, o que deve nos tornar menos incautos diante das pretensões do cristianismo em traçar uma linha divisória estrita entre o milagre e a magia.

\section{Magia e demonologia no Império Romano}

No início do período imperial, constatamos, na bacia do Mediterrâneo, o súbito aumento dos especialistas itinerantes da magia que oferecem os seus serviços pelas ruas das cidades e que, de quando em quando, são alvo de ataques e de perseguição, tanto por parte das autoridades públicas quanto da comunidade local, de algum modo ameaçadas pela atuação de indivíduos aos quais se atribuía a capacidade de prever até mesmo a morte do imperador. O vocabulário empregado pelos antigos para identificar essas personagens era bastante variado: magus, mantis, goes, vates, vaticinator, mathematicus, maleficus, hariolous, philosophus e caldeu, exprimindo, nas entrelinhas, a gama de conhecimentos necessários para o exercício da profissão, como nos informa Plínio, o Velho, que, em sua História Natural (30,1-3), define a magia como um saber bastante complexo, resultante da combinação da medicina, da religião e da astrologia cujas origens remontariam a Zoroastro, o célebre profeta iraniano. Vale a pena lembrar que, no Império Romano, havia diversas tradições culturais vinculadas ao exercício da magia, com destaque para as "escolas" de procedência oriental, como a babilônica, a judaica e, especialmente, a egípcia. De fato, o Egito era reputado como a pátria dos feiticeiros, um local para onde os neófitos se dirigiam em busca de iniciação nos saberes esotéricos, a exemplo de Moisés e de Jesus, tidos, na Antiguidade, como fundadores de potentes escolas de magia (Janowitz, 2001: 12-3). 
Sob o Império Romano, os magos, adivinhos e feiticeiros costumavam recorrer a entidades sobrenaturais de diversas categorias na execução dos ritos mágicos e divinatórios. Dentre elas, uma das mais importantes eram os manes, os espíritos dos mortos, em geral dos antepassados da família que, tendo falecido de causa natural, foram sepultados segundo os iura manum, ou seja, os ritos funerários tradicionais, que incluíam a oferta de vinho, mel, leite e flores, bem como a realização periódica, nas tumbas e sepulturas, dos convivia, banquetes reunindo mortos e vivos numa celebração solidária (Vázquez Hoys; Munõz Martín, 1997: 270; Jensen, 2008: 117 e ss.). O descuido para com o culto funerário poderia dar ensejo a manifestações de ira por parte do falecido, verificando-se distúrbios na vida cotidiana, como a irrupção de moléstias e o nascimento de aberrações. Sobre os manes, honrados conforme a tradição, os magos e feiticeiros não possuíam, a princípio, qualquer influência. Todavia, sob o seu controle estavam as larvas e lêmures, os espíritos dos mortos que não haviam recebido sepultamento adequado (insepulti) ou que haviam morrido de forma violenta e prematura (immaturi). Repletos de ódio e de amargura, larvas e lêmures prestavam-se bastante bem à manipulação dos magos, sendo amiúde invocados nos sortilégios agressivos. Dentre os insepulti, os afogados e todos os desaparecidos no decorrer de uma viagem eram tidos como os mais temíveis. Já dentre os immaturi, as almas dos infantes, dos supliciados e dos suicidas eram reputadas como potencialmente hostis (Massoneau, 1934: 401). Ao lado das larvas e lêmures, os feiticeiros costumavam invocar também as divindades do panteão greco-romano, especialmente aquelas de origem ctônica, a exemplo de Perséfone, Plutão, Proserpina e, acima de tudo, Hécate, tida como líder das falanges de larvas e companheira de todos aqueles que faziam da magia o seu ofício. A divindade padroeira dos feiticeiros era a Hécate Trívia, ou seja, "a das três faces" - em oposição à Hécate de uma só face, por vezes associada a Ártemis -, uma divindade infernal que habitava as encruzilhadas, onde eram erguidas suas estátuas. Assim como se fazia com os mortos, eram-lhe oferecidos pães e bolos de mel. Os cães, seus animais favoritos, eram a ela imolados. Mãe de Circe e de Medeia, Hécate havia ensinado à humanidade as artes magicae. Seu culto era bastante difundido no Império, sendo a divindade invocada com frequência nos ritos de magia e de adivinhação (Paris, s/d: 45-52).

Ao longo do tempo, e por interferência direta do cristianismo, todos esses agentes espirituais conscientes próprios do paganismo serão pouco a pouco assimilados à categoria de demônios (daimones, em grego), de acordo com uma tendência à polarização entre as forças do bem e do mal presente em diversos outros sistemas religiosos contemporâneos, como o gnosticismo e o maniqueísmo. No início do Principado, já era corrente a ideia segundo a qual haveria um poder supremo responsável por comandar o mundo de modo inteligente, como acreditavam, por exemplo, os estoicos, judeus e cristãos. Esse movimento de difusão de uma cosmovisão monoteísta ou tendente ao 
monoteísmo exigiu, de certa forma, a acomodação de um sem número de deuses, espíritos e potestades numa espécie de síntese, o que deu margem à emergência da demonologia, ou seja, de um sistema religioso dedicado à compreensão da natureza e dos atributos de todos os pneumata, seres inferiores quando comparados a Iavé ou ao Supremo Bem, ou seja, à divindade tida como todopoderosa. ${ }^{3}$ Estes espíritos eram identificados genericamente como daimones, demônios, podendo incluir os espíritos dos mortos, os heróis da mitologia grecoromana e os deuses do paganismo, entre outros. Em sentido original, o vocábulo grego daimon identificava uma força (dynamis) incontrolável, como vemos em Homero. Todavia em Os trabalhos e os dias, de Hesíodo, os daimones já aparecem assimilados às almas dos mortos (Hornblower; Spawforth; Eidinow, 2012: 410). No entanto, Platão, em O banquete (202-3), é quem elabora a definição de daimon por muito tempo vigente na Antiguidade: uma entidade intermediária entre os homens e os deuses encarregada da adivinhação e demais saberes esotéricos. Cumpre salientar que, conforme o pensamento grego, o daimon era obediente e prestativo, não exibindo assim inclinação para o malefício, como veremos mais tarde, por influxos da tradição oriental, em especial do judaísmo.

Entre os povos do Oriente, os semitas acreditavam na existência de mensageiros dos deuses - os ditos anjos, angelloi-, uma vez que a verdadeira forma divina não poderia ser dada a conhecer aos homens, como comprova a antiga concepção síria segundo a qual a divindade, em sua essência, seria onipotente, eterna e incognoscível, residindo além das estrelas. Esses mensageiros, na condição de seres intermediários, se organizariam em falanges militares subordinadas a líderes distintos. Filon de Alexandria, um judeu helenizado ativo no século I, foi o principal responsável por assimilar os anjos da tradição semita aos daimones gregos, forjando-se aos poucos a distinção dualista entre anjos bons e anjos maus, como veremos, mais tarde, em Agostinho (Berardino, 2002: 390). $\mathrm{Na}$ segunda metade do século III, por iniciativa de Porfírio, um dos expoentes do neoplatonismo, cristaliza-se a distinção entre os anjos, seres superiores e benfazejos, e os demônios, seres inferiores e maléficos, num contexto em que o cristianismo se encontra em franca expansão. Para os cristãos, os demônios seriam os deuses do paganismo greco-romano que submetidos a Satanás, o príncipe deste mundo, conforme ensinam os Evangelhos, responderiam por todos os malefícios, moléstias e calamidades. Seu efeito, contudo, poderia ser neutralizado apelandose aos anjos da guarda, ou seja, aos protetores espirituais dos justos, cuja crença começa a se fortalecer nesse mesmo período. Como entidades poderosas, anjos

\footnotetext{
${ }^{3}$ Pneuma é um termo grego que, em sua acepção original, significa "vento", "sopro". Na linguagem bíblica, o vocábulo pneuma, empregado no singular, se equipara ao logos divino, à força imanente da divindade. Já o plural pneumata exprime uma categoria aplicada a espíritos diversos, bons ou maus. No uso corrente, pneumata terminou por se consagrar como um dos sinônimos de daimones Berardino, 2002: 1172.
} 
e demônios comparecem igualmente nas invocações dos adivinhos e feiticeiros, mas sem que tenhamos o abandono das larvas e lêmures, que seguem colaborando nos ritos de magia. Devemos acrescentar que, no Império Romano, a iniciação de um mago tinha por finalidade conceder-lhe um paredros ou daimon, ou seja, um assistente espiritual por intermédio do qual poderia realizar seus encantamentos, dentre os quais os mais comuns constituíam fórmulas de tratamento médico, pois, ao contrário do que se supõe, a maioria dos ritos de magia praticados na Antiguidade visava à cura de alguma enfermidade física ou espiritual, motivo pelo qual os magos e feiticeiros não raro desempenhavam a função de médicos e exorcistas, expulsando do corpo do paciente a entidade que supostamente o estaria prejudicando, como havia feito Jesus, não por acaso reputado como um poderoso feiticeiro, como sustenta Smith (1978).

$\mathrm{Na}$ Antiguidade Tardia, período no qual o cristianismo adquire notável visibilidade, em particular nos núcleos urbanos, locus primário da cristianização, a crença na magia e no poder maléfico dos daimones parece uma realidade bem consolidada, como verificamos por intermédio da atuação de Constâncio II, responsável pelo agravamento das penalidades contra os réus de veneficium, de crime de magia, que, em meados do século IV, é definido em lei como maleficium, ou seja, como ato deliberado visando a causar dano a alguém (Silva, 2003: 233). ${ }^{4}$ Não obstante esta constatação sobre o caráter corriqueiro da magia no Império tardo-antigo, o tratamento historiográfico do assunto ainda nos impõe alguns desafios. Em artigo recente, Kalleres (2015b) traça um importante panorama sobre os estudos acerca das práticas de magia e da atuação dos daimones entre os séculos III e V. Segundo a autora, a narrativa em torno do fim do Império Romano proposta por Edward Gibbon, em sua obra monumental, The history of the decline and fall of the Roman Empire, publicada em seis volumes entre 1776 e 1788, teve como um dos seus maiores inconvenientes a equiparação dos daimones da tradição clássica com espíritos malévolos que, invocados por mentes supersticiosas, alimentariam a espiral de irracionalidade própria do final do Mundo Antigo, opondose assim a tudo o que o Império Romano, em seus melhores dias, teria simbolizado: a civilização, a ordem racional do mundo. Para além das reflexões de Gibbon, eivadas de um evidente juízo de valor contra uma época tida já como prenúncio do medievo, autores contemporâneos, dentre os quais Dodds (1975) e Peter Brown (1982), buscaram compreender a demonologia tardo-antiga em seu contexto sócio-religioso, no qual o exorcismo constituía um poderoso "instrumento ritual que ordenava o mundo do irracional

${ }^{4}$ Desde 81 a.C., com a promulgação da Lex Cornelia de Sicariis et Veneficis por Sila, o Direito romano passou a dispor de uma legislação específica visando a regular o crime de magia, qualificado, em termos jurídicos, como veneficium, pois imaginava-se que o caráter potencialmente nocivo dos magos derivava do fato de manipularem substâncias (venena, medicamenta) com a intenção de matar ou de diminuir a capacidade de resistência da vítima Silva, 2003: 228. 
e do nãocivilizado". Todavia, esses autores ainda pressupunham a existência de "divisões entre o espaço do racional, da civilização [...] e a representação obscura da irracionalidade, do primitivismo e do declínio" (Kalleres, 2015b).

Tal dicotomia se, por um lado, configura um entrave à abordagem do assunto, por outro nos indica o método por meio do qual podemos investigar a percepção tardoantiga sobre os agentes espirituais conscientes, comumente descritos como pneumata ou daimones. Ao contrário do que supunham Gibbon e tantos outros que o sucederam, as crenças e ritos rotulados como demoníacos não devem ser interpretados como fruto de um pensamento selvagem e irracional, pois tais qualificativos derivam de uma reflexão complexa elaborada pela elite eclesiástica da época tardia que, desafiada pela tarefa de acomodar, nas fileiras da congregação, amplos contingentes populacionais, desenvolveu todo um discurso e uma práxis refratários aos procedimentos religiosos característicos do judaísmo e do paganismo, qualificando-os como superstitio, ou seja, como crença falsa, errônea e não raro estrangeira, como vemos acontecer, em Antioquia, no contexto da atuação pastoral de João Crisóstomo. ${ }^{5}$ De fato, o pregador demonstra, em suas homilias, uma preocupação recorrente com a atuação dos daimones e com a permanência, entre os fiéis, da crença na magia e na adivinhação. Segundo João, os demônios não seriam apenas vetores de enfermidades orgânicas, mas também promotores de tumultos e sedições na pólis, perturbando ao mesmo tempo a harmonia do corpo físico e do corpo social. Tal argumento, é bom que se diga, não é fortuito, pois, segundo os cristãos, o mundo da Antiguidade Tardia era repleto de entidades malévolas que adquiriam por vezes um suporte material, já que os objetos e imagens empregados nas cerimônias do paganismo podiam servir de abrigo aos demônios, ${ }^{6}$ exigindo-se dos sacerdotes, em especial dos bispos que, no século IV, tornam-se personagens de destaque, uma atitude enérgica no combate aos espíritos que tentavam, a todo custo, impedir o progresso da Boa Nova.

\section{OS DEMÔNIOS, VETORES DO NÓSOS E AGENTES DA STÁSIS}

A afirmação da autoridade episcopal a partir do século II esteve estreitamente associada ao controle do capital simbólico pelos bispos, que cedo se apresentaram como os interlocutores privilegiados com o domínio sobrenatural, o que os habilitava, inclusive, a executar atos taumatúrgicos, praticando a cura dos enfermos e a expulsão dos demônios, assim como outrora havia feito Jesus. Num mundo marcado por um sentimento de aguda proximidade com o divino, bispos, presbíteros, diáconos e monges viviam todo o tempo em companhia de seres sobrenaturais, fossem eles santos, anjos ou demônios, de acordo com uma

\footnotetext{
${ }^{5}$ Para mais informações sobre o sentido de superstitio, consultar Bustamante (2006).

${ }^{6} \mathrm{Em}$ Making and breaking the gods (2013), Kristensen apresenta vários casos como esse, sob uma perspectiva cristã.
} 
lógica de polarização entre as forças do bem e do mal que interferia diretamente na dinâmica sociopolítica. João Crisóstomo, mesmo antes de ser ordenado presbítero, em 386, já se dedicava a refletir sobre o tema, sustentando a ideia segundo a qual tanto os bispos quanto os presbíteros deveriam intervir na vida política da cidade e mesmo do Império, na condição de intérpretes privilegiados da vontade divina e de responsáveis pela defesa da pólis contra os inimigos espirituais. Em seu Tratado sobre o Sacerdócio (VI, 12-13), por exemplo, João constrói uma vívida imagem da luta sem trégua travada pelos bispos contra as forças do mal. Além disso, em suas homilias aos catecúmenos, destaca a importância do batismo como um recurso fundamental no sentido de, se não conceder imunidade espiritual ao cristão, ao menos protegê-lo contra a influência dos demônios, o que tornava os sacerdotes, os oficiantes do rito batismal, ao qual se conferia uma evidente capacidade apotropaica, figuras indispensáveis na defesa da assembleia contra as artimanhas de Satanás (Cathechesis ad iluminandos, 4, 6; Harkins, 1963: 334, n. 53). Nessa cruzada incessante contra os daimones, João Crisóstomo não estava sozinho, pois diversos outros Padres da Igreja, a exemplo de Cipriano de Cartago e Agostinho de Hipona, apenas para citar dois dos mais conhecidos, também se ocuparam do assunto, mas não resta dúvida de que os argumentos de João Crisóstomo merecem atenção particular, na medida em que a atuação dos demônios e o uso da magia comparecem em vários momentos da sua volumosa pregação, o que demonstra a relevância que atribuía a ambos.

Ao analisar a composição da audiência de João Crisóstomo, em Antioquia, Maxwell (2006: 85) constata a presença, na congregação, de indivíduos que sofriam possessão demoníaca, não raro na condição de portadores de alguma moléstia (nosos) resistente aos tratamentos. A existência de possessos entre os ouvintes nos sugere, segundo a autora, duas conclusões. Em primeiro lugar, que parte da liturgia incluía orações para repelir os daimones e, portanto, como seria de se esperar, os possessos afluíam amiúde aos ofícios religiosos na intenção de serem curados. Em segundo lugar que, como prova tangível dos poderes divinos dos quais eram detentores, os sacerdotes deveriam ser capazes de comandar os maus espíritos, praticando assim o exorcismo. Nesse sentido, é possível formular a hipótese segundo a qual a existência dos daimones, embora tida como algo indesejável e até certo ponto extraordinário, era, no fim das contas, indispensável para a construção da própria autoridade episcopal, pois João Crisóstomo, em mais de uma oportunidade, afirma que, dentre todos os membros do corpo sacerdotal, é o bispo o mais autorizado a combater os demônios. Como excelso representante da divindade judaico-cristã e agindo no âmbito da $L e x D e i$, o bispo seria o mais capacitado para extirpar o mal que teimava em se apoderar das vítimas inocentes, o que, em contrapartida, representava um agudo reforço dos atributos místicos episcopais, tornando-se o bispo mais uma modalidade de theios aner, de homem divino, personagem bastante conhecida na Antiguidade Tardia. Segundo Peter Brown (1982: 107), 
Para um homem romano tardoantigo, o drama do exorcismo era a demonstração do poder de Deus, que imbrica em uma autoridade incontestável. Na cura do possesso, os praesentia do homem divino são registrados com precisão infalível e seu poder ideal, sua potentia, se mostra mais plenamente, reafirmando sua autoridade.

A autoridade espiritual do bispo não se restringia, no entanto, ao exorcismo dos demônios que porventura habitassem o corpo do possesso, pois, na Antiguidade Tardia, a esfera de atuação dos daimones incluía praticamente todos os setores da vida social. Assim como travavam o bom funcionamento do corpo humano, esses espíritos eram capazes de provocar distúrbios no corpo social, de promover a stasis, o conflito, a guerra civil, colocando em risco a pólis e seus habitantes. Um exemplo do quanto os demônios poderiam ser nocivos à ordem pública nos é fornecido no contexto do Levante das Estátuas, que irrompeu em Antioquia no dia 25 ou 26 de fevereiro de 387, estendendo-se até finais de abril. Seu estopim foi um decreto do governador (consularis) da Síria anunciando a imposição de uma nova e exorbitante taxa destinada a financiar os decennalia de Teodósio, no ano seguinte (Kelly, 1995: 73). Insuflada pela claque do teatro, um contingente de espectadores pagos para aplaudir os atores e dançarinos cujo comportamento era amiúde explosivo (Browning, 1952: 16), a população, enfurecida, avança sobre as estátuas e imagens imperiais, depredando os painéis de madeira que portavam as efígies de Teodósio e seus familiares e arrastando pelas ruas da cidade as estátuas de bronze do imperador, de seu filho, Arcádio, e de sua esposa Flacila, já falecida, numa ação considerada ao mesmo tempo crime e sacrilégio. Fazendo um balanço dos possíveis móveis da revolta e na tentativa de propor uma atenuante para o desatino da população, que havia atraído a cólera do imperador contra a cidade, João Crisóstomo sugere que os antioquenos, ao se insurgirem, o teriam feito sob inspiração demoníaca. Na segunda homilia da série sobre o Levante das Estátuas, pronunciada no decorrer da quaresma de 387, João se refere à gravidade da situação nos seguintes termos:

O que devo dizer, ou do que devo eu falar? O presente momento é para lágrimas, $e$ não para palavras; para lamentação, não para discurso; para rezar, não para pregar. Tamanha é a magnitude da audaciosa ação cometida; tão incurável é a ferida, tão profunda a chaga, até mesmo acima do poder de todo tratamento, que anseia assistência de cima (Hom. in Stat. 2, 1).

De acordo com o pregador, a destruição das estátuas da família imperial teria sido um acontecimento extremamente grave, comportando atos audaciosos e inimagináveis, não havendo assim palavras para descrevê-la ou mesmo remédio humano para reverter o ultraje perpetrado contra a majestade imperial. Para João Crisóstomo, a resolução do conflito somente seria alcançada mediante auxílio 
divino, o que, de certa maneira, justifica seu interesse no assunto, na condição de especialista do sagrado. A menção aos sediciosos como vítimas de possessão ocorre na terceira homilia da série, quando o pregador descreve as primeiras medidas tomadas pelas autoridades locais na tentativa de conter a revolta:

E alguns pereceram pela espada, alguns pelo fogo; alguns foram dados às feras selvagens, e não apenas homens, mas crianças. E nem mesmo essa idade da imaturidade, nem o tumulto das pessoas, nem as circunstâncias de que eles estavam enfurecidos pelos demônios quando perpetraram as açôes; nem que a exação pensada era intolerável; nem a pobreza; nem ter ofendido em companhia de todos; nem a promessa de que daqui por diante eles não ousariam repetir tais feitos; nem outra coisa poderia salvá-los [...] (Hom. In Stat. 3,17).

Segundo Setton (1941: 201), “as imagens imperiais simbolizavam o poder do imperador reinante e eram objetos de grande veneração”, mesmo para os cristãos, não devendo nos causar estranheza que a maioria dos Padres da Igreja tenha advogado em favor da reverência prestada às imagens imperiais, a exemplo de João Crisóstomo, para quem urgia punir com severidade os autores de tamanha ofensa. No entanto, em sua opinião, os acusados não eram os verdadeiros responsáveis pelo crime. De acordo com o pregador, as autoridades municipais, ao reprimirem a revolta, não teriam levado em consideração o fato de que muitos dentre os sediciosos se encontravam "enfurecidos pelos demônios", o que reclamaria, antes de qualquer outra providência, a consulta ao bispo da cidade, ou seja, a Flaviano, o que não ocorreu. Ao longo de toda a série, João argumenta em favor da população, sustentando que esta não poderia ser responsabilizada pelas atrocidades cometidas contra as estátuas, pois tal acontecimento teria sido provocado por agentes externos, vale dizer, pelos demônios, que se apoderaram dos antioquenos.

Em algumas circunstâncias, João Crisóstomo parece sugerir que os verdadeiros autores do crime teriam sido estrangeiros de índole duvidosa que irromperam na cidade trazendo consigo o estigma da blasfêmia e do pecado. De fato, em diversas passagens das homilias que compõem a série, João referese aos culpados como "certos estrangeiros e aventureiros" (Hom. In Stat. 3, 3), "estrangeiros" (Hom. In Stat. 2, 10), "homens das mais diversas raças" (Hom. In Stat. 2, 10), "pecadores incontroláveis" (Hom. In Stat. 13), "blasfemos" (Hom. In Stat. 10). A esses, sim, deveria ser aplicada a lei com todo rigor (Hom. In Stat. 2,10). Não as leis romanas (legis), que tratariam o episódio nos termos de crime de lesa-majestade (maiestas), mas a Lei de Deus (Lex Dei), superior àquela. Para o autor, a ordem romana teria por origem a ordem sagrada, da qual seria Deus o artífice. Na realidade, Deus seria o senhor das duas ordens, de maneira que nada poderia ocorrer no mundo ou fora dele sem o consentimento divino, raciocínio empregado por João para justificar, em termos teológicos, o Levante 
Gilvan Ventura da Silva

Érica Cristhyane Morais da Silva

das Estátuas:

Pois, assim como o diabo assaltou violentamente o rebanho, e a multidão de pessoas, e toda a substância do homem justo, então agora ele se tem enfurecido contra esta cidade. Mas este tempo, na verdade, Deus o permitiu; foi neste tempo, de fato, que Ele pôde fazer o homem justo mais nobre pela grandeza de seu teste; é neste presente momento que Ele pode nos fazer mais esclarecidos pelo rigor desta atribulação (Hom. In Stat. 2, 1).

Desse modo, João Crisóstomo não minimiza a gravidade da ofensa cometida, mas a atenua ao supor que seus agentes foram entidades malévolas, o que o credencia a rejeitar a aplicação indiscriminada da lei romana, implacável contra todos os envolvidos no crime a despeito de idade, gênero ou condição social, em prol da aplicação da lei divina, fundada no perdão incondicional e no aprendizado pelo sofrimento, muito mais eficazes na correção dos desvios da conduta humana. Na sétima homilia da série, ao discorrer sobre a passagem do Livro do Gênesis contendo a descrição do julgamento de Adão, João se refere à importância da misericórdia divina nos seguintes termos: "Quando um homem, então, foi enganado e iludido pelo demônio, devemos observar como Deus o tratou depois de ter ele cometido um pecado tão grave. Ele decidiu destruílo completamente ?" (Hom. In Stat. 7, 5). Ao mencionar o pecado original cometido por Adão sob influência de Satanás, João Crisóstomo, no fim das contas, alude ao contexto do Levante das Estátuas, de modo a reforçar o argumento segundo o qual aqueles sob possessão não deveriam ser julgados com rigor, mas com compaixão. Nesse aspecto, o pregador nos revela, uma vez mais, os contornos do seu pensamento político, pois, segundo ele, o Império Romano seria antes e acima de tudo um governo eleito por homens para administrar as coisas humanas (Sandwell, 2004: 38), o que privava a basileia, a realeza da época tardia, de qualquer conotação sobrenatural. No que dizia respeito ao âmbito do sagrado, da res sacra, somente aos sacerdotes caberia opinar. Considerando que os insurgentes se encontravam, por ocasião do Levante, reféns dos demônios, a matéria escapava das instâncias jurídicas convencionais, devendo ser apreciada pela corte episcopal, a única com competência suficiente para emitir um parecer sobre o caso. Como é possível perceber, diante da situação de calamidade que se instaurou em Antioquia na quaresma de 387, João Crisóstomo não perde a oportunidade de reforçar a autoridade do bispo, tomando como contraponto a atuação perversa dos demônios.

\section{Magia e superstição na igreja de Antioquia}

$\mathrm{Na}$ sua militância em favor da cristianização da pólis, João Crisóstomo não apenas declara combate aos demônios, causa de inúmeras atribulações 
corporais e sociais, como temos visto, mas também aos adivinhos e feiticeiros, personagens que disputavam lado a lado com os representantes da hierarquia eclesiástica o monopólio dos bens de salvação, incluindo, necessariamente, a capacidade de comandar as potestades sobrenaturais, fossem elas benéficas ou maléficas, conforme o ponto de vista. A influência, mesmo entre os membros da congregação antioquena, dos especialistas nas artes mágicas é mencionada por João Crisóstomo que, numa série de oito homilias Adversus Iudaeos pronunciadas entre 386 e 387, logo após sua ordenação como presbítero, se dedica a confrontar aqueles que, na expectativa de obter a cura de suas enfermidades, recorriam a médicos judeus. Segundo o pregador, esses médicos seriam, na realidade, feiticeiros disfarçados, o que o leva a conclamar a audiência para que exponha à luz do dia a verdade sobre a suposta expertise terapêutica dos judeus, como vemos na seguinte passagem:

Suponham que ele [i.é, o paciente] evoque as curas que os judeus efetuam como suas desculpas. Suponham que ele diga: "eles me prometeram fazer o bem, assim eu vou até eles". Então vocês devem revelar os truques que eles usam, seus encantamentos, amuletos, feitiços e encantos. Essa é a única via pela qual eles têm a reputação de curar. Eles não efetuam curas genuinas. Os céus proíbam que eles o façam! Deixem- me ir ao ponto de dizer que se eles de fato curam vocês, é melhor morrer que correr para os inimigos de Deus e ser curado desse modo (Adv. Iud. 8, 935).

João Crisóstomo, ao proibir que os cristãos recorram aos médicos judeus, a despeito da sua reconhecida habilidade terapêutica, nos revela, nas entrelinhas da sua prédica, o prestígio alcançado à época pelos sábios judeus, o que contraria frontalmente a antiga tese segundo a qual, na Antiguidade Tardia, o judaísmo seria uma religião obsoleta, como assinalamos em mais de uma oportunidade (Silva, 2010 e 2012). A julgar pelos ataques do pregador, os judeus, em Antioquia, eram reputados como detentores de um saber médico amiúde confundido com a magia, como bem assinala Klee (1992: 15), o que elevava o seu status na cidade, colocando-os em concorrência direta com as lideranças eclesiásticas. Sabemos que, no Império Romano, uma das escolas de magia mais respeitadas era justamente a judaica, atribuindo-se um poder incomensurável, nos papiros mágicos greco-egípcios, a diversos expoentes do judaísmo, como Moisés e Salomão, tidos como exímios feiticeiros. A própria língua hebraica, cujo emprego, nas sinagogas da Diáspora, era bastante raro, surge frequentemente nas inscrições, papiros e amuletos na condição de idioma esotérico e ao mesmo tempo repleto de dynamis, de energia mágica (Simon, 1996). Os rabinos, por sua vez, eram célebres por suas habilidades como médicos e exorcistas, o que sem dúvida contribuiu para reforçar a atração do judaísmo sobre as populações cristãs na passagem do III para o IV século, quando se afirma com vigor a tradição que fazia dos rabinos os equivalentes judaicos dos theioi andres, dos homens divinos 
Gilvan Ventura da Silva

Érica Cristhyane Morais da Silva

pagãos e cristãos (Kalleres, 2015a: 25), o que suscitava em João Crisóstomo profunda irritação. De fato, a concorrência dos médicos (ou magos) judeus era por ele interpretada nos termos de uma oposição entre os verdadeiros e os falsos profetas, entre os detentores de um saber legítimo acerca do sobrenatural e aqueles que operavam curas e prodígios mediante a invocação dos demônios:

[...] suponham que alguns profetas digam a vocês: "Eu posso trazer um morto à vida ou curar um homem cego. Mas vocês devem obedecer-me quando eu disser: "vamos adorar os demônios ou vamos oferecer sacrificio aos ídolos". Então, suponham que aquele que disse isso possa curar um homem cego ou trazer um morto de volta à vida. Deus diz que vocês não devem prestar atençẫo a ele devido aos sinais e maravilhas que opera. Por que? Porque Deus está testando vocês ao permitir que tal homem tivesse esse poder. Não é que Deus não conheça seus pensamentos, mas ele está dando a vocês uma chance para provar que de fato $O$ amam. E há homens que estão ansiosos para nos afastar de nosso Amado. Mesmo se eles apresentam mortos que voltaram à vida, aquele que ama a Deus não irá permanecer apartado de Deus por ter visto tais sinais e maravilhas" (Adv. Iud. 8, 935).

A intenção de João Crisóstomo, ao denunciar as artimanhas dos judeus, não é refutar a suposta perícia de seus médicos e rabinos, mas alertar a assembleia para o perigo que corre ao se colocar nas mãos de homens que realizam curas e prodígios mediante a intercessão dos demônios ou dos ídolos, ou seja, que manipulam as forças sobrenaturais de modo errôneo, indigno, nocivo, o que levaria os cristãos a se afastarem de Deus, mesmo sem o perceber. João Crisóstomo recomenda, assim, aos fiéis que se mantenham alerta contra os "falsos profetas", ou seja, os médicos, taumaturgos, magos e adivinhos, pois estes, ao executarem suas proezas, sabotam a autoridade espiritual dos bispos, presbíteros e diáconos, desautorizados como especialistas do sagrado num contexto no qual, como mencionamos, as autoridades episcopais se empenham em obter o controle da cidade antiga. Nessa empreitada, João Crisóstomo coíbe igualmente as práticas supersticiosas executadas pelos membros da sua congregação, como vemos numa das homilias da série sobre a primeira carta de Paulo aos coríntios:

Se do casamento nascer um filho, veremos a mesma loucura e muitas cerimônias ridiculas. De fato, ao dar um nome à criança, não lhe dão o nome de santos, como outrora se fazia; mas acendem-se fachos aos quais se apõem nomes, e atribuem ao recém-nascido a denominação daquele que durar mais tempo, conjecturando deste modo uma longa vida. Em seguida, se sucede advir prematura morte (como às vezes acontece), ri-se muito o diabo, por ter escarnecido deles quais meninos estultos. O que dizer das ligaduras e amuletos suspensos da mão e da fita de púrpura e muitas outras coisas loucas; quando importaria não cercar o menino senão da proteção da cruz? Agora, porém, é menosprezada a cruz que converteu todo o orbe, e infligiu grave ferida no diabo e subverteu todo o seu poder. [...] As amas e as escravas retiram lodo do 
A luta pelo monopólio do sagrado em antioquia: joão crisóstomo e o ataque à magia e seus agentes (séc. iv d.C.)

balneário e com a ponta do dedo marcam a fronte da criança. E se alguém pergunta: o que significa o lodo, a lama? Afasta o mau olhado, respondem, o ciúme e a inveja. Ab! Como é grande o poder, a força do lodo, da lama! Tão grande que afugenta o exército diabólico inteiro. Não corais de vergonha? Dizei-me. Não percebeis enfim as ciladas diabólicas, como desde a mais tenra idade o diabo aos poucos insinua seus malefícios? [...] Certamente, não é de espantar que entre os pagãos se empreguem tais práticas, mas que entre os adoradores da cruz e participantes dos mistérios arcanos e que possuem tão elevada sabedoria haja tão vergonhoso uso, é sem dúvida de se chorar com copiosas lágrimas" (Hom. In ICor. 12, 12).

João Crisóstomo condena aqui algumas práticas de magia executadas pelos próprios cristãos, que se mantêm apegados a crenças e superstições de matiz pagão, como o hábito de medir a extensão da vida dos recém-nascidos por meio da duração de velas e candeias e o emprego de amuletos e talismãs contra a inveja (fascinum), preocupação recorrente entre os antigos, para quem a inveja era a principal causa do malogro de qualquer iniciativa (Vázquez Hoys; Munõz Martín, 1997: 170). Visando a obter proteção espiritual para as crianças, os cristãos de Antioquia não hesitavam em besuntar a fronte daquelas com lodo e lama, na expectativa de que as propriedades terapêuticas contidas em tais substâncias fossem capazes de neutralizar as vibrações negativas do ciúme e da inveja. Na opinião do pregador, recorrer à magia em busca de proteção espiritual para si e sua prole era um procedimento inadmissível, pois as artes magicae teriam sido inventadas pelos demônios com o objetivo de corromper os justos. João Crisóstomo nos permite avaliar, nesse excerto, o quanto o cristianismo antigo dependia, para sobreviver e se difundir, da sua habilidade em substituir as antigas crenças e práticas religiosas de matiz pagão e/ou judaico por uma variante cristã eficaz, razão pela qual evoca o símbolo da cruz, poderoso o suficiente para repelir qualquer influência maléfica, colocando o recém-nascido sob os cuidados de Cristo. A cruz é assim apresentada como o artefato aprotropaico por excelência, por meio do qual as forças do demônio teriam sido irremediavelmente superadas, um tema que começa a se tornar comum nos textos dos Padres da Igreja ao longo do século IV, como desdobramento da festa da Inventio Crucis que emerge em 325, no contexto da dedicatio das basílicas do Santo Sepulcro e do Santo Calvário por Constantino, quando então se multiplicam as referências às propriedades redentoras da cruz invicta como signum victoriae (Berardino, 2002: 369-370). Ao investir na potência mágica da cruz, João Crisóstomo a converte num supremo talismã, cujo emprego na luta permanente dos cristãos contra as forças do mal se tornará doravante cada vez mais frequente.

\section{Considerações finais}

A partir do século IV, com a ascensão de Constantino, o processo de cristianização do Império Romano, já em andamento desde pelo menos a 
Pequena Paz da Igreja (260-305), recebe um novo e vigoroso impulso, quando então os cristãos buscarão implementar um conjunto de estratégias visando a obter a conversão forçada ou voluntária dos pagãos e dos judeus, mas sem que tenhamos, é bom que se diga, uma situação de hegemonia por parte do cristianismo. Como bem observa Lim (2012: 497), em face do caráter precário, instável da cristianização, talvez fosse mais apropriado falarmos de um Império Romano cristianizante e não de um Império cristianizado. Não obstante a cristianização nunca ter se completado da maneira como supunham, outrora, autores por demais comprometidos com a perspectiva dos Padres da Patrística sobre o assunto, não resta dúvida que as lideranças eclesiásticas foram bastante enfáticas na condenação das crenças e ritos conectados com o paganismo, o judaísmo e com tudo aquilo que classificavam, de modo unilateral e pejorativo, como heresias (novacianismo, arianismo, pelagianismo e outras), num momento em que os bispos consolidavam a sua posição como agentes de poder, em especial no ambiente urbano. A despeito das funções políticas, administrativas, econômicas e inclusive militares desempenhadas pelos bispos na Antiguidade Tardia, o que por vezes faz com que eles se assemelhem a sucessores dos magistrados romanos, não devemos esquecer que os bispos e demais integrantes da hierarquia sacerdotal (presbíteros, diáconos) eram - e nunca o deixarão de ser - especialistas do sagrado, ou seja, indivíduos revestidos com determinados carismas para viabilizar a Boa Nova proclamada nos Evangelhos, que incluía, entre outras tarefas, o combate aos demônios e seus parceiros humanos, ou seja, os mistagogos, rabinos, feiticeiros, adivinhos, astrólogos, todos portadores de autoridade para também lidarem com as forças sobrenaturais. Nesse sentido, a história da cristianização é, em boa parte, a história da maneira pela qual as lideranças eclesiásticas obtiveram pouco a pouco o monopólio do sagrado mediante o esvaziamento da autoridade dos seus concorrentes pagãos e judeus, cujo poder para comandar as entidades sobrenaturais era agora suprimido pelo signo redentor da cruz, como vemos ocorrer em Antioquia à época de João Crisóstomo. 
A luta pelo monopólio do sagrado em antioquia: joão crisóstomo e o ataque à magia e seus agentes (séc. iv d.C.)

\section{Bibliografia}

\section{DOCUMENTAÇÃO PRIMÁRIA IMPRESSA}

João Crisóstomo (1979), Sobre o Sacerdócio. Petrópolis.

John Chrysostom (2004), The homilies on the statues to the people of Antioch, in P. Schaff (Ed.), Nicene and post-Nicene Fathers. Peabody, p. 315-489, t. IX.

John Chrysostom (1995), Instructions to Catechumens, in: P. Schaff, A select library of Nicene and Pos-Nicene Fathers of the Christian Church. Michigan, Series I, v. IX.

Platão (1972), Diálogos: O banquete, Fédon, Sofista, Político. São Paulo.

Pline L'Ancien (1963), Histoire naturelle. Paris, 1. XXX.

São João Crisóstomo (2010), Comentário às cartas de São Paulo. São Paulo, v. 2.

St. John Chrysostom (1999). Discourses against Judaizing Christians. Washington.

\section{ObRAS DE APOIO}

Berardino, A. (org.) (2002), Dicionário patrístico e de antigüidades cristãs. Petrópolis.

Brown, P. (1982), The cult of the saints: its rise and function in Latin Christianity. Chicago.

Browning, R. (1952), The riot of A.D. 387 in Antioch: the role of the theatrical claques in the Later Empire, JRS 42: 13-20.

Bustamante, R. M. C. (2006), Rituais de sacrifício entre a religio e a superstitio: análise comparativa entre o discurso jurídico imperial e o imagético provincial no Baixo Império, in G. V. Silva; M. B. Nader; S. P. Franco (org.), As identidades no tempo. Vitória, 321351.

Cross, F. L.; Livingstone, E. A. (2005), The Oxford dictionary of the Christian Church. Oxford.

Dodds, E. R. (1975), Paganos y cristianos en una epoca de angustia. Madrid.

Frazer, J. (1994), La rama dorada. México.

Floristán Samanes, C.; Tamayo-Acosta, J. J. (1999), Dicionário de conceitos fundamentais do cristianismo. São Paulo.

Geertz, C. (2001), Nova luz sobre a Antropologia. Rio de Janeiro.

Harkins, P. W. (1963), Introduction and notes, in P. W. Harkins, St. John Chrysostom: baptismal instruction. New York.

Hornblower, S.; Spawforth, A.; Eidinow, E. (ed.). (2012), The Oxford Classical Dictionary. Oxford. 
Gilvan Ventura da Silva

Érica Cristhyane Morais da Silva

Janowitz, N. (2001), Magic in the Roman world. London.

Jensen, R. M. (2008), Drinking with the dead: from the mensa to the altar in Christina Late Antiquty, in L. Brink; D. Green (ed.), Commemorating the dead. Berlin, 107-143.

Kalleres, D. S. (2015a), City of demons: violence, ritual, and Christian power in Late Antiquity. Berkeley.

Kalleres, D. S. (2015b), Demon, in C. M. Chin; M. Vidas, Late Ancient Knowing. Oakland, 259284.

Kelly, J. N. D. (1995), Golden Mouth; the story of John Chrysostom - ascetic, preacher, bishop. London.

Klee, H. C. (1992), Medicina, milagro y magia en tiempos del Nuevo Testamento. Córdoba.

Kristensen, T. M. (2013), Making and breaking the gods: Christian responses to pagan sculpture in Late Antiquity. Aarhus.

Lévi-Strauss, C. (1975), Antropologia estrutural. Rio de Janeiro.

Lim, R. (2012), Christianization, secularization, and the transformation of public life, in P. Rousseau (ed.), A companion to Late Antiquity. Oxford, 497-511.

Massoneau, E. (1934), La magie dans l'antiquité romaine. Paris.

Mauss, M. (2003), Sociologia e Antropologia. São Paulo.

Maxwell, J. L. (2006), Christianization and communication in Late Antiquity. Cambridge.

Montero, P. (1990), Magia e pensamento mágico. São Paulo.

Paris, P. Hecate, (s/d), in: C. H. Daremberg; E. Saglio (éd.). Dictionnaire des antiquités grecques et romaines, Paris, 45-52. t. III, 1ére partie.

Philsooph, H. (1971), Primitive magic and mana. Man 6, n. 2, 182-203.

Sandwell, I. (2004), Christian self-definition in the fourth century AD: John Chrysostom on Christianity, imperial rule and the city, in I. Sandwell; J. Huskinson (ed.), Culture and society in Later Roman Antioch. Oxford, 35-58.

Setton, K. M. (1941), Christian attitudes toward the emperor in the fourth century, especially as shown in adresses to the emperor. New York.

Silva, G. V. da. (2003), Reis, santos e feiticeiros: Constâncio II e os fundamentos místicos da basileia (337-361). Vitória.

Silva, G. V. da. (2010), As relações entre o judaísmo e o cristianismo no Império Romano: uma nova interpretação a partir do paradigma culturalista, História da historiografia 5: 58-70.

Silva, G. V. da. (2012), A sinagoga como heterotopia segundo João Crisóstomo. Phoînix 18: 134-156. 
A luta pelo monopólio do sagrado em antioquia: joão crisóstomo e o ataque à magia e seus agentes (séc. iv d.C.)

Simon, M. (1996), Verus Israel. London: The Littman Library of Jewish Civilization.

Smith, M. (1978), Jesus, the magician. New York: Harper \& Row.

Vázquez Hoys, A. M.; Muñoz Martín, O. (1997), Diccionario de magia en el Mundo Antiguo. Madrid. 
(Página deixada propositadamente em branco) 


\title{
MANIA, MAGIA Y SOPHIA. \\ LOS AVATARES DE LA ALIANZA \\ (Mania, magic and sophia. The avatars of the alliance)
}

\author{
María Cecilia Colombani. \\ Universidad de Morón / Universidad Nacional de Mar del Plata \\ (ceciliacolombani@hotmail.com)
}

\begin{abstract}
Aвstracto - TEl proyecto del presente trabajo consiste en abordar una dimensión particular en el escenario identitario de Apolo: la mántica o el saber oracular del cual el dios es su vicario mítico. Nos valdremos de un texto inspirador de la presente reflexión, La sabiduría griega de Giorgio Colli. Nos permitiremos tomar aquellos fragmentos rastreados por el filósofo italiano referidos al proceder adivinatorio para ampliar, dentro de nuestras posibilidades, sus comentarios a fin de enriquecer el texto. En este contexto, en el que la adivinación constituye quizás el rasgo identitario más potente del dios, queremos indagar la relación entre mania y sabiduría para pensar los juegos de saber-poder que se dan en esa alianza. Asimismo, cuando el texto lo permita, queremos marcar las diferencias entre Apolo y Dioniso a propósito de este tópico. Palabras clave: Dios Apolo; culto, conocimiento oracular, manía, sabiduría
\end{abstract}

Aвstract - This work aims to address a particular dimension of Apollo's identity: the mythical or oracular knowledge of which the god is his mythical vicar. We will use a text inspiring for this reflection, Greek wisdom of Giorgio Colli. We will allow ourselves to take those fragments traced by the Italian philosopher referred to divinatory procedure to expand, within our possibilities, his comments in order to enrich the text. In this context, which divination is perhaps the most powerful identity trait of the god, we want to investigate the relationship between mania and wisdom in order to think about the games of know-power that occur in that alliance. Also, when the text allows, we want to mark the differences between Apollo and Dionysus on this topic.

KEYs word: God Apollo; worship, oracular knowledge, mania, wisdom

\section{A. Mania Y PODer}

Tal como sostiene Giorgio Colli, "Apolo es el dios de la sabiduría, de modo explícito y pacífico. Efectivamente, en el ámbito arcaico, la plenitud del conocimiento, la presunción de conocer, pertenece sólo al arte adivinatoria; y ese arte es un don de Apolo" (Colli, 1998: 25). En este contexto, donde la adivinación constituye quizás el rasgo identitario más potente del dios, queremos indagar la relación entre mania y sabiduría para pensar los juegos de saber-poder que se dan en esa alianza. Asimismo, cuando el texto lo permita, queremos marcar las diferencias entre Apolo y Dioniso a propósito de este tópico, una de las cuales 
está presente en la cita escogida ya que la experiencia pacífica que representa la adivinación apolínea contrasta con la explosión colectiva que supone la sabiduría dionisíaca.

\section{B. TAl como anticipamos, comenzaremos TRANSCRIBIENDo Los TESTIMONIOS Y PASAREMOS A ANALIZARLOS.}

"Calcante, bijo de Testor, el mejor de los augures, que conocía lo presente, lo futuro y lo pasado, y habia guiado las naves aqueas hasta Ilión por medio del arte adivinatoria que le habia concedido Febo Apolo" (Hom, Il. 1. 69-72)

El primer elemento a considerar es la personalización en el marco de lo que podríamos llamar la lógica del don. El dios otorga el arte adivinatoria a quien elige y pasa a ser un sujeto excepcional en el escenario de una relación saber-poder, que se vigoriza por el tipo de visión que le es otorgada al sujeto elegido. Se trata de una "omnisciencia de carácter adivinatorio". Estamos utilizando la definición que da Marcel Detienne (1986) para referirse a la esposa de Zeus, madre de sus deliciosas hijas, las nueve Mousas en el relato hesiódico. En una constelación de pensamiento presidida por Mnemosyne, omnisciencia de carácter adivinatorio, la única que sabe lo que fue, lo que es y lo que será, el olvido se inscribe en el registro de la falta, de la ausencia, de la noche y la oscuridad. Coincidimos además que en este contexto, Mnemosyne, fuente de un saber primigenio, podría ser calificada como tópicamente femenina, "dado que su carácter sólo se manifiesta a través de su condición de hija, de esposa y, sobre todo, de madre" (Iriarte Goñi, 2002: 34). Enfatizamos este rasgo para comprender, de algún modo, la presencia de la pitia en el escenario mántico.

Saber la totalidad implica, de algún modo, romper la fragmentariedad del tiempo que manejamos los mortales desde nuestra precariedad ontológica. La divinidad conoce la totalidad y así lo entrega a quien recibe el don de videncia; un don que hace estallar las coordenadas humanas de la visión para poder penetrar en una realidad suprasensible. El don de visión permite al adivino tomar contacto con ese orden donde el pasado, el presente y el futuro constituyen una bólon temporal absoluta y única.

Si proponemos establecer el vínculo entre Mnemosyne y la visión de un augur como Calcante, conviene que repasemos la presencia de la diosa en la Teogonía de Hesíodo: Mnemosyne es la señora de las colinas de Eleuter, quien amancebada con el Padre Crónida alumbró a las nueve deliciosas jóvenes en Pieria. El verbo es elocuente y habla, por supuesto, de contacto amoroso, lo cual permite la reproducción sexuada. Nueve noches se unió con la diosa el prudente Zeus, subiendo al lecho sagrado y alejado de los Inmortales, lo cual supone un desplazamiento del padre de dioses y hombres en busca de su esposa. Cuando el 
ciclo de las estaciones hubo culminado, "nueve jóvenes de iguales pensamientos, interesadas sólo por el canto y con un corazón exento de dolores en su pecho, dio a luz aquélla, cerca de la más alta cumbre del nevado Olimpo" (Th. 60-63). La señora de Eleuter es la Memoria sacralizada, esa omnisciencia de carácter adivinatorio que nos convoca y que, además pone en un punto de igualdad al adivino y al poeta, en tanto receptor de esta misma memoria (Colombani, 2005).

Ahora bien, es este horizonte dominado por la visión de lo que fue, lo que es y lo que será lo que Colli considera propiamente adivinación: "Esa fórmula define el significado estricto de 'sabiduría' y lo distingue de otros sentidos antiguos más

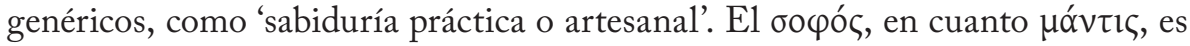
el que 'conoce' todo: presente, pasado y futuro" (Colli, 1998: 383). El sabio aúna así el vínculo más prestigioso entre saber y poder. Conoce más allá del futuro, que pareciera ser la dimensión que al arte adivinatoria le corresponde, y puede disponer de esa visión para transmitirla.

$\mathrm{El}$ objeto que conoce es de máximo prestigio. Alcanza retornar los versos homéricos para dar cuenta de la relación entre su palabra y la empresa que implica marchar a Troya. Del mismo modo su papel queda atestiguado a continuación de los versos citados en la intervención que hace en medio de los aqueos a quienes se dirige:

“Aquiles! Me mandas, caro a Zeus, declarar la cólera de Apolo, el soberano flechador. Pues bien, te lo diré. Mas tú comprométete conmigo, y jura que con resolución me defenderás de palabra y de obra, pues creo que voy a irritar a quien gran poder sobre todos los argivos ejerce y a quien obedecen los aqueos" (Il. 1, 74-79) (i)

Los versos devuelven otra arista de Calcante, el mejor de los augures: la familiaridad con lo divino. La propia experiencia mántica determina un grado de comunicación que parece romper la heterogeneidad de planos entre lo humano y lo divino. En aras de ello Calcante es el encargado de transmitir a los aqueos el estado de ánimo de Apolo, a riesgo de despertar la cólera del jefe. Riesgos de aquellos que ocupan un lugar de saber y de poder de registro peculiar

\section{El segundo testimonio corresponde a Alceo, poeta lírico del siglo VII a. C., proveniente de Mitilene.}

“...Zeus le envió a Delfos <y> a las corrientes de la fuente Castalia, para que desde alli profetizase a los griegos la justicia y la equidad. Pero él [Apolo] montó en su carroza y mandó a los cisnes que se dirigieran a [el país de] los hiperbóreos. Pero los habitantes de Delfos, al darse cuenta, compusieron un peán con música, organizaron danzas de jóvenes en torno al tripode invocaron al dios para que regresase de [el país de] los hiperbóreos. Él, por su parte, después de un año entero de pronunciar oráculos a los habitantes de aquella tierra, cuando creyó oportuno que también los de Delfos 
tocasen sus tripodes, dio orden a los cisnes de regresar de [el pais de] los hiperbóreos. Era verano - hacia mediados de la estación-cuando Alceo bizo regresar a Apolo desde [el país de] los hiperbóreos" (Alc. fr. 142).

El fragmento es rico en una variedad de marcas propias del dios. En primer lugar, su relación con Zeus, su padre, quien le ordena dirigirse a Delfos. Según Hesíodo, un nuevo contacto amoroso, de todos los que van constituyendo la progresión de la gran familia olímpica, pone a Zeus en relación con Leto, una nueva esposa. Dos vástagos brillantes nacerán de ese matrimonio divino, Apolo y Artemisa; dos hijos funcionales a la organización del universo como todo ordenado, porque representan valores y comportamientos indispensables para la construcción de un modelo cósmico. Apolo sintetiza las dos tradiciones que la Grecia arcaica y clásica vinculan a la soberanía: la de justicia y la ley, y la de la música y la poesía.

Su padre lo envía a Delfos para que el pueblo se regocije con sus oráculos pero Apolo parece desoír el mandato y se dirige al norte, fundando así las relaciones que marcan su identidad con el país de los hiperbóreos. Este vínculo "cuenta con el apoyo de toda una serie de pasajes en los que se atribuye una relación con los hiperbóreos a ciertos personajes apolíneos, como Abaris y Aristeas, que se distinguen por sus dotes chamánicas, adivinatorias y extáticas" (Colli, 1998: 383). A su vez, pone de manifiesto un rasgo nomádico de Apolo, rasgo que habitualmente se atribuye a su par complementario, Dioniso. Un Apolo viajero que se dirige al país del norte a llevar su arte. El contacto con figuras chamánicas como las citadas realza la condición de médium del adivino o chamán, en un intento de achicar la brecha ontológica que define las dos razas o los dos mundos a los que se refiere Gernet (1982). Otro personaje que la tradición griega identifica con esas figuras excepcionales es Zalmoxis; por ejemplo, dice el historiador griego Heródoto: "fue un hombre que sirvió como esclavo en Samos: estuvo al servicio de Pitágoras, hijo de Mnesarco" (Hdt. 4. 95, 1), y, según Platón (Chrm. 158 b), se lo relacionaba con Abaris, otro inspirado por Apolo que, se decía, recorría la tierra montado en la flecha de oro de Apolo "sin tomar alimento alguno" (Hdt. 3. 36, 1). Dice Dodds sobre Abaris: "Desterraba la peste, predecía terremotos, componía poemas religiosos y propagaba el culto de su dios nórdico, a quien los griegos llamaron Apolo Hiperbóreo" (1997: 138). Apolo Hiperbóreo se convirtió en el dios de estos chamanes nórdicos, y en el representante, para los griegos, de las características que estos seres excepcionales tenían. Una misma tradición, un mismo hilván donde el viaje es el tránsito al más allá. Poetas, adivinos, rey de justicia, purificadores envueltos en una misma metáfora donde el topos de la sabiduría supone un viaje iniciático.

Es allí donde retorna la metáfora del saber-poder. Estos hombres están dotados de una arche que excede la habitual configuración antropológica, un tipo de saber y de poder que los sitúa directamente en un más allá reservado a unos pocos. 
El segundo aspecto radica en la competencia entre ciudades por la presencia de Apolo. Delfos era el destino originario que el dios torció pero que ahora es reclamado. La ciudad lo espera con sus mejores galas, la música y la danza, para que la ciudad "toque" sus trípodes en una nueva marca y alusión a su proceder adivinatorio.

Hay un rasgo muy importante que vincula mántica y adivinación. En efecto, su padre lo envía a Delfos para que desde allí "profetizase a los griegos la justicia y la equidad"; la justicia está íntimamente vinculada a la mántica y prueba de ello es la presencia de Nereo, el anciano del mar. Así, el campo de la soberanía en la Grecia Antigua parece consolidarse a partir del rastreo genealógico de la figura de Nereo, el Anciano del Mar. Nereo, hijo de Ponto y cabeza de un largo linaje de divinidades oraculares, aparece en la Teogonía hesiódica como un dios marítimo, hijo del ya aludido Ponto en unión con Gea, dotado de poderes adivinatorios y capaz de cambiar de apariencia. Desde este lugar, y con esas relaciones con la arkhé y las Moûsai, el rey de justicia es aquél maestro que abre, ahora, el campo de la Dike y, por lo tanto, del fundamento de todo orden social. Es la figura que la leyenda perpetúa en el rey Minos y que parece tener su antecedente mítico en Nereo, el Anciano del Mar.

Algunos adjetivos representan la constelación de predicaciones que un maestro de alétheia debe poseer. Pensemos al respecto, en los que Hesíodo enumera para los descendientes de Ponto y ubica a Nereo en primer lugar. En Teogonía leemos: "El Ponto engendró al sincero [Apseudés] y veraz [alethés] Nereo, el mayor de sus hijos. Además le llaman Viejo, porque, infalible [Nemertés] y benévolo [épios], no se le ocultan las leyes divinas, sino que conoce justos y sabios designios" (Th. 233-236). He allí los cuatro adjetivos que configuran el campo de la eficacia adivinatoria. Es desde este doble campo de pronunciar la justicia y jamás olvidar la equidad, sumado a la capacidad adivinatoria, que Nereo guarda, a nuestro parecer, un estrecho parentesco con Apolo y aquel mandato del padre Zeus de no olvidar la justicia. El epíteto Apseudés es habitual para calificar al personaje que, como Nereo, el Anciano del Mar, no persigue el engaño, del mismo modo que el adivino en la palabra oracular. Apolo es, en última instancia mantis apseudés, tal como alude Esquilo en su tragedia Coéforas. Nereo es verdadero, en tanto su acción de-vela, des-cubre y realiza. Es apseudés y con ello aleja la sombra del engaño, de lo aparente, de aquello que usurpa el lugar de lo verdadero desde el tópos de lo engañoso.

\section{El nuevo Fragmento corresponde a Baquílides, poeta lírico de Ceos, del siglo Vi a. C.}

“...entonces, Apolo, nacido en Delos, llevó al viejo a [el país de] los hiperbóreos y lo estableció junto a las jóvenes de torneados tobillos, por su religiosidad, porque la cuestión más acuciante de los mortales habia presentado a la noble pitonisa." (B. 3, 58-62). 
Apolo conduce a Creso al país del norte y allí se abre una nueva marca del dispositivo adivinatorio: la presencia de la pitonisa, sacerdotisa de Apolo, elemento femenino que acompaña al dios, emparentándolo, desde otro andarivel, con su par complementario. La pitonisa representa una figura capital en el marco de la adivinación porque a ella el dios entrega la capacidad profética, convirtiéndola en una especie de funcionaria del poder del dios. Si bien la compañía de lo femenino es dominante en el dionisismo, esta presencia atestigua un contacto de Apolo con lo femenino en un aspecto capital de su rasgo identitario.

Desde otro aspecto, cabe destacar que en el marco de la tradición cultural griega, los hiperbóreos constituían un pueblo imaginario que habitaba en el límite septentrional del mundo conocido. Su presencia dentro de esa misma tradición corresponde a una época remota, a pesar de no ser mencionado en los poemas homéricos.

Es nítida la presencia de la joven pitonisa a quien el dios confía cuestiones acuciantes; estas son exactamente las cuestiones que los hombres van a consultar. De allí la hondura del oráculo, de allí la innegable presencia del dios cuando los mortales han claudicado en sus respuestas. Como sabemos, "Apolo suscita la locura en el adivino, pero él se queda lejos” (Colli, 1998: 27), marca identitaria de quien hiere de lejos.

\section{E. Magia y Poder}

A continuación nos proponemos indagar el estatuto de un mago como Epiménides de Creta en el territorio de los maestros de verdad, que Marcel Detienne ubica en la dimensión del pensamiento mágico religioso, donde cierta figuras dotadas de un don de videncia son capaces de "ver" y tomar contacto con el más allá; así, se relacionan con prácticas de purificación y despliegan por el propio estatuto de su ser privilegiado un tipo de poder-saber inscrito en el horizonte de la magia como ejercicio, precisamente de ese poder.

La experiencia purificadora abraza una doble territorialidad: la ciudad antigua exige la presencia de un maestro divino, un aner theios, capaz de devolverle el orden de lo puro, conjurando con sus poderes mágicos la amenaza de lo impuro y la mancha. En este sentido, ubicarnos en los procederes mágicos implica instalarse en la prehistoria del arte de curar, ya que, más tarde, la incipiente medicina devuelve la presencia del médico, capaz de restablecer la harmonia, el encastre, de un cuerpo que ha perdido con la enfermedad el equilibrio de sus partes como forma de salud. En ambos casos, ya sea en el horizonte de la magia, ya en el horizonte de la medicina clásica, la tarea habrá de sostenerla quien esté calificado para ello, aunando precisamente esas relaciones de saber-poder que sostienen los regímenes de verdad de una determinada configuración epocal. En esta línea de sujetos excepcionales se inscribe el chamán, el médico y, más tarde, el filósofo de la utopía platónica, capaz de "curar" a la ciudad, cuando ésta 
se halla presa de la injusticia como forma de enfermedad, en el marco de lo que podemos considerar la metáfora médica que atraviesa parte de la obra de Platón.

A continuación nos referiremos a la figura del chamán, aludiendo a una doble dimensión que lo constituye identitariamente: su poder, como patrimonio de su excepcionalidad ontológica, y el viaje, como modo de acceso al más allá, a un tópos áltero, inaccesible y restringido al resto de los mortales, travesía que resulta imprescindible frente a cualquier pretensión purificadora y sanadora.

\section{F. LA SAbiduría QUe llega del Norte: la tradición CHAMánica}

Para comprender la excepcionalidad de ciertos personajes es necesario situarse en un plano intermedio entre la divinidad y el resto de los hombres. Nos estamos refiriendo a la figura emblemática del aner theios, especie de hombre divinizado, capaz de achicar la distancia natural que existe entre dioses y hombres, a partir de la disimetría estatutaria y de los diferentes regímenes ontológicos que hablan de dos topoi, en tanto diferente condición de ser. Si seguimos la hipótesis de Louis Gernet en torno a la existencia "de dos razas o mundos, impermeables la una a la otra" (1981: 15-25), el viaje cobra plenitud de significado, ya que sólo a través de una travesía se da el doble proceso de asimilación y aproximación con la divinidad al que el mismo Gernet alude.

La asimilación implica una categoría ontológica. Es el ser mismo del hombre, su naturaleza, la que se transforma hasta devenir él mismo "como un dios". Su ser se asimila al ser divino y en tal asimilación se convierte en un aner theios, en un varón divinizado. Es allí donde se inscribe la dimensión del poder. Estos hombres están dotados de un tipo de poder que los sitúa directamente en un más allá reservado a unos pocos. Es en nombre de ese poder extra-ordinario que son capaces, entre otras cosas, de purificar lo impuro, de sanear lo contaminado, y lo hacen a través de procederes mágicos, que abren otro registro de ser, de comprensión y de instalación en lo real.

Es en este cuadro de consideraciones que debemos pensar la figura del chamán desde el marco interpretativo que hemos propuesto. El alma del chamán puede emigrar, tiene la particularidad de abandonar el cuerpo y, desde ese nomadismo estructural, trasladarse en el tiempo y en el espacio. Esto implica una peculiar visión del alma, la cual puede, como una entidad autónoma, liberarse del peso y la tiranía del cuerpo e iniciar una travesía purificadora. Se da lo que Dodds llama "un yo profundo", una dimensión otra del yo antropológico, que vuelve a poner el tema en términos ontológicos. Se trata de una modificación de la vieja creencia en mensajeros divinos que se comunican con el hombre en sueños y visiones; ahora tales experiencias se vinculan con una facultad oculta, innata del mismo hombre. He allí el núcleo de ese "yo profundo" (Dodds, 1997: 133).

En primer lugar, el alma es el asiento de la presencia divina en el hombre. La psyche alberga la llama de la divinidad que, a su vez, diviniza al hombre en 
su asimilación. En segundo lugar, no hay posibilidad de tal asimilación con lo divino si no media el sueño o, incluso, la muerte. Se trata de desplazar ese yo consciente, superficial, para que emerja el yo más profundo. Tal como sostiene Dodds, la idea de ese "yo oculto" es una de las claves interpretativas de la cultura chamanística, del legado nórdico, de una sabiduría que viene del Norte, de las tierras del Apolo Hiperbóreo.

¿Qué es propiamente un chamán? Dice Dodds: "El chamán puede describirse como una persona psíquicamente inestable que ha recibido una vocación religiosa. Como resultado de su vocación se somete a un período de riguroso entrenamiento, que ordinariamente incluye la soledad y el ayuno, y que puede incluir un cambio psicológico de sexo. De este 'retiro' religioso sale con el poder, real o supuesto, de entrar a voluntad en un estado de disociación mental. En estas condiciones no se cree que el chamán, como la Pitia o como el medium moderno, esté poseído por un espíritu ajeno, sino que su propia alma ha abandonado su cuerpo y viaja a partes lejanas, con máxima frecuencia, al mundo de los espíritus. A un chamán puede de hecho vérsele simultáneamente en diferentes sitios; tiene el poder de la bilocación. De estas experiencias, que narra en cantos improvisados, deriva su pericia hacia la adivinación, la poesía religiosa y la medicina mágica que le hacen socialmente importante. Se convierte en el depositario de una sabiduría supranormal" (1997: 138).

La caracterización del chamán en el texto de Dodds corrobora las dimensiones que propusimos y las solidariza. El viaje, como tránsito a una sabiduría excepcional, es el pasaporte a un poder extraordinario que retorna en pericia médica, entre otras capacidades suprahumanas.

El chamán recibe un llamado, una convocatoria de ese plano que no todo hombre sabe escuchar, ni puede penetrar. El topos de ese llamado es un territorio otro, al que no todos pueden acceder. El sujeto privilegiado reúne en su ser algo de ese esse divino, que lo convierte en un maestro religioso, en una maestro de aletheia, con un estatuto de saber-poder semejante al del poeta inspirado, el adivino o el rey de justicia.

Ahora bien, responder al llamado, forma de elección de los dioses, lo convierte en un epoptes, en un elegido y ello implica cierta askesis distintiva, que lo muda en un servus dei. Prueba de ello es, en el marco de ciertas interpretaciones dispares, la aparición de tatuajes en la tradición chamanística. Parece responder a una doble finalidad: corroborar la singularidad del varón divinizado, al tiempo que supone la entrega a la divinidad, como forma de certificar el lazo de familiaridad. Ser un aner theios significa sostener una relación funcional con la divinidad, que reafirma ese doble movimiento que nos preocupara: la asimilación y la aproximación. Indudablemente el viaje es la posibilidad de tomar contacto con otro topos, con esa geografía prestigiosa del más allá, que tensiona las díadas que configuran la experiencia religiosa: el espacio y el tiempo sagrado frente al profano. 
La pericia del chamán merece algunas consideraciones. La clave interpretativa parece ser la noción de sabiduría. Se trata de una sabiduría suprahumana que emparienta al chamán con lo que Marcel Detienne denomina "maestros de verdad". Un maestro de verdad es una figura excepcional, capaz de entrar en sintonía con el más allá, por puro favor de los dioses, que, como en el caso del adivino, supone dos nociones complementarias: extasis y enthusiasmos, y, en el del poeta, dos conceptos, también complementarios, el de Mousa y Mnemosyne. En todos los casos, la experiencia se juega en el marco de una lógica de la ambigüedad, dominada por la tensión entre aletheia y letho, propia del mythos.

Lo que hace un maestro de verdad es de-velar la aletheia, des-cubrir lo oculto, des-ocultar lo verdadero, que se halla más allá de la visión ordinaria de los comunes. El chamán, como el adivino, se mueve en la misma tensión; por ello posee el don de la adivinación. Tener una adivinación implica poseer una Memoria sacralizada, aquello que el mismo Detienne define como "una omnisciencia de carácter adivinatorio" (1986: 21-38). Tal memoria difiere de la facultad psicológica humana de recordar y reconstruir temporalmente un episodio acontecido en el pasado. Se trata propiamente de Mnemosyne, la virgen Memoria, madre de las Mousas, la única capaz de "hacer acordar" lo acontecido "in illo tempore". Tal es la memoria-don de la que está dotado el poeta de tipo inspirado, capaz, con su don de videncia, de penetrar en el más allá. Nuevo rasgo de parentesco, ya que la experiencia chamánica da cuenta de la capacidad del chamán para la poesía religiosa. Poesía, adivinación y medicina mágica parecen ser los topoi de una figura excepcional, que guarda líneas de parentesco con figuras mítico-legendarias que la más remota tradición griega ubica en la geografía de la arche, en tanto maestros de aletheia.

Retornemos a la caracterización del "maestro religioso" y pensemos en la askesis que su consagración implica. El retiro religioso impacta directamente sobre el plano estrictamente antropológico: largos períodos de enclaustramiento, ayunos, abstinencia sexual, soledad. La exigencia de los dioses sabe ser muy alta para con sus elegidos; el costo es enorme, pero la recompensa, altísima.

Todo lo que hasta aquí hemos comentado en torno a la experiencia chamánica y sus puntos de contacto con otras figuras de la iniciación religiosa, parece dar cuenta de otra metáfora, emparentada con las anteriores: la metáfora lumínica. La sabiduría es la máxima luminosidad. La sabiduría, de la que está dotado un chamán, es esa posibilidad única de "ver", de estar instalado en el seno de la Memoria: "la aletheia que Epiménides de Creta tiene el privilegio de ver con sus propios ojos; la 'llanura de aletheia' que el alma del iniciado aspira a contemplar" (Detienne, 1986: 18).

En el marco de esta configuración religiosa, aletheia es complementaria de Dike: no hay distancia entre lo verdadero y lo justo y el propio Epiménides. Un chamán griego, "va a pleno día a la gruta de Zeus Diktaios, y permanece allí 
soñando durante numerosos años, conversa con los dioses y habla con Aletheia y Dike" (Detienne, 1986: 43). La imagen evoca la familiaridad del maestro religioso con la divinidad. Allí está Epiménides "conversando" con los Inmortales, dando testimonio de la familiaridad con ese mundo extraño al humano.

A propósito de Epiménides, conviene que nos detengamos en las vías de transmisión de la experiencia chamanística y en el legado recibido del norte. En Escitia y, probablemente en Tracia, los griegos, luego de la reanudación del contacto marítimo y la apertura a la colonización griega del Mar Negro, alrededor del siglo VII, parecen tomar contacto con la cultura chamanística. Producto de ello es la presencia, sobre finales de la Edad Arcaica, de figuras como los iatromanteis, videntes curanderos mágicos, entre los que se destaca Abaris, venido desde el Norte y Aristeas, un griego del Mar de Mármara, quien, por orden de Apolo Hiperbóreo, relató sus experiencias en un poema, al modo de un poeta inspirado.

Se dice de Abaris, precisamente, que "desterraba las pestes, predecía los terremotos, componía poemas religiosos, propagaba el culto de su dios nórdico, a quienes los griegos llamaron Apolo Hiperbóreo" (Dodds, 1997: 138). Abanico de capacidades que hacen pensar en un curandero mágico, pero también en un poeta y en un adivino, en un mago, capaz de predecir el comportamiento de la naturaleza, al modo de un "señor de las estaciones", exactamente en la línea del rey de justicia. En definitiva, los rasgos de un maestro de aletheia. Las distintas experiencias parecen obedecer a un fondo común. Corresponden todas a una misma excepcionalidad ontológica, donde curar mágicamente, desterrar las pestes, predecir un terremoto o componer un poema, son formas de una misma y única sabiduría supranormal.

Estas son las características que se le atribuyen a Epiménides, el vidente cretense, a quien se debe la purificación de Atenas, tras la peligrosa contaminación contraída por la violación de un derecho de asilo. Originario de Cnossos, de la prestigiosa ciudad de Micenas, Epiménides parece ser el portador de una sabiduría antiquísima, atestiguada en la posibilidad de restablecer el orden de Atenas, de limpiar la mancha vertida y la contaminación que opaca los destinos de la ciudad. La purificación, en tal sentido, aparece como una tarea higiénica, que conjura los peligros de las mezclas y devuelve el brillo, jugando precisamente, con la tensión aletheia-lethe, que hemos privilegiado. Tal es los prestigios de los kathartai, purificadores, emparentados con la leyenda de Apolo, quien tras matar a la serpiente Pitón y consagrar su soberanía oracular, fue purificado por Karmanor el Cretense.

\section{Conclusiones}

El proyecto de la presente comunicación ha consistido en abordar la dimensión mántica en el escenario identitario de Apolo, rasgo que lo emparienta 
con la primera sabiduría y las relaciones de saber-poder que la misma entraña. Nos ajustamos al texto La sabiduría griega de Giorgio Colli, y nos permitimos tomar algunos fragmentos rastreados por el filósofo italiano para ampliar los comentarios y enriquecer el texto. Asimismo, cuando el texto lo permitió, marcamos las diferencias entre Apolo y Dioniso, para mostrar cómo ambos dioses abrazan por completo el ámbito de la manía y de la primera sabiduría.

El segundo segmento del trabajo estuvo dedicado a la magia y a sus relaciones con la dimensión chamánica, a partir de las correspondencias entre la configuración apolínea y chamanismo. Pudimos comprender así la excepcionalidad ontológica de ciertos personajes, capaces de situarse en un plano intermedio entre los dioses y los mortales, alcanzando el estatuto del aner theios. En ese marco relevamos el registro de un mago como Epiménides de Creta, un maestro de verdad, dotado de un don de videncia, privilegio afín a su estatuto ontológico, que lo vincula con prácticas de purificación, desplegando un tipo de poder-saber inscrito en el horizonte de la magia como ejercicio, precisamente de esa ecuación. 


\section{Bibliografía}

Colli, G. (1994), El nacimiento de la filosofía, Barcelona.

Colli, G. (1998), La sabiduría griega, Madrid.

Colombani, M. C. (2005), Hesiodo. Una introducción crítica. Buenos Aires.

Detienne, M. (1986), Los maestros de verdad en la Grecia Arcaica, Madrid.

Detienne, M. (2001), Apolo con el cuchillo en la mano. Una aproximación experimental al politeismo griego, Madrid.

Dodds, E. R. (1997), Los griegos y lo irracional, Madrid.

Gernet, L. (1981), Antropología de la Grecia Antigua, Madrid.

Iriarte Goñi, A. (2002), De amazonas a ciudadanos. Pretexto ginecocrático y patriarcado en la Grecia Antigua, Madrid. 


\title{
A magia actuante da palavra em ésquilo, SETE CONTRA TEBas (The actuant magic of the word in Aeschylus' Seven against Thebes)
}

\author{
Maria do Céu Fialho \\ Universidade de Coimbra \\ (mcfialhofluc@gmail.com)
}

Resumo - Sete contra Tebas apresenta-nos já sinais de um processo de barbarização da facção atacante, em guerras civis gregas que, entre outros recursos, é feito através da descrição de práticas rituais de juramento, nocturnas, alheias ao padrão de juramentos helénicos oficiais, nas suas variações possíveis. Para além disso, a peça cria toda uma atmosfera de presságio e magia ameaçadora na cena dos escudos, através da descrição dos ícones actuantes no escudo dos atacantes, sublinhados por inscrições cujo espírito não anda longe do das defixitiones. O soberano de Tebas seis vezes procede a uma espécie de ritual de antídoto, também pela palavra que desmonta ou reverte o símbolo, e pelas medidas tomadas. No sétimo escudo descrito, juntamente com a revelação do seu portador, Polinices, Etéocles não só reverte os símbolos e a maldição contra Polinices como mergulha neles, fechando, por assim dizer, o anel com que salvará a cidade.

Palavras-chave: Sete contra Tebas, escudos falantes, magia/contra-magia, juramento.

Aвstract - Seven against Thebes presents us with signs of a process of barbarization of the attacking faction in Greek civil wars that, among other resources, is made through the description of ritual oath practices, nocturnes, foreign to the standard of official Hellenic oaths, in their possible variations. In addition, the piece creates an atmosphere of omen and threatening magic in the scene of the shields, through the description of the icons acting on the shield of the attackers, underlined by inscriptions whose spirit is not far from that of the defixitiones. The ruler of Thebes six times proceeds to a kind of antidote ritual, also by the word that disassembles or reverses the symbol, and by the measures taken. In the seventh shield described, along with the revelation of its bearer, Polinices, Ethéocles not only reverses the symbols and curse against Polinices but plunges them, closing, so to speak, the ring with which he will save the city.

KEYwords: Seven against Thebes, speaking shields, magic/ counter-magic, oath.

A força primordial do acto de nomear as coisas, do gesto de invocar o nome de coisas ou seres vivos sempre pareceu, desde o alvor das civilizações, estabelecer um elo de posse sobre o nomeado, capaz de o convocar, de o manipular ${ }^{1}$. Invocar eficazmente deuses ou entidades do mundo dos mortos constituía privilégio de vates e xamanes - e constitui ainda, em várias civilizações -, assim como de poetas, em relação às Musas, num contexto grego que se perde na memória dos

\footnotetext{
${ }^{1}$ Estudo desenvolvido no âmbito do projeto UID/ELT/00196/2013, financiado pela FCT - Fundação para a Ciência e Tecnologia.
} 
tempos, não como gesto de posse, perante um âmbito de poderes superior, mas como capacidade de se fazer ouvir e de se fazer atender, de modo a provocar a epifania dos invocados sob forma de inspiração concedida ao poeta. Nessa tradição assentam as invocações nos Poemas Homéricos, nessa tradição assenta a cena conhecida como 'investidura do poeta' no proémio da Teogonia ${ }^{2}$.

A construção do discurso, neste âmbito, mais do que a invocação pela simples palavra, convocaria, assim, mais do que seres, tramas complexas de acontecimentos passados, no canto dos poetas, ou daquilo que ainda não aconteceu mas espera o homem, mais à frente, no caminho da vida.

Por outro lado, esta relação de causa-efeito, que o discurso, mesmo o discurso iconográfico, potencialmente é capaz de provocar, é válida no sentido inverso, o da referida manipulação de mundo. Isto corresponde à convicção de que o discurso, incluindo o discurso iconográfico, prevalece sobre o curso dos acontecimentos, manipula-o, domina-o e domina os homens que neles estão envolvidos, como agentes ou como entidades por eles afectadas, como se o discurso constituísse uma teia: essa teia ou trama que é já motivo referencial, com cambiantes diversos, nos Poemas Homéricos, em particular na Odisseia (Circe, Penélope). Preso nessa teia, o homem vê a sua acção condicionada, sente a incapacidade de agir de motu próprio, dominado por forças contra as quais não pode lutar. Preso numa teia ou rede se sente o poeta da arcaica, quando Eros, com seus encantos e magias, lhe dá caça (e.g. Íbico, frg. 285 PMG).

Tendo em conta a genuína dimensão cultual da representação dramática na Hélade, desde as origens do seu teatro, e tendo, também, em conta, a justeza das observações aristotélicas, recorrentes no texto da Poética, sobre o mythos narrado dramaticamente (utilizando aqui modernas concepções de narrativa, alargadas ao teatro), como mimesis praxeos, afigura-se-nos particularmente rico, no que toca a essa dimensão mágico-ritual da linguagem performativa, o exemplo de Sete contra Tebas.

A peça conheceu, já na Antiguidade, um êxito retumbante que a fez ser eleita como uma das sete peças de Ésquilo a figurar no florilégio organizado com fins didácticos no tempo de Adriano. E assim foi separada de Laio e de Édipo, as duas primeiras peças da trilogia a que pertencia, que se perderam, delas tendo chegado até nós escassos fragmentos.

Como terceira peça da Trilogia Tebana, nela convergem e ganham força antiquíssimas vozes, concatenadas, de oráculos divinos e de maldições familiares, verbalizadas por antepassados e accionadas sobre os seus descendentes.

\footnotetext{
${ }^{2}$ Note-se a substancial diferença entre a concepção de 'inspiração' homérica e hesiódica: a primeira remete para um primado da visão. $O$ poeta pede que a Musa o inspire a cantar os factos como se ele lá tivesse estado, ou seja, que a Musa lhe conceda uma espécie de memória ficcional. No segundo é flagrante o primado do ouvido, porventura de influência de culturas da Ásia Menor (cf. a manifestação de Jahvé no Antigo Testamento). Sublinhe-se a ascendência das Musas: Zeus e Mnemosyne, a Memória. Vd. Snell (1990: 9-43).
} 
Esta tragédia abre numa atmosfera de urgência, com a ameaça de invasão iminente sobre Tebas, sitiada pelo inimigo. Etéocles surge em cena, às portas do palácio real, e as primeiras palavras desta tragédia correspondem ao discurso enérgico do soberano, num gesto determinado de defesa da cidade. Esse gesto e essa disposição do protagonista, descendente da casa de Laio, filho da relação incestuosa de Édipo, representam, simultaneamente, um gesto de tentativa de neutralização de uma maldição pendente sobre a cidade e sobre a sua casa e o seu destino. Assim, Etéocles invoca, nesta sua primeira intervenção, deuses olímpicos - Zeus Alexeterios (Zeus Protector, v.8) - e convida o povo a prestar culto, também, nos altares dos theon enchorion (dos deuses desta terra, v.14), a fim de que o povo e a Terra sejam protegidos. Isto é, a tónica da invocação está posta no domínio olímpico, ainda que Etéocles, ao referir os deuses desta terra, o faça de modo a sugerir não só a relação de tutela dos deuses em relação ao espaço ameaçado, mas também, ainda que numa ambígua subtileza, a possível natureza desses deuses ou de parte desses deuses: seriam deuses ctónios, alguns deles, heróis tutelares. Esta sugestão prepara invocações futuras e insinua a actuação futura de forças divinas que se fará sentir.

Por fim, Etéocles há-de compreender que todo o seu esforço em neutralizar a força do inimigo concentra, sobre si e sobre seu irmão, a necessidade de cumprimento de uma maldição a que se entrega, para salvação da cidade, para libertação da cidade de uma ameaça que quase a aniquila (vv. 672-675):

Com esta convicção [de que a Justiça, representada no escudo de seu irmão, não está do lado de Polinices] irei eu mesmo ao seu encontro: que outro guerreiro se ajustaria melhor? Chefe contra chefe, irmão contra irmão, inimigo contra inimigo. Assim será este combate.

O escudo de Polinices ostenta a Justiça (Dike), conduzindo pela mão um guerreiro que pretende ser Polinices, com a seguinte legenda: conduzirei este homem para que ele recupere a sua cidade e a mansão paterna (vv. 647-648). Fazse luz no espírito de Etéocles sobre o sentido de antigas maldições, proferidas por Édipo, e sonhos premonitórios: os dois irmãos hão-de ver repartida a sua herança por um estrangeiro vindo da Cítia. Este estrangeiro é a espada, em cujo fabrico e tempero os citas se tornaram famosos. A cidade será libertada quando a maldição e o sonho se cumprir nos dois irmãos. Neste caso, Etéocles não só faz reverter a legenda como se envolve na sua eficácia, fechando o círculo - qual escudo de Polinices - que prende, num elo mortífero, os dois irmãos.

Mas ainda no prólogo, mal Etéocles finda o seu discurso, chega o Mensageiro, incumbido de espiar as manobras do inimigo. A cena que observou é terrível e ele chega, ainda sob a impressão e terror que esta lhe causou. Trata-se de uma inusitada prática de juramento em terra grega aquela que é narrada pelo Mensageiro. Os sete chefes, não nomeados, selam um pacto de vida ou morte - ou conquistam e arrasam Tebas, ou seja esta terra nutrida pelo sangue que ao morrer eles derramarem. De novo aflora ao discurso o motivo da terra (vv. 
46-48), num terrífico contexto. O pacto é celebrado enquanto os sete guerreiros mergulham as suas mãos no negro sangue de um touro, aparado sobre um escudo de guerra e derramado num rito sacrificial.

Do ritual do juramento, anterior ao início da peça e contado pelo Mensageiro quando chega, fica o espectador com a impressão de que decorreu ainda a coberto das últimas sombras da noite, antes do raiar desta ameaçadora madrugada do dia decisivo. Nele acordaram os chefes atacantes qual dos sete se destinava a atacar cada uma das sete portas da cidade, como se o escudo representasse a cidade, por antecipação, banhada em sangue de touro, que representa o sangue da cidade, atacada pelas suas sete portas por aqueles homens revestidos de um poder e força bestiais ${ }^{3}$.

Esta encenação simbólica, para além da sua força de pacto, pretende antecipar, por manipulação actuante dos símbolos, a queda da cidade - invocando Ares como sinónimo de morte ${ }^{4}$, o Terror (v. 45), reforçado pelo estrépito do touro ao ser sacrificado, pelo sangue negro sobre o escudo, pelas mãos nele mergulhadas, pelo compromisso de matar ou 'alimentar a terra' com o próprio sangue, num cenário nocturno, contém todos os ingredientes de um ritual mágico, a que serão sensíveis as entidades ctónias mais temidas, associadas à prática da magia. A comum tríplice invocação dos juramentos é aqui feita (Ares, Enio, Terror) recorrendo ao desdobramento de um epíteto de Ares - Enyo ou Enyalios - que decorre da fusão do deus com uma antiga divindade da Cária, patrono do morticínio e da guerra - precisamente Enyo ou Enyalios -, já atestado em solo grego no período micénico. Já em Homero se tornam ambos sinónimos 5 .

Que efeito pretende Ésquilo obter desta invocação, desta descrição de cena nocturna? Acender laivos de barbarização do exército atacante, que acentuará pouco depois, na descrição dos sete chefes atacantes (Fialho 2001: 58-59) ${ }^{6}$.

${ }^{3}$ Nota Hutchinson (1994: comm. ad 42-56): "This description was famous in antiquity. Stobaeus quotes no other passage from A. more than five lines long. Lysistrata refers to the oath in a way that implies its celebrity (Ar. Lys. 187-9)".

${ }^{4}$ Nota RE s.v. 'Ares' que tal ocorre já na Ilíada, 13,630; 17, 490; 21, 112).

${ }^{5} \mathrm{RE}$ s.v. 'Ares'.

${ }^{6} \mathrm{~A}$ forma de juramento que mais se lhe aproxima é a documentada em Plateias - o que, por sua vez, conferiria verosimilhança à cena descrita, tendo em conta a proveniência peloponésia do exército (a que, todavia, não esqueçamos, pertence Polinices). O modo como é descrito sublinha, no entanto, uma dimensão quase mágica, não grega. Sobre a similaridade com o juramento de Plateias, veja-se Sommerstein (2013: 25) : "The Oath at Plataea also provides us with a glimpse of the ritual that might have accompanied the swearing of the Spartan citizenship oath. The inscription recording the oath describes how the swearers placed their shields on the sacrificial victims as they swore their oath. Having accepted van Wees' hypothesis that this oath was based on the Spartan oath of the enomotiai, it is tempting to see this as a peculiarly Spartan rite. It does appear at the very least to be a ritual associated with Peloponnesians. Xenophon (Anab. 2.2.9) reveals that when the Spartan commander of the Ten Thousand, Clearchus, concluded an alliance with the Persians who had fought for Cyrus, they sealed their oaths "by sacrificing a bull, a wolf, and a boar over a shield". This elaborate ritual is not unlike that in the Oath at Plataea, and it bears more than a passing resemblance to Aeschylus' portrayal (Seven 42-48) of 
Precisamente, quanto à forma de juramento propriamente dita, ela inscreve-se, propositadamente, fora dos parâmetros do comportamento grego: há testemunho da prática de sacrifício de animais e do juramento feito, tocando o animal sacrificado, sobretudo em sede judicial (e. g. Antifonte, 5. 12; Ésquines, 1. 114; Licurgo 20). Heródoto, 6. 68 descreve um juramento espartano selado, sustentando nas mãos entranhas do animal sacrificado. Xenofonte (An. 2. 2. 9) descreve uma forma mais próxima da da peça: a de um pacto de aliança feito sobre o sacrifício de animais num escudo de guerra. Porém, em Xenofonte, as partes envolvidas apenas mergulham as suas armas no sangue sacrificial (cf. Hutchinson 1994: comm. ad 43 sq.).

Perante este relato (vv. 39-68) ganhará Etéocles a nebulosa percepção de que Polinices está entre os sete atacantes? A invocação da sua intervenção inicial a Zeus Alexeterios (v. 8) e à Gei te metri, ...philtatei trophoi (v. 17), toma agora uma nova cambiante: é Zeus, a Terra, os deuses tutelares da pólis, mas também as Arai e $a$ poderosa Erinia paterna (v. 70) a serem convocados por Etéocles em defesa da cidade.

Esta aliança entre Olímpicos e Ctónios, na boca de Etéocles (vv. 69-70), torna presentes antigos oráculos e maldições familiares. Contra o peso dessas ancestrais previsões, saídas da Terra ${ }^{7}$ ou invocando terríveis forças ctónias, como as Erínias, peso esse reforçado, de fora, por este tenebroso ritual bárbaro, mágico-religioso nocturno, o público ganha a percepção de que a invocação de todo o universo, nestas cinco apóstrofes de convocação é necessário para fazer face, com vantagem, aos sinais múltiplos de ameaça que paira sobre Tebas. Os esforços e a decisão de Etéocles salvarão a cidade mas destruirão a casa de Laio, o irmão atacante e o irmão defensor, já que ambos são nascidos da mesma casta, e se encontram cobertos por uma maldição comum.

Não se pode perceber, todavia, se esta capacidade 'quase-xamânica' de Etéocles, por cuja palavra e acção as antigas maldições começam a tomar um ritmo mais veloz para o seu cumprimento, é de todo consciente para o protagonista ou vagamente pressentida.

O episódio II deve ter provocado, como texto cénico, uma fortíssima impressão, na sua alternância lírico-epirremática entre diálogo recitativo e breve comentário cantado, em sete partes, tantas quantas as portas de Tebas e

the Seven who "slaughtered a bull over a black shield, and then touching the bull's gore with their hands swore an oath", which has added significance when one considers that five of the Seven were Peloponnesian”. De qualquer modo, como sublinha o ilustre helenista, nada tem a ver esta forma de juramento com a dos efebos atenienses, que se vinculavam a não desertar, deixando desprotegidos os companheiros.

${ }^{7}$ Falo aqui de previsões saídas da Terra, tendo em conta que a maldição constitui uma forma de previsão forçada por quem a formula e invoca as deusas ctónias que a ela presidem, tratando-se de um pai a pronunciá-la sobre a geração seguinte. Quanto ao oráculo de Apolo: é de não esquecer que o deus olímpico se manifesta através da inspiração profética da Pitonisa, após a inalação, por parte desta, na gruta, por baixo do templo, em Delfos, de folhas de louro, depositadas com farinha numa abertura no chão da rocha e queimadas. Há quem pense que às fumigações se juntavam emanações de gases vulcânicos. Contra esta explicação veja-se Burkert (1993: 236-237). 
os pares de atacante-defensor. Mas o número sete, associado ao movimento dos discursos, assume aqui uma força mágica assustadora para o Coro de Mulheres de Tebas, representante do lado mais frágil e mais exposto de uma cidade em tempo de guerra, ameaçada pela invasão e pelo saque: a população feminina.

De novo regressado da sua missão, o Mensageiro sabe agora, ao certo, a identidade dos atacantes e o modo como se revestem de imagens ameaçadoras, gravadas como símbolos actuantes nos seus escudos. Rosenmeyer (1963: 34) define-os como "escudos falantes". A revelação de identidades e da ameaça que cada guerreiro representa é feita em crescendo. O mote da bestialidade está presente como se, de algum modo, ainda que a luta seja de Gregos contra Gregos, a barbárie estivesse presente do lado daqueles que juram sobre sangue de touros sacrificados, não invocando Zeus ou Hélios.

$\mathrm{O}$ primeiro de entre os chefes nomeados é Tideu, gritando como uma serpente (v. 381) - expressiva comparação com um animal do âmbito do ctónio - e exibindo um escudo onde um céu nocturno é iluminado por estrelas e pela lua, maior que qualquer astro brilhante, como olho da noite (v. 390), tal como o guerreiro que a transporta. Etéocles logo se apressa a declarar que as armas de um guerreiro não provocam medo e que os seus semata não têm eficácia (v. 398). Acrescenta (vv. 400-406):

Quanto a essa noite que descreves no escudo, com suas estrelas cintilantes no firmamento, talvez eu conheça para quem ela pode ser funesto vate. Que esta noite se abata sobre os seus olhos moribundos. E é ao guerreiro que o transporta que esse sinal de soberba se irá precisa e justamente aplicar. Foi contra si mesmo que ele profetizou esse oráculo de desmesura!

Terão os rhemata de Etéocles mais força que os semata dos escudos? À eficácia operativa e manipuladora do ícone sobre a realidade contrapõe, por cinco vezes, Etéocles, a convicção da eficácia superior da descontrução do símbolo pela palavra, mais ainda, da construção de um antídoto verbal para o ícone, tal como nas fórmulas de magia em que se pretende fazer reverter os efeitos de ritos de feitiçaria de modo a que eles recaiam sobre quem começou por praticá-los.

Simultaneamente, pela construção de toda a cena - discurso/contradiscurso/canto - o espectador vê-se envolvido num ritmo que balanceia o fazer e desfazer da teia, sublinhado e potenciado, a cada passo, por uma breve intervenção cantada pelo Coro. Estas intervenções são diferenciadas e aplicadas a cada par de discursos, mas evocam, no entanto, a estrutura da palavra mágica, reforçada por um refrão. Veja-se, por exemplo, a construção mimética de uma prática mágica em que o refrão está presente no Idílio II de Teócrito ${ }^{8}$.

${ }^{8}$ Este Idílio foi objeto de estudo aprofundado, tradução e comentário por parte de C. R. Cravo da Silva na sua dissertação de Mestrado apresentada à Faculdade de Letras da 
Nos cinco pares de discursos se verifica que um dos processos a que Etéocles recorre para conferir eficácia à sua desconstrução icónica e à reconstrução de leitura contra o portador do escudo consiste no comentário de carácter éticoreligioso, pelo qual ele lê sinais de hybris, contra diversos deuses ou contra a pólis, na iniciativa do guerreiro atacante ao ostentar tais imagens pretensamente actuantes no respectivo escudo. Trata-se de um processo que antecipa, de algum modo, salvaguardadas as devidas diferenças, o gesto de Clitemnestra quando convida Agamémnon a entra no palácio passado sobre o tapete de púrpura. Agamémnon é já hybristes, mas esta última hybris provocada sanciona a sua punição, convoca os deuses vingadores. Também o comentário de Etéocles tem, como intenção, chamar sobre o guerreiro atacante o castigo divino e acelerar esse processo, que o levará à aniquilação.

O processo, como se pode verificar no desenvolvimento da cena, vai sendo ampliado de Tideu a Capaneu e a Etéoclo, a Hipomedonte, muda de estilo, mas não de gravidade com Partenopeu.

O guerreiro inimigo destacado para a segunda porta, Capaneu, é pelo Mensageiro descrito como pior que o primeiro (vv. 424-425), de desmedida arrogância, manifestação da sua hybris, a ponto de clamar que destruirá a cidade, interpelando as suas muralhas, ainda que a ira de Zeus sobre ele se abata (vv. 426 sqq.). O seu escudo é imagem viva desta arrogância e da determinação absoluta de destruição, para além dos desígnios do próprio Olímpico: ostenta a representação de um guerreiro portador de fogo e uma legenda falante - Vou incendiar a cidade (v. 434). Este escudo, o paralelismo entre as ameaças verbais do guerreiro e a representação iconográfica da sua disposição, reforçada pela legenda, aproxima-se do carácter de uma inscrição de defixio, singularmente expressiva. Por isso, o discurso subsequente de Etéocles denuncia particular preocupação em reverter a maldição sobre quem a pronuncia e representa, invocando os deuses ofendidos (Zeus, v. 443), senhores de um fogo de punição, enquanto, no plano humano, destaca um guerreiro animado pelo fogo da coragem (vv. 447-448), temente aos deuses ofendidos 9 . Sublinha o Coro, cantando, a invocação do fogo divino punitivo, como merecida maldição sobre o atacante (vv. 452-455).

Análoga natureza tem a iconografia do escudo de Etéoclo, o terceiro guerreiro, cujos cavalos resfolegam com bárbaro ruído (v. 464): um guerreiro escala as

Universidade de Coimbra, Magia Erótica e Arte Poética no Idílio 2 de Teócrito, e disponível em: $\quad$ ttps://estudogeral.sib.uc.pt/bitstream/10316/7538/3/Magia\%20Er\%C3\%B3tica\%20 e $\% 20$ Arte $\% 20$ Po\%C 3\%A 9tica\%2 0 no\%2 0Id\%C3\%ADlio\%2 02\%20\%20 de $\% 20$ Te\%C3\%B3crito\%20-\%20Cl\%C3\%A1udia\%20Raquel\%20Cravo\%20da\%20Silva.pdf

${ }_{9}^{9}$ Assim, não está de todo certa a perspectiva de Watson, citado por Serena (2013: 78), sobre o carácter trivial e nebuloso da arai literárias, a ponto de não poderem dar uma ideia do uso das maldições na vida real. O autor do trabalho ocupa-se do poeta helenístico Eufórion para estabelecer um paralelismo que, todavia, é já perceptível na peça de Ésquilo (assim houvesse abundância de material arqueológico da época para dar mais consistência às considerações aqui tecidas). 
muralhas. Reforça a eficácia deste guerreiro a legenda falante que o faz afirmar que nem Ares o impediria de derrubar estas muralhas (v. 469). Se a bybris deste combatente ultrapassa a dos anteriores, a natureza de defixio do seu escudo é análoga à do de Capaneu. É subtil a escolha de Etéocles ${ }^{10}$ : seu primo Megareu, isento de arrogância, nascido da descendência dos Spartoi, os guerreiros brotados da terra, dos dentes semeados do dragão de Ares (vv. 474 sqq.). Por um lado, Etéocles traz à lide o próprio Ares ofendido, por outro, responde com armas imbatíveis - é como se a própria terra de Tebas sacudisse o invasor. Além disso, a 'autoctonia' deste guerreiro reforça a sua natureza de poderoso antídoto, já que, contra a magia arrogante do escudo invasor, uma força ctónia anima o contra-atacante.

A brutalidade do quarto guerreiro, Hipomedonte, fá-lo eleger como ícone uma série de monstros ctónios, com Tifeu ao centro, no auge da sua força aterradora. Porém, facilmente se desmorona a eficácia pretendida de tão horripilante representação: este velho inimigo de Zeus por Zeus foi outrora vencido e castigado. Basta que seja enviado um guerreiro de nobre estirpe que ostente Zeus no seu escudo. Um ícone prevalecerá sobre o outro. E assim o deseja e crê o Coro, no seu canto, desta vez de uma forma particular e inusitadamente convicta e firme, como se pode apreciar em vv. 521-525.

O escudo do quinto atacante possui, tal como este, uma pérfida peculiaridade: desta vez o ícone representado é silencioso, não ostenta legendas. É o grito sacrílego do guerreiro que o completa, assegurando que reverência mais a sua lança do que qualquer outra divindade, incluindo Zeus. Atacará a porta norte, junto à qual se encontra o túmulo de um filho de Zeus. Mas a peculiaridade icónica resulta do facto de, como aliás já foi notado, ostentar não uma ameaça vinda de fora, mas um monstro - a Esfinge - que faz parte da história sangrenta de Tebas. E essa Esfinge está representada com uma presa nas suas garras, um tebano (vv. 539-542).

Qual o objectivo de eficácia deste escudo? Que sobre o guerreiro seja lançado o maior número de dardos possível (v. 544). Ou seja, este escudo inverte a dinâmica de magia dos anteriores e, por isso, se torna mais ameaçador: ele representa um perigo que vem de dentro de Tebas, que interferiu no destino da casa real da cidade, como instrumento dos deuses. Quanto à representação do tebano sobre as suas garras: diferentemente das estatuetas de cera, crivadas de agulhas pelo agente de magia de modo a operarem sobre o objecto da sua má vontade, Partenopeu, o quinto guerreiro, traz representado o tebano, presa da Esfinge, para que sejam os próprios tebanos a crivá-lo de dardos. Assim o objecto de magia é envolvido no processo como agente de uma magia que contra si reverterá. Partenopeu percebeu, de facto, que a ameaça que paira sobre Tebas foi outrora desencadeada a partir da prória Tebas, ou melhor, da geração de

${ }^{10}$ Sobre a questão, tão discutida, do momento da escolha dos chefes tebanos, vide Fialho (1996: 39-48). 
Laio. Dispensa-se, pois, a necessidade de legenda. Tão enigmático quanto a Esfinge é o próprio guerreiro, por natureza, de face graciosa, quase infantil, a que corresponde uma crueldade imensa (vv. 532 sqq.).

É singular a forma com o adivinho Anfiarau, o sexto atacante que não logrará chegar à sexta porta, já que a terra o engole, se apresenta: de uma forma mais perigosa porque destituída de hybris e de arrogância, destituída dessa ingénua convicção de que dos ícones gravados nas armas se desprende uma força actuante sobre o adversário, à maneira dos guerreiros orientais. Anfiarau não ostenta ícones. O seu escudo é liso, para que a coragem do guerreiro apareça, por si, como se a iconografia própria das armas bárbaras não a potenciasse, mas a escondesse (vv. 590-591). Anfiarau cala a aparência para fazer valer as acções e esta constitui a sua verdadeira e mais terrível arma, a arma do mantis, do único e verdadeiro mantis - que não chegará, todavia, à batalha.

Ao reproduzir o seu discurso, o Mensageiro refere Polinices, presente no combate. Etéocles não pode ignorar por mais tempo, ou calar por mais tempo esse pressentimento, de que seu irmão está ali, pronto para o ataque. Não é já possível ignorar, para Etéocles, a iminência do fratricídio. Ainda assim, pesa o silêncio de um nome na sua boca. Contrapõe a presença de um justo (dikaion andra, Anfiarau) entre tois dyssebesterois (v.v. 598), diluindo, neste plural, 'o nome', por excelência. Sublinham alguns comentadores que seria agora o momento de evitar o confronto fratricida, já que Etéocles não pode mais ignorar que Polinices está presente. Seria a ocasião de se auto-destinar a defrontar Anfiarau.

Tanto quanto a força da maldição, Etéocles faz sua a vontade do confronto, para pôr fim, pelo seu cumprimento, à maldição e ao perigo que aquela casa real passou a representar para Tebas.

O sétimo atacante, como era esperado e foi silenciado, é Polinices. Inesperado é o ícone do seu escudo: a Justiça, Dike, que o reconduz a tomar conta da cidade e da casa paterna. Esta é a fronteira que separa a cegueira absoluta de Polinices do processo que, pouco a pouco, foi clarificando a visão de Etéocles, ainda que no que silencia em função da cidade. Etéocles destina-se ou destinara-se já a um confronto há muito determinado pelos deuses, pela maldição da sua raça, reforçada pela maldição paterna. Por isso a sua explosão expressiva, na rhesis que se inicia em v. 653, não tem como objecto o infortúnio da sua existência, não representa uma reflexão sobre esse seu mesmo destino, mas é mais ampla (vv. 653-657):

Ó estirpe de Édipo, minha estirpe, enlouquecida pelos deuses, motivo de ódio imenso para os deuses! Ai de mim, hoje se cumprem as maldições paternas. Mas não é tempo de lamentações ou de gemidos, que poderiam gerar prantos ainda mais desesperados.

Nestes versos se condensa a expressão-chave do comportamento de Etéocles. As maldições proferidas sobre Polinices são as de quem se reconhece envolvido 
pelo mesmo destino sangrento, mas que para ele corre, disposto ao sacrifício pela cidade, pondo fim a uma raça amadiçoada - a mesma a que pertence e com que, por isso mesmo, soçobrará. A pesada parbasia (v. 472) a que Laio não resistiu, nas suas philai abouliai (v. 750), que outra coisa não são que o poder de eros, levou-o a engendrar uma geração que, segundo o oráculo de Apolo, poria em risco a cidade: ou ter descendência ou salvar a cidade, são as alternativas postas a Laio por Apolo. Perigos futuros para a pólis, sangue familiar futuramente derramado na casa dos Labdácidas pelas mãos dos próprios filhos, incesto e maldição sobre a descendência, eis a cadeia de anomalias e poluições a que a casa real e Tebas estará sujeita. Outro filão se encontra aqui subjacente: o do poder subjugador de eros que vem potenciar a ameaça de jugo inimigo lançado sobre a cidade.

Por isso mesmo, conforme o Etéocles o verbaliza no kommos que se segue (vv. 689-691), Etéocles entrega-se à navegação que conduz toda a raça maldita às águas do Cocito. Ele mesmo convoca sobre Polinices, mas também sobre si, a maldição antiga, proferida por Édipo, reforçada por si. O esforço de neutralização e retorno da magia dos escudos teve êxito. $\mathrm{O}$ êxito na batalha pela salvação de Tebas depende agora do cumprimento de uma das alternativas do oráculo de Apolo - a anulação da descendência de Laio - reforçada pela maldição proferida por Édipo e convocada agora por Etéocles: sobre o atacante e sobre si mesmo. Oráculos, maldições e visões de sonhos convergem. O repartidor de heranças, vindo da Frígia, deixará a cada um dos irmãos o espaço de terra suficiente para a sua sepultura.

Entre o primeiro relato do Mensageiro e a cena dos escudos, no estásimo I, o Coro de Mulheres de Tebas entoa, em pânico, um canto em que antevê os horrores dos seus destinos de mulheres, se a cidade for invadida. De súbito, as fortes muralhas de Tebas, com as suas sete torres, não parecem mais constituir uma defesa, mas um recinto de prisão, orkana (v. 345), uma espécie de rede onde o Coro se sente como um animal aprisionado, ou de roda que o aperta, cada vez mais, à medida que os nomes dos atacantes vão sendo mencionados e se convertem, pela palavra, na ameaça presente. Etéocles, pelo seu gesto espontâneo, assume-se como agente do oráculo e da maldição que, ao cair sobre Polinices, cai também sobre si e avança para o fratricídio que o há-de matar, na sétima porta. Mas com este destino entrelaçado dos dois irmãos (vv. 939-940) salva-se a cidade, as muralhas recuperam o seu estatuto de muralhas defensivas, porque não representam já a prisão, nem rede que tolhe e amarra. A roda asfixiante quebrou-se, de modo determinante, na sétima porta e, com ela, toda a teia mágica dos escudos ${ }^{11}$.

${ }^{11} \mathrm{O}$ estudo de analogias do mito de Septem com lendas babilónicas, em que o elemento mágico está presente com todo o vigor, foi profundamente desenvolvido por Burkert (1981). 


\section{Bibliografia}

Burkert, W. (1993), Religião grega na época arcaica e clássica (trad. do al. 1977). Lisboa.

Burkert, W. (1981), Seven against Thebes: an oral tradition between Babylonian magic and Greek literature. Padova.

Fialho, M. C. (1996), A nau da maldição. Estudo sobre Os sete contra Tebas de Ésquilo. Coimbra.

Fialho, M. C. (2001), "Helenos e Bárbaros em Ésquilo. Autognose e problematizaçãoo do Eu na representação do Outro" in M. F. Brasete (coord.), Máscaras, vozes e gestos: nos caminhos do teatro clássico. Aveiro: 5169.

Hutchinson, G. O. (1985), Aeschylus. Seven against Thebes. Ed. w. introd. and comm. Oxford.

Rosenmayer, Th. (1963), "Seven against Thebes. A tragedy of war" in Th. Rosenmeyer, The masks of tragedy. Austin: 7-48.

Clua Serena, J. A. (2013), “Defixiones et Arai littéraires et de la tabella à la loidoria: le voleur" in E. Suárez de la Torre, A. Pérez Jiménez (eds.), Mito y magia en Grecia y Roma. Barcelona: 77-84.

Snell, B. (1978), Der Weg zum Denken und zur Wahrheit. Studien zurfrügriechischen Sprache. Göttingen.

Sommerstein, A. (2013), Oath and State in Ancient Greece. Berlin. 
(Página deixada propositadamente em branco) 


\title{
A PRÁtica da MAgia AMOROSA \\ NO PERÍODO HELENÍSTICO \\ (The practice of love magic in the helenistic period)
}

\author{
Maria Regina Candido \\ Universidade do Estado do Rio de Janeiro (UERJ) \\ (medeiacandido@gmail.com)
}

\begin{abstract}
Resumo - A pesquisa nos informa sobre o desempenho das práticas mágicas e suas vítimas. No entanto, percebemos a falta de informações sobre os responsáveis pelos procedimentos mágicos. Isso é; homens e mulheres consideravam especialistas em magia, definidos como magus, pharmakos, feiticeiros e qualificados para nós como profissionais da magia. A narrativa sobre a maldição do amor ou mágica erótica à qual propomos analisar neste artigo integra o repertório poético de Teócrito de Siracusa.

Palavras-chave: katadesmos; magia amorosa; imprecação; vingança; feitiçaria
\end{abstract}

Aвstract - The research tells us about the performance of magical practices and their victims. However, we realized the lack of information about those responsible for the magical procedures. That is; men and women considered experts in performing magic, defined as magus, pharmakos, wizards and qualified for us as professionals of magic. The narrative about love curse or magic erotic to which we propose to analyze in this paper integrates the poetic repertoire of Theocritus of Syracuse.

KeYwords: katadesmos; loving magic; imprecation; revenge; witchcraft

A poesia de Simeta nos chama a atenção pelo fato da protagonista atuar como usuária da magia dos katadesmoi. Os pesquisadores da área das Ciências Humanas têm produzido informações sobre as práticas mágicas, junto à antiguidade grega e romana, disponibilizando publicações sobre os amuletos, os papiros mágicos e as imprecações presentes nos artefatos de chumbo identificados como defixiones (latim) ou katadesmos (grego). Estas lâminas de chumbo com inscrições em sua superfície, usados nas práticas da magia e identificados como katadesmoi ou defixiones requerem um conjunto de heterogêneo de agentes sociais e materiais, a saber: a lamina de chumbo, a presença do solicitante e usuário da magia, conhecimento das palavras mágicas, o nome da vítima da maldição e o local de interdito para o desenvolvimento da ação. O texto que compõe o discurso magico dos katadesmoi forma um código a ser decifrado o que nos possibilita reconstruir o passado da maneira de fazer dos usuários da magia de fazer mal ao inimigo. O solicitante recorre as práticas magicas por estar envolvido em situação pessoal: de um lado sente-se lesado, prejudicado pelo seu oponente mais forte e de forma preventiva, o solicitante 
faz uso da magia dos katadesmoi para assegurar a vitória sobre o seu adversário. Entretanto, o usuário da magia pode ser acometido pelo sentimento de inveja e despeito diante do sucesso de alguém próximo e decide impor de forma ofensiva a ruina através das práticas da magia.

Não podemos esquecer que o usuário da magia das defixiones é alguém que se sente ameaçado em algo de valor que teme perder. A natureza específica do desejo de realização do solicitante e usuário da magia detém seus indícios na diversidade de artefatos de chumbo cujas fórmulas mágicas inscritas nas superfícies indicam para a imprecação contra os ofícios (atividades de artesão e ceramistas), imprecação contra processos jurídicos (com nomes de integrantes da aristocracia), imprecação amorosa na qual homens e mulheres buscam assegurar a atenção ou se vingar do ser amado diante da rejeição.

Recentemente, a pesquisadora Eleni Pachoumi no artigo The Erotic and Separation Spell of the Magical Papyri and Defixiones (2013) analisou os papiros mágicos visando a possibilidade em identificar o gênero e a condição social dos usuários das práticas da magia amorosa. A autora dialoga com J.J. Winkler por considerar que tanto nos papiros mágicos quanto nas laminas de chumbo, o predomínio do usuário aponta para homens em busca de afeição das mulheres. Fritz Graf concorda com essa premissa e ratifica que os homens usavam da prática da magia amorosa para assegurar para si o amor da mulher amada. Entretanto, D. Faraoni considera que a magia erótica era praticada tanto pelos homens quanto pelas mulheres (Pachoumi,2013: 295).

As pesquisas sobre os vestígios da cultura material nos informam sobre a realização das práticas mágicas e as vítimas de imprecação. Entretanto, percebemos a escassez de informação sobre os responsáveis pelos procedimentos mágicos, ou seja, os homens e as mulheres considerados especialistas na realização da magia, definidos pela literatura como magus, pharmakos, feiticeiros. Nós os consideramos como detentores de um saberfazer especifico, conhecimento especializado que nos leva a qualifica-los como profissionais da magia.

A narrativa sobre imprecação amorosa ou magia erótica ao qual nos propomos analisar neste ensaio integra o repertório poético de Teócrito de Siracusa (Gow, 1973:xvi), poeta alexandrino considerado o precursor da monologo dramático-narrativo denominado de idílio que integra o gênero bucólico grego e também conhecido como pastoral romano. O gênero literário bucólico esteve presente no universo grego da região da Sicília, região de Cós e entre a elite de Alexandria no período helenístico e foi considerado como poesia de inovação. O gênero pastoral tem por base a narrativa de pessoas simples do campo ou do meio urbano envolvidas em questões relacionadas as perdas amorosas. Os escólios justificam a emergência do gênero bucólico como resposta nostálgica ao passado vivenciado longe da dinâmica da Cosmópolis 
que possibilitava ao homem grego ser um anônimo em meio à multidão multicultural e multiétnica.

O texto, suporte de informação pertence ao universo da literatura ao qual nós, historiadores e helenistas, consideramos como um documento textual por nos trazer informações sobre materialidade das práticas mágico-religiosas que circulavam junto ao imaginário social do mundo helenístico.

A obra de Teócrito que selecionamos denomina-se Idílio de Simeta ou A Feiticeira cujo termo idílio tem por origem a palavra grega eidylion que significa uma pequena peça dramática específica para ser recitada e não representada. Charles Witke considera a existência de uma interface entre o idílio de Teócrito e as cenas mágicas de Sófron, resultando na poesia pastoral (C.Witke, 1970:32). O idílio tem como predecessor o pouco conhecido poeta Sófron de Siracusa que no final do V sec. a.C já fazia uso de mimos como expressão poética. Os mimos de Sófron de Siracusa detinham uma linguagem regional que retratava cenas cômicas da vida diária de pessoas simples que viviam no meio tipicamente urbano. $O$ gênero poético narra as situações existências de mulheres e hetairas e os seus envolvimentos amorosos que faziam parte do cotidiano das ruelas e becos das cosmopoleis helenísticas de Atenas e de Alexandria. Havia a presença da marcação de gênero com a divisão de mimoi andreoi (homens embriagados, desilusões amorosas) e o mimoi gnaikkeioi - gynaikeioi (mulheres alcoviteiras, hetairas e feiticeiras) pelo fato de ressaltar cenas de forma metafórica indicando o intercurso sexual como o uso do dildo (instrumento de prazer sexual), ato de felação e ações homoeróticas.

Consideramos que o poeta Teócrito, apreende o gênero de Sófron de Siracusa e constrói o restrito monólogo do Idílio de Simeta que segue o gênero dos mimos, porém com certo requinte dramático de situações vivenciadas pela protagonista. $\mathrm{O}$ poeta busca retratar a vida comum das mulheres estrangeiras que circulavam e trabalhavam em tabernas, por vezes, envolvidas em paixão não correspondida, sofriam com a rejeição e buscavam reagir diante do amor perdido.

O Idílio de Simeta tende a seguir esta temática, pois o enredo narra a situação de uma jovem mulher urbana, apaixonada e que se vê abandonada pelo seu amado, o jovem vitorioso atleta dos jogos olímpicos chamado Délfis. Simeta recorre à magia erótica para garantir o retorno de seu amado a quem não vê por onze dias. A protagonista deixa transparecer que, caso não consiga seu objetivo, irá decidir pela destruição do objeto amado junto a porta do Hades, o que equivale decretar a sua destruição e morte.

O recorte temático do Idílio de Simeta se pauta na prática da magia que transita entre a magia amorosa e aquela que visa fazer mal ao inimigo. O que nos chama a atenção está na constatação da permanência da magia de encantamento para a sedução ou vingança junto ao repertório dos helenos cujo tema está presente desde o período arcaico, a saber: 


\begin{tabular}{|c|c|c|c|c|}
\hline Documento & Solicitante & Ação mágica & $\begin{array}{l}\text { Divindade } \\
\text { evocada }\end{array}$ & Objetivo \\
\hline $\begin{array}{l}\text { Ilíada } \\
\text { Período } \\
\text { arcaico }\end{array}$ & $\begin{array}{l}\text { Hera } \\
\text { vv. 214-221 }\end{array}$ & $\begin{array}{l}\text { Efeito de sedução } \\
\text { através do uso de uma } \\
\text { cinta mágica }\end{array}$ & Afrodite & $\begin{array}{l}\text { Tornar a usuária da } \\
\text { cinta mágica uma } \\
\text { mulher irresistível }\end{array}$ \\
\hline $\begin{array}{l}\text { Odisseia } \\
\text { Período } \\
\text { arcaico }\end{array}$ & $\begin{array}{l}\text { Circe } \\
\text { vv.299-301 }\end{array}$ & $\begin{array}{l}\text { Reter junto de si } \\
\text { a presença do ser } \\
\text { amado: Odisseus }\end{array}$ & $\begin{array}{l}\text { Intersecção de } \\
\text { Hermes }\end{array}$ & $\begin{array}{l}\text { Através da erva } \\
\text { denominada de } \\
\text { moly, Odisseus evita } \\
\text { a realização do } \\
\text { encantamento }\end{array}$ \\
\hline $\begin{array}{l}\text { Sófocles } \\
\text { Período } \\
\text { clássico }\end{array}$ & $\begin{array}{l}\text { Dejanira } \\
\text { vv.555-560 }\end{array}$ & $\begin{array}{l}\text { umidece a túnica de } \\
\text { Héracles com sangue } \\
\text { de centauro Nesso. A } \\
\text { ação foi movida pelo } \\
\text { ciúme }\end{array}$ & Centauro Nesso & $\begin{array}{l}\text { Impedir o marido de } \\
\text { olhar e/ou desejar } \\
\text { sexualmente outra } \\
\text { mulher }\end{array}$ \\
\hline $\begin{array}{l}\text { Eurípides } \\
\text { Período } \\
\text { clássico }\end{array}$ & $\begin{array}{l}\text { Medeia } \\
\text { vv.375-385 }\end{array}$ & $\begin{array}{l}\text { Veneno na roupa da } \\
\text { noiva de Jasão, a } \\
\text { jovem Creúsa. }\end{array}$ & Hécate & $\begin{array}{l}\text { Eliminar a rival } \\
\text { através de veneno } \\
\text { nas vestes e em } \\
\text { meio às chamas }\end{array}$ \\
\hline $\begin{array}{l}\text { Teócrito } \\
\text { Período } \\
\text { helenístico }\end{array}$ & $\begin{array}{l}\text { Simeta } \\
\text { vv. 15-16 }\end{array}$ & $\begin{array}{l}\text { Queimar o amado } \\
\text { representado por } \\
\text { uma figura de cera } \\
\text { representando Délfis. }\end{array}$ & $\begin{array}{l}\text { Medeia } \\
\text { Circe }\end{array}$ & $\begin{array}{l}\text { Reaver o amor de } \\
\text { Délfis ou destruí-lo } \\
\text { através da pratica } \\
\text { das defixiones. }\end{array}$ \\
\hline
\end{tabular}

Os procedimentos mágicos amorosos realizados no período arcaico circulavam pela boca e pelo ouvido junto à sociedade dos helenos. $O$ poeta Eurípides não descreve as etapas do ritual mágico de Medeia diante do palco do teatro de Atenas. A motivação do silêncio se deve, talvez ao preconceito, ao interdito ou mesmo temor da reação do público presente no teatro de Atenas. Entretanto, o seu contemporâneo Sófron de Siracusa descreveu no fragmento Mimos Gynaikeioi Fr.4a/4PS-1214 (Hordern 2004:34,), os procedimentos mágicos realizados para Hécate, a saber:

Ponha a mesa imediatamente. Pegue um punhado de sal na mão e coloque as folhas de louro em torno de suas orelhas. Agora, vá para a lareira e sente-se ali. Você dáme o machado e leve o cão para aquele lugar. Onde está o betume? Mantenha a tocha e os incensos acesos. Vinde, pois, todas as portas serão abertas! Você assiste a partir de onde você está. Silêncio agora, enquanto nomeio estas mulheres aqui. Eu faço a minha parte e a senhora, receberá a sua parte da oferenda ${ }^{1}$.

Teócrito deixa transparecer ter interagido com Sófron de Siracusa ao descrever os procedimentos mágicos no monólogo de Simeta, a saber: “ a ti,

\footnotetext{
${ }^{1}$ Tradução livre do autor a partir do documento textual. Da mesma forma, referente ao texto de Teócrito e outros textos.
} 
deusa, num murmúrio, entoarei os meus encantamentos a Hécate. Diante dela até os cães tremem, quando passa por entre os túmulos dos mortos e o sangue negro. Salve, ó Hécate terrível !" (Teócrito 2.15) Na citação, protagonista também evoca a feiticeira Hécate como fez Sófron de Siracusa ao mencionar que a deusa, ao transitar pelo Hades, fazia com que até os cães tremessem ao passar por entre os túmulos dos mortos. A referência ao temor dos cães se deve ao fato de Hécate receber como oferenda o cão como animal de sacrifício. $O$ poeta traz a memória de seus leitores do período helenístico, o saber mágico que antecede o seu tempo como as práticas magicas de Circe, de Medeia, de Calipso e de Hécate conhecidas no mundo helenizado como feiticeiras, pharmakides, fato que justifica a sua presença junto aos procedimentos mágicos de Simeta.

A poesia do Idílio de Simeta traz à memória dos povos helenizados o repertório dos procedimentos mágicos presentes nos tabletes de imprecação denominados de defixiones ou katádesmoi que tem por finalidade fazer mal ao inimigo. No caso, temos por suposição que Simeta não parece ser especialista nos procedimentos mágicos, pois atua como usuária da magia na condição de aprendiz de feiticeiro que busca realizar o ritual presentes em manuais de magia. O poeta coloca Simeta como alguém que usa de procedimentos mágicos em benefício próprio sem a presença de um especialista na magia de fazer mal ao inimigo. Como usuário da magia dos filtros amorosos, tudo indica que ela segue o que prescrevia as fórmulas mágicas que circulavam entre os praticantes da magia, cuja tradição chegou até nós através dos Papiros Mágicos Gregos, conhecidos como PGM e publicado por Hans Dieter Betz.

As várias fórmulas mágicas indicam que a tradição prescrevia que, antes de iniciar as práticas mágicas, cabe ao solicitante efetuar o ritual de purificação por três dias. Durante esse tempo, o solicitante deveria oferecer incenso aos deuses e evocando sempre o nome do amado. O procedimento deveria ser continuar pelo prazo de sete dias para depois iniciar a elaboração dos filtros mágicos na forma de inscrição na lâmina de chumbo e da confecção da pequena figura humana em cera ou chumbo. A jovem Simeta, evoca na poesia o nome de mulheres praticantes da magia e de personalidade fortes e ativas como Circe e Medeia. Durante a realização da magia erótica, ela evoca também a deusa dos mortos, vejamos a citação:" Saúdo, Hécate ,atenda-me nesta empreitada e torne os meus procedimentos mágicos tão fortes quanto os de Circe e de Medeia (Teócrito 2.15).

A jovem protagonista evoca as divindades ctônias para auxilia-la nos procedimentos mágicos que se inicia ao queimar um ramo de louro. As folhas secas de louro simbolizam a coroa da vitória de Délfis nas competições atléticas e a jovem cita: eu queimo este ramo de louro e assim como ele arde em brasa...que queime também em chamas o corpo de Délfis (Teócrito 2.25). No ritual de realização do filtro amoroso o ato de queimar não significa precisamente a destruição do objeto, mas a intenção de que o corpo de seu amado se torne ardente de desejo como as chamas da paixão. A intensidade da chama simbolizava para Simeta a 
intensa vontade que ela tinha em despertar o desejo, o interesse e a paixão em Délfis.

As solicitações da jovem apaixonada detêm proximidades com o ritual que usa as laminas de chumbo, ou seja, dos katádesmoi ou defixiones. Ambos expõem o acentuado envolvimento emocional do usuário da magia amorosa que deseja a exclusividade na relação de amor como nos aponta Simeta ao mencionar que três vezes eu faço esta libação e por três vezes eu pronuncio estas palavras....quem quer que se deite com ele, seja homem ou mulher que ele esqueça completamente assim com Teseu esqueceu Ariadne (Teócrito 2.45). A narrativa poética de Simeta menciona, de maneira detalhada, os procedimentos da magia amorosa de como reaver o amor perdido. A ação se materializa através de uma pequena figura humana moldada em cera ou chumbo denominado de philtron katadesmos (grego) ou vudu doll (inglês). Simeta nos revela a realização do ritual ao citar: eu faço fundir esta cera com auxilio da deusa e assim despertar o amor de Délfis (Teócrito 2.30).

O documento PGM IV:296-466 deixa transparecer com detalhes a elaboração e as palavras mágica que devem ser proferidas no ato de confecção dos katadesmoi que faz uso de figura humana de cera ou chumbo. No caso, a representação do jovem Délfis passa a ser uma figura moldado em chumbo, com meio palmo de altura, as mãos devem estar atadas as costas, não esquecendo de ressaltar a proeminência do órgão genital masculino. Após ter confeccionado e encantado a pequena figura humana feita de chumbo, o usuário da magia erótica deve complementar a ação realizando a materialização de sua vontade. $\mathrm{O}$ seu desejo deve ser inscrito na superfície da fina lamina de chumbo, com estilete de bronze, evocando as divindades Circe e Hécate visando trazer e manter preso o desejo do ser amado. Os verbos devem estar na primeira pessoa do singular e no modo imperativo, em seguida deve escrever o nome do amado e realizar a evocação as divindades ctônias.

O Papiro Mágico Grego, PGM nos revela um outro ritual para manter preso o ser amado. A primeira ação: o usuário da magia deve selecionar treze pequenas estiletes de chumbo denominada de passalos para efetuar as perfurações na figura moldada em cera ou chumbo. Em seguida, deve recitar os seguintes dizeres enquanto perfura a figura de cera ou chumbo, a saber:

“...eu estou perfurando este prego na sua cabeça fulano, enterro dois em seus ouvidos, dois em seus olbos e um na sua boca... dois em sua peito.....um em cada mão....um eu enterro em sua genitália e dois em seus pés. Eu enterro estes pregos em cada uma de suas parte de seu corpo fulano, para você não se interessar por ninguém, mas que tenha os olhos somente para mim, só pense em mim”.(PGM IV,296:325).

Como podemos observar o repertório de procedimentos mágicos de Simeta integra um conjunto de fórmulas mágicas que apresentavam pequenas variações nos dizeres, mas, seguia sempre o mesmo padrão como nos indica o conjunto de 
imprecações dos PGM: que fulano, filho de sicrano (nome da mãe) me ame e me deseje com paixão e que não tenha relações sexuais pela frente ou por detrás, que ele não busque prazer com homens e nem mulheres, mas somente comigo (PGM IV,296:350-355). Outra fórmula mágica para despertar a paixão na pessoa amada, a saber: evoca a divindade ctonia e pede para que faça com que fulano não possa beber, comer, pensar, gozar de saúde se insistir em ficar afastado de mim; que fulano não consiga dormir sem mim......perturbe suas entranhas, sua alma em cada momento de sua vida.... até que ele venha a mim epermaneça unido a mim (PGM. IV,296:360).

Entretanto, caso o solicitante e usuário da magia dos philtroi amorosos não consiga a realização do seu desejo, o amor parece que se transforma em ódio e com um intenso desejo de destruição do objeto amado como deixa transparecer a jovem Simeta ao mencionar que "eu quero encantar Délfis com os meus philtroi mágicos... mas se ele me desprezar será pela porta do Hades que irá bater levado pelas Moiras...pela potência do meu veneno" (Teócrito 2.160).

Após a elaboração dos filtros katadesmoi, o usuário da magia deveria enterrar a lâmina junto com a figura humana feita de cera ou chumbo na sepultura de vítimas de morte violenta. O conjunto (lamina e a figura) devem ser envolvidos com fios de cabelos, pedaço de roupa e de unhas do ser amado e colocado no interior da sepultura. O morto escolhido para o enterramento deve ser uma vítima de morte violenta/biaios como por exemplo uma criança prematura/ aoros, um suicida ou vítima de assassinato. Nesta parte a poesia de Simeta traz a memória de seus leitores, o modelo herdado do período clássico presentes na ação de Dejanira, Medeia, Fedra, ou seja, mulheres que decidiram pela ação de prejudicar, destruir o ser amado diante do abandono e da rejeição de seu amor.

Concluimos que a prática da magia erótica compõe um conjunto singular de documentação que nos permite analisar o imaginário social da magia no mundo helenístico como nos aponta The German Archaeological Institute in Athens. O instituto atua como o responsável pelas escavações realizadas no Cemitério do Ceramico e nos informa que das 625 laminas de chumbo com imprecações que datam do $\mathrm{V}$ e do IV século a.C., 325 foram encontradas em sepulturas na região de Atenas (D.Ogden,1999:15). Faraone complementa a informação indicando que desse acervo, um total de sessenta e nove laminas de chumbo foram identificadas como philtros katadesmos (Faraone, 2000:43). O interessante que o usuário da magia amorosa nos aponta que a maior parte era praticada por homens e mulheres que buscavam reaver, assegurar ou despertar o interesse sexual de seu amado. O tema sobre as práticas da magia no mundo helênico proporciona estabelecer um campo de experimentação comparada visando comparar a magia das defixiones do período clássico, cuja eficácia dependia da interação entre o magus e o solicitante com a do período helenístico cujo discurso aponta para o usuário da magia, de maneira individual e só, realiza os procedimentos mágicos talvez, seguindo um manual. Outro dado que nos chama a atenção está em verificar se havia a presença de sangue junto aos defixiones assim como cotejar 
quais os animais usados na realização de sacrifício de sangue junto ao ritual dos philtroi katadesmoi. Retomando a discussão sobre a predominância de gênero, ou seja, afirmamos que tanto os homens quanto as mulheres recorreram a realização dos philtroi katadesmoi visando a prática da magia amorosa. As inscrições nas superfícies das laminas nos permite cotejar e apreender a materialidade dos sentimentos, dos sonhos e desejos de parte de alguns homens e mulheres do mundo helenístico que recorriam a pratica dos filtros amorosos visando manter junto de si o ser amado e assim alcançar a realização amorosa. Agora, se eles conseguiram alcançar seus objetivos, tornando-os realidade...isso é uma outra história.... 


\section{Bibliografia}

Aristóteles. (1996) Constitution d'Athènes. Trad. G. Mathie. Paris: Les Belles Lettres.

Eurípides. (1991) Medeia. Trad. Jaa Torrano (bilingüe). São Paulo : Hucitec.

Platão.(1993) República. Trad. Maria H. da R Pereira . Lisboa : Fund. Caloustre Gulbekian

Platão (1984) The Laws. Trad. R.G. Bury. London: William Heinemann, 2 vols.

Sófron de Siracusa. (2004) Mimes. trad. J.H.Horden. Oxford :Oxford University Press,

Teócrito (1925) Les Magiciennes. IN: Bucoliques Grecs Paris: Belles Lettre

Kunze-Götte, Erika. (1999) Die Nekropole von der Mitte des 6.bis zum ende des 5. Jahrbunderts. Müncchen: Himer Verlag,

Michael, Charles. ( 1912) Recueil d'Inscriptions Grecques. Paris: Ernest Leroux,

Peek, Werner (1941) Inschriften Ostraka Fluchtafeln. Berlin: Walter de Gruyter \& CO.

Bernard, Andre. (1991) Sorciers Grecs. Paris; Fayard.

Betz, H. Dieter. (1992) The Magical Papyri in Translation. Chicago: University Chicago Press.

Candido, Ma Regina. (2004) A Feitiçaria na Atenas Clássica. Rio de Janeiro: Letra Capital/FAPERJ.

Candido, Ma Regina. (2007) Médeia, mito e magia: a imagem através do tempo. Rio de Janeiro: Edit.NEA/UERJ.

Csapo, Eric et alli. Greek Theatre in the Fourth Century B.C. Berlin: W. de Gruyter,

Dickie, Matthew W. (2003) Magic and Magicians in the Greco-Roman World. London: Routledge.

Dietz, Soren (1998). Proceedings of the Danish Institute at Athens II.Athens: Dia, Durand, Jean-Louis (1986) Sacrifice et Labour en Grece Ancienne:ensai d'Anthropologie religieuse. Rome: EFR.

Faraone,Chr. (1991) Magika Hiera: ancient greek magic E religion. Oxford: Oxford University Press.

Festugiere, A J. (1980) La vie spirituelle en Grece à l'époque hellenistique. Paris: Picard.

Flint, Valerie. (1999) Witchcraft and Magic in Europe. London: The Athlone Press.

Freyburger, Gerard. (1986) Sectes Religieuses en Grece et a Rome. Paris: Belles Lettres. 
Gager, John G.(1999) Curse Tablet and Binding Spells from the Ancient World. New York: Oxford University Press.

Gow,A.S.F. (1973) Theocritus. Cambridge: Cambridge University Press.

Hansen, M. H. (2006) Polis: an introduction to the ancient Greek city-state. New York, Oxford University.

Hordern, J. H. (2004).Sophron's Mimes. Berlin-New York: Oxford University Press.

Hultin, Jeremy E. (2008) The Ethics of Obscene Speech in Early Christianity and its Environment. Leiden: Brill,

Hunter, Richard L. (1996). Theocritus and the Arcaeology of Greek poetry. Cabridge: Cambridge University Press,.

Jordan,David R. (1999) The World of Ancient Magic. Bergen: John Grieg AS,

Luck, G. (1995)Arcana Mundi: magia Y ciencias occults en el mundo griego y romano. Madrid: Gredos.

Nielsen, Inge (et alli) (2000) Proceedings of the Danish Institute at Athens III. Athens: DIA

Meyer, Marvin (2001) Ancient Magic and Ritual Power. Boston: Brill Academic Publishers.

Morris, Ian (1989) Burial and ancient society. Cambridge: Cambridge University Press.

Ogden, D. Binding Spells:curse tablet and voodoo dolls in Greek and Roman World.in: Witchraft and Magic in Europe. London: The Athlone Press, 1999, vol.2, p.3-86.

Ogden, D. (2002). Magic, Witchcraft and Ghosts in the Greek and Roman World. New York: Oxford Press

Ogden, D. (2007) In Search of the sorcerer's apprentice. London: Gomer Press.

Pachoumi, Eleni . (2013) The Erotic and Separation Spell of the Magical Papyri and Defixiones. Greek, Roman, and Byzantine Studies 53 p. 294-325.

Parker, Robert. (2007) Polytheism and Society at Athens. Oxford: Oxford University Press,

Payne, Mark (2006) Theocritus and the Invention of Fiction. Cambridge: Cambridge University Press,.

Peek, Werner. (1941) Inschriften Ostraka Fluchtafeln. Berlin: Walter de Gruyter. 


\title{
Uma cena de necromancia em Flávio Josefo (A scene of necromancy in Flavius Josephus)
}

\author{
Nuno Simões Rodrigues \\ Universidade de Lisboa ${ }^{1}$
}

\begin{abstract}
Resumo - Este ensaio analisa um passo de Flávio Josefo, o da visita do rei Saul ao medium de En-Dor (AJ 6.327-339), em que o historiador helenístico faz uma paráfrase do texto bíblico (1Sm 28,21-25), mas amplificando-a consideravelmente. Nessa amplificação, Josefo faz uso das suas ferramentas helenísticas e recria uma cena de necromancia com evidentes ressonâncias nas culturas circundantes, sendo o passo joséfico comparável, e provavelmente influenciado, a e por outros textos gregos e a narrativas latinas como a Odisseia, os Persas de Ésquilo, a Hécale de Calímaco, as Metamorfoses de Ovídio e, sobretudo, a Farsália de Lucano. Comprova-se assim, uma vez mais, que Flávio Josefo foi notoriamente um homem do seu tempo.
\end{abstract}

Palavras-Chave: Necromancia, Flávio Josefo, Livro de Samuel, Magia helenística.

Aвstract - This essay examines a passage by Flavius Josephus, that of King Saul's visit to the witch of En-Dor $(A J 6,327-339)$, in which the Hellenistic historian paraphrases the biblical text (1 Sam 28: 21-25), but amplifying it considerably. In this amplification, Josephus makes use of his Hellenistic tools and recreates a scene of Necromancy with evident resonances in the surrounding cultures, being Josephus' passage comparable to, and probably influenced by, other Greek texts and Latin narratives as the Odyssey, the Persians by Aeschylus, the Hecale by Callimachus, the Metamorphoses by Ovid and, above all, the Pharsalia or On the Civil War by Lucanus. It is thus proved, once again, that Flavius Josephus was notoriously a man of his time. Key-words: Necromancy, Flavius Josephus, The Book of Samuel, Hellenistic Magic.

No primeiro Livro de Samuel, cuja composição final se deverá a um autor deuteronomista ${ }^{2}$, lemos a narrativa da fundação da monarquia de Israel, na qual a figura de Saul assume um papel axial. De herói aclamado, porém, Saul rapidamente passa a herói rejeitado, entregando o protagonismo a David, que não só virá a ser o segundo rei de Israel, como legitimará, em termos historiográficos, a sua acessão, que assenta num elo familiar com Saul, numa opção divina. O processo da escolha e rejeição de Saul levou, aliás, a que vários autores considerassem estarmos perante uma narrativa de tónica trágica na

\footnotetext{
${ }^{1}$ nonnius@letras.ulisboa.pt

${ }^{2}$ Jones 2001,199. Este estudo é financiado por Fundos Nacionais através da FCT - Fundação para a Ciência e a Tecnologia, I.P., no âmbito dos projectos CH-ULisboa: UIDB/04311/2020 e UIDP/04311/2020; CECH-UC: UIDB/00196/2020; CEC-ULisboa: UIDB/00019/2020 e UIDP/00019/2020.
} 
historiografia de Israel ${ }^{3}$. Este complexo narrativo faz com que os três principais temas de 1 Samuel sejam precisamente a fundação da monarquia com Saul (715), a acessão de David (16-27) e a narrativa da sucessão (28-31), que termina com a rejeição do primeiro rei e a entronização do segundo.

É já no âmbito da última parte desta divisão tripartida, a narrativa da sucessão, que encontramos o episódio da consulta do medium de En-Dor (28,3-25). A aç̧ão, numa perspectiva macro-analítica, enquadra-se na história de David e da luta do jovem contra os Filisteus, mas centra-se na figura do rei ainda em exercício, Saul. Como nota G. H. Jones, de certa forma, o passo funciona como uma interrupção da narrativa central, que pertence a David. Mas é também evidente que este faz parte do ciclo.

Acampado em Guilboa, Saul prepara-se para defrontar os Filisteus que tinham acampado em Chuném $(28,3)$. Mas o rei de Israel está desesperado, pois sente ter perdido o apoio de Javé, sendo que a morte do profeta Samuel parece ter-lhe bloqueado o acesso a Deus. $\mathrm{O}$ autor do texto relembra que, tempos antes, Saul havia expulsado do território todos os que praticavam a adivinhação e a invocação dos mortos $(28,3)$, o que aliás estava de acordo com a Lei (cf. Lv 19,$31 ; 20,6.27 ;$ Dt 18,11). Este alerta implica a ideia de que o acto que Saul está prestes a cometer é particularmente condenável por parte do Deus de Israel, o que servirá de motivo acrescido para rejeitar o rei e legitimar a acessão de David. Com efeito, perante o silêncio de Deus, Saul decide enveredar por um dos caminhos proibidos por Javé: a necromancia. Esta má decisão, todavia, não deixa de ser paradoxal, pois é através desse mesmo meio que o rei pretende conhecer a vontade de Deus.

Por conseguinte, a decisão de Saul consultar o medium em En-Dor revela-se uma transgressão das suas próprias leis. O texto bíblico regista que Saul «disfarçou-se, mudou de roupa, e pôs-se a caminho com dois homens» $(28,8)$, chegando de noite à casa da mulher. O cenário nocturno faz parte da composição narrativa cujo objectivo é também criar um ambiente tenebroso, concordante com a acção que ali se vai praticar. Por outro lado, como nota R. P. Gordon, o disfarce poderá estar mais relacionado com a necessidade de passar pelo acampamento filisteu a caminho de En-Dor, que se localizava a nordeste de Chuném, do que propriamente com uma intenção de passar incógnito na visita à mulher ${ }^{5}$. Mas há que não olvidar que o acto de se despojar das vestes reais durante todo este processo poderá ser igualmente metafórico, tanto porque representa o fim do reinado de Saul ${ }^{6}$, como também pelo facto de separar o acto da consulta necromântica da instituição realeza. De qualquer modo, o disfarce

\footnotetext{
${ }^{3}$ Rodrigues 1996-1997, 89122.

${ }^{4}$ Jones 2001, 213.

${ }^{5}$ Gordon 1986.

${ }^{6}$ Como assinala Edelman 1991, 242-243.
} 
é eficaz e a mulher começa por não reconhecer o rei, o que também motiva a personagem a relembrar uma vez mais, e como tal a reforçar, que havia sido o próprio Saul a proibir a necromancia em Israel $(28,9)^{7}$.

O medium invoca o espírito de Samuel e no momento em que este se manifesta, subindo da terra, pois havia entre os Hebreus a convicção de que os mortos estavam encerrados no Cheol, a mulher acaba por reconhecer também quem é o homem que lhe encomendou a invocação. Segue-se uma descrição da consulta necromântica, em que o espírito de Samuel pergunta a Saul a razão por que o rei perturbou o repouso do profeta. Saul dizlhe que o chamou porque, estando numa "grande angústia» porque os Filisteus o atacavam e Deus se havia afastado dele, necessitava de orientação para agir. Daí a razão por que recorria ao espírito do profeta já morto $(28,15)$. Samuel confirma a Saul o afastamento de Javé, prenunciando igualmente não só a derrota de Israel como a morte do rei e dos próprios filhos. Saul fica estarrecido e desfalece $(28,17-18)$, o que leva o medium a manifestar a sua hospitalidade, alimentando o rei, que não havia comido em todo o dia. A mulher mata um bezerro cevado que tinha em casa, amassa e coze pão, servindo a refeição a Saul e aos seus homens. Depois da refeição, a comitiva régia parte, sendo ainda noite $(28,21-25)$.

Esta é, em síntese, a narrativa da consulta do medium de En-Dor pelo rei de Israel. O objectivo da narrativa é claro: apresentar Saul como desobediente a Deus, na sequência de outras transgressões, e totalmente afastado de Javé por recorrer à necromancia. A cena em causa confirma a anatematização do rei, que se materializa com a vitória dos Filisteus, o suicídio de Saul e a morte da própria família real às mãos do inimigo ${ }^{8}$.

Como não podia deixar de ser, o episódio da necromancia em En-Dor faz parte da paráfrase bíblica escrita por Flávio Josefo em grego no século I d.C. Uma vez que a cena contém elementos essenciais para caracterizar Saul como um rei maldito e rejeitado, ela não poderia deixar de estar presente na reescrita joséfica da narrativa. Mas, como veremos, houve razões suplementares para o historiador judeu o ter feito e da forma como o fez.

Como é hábito de Josefo, a narrativa bíblica em torno de Saul é consideravelmente amplificada, traduzindo já uma fórmula de hermenêutica feita pari passu, de acordo com a cadência da escrita do próprio texto ${ }^{9}$. $\mathrm{O}$ episódio do medium de En-Dor não é excepção. As palavras de Josefo entre os capítulos 327 e 339 do livro VI das Antiguidades Judaicas são mais uma confirmação desta norma do historiador. Aí, lemos acerca da consulta à mulher de En-Dor, sendo que o historiador redige o seu texto levando em conta as várias informações que

\footnotetext{
${ }^{7}$ Sobre os problemas filológicos do passo em causa, ver Jones 2001, 213.

${ }^{8}$ Jones 2001, 213; cf. 1Sm 31.

${ }^{9}$ Sobre esta questão ver Rodrigues 2000; Feldman 1982.
} 
deverão ter sido lidas no texto bíblico original. No essencial, todas as referências presentes na versão hebraica são repetidas ou incluídas na leitura de Josefo, não se verificando omissões significativas. Em contrapartida, há elementos novos no texto grego, que são de destacar pela sua pertinência e pelo valor que traduzem relativamente à originalidade do trabalho de Flávio Josefo.

Em primeiro lugar, ao usar esta terminologia, o historiador helenístico integra o medium no grupo dos engastrimythoi, termo normalmente traduzido por «ventríloquo» e que traduzia a ideia daquele que transmitia oráculos ou fazia previsões falando pelo ventre, e no dos tethnekoton psykhas ekkaloumenoi («evocadores das almas dos mortos», 6.329). Estas expressões gregas pretendem traduzir a ideia de «aquele que invoca os espíritos dos mortos», que se encontra em $1 \mathrm{Sm}$ 28,7. Pela descrição de Josefo, facilmente percebemos que o historiador tem a preocupação de fornecer informação adicional que funciona já como exegese do texto bíblico, associando o medium ao ventriloquismo. Esta seria, por certo, uma técnica reconhecida no meio cultural em que Josefo escreve e que estava necessariamente ligada à esfera da magia e do paranormal. Não podemos excluir, porém, a hipótese de a classificação joséfica remeter para um tipo de prática eventualmente considerada charlatanismo, visto que a capacidade de falar sem mover os lábios, fazendo com que o som saísse do diafragma e do estômago, facilmente poderia remeter para uma técnica que pretenderia iludir o interlocutor do técnico de adivinhação, ao criar a sensação de existir uma terceira entidade a proferir sons. Por outro lado, há que considerar que esse tipo de prática tinha eco no que os Gregos chamavam de entheos, «inspirado pelos deuses», ou enthousiasmos, «estar inspirado pela divindade», «estar fora de si» ou «estar possuído por uma inspiração profética». Este contexto teria naturalmente um impacte significativo, ao nível das ressonâncias culturais, nas audiências de Josefo. Por conseguinte, a escolha das palavras para descrever o episódio da mulher de En-Dor dificilmente terá sido aleatória ${ }^{10}$. $\mathrm{Na}$ sequência das reflexões de Dodds, salientamos que um comportamento como o do medium bíblico configura um acto de espiritismo, um tipo de prática mágico-religiosa que se compreende melhor no período helenístico, depois de "pitagóricos e estóicos terem trazido os mortos para mais perto dos vivos, transferindo a localização do Hades para o $\operatorname{ar}^{\aleph^{11}}$. Ainda assim, há que não esquecer que Josefo segue a indicação bíblica de que o espírito de Samuel teria subido do Hades (anago ex aidou, 6.332), o que parece corresponder à tradição hebraica de localizar o Cheol no nível infernal.

Assinale-se também o facto de Josefo se referir ao medium como uma «mulherzinha» (gynaion, 6.330) ou uma «mulherzinha que era ventríloqua e

\footnotetext{
${ }^{10}$ Rodrigues 2000, 163-164.

${ }^{11}$ Dodds 1988, 124.
} 
evocadora de almas de mortos» (6.329), que fazia da sua profissão a evocação de almas dos mortos. Note-se que, em parte alguma, Josefo formula qualquer tipo de juízo negativo acerca da actividade da mulher, apesar de ela se integrar numa classe profissional que havia sido interditada pelo rei de Israel, na sequência da política assente nas normas do javeísmo, tal como explícito em Lv 19,31; 20,6.27 e Dt 18,11 12 . Antes pelo contrário. Ao usar o termo gynaion, o historiador referese à mulher com um sentido afectivo. Esta postura do historiador parecenos pertinente e consideramo-la justificável apenas no quadro cultural helenístico em que Josefo se insere. Não significa isso que Josefo aprovasse a necromancia, mas tão-somente que se abstém de formular juízos de valor sobre ela, eventualmente pela importância que ela teria na sociedade do seu tempo.

Com efeito, a forma como o historiador se lhe refere cria um retrato claramente positivo do medium. Consideramos que essa caracterização se faz com recurso a três aspectos. Em primeiro lugar, a mulher começa por reagir mal à solicitação de Saul, começando por recusar o pedido do rei disfarçado. $\mathrm{Na}$ verdade, esta atitude está de acordo com a lei promulgada pelo próprio rei, o que faz da mulher uma respeitadora das normas de Israel. Ela acusa mesmo o rei de querer montar uma emboscada para que ela nela caia e assim seja punida, de acordo com a legislação em vigor (6.331). Mas o desespero de Saul leva-o a convencer o medium, que também no texto joséfico acaba por fazer a invocação, chamando o espírito «do Hades» (ex aidou, 6.332). O recurso a esta expressão traduz uma necessária helenização do episódio que faz coincidir o Cheol hebraico com o Hades grego. Josefo é aqui bem mais explícito do que o texto bíblico, o que é produto da sua tradicional exegese, e atribui à invocação do espírito de Samuel a revelação que leva a mulher a reconhecer Saul como o rei de Israel (cf. 1Sm 28,12-13).

Os dois outros elementos que permitem uma caracterização francamente positiva da mulher de En-Dor são o comportamento hospitaleiro do medium para com o rei e a laudatio assumida que o historiador acaba por fazer da personagem. Em relação a este primeiro tópico, Josefo retoma o que lemos no texto de 1 Samuel e reforça a ideia de que, perante o desfalecimento do rei quando fica a par das más notícias, a mulher não hesita em oferecer-lhe, e aos seus acompanhantes, uma refeição constituída por um carneiro que mantinha em sua casa. Josefo enfatiza mesmo a ideia de que teria sido inclusive a mulher a "pagar» a visita de Saul ao oferecer-lhe o único animal de criação que possuía e a quem se tinha afeiçoado em particular (6.339). Além disso, Josefo destaca a condição de pobreza da mulher que, ainda assim, não hesita em alimentar o seu rei, que a tentara enganar, com

${ }^{12}$ É pertinente que em 3.224-286 e 4.199-301, passos em que Josefo sistematiza a maioria das normas que lemos no Levítico e no Deuteronómio, não consta qualquer referência a esta norma do espiritismo. 
o pouco que tinha. Em relação ao segundo tópico, podemos lê-lo nos capítulos 340 a 342 do livro VI das Antiguidades, e ele constitui o verdadeiro ineditismo de Josefo na paráfrase que faz do episódio. Com efeito, nestes dois capítulos, o historiador tece uma série de considerações que funcionam como balanço geral da cena e cujo objectivo é sobretudo o de elogiar o carácter e comportamento do medium, através dos quais a personalidade de Saul sai por contraposto algo diminuída. É o próprio Josefo que considera ser de justiça render homenagem à mulher de En-Dor (dikaion de apodexasthai tes philotimias tem gynaika, 6.340), pois ela, apesar de ter sido proibida de exercer a sua profissão por Saul, não lhe guardou rancor depois de reconhecê-lo, não só não hesitando em ajudá-lo e em alimentá-lo, como ainda oferecendo-lhe o único bem alimentício que possuía. A mulher de En-Dor revela-se assim uma exímia hospitaleira, bem ao gosto do contexto cultural mediterrâneo, seja ele hebraico ou grego. Mais, sabendo que o destino de Saul estava próximo de se concretizar na morte do rei, não havendo portanto muito a esperar daquele homem, o medium manteve o seu altruísmo e a sua postura de ajuda, não negando a Saul o auxílio de que ele necessitava naquele momento.

Josefo transforma assim a mulher de En-Dor num exemplo a ser seguido, abstendo-se de juízos negativos quanto à sua profissão e admitindo mesmo, como se deduz pelas suas palavras, a validade das informações obtidas através do exercício da necromancia. Com a frase «é suficiente o que se disse sobre esta mulher» (6.342), Flávio Josefo rotula definitivamente o medium de En-Dor como um paradigma ético e de comportamento.

Mas porque fazê-lo, se a Lei de Israel condenava ferozmente as práticas mágicas em geral e necromânticas em particular?

Como assinalámos, é no quadro cultural helenístico que devemos procurar as razões do encómio joséfico da mulher de En-Dor e a quase neutralização do episódio da necromancia nesta paráfrase grega da Bíblia. Com efeito, o gosto helenístico parece favorecer ambientes que poderíamos classificar de «góticos vanguardistas», que no entanto encontra raízes em textos ainda do período clássico, senão mesmo arcaico ${ }^{13}$. Recordamos que, na Odisseia, a catábase de Ulisses é já feita de um ambiente essencialmente necromântico, do qual se destaca a figura da alma de Tirésias (11.90-151) e na Ilíada o aparecimento do fantasma de Pátroclo a Aquiles é um dos momentos altos do poema (23.59-101). Esta, porém, não é estritamente uma cena necromântica, pois não há propriamente uma evocação do defunto, que aparece a Aquiles em sonho, e, apesar de haver uma profecia do futuro, o objectivo do espectro de Pátroclo é pedir a Aquiles que lhe dê uma sepultura condigna para que a alma possa repousar junto dos restantes mortos.

\footnotetext{
${ }^{13}$ Cf. Bremmer 2015.
} 
De facto, é em Ésquilo que encontramos a primeira grande cena necromântica da literatura grega, essencial à estrutura narrativa de Os Persas. Nesta peça, o espectro ${ }^{14}$ do rei persa Dario aparece em cena na sequência de um chamamento feito pelo coro de anciãos persas, causando um efeito cénico particularmente eficaz (vv. 626-841) ${ }^{15}$. A associação da necromancia aos Persas, povo oriental, é particularmente pertinente, pois vincula o ritual a um universo bárbaro e estrangeiro e, por conseguinte, neste contexto, culturalmente negativo ${ }^{16}$. Da mesma época, data o texto de Heródoto, em que se narra a história de Periandro, tirano de Corinto, que, apesar de ter conduzido a cidade à prosperidade, teria assassinado a própria mulher, Melissa, e terseia unido ao corpo dela num acto de necrofilia $(3.50$; 5.92). Mas Periandro teria também ficado conhecido por ter enviado mensageiros ao nekyomanteion do Aqueronte, com o objectivo de invocarem o espectro de Melissa, para que ele lhes revelasse onde estava um dinheiro que lhe fora confiado por um hóspede. O fantasma de Melissa fornece a informação requerida, mas só depois de exigir um ritual que o marido leva a efeito. Para entendermos a pertinência deste episódio em Heródoto, há que ter em conta que o Aqueronte era um rio que se localizava no Epiro e cujo curso incluía partes pantanosas e partes subterrâneas, acabando por entrar numa garganta que lhe conferia um aspecto sinistro. Por estas razões, o rio foi entendido pelos Gregos como uma das vias de acesso aos Infernos e por isso também ter-se-ia considerado o lugar um espaço sagrado de consulta dos mortos, um nekyomanteion. Mas, como nota C. L. Soares, a prática da necromancia teria entrado na esfera da magia e da feitiçaria ou «simples bruxaria», por ficar à margem da lei das poleis gregas ${ }^{17}$.

Já no século III a.C., o alexandrino Calímaco compôs um epílio, uma espécie de epopeia curta que fez escola durante o período helenístico, chamado Hécale. Trata-se de um texto que nos chegou apenas sob a forma de fragmentos. O tema de base do poema seriam as aventuras do herói ático Teseu, em particular o combate contra o touro de Maratona. Aparentemente, durante a viagem em demanda do animal, Teseu teria sido surpreendido por uma tempestade que o teria obrigado a refugiar-se na casa de uma anciã de nome Hécale (Call. Hec. frgs. 238-257). Apesar de pobre e detentora de parcos recursos, a velha recebia Teseu da forma mais hospitaleira possível, oferecendo-lhe o que de melhor possuiria

${ }^{14} \mathrm{O}$ inventário dos termos greco-latinos utilizados para referir os mortos retornados ao mundo dos vivos foi feito por Ogden 2001, 219-221. Neste estudo, não tivemos a preocupação de estabelecer as várias diferenças, uma vez que é a estrutura da cena de ambiente necromântico que nos interessa analisar e enquadrar. Recorremos assim de forma quase aleatória a termos como «alma», «espírito», «espectro» ou «fantasma». Mas estamos conscientes das especificidades e diferenças inerentes a cada conceito utilizado pelos autores e documentos antigos.

${ }^{15}$ Cf. Bremmen 2015, 123-124.

${ }^{16}$ Cf. Ogden 2001, 95-96.

${ }^{17}$ Silva, Soares 2007, 136, n. 280; ver Ogden 2001, 43-60; Bremmen 2015. 
e teria inclusive prometido sacrifícios a Zeus, a quem teria oferecido o único animal em sua posse (Call. Hec. frgs. 252). Teseu teria ficado particularmente bem impressionado com a atitude hospitaleira da velha e, uma vez regressado vitorioso da luta contra o touro, procura a velha, mas fica a saber que ela já morreu. Teseu chorava então a morte da mulher e, em sua honra, teria dado o nome «Hécale» ao demo recém-fundado, ao mesmo tempo que dedica um templo a Zeus Hecálio, celebrado nas festas conhecidas como Hecalésias (cf. Plu. Thes. 14) ${ }^{18}$.

É evidente, pelo desenrolar do poema, que esta criação de Calímaco funcionaria como aition ou poema etiológico, para a designação do demo ático. Mas o texto integrava também uma série de características típicas do alexandrinismo, como o foco colocado sobre um episódio determinado do ciclo de Teseu, a visita à velha senhora que dá o título à composição, deixando outros momentos, como o combate contra o touro, à margem. O tema terá sido recolhido na tradição atidográfica ${ }^{19}$, eventualmente na obra de Filócoro de Atenas, também referido por Plutarco na biografia que dedicou ao rei ateniense (Thes. 14).

Parece-nos significativo que a composição de Calímaco seja coeva da mais antiga tradução conhecida dos textos da Bíblia hebraica para grego: os Setenta. Essa tarefa terá sido realizada em Alexandria, sob o reinado de Ptolemeu II Filadelfo (283-246 a.C.), i.e., precisamente no tempo de Calímaco. Por conseguinte, parece-nos verosímil que haja na criação do poeta grego uma eventual, ou pelo menos possível, influência do tema do I Livro de Samuel. Parece-nos que uma possível intertextualidade dessa natureza não é de todo inverosímil. De igual modo, é teoricamente possível que o poema de Calímaco fosse conhecido de Josefo e que o historiador judeu tivesse acabado por ser influenciado por essa versão da história, a qual, por usa vez, talvez radique no tema judaico. Se assim for, estaremos perante uma rede de intertextualidades, cujas origens se perdem num emaranhado de fios interconectados, que só um período culturalmente riquíssimo como o helenístico poderá explicar.

Os exemplos citados são anteriores a Josefo e, apesar de, nos primeiros casos, dificilmente os podermos considerar influências directas no relato joséfico dada a fonte bíblica em que este assenta, não nos parece inverosímil que o historiador do século I tivesse conhecimento deles e os tivesse em conta no momento da redacção grega do episódio de En-Dor. Como assinalámos, porém, já o caso de Calímaco parece-nos particularmente expressivo de uma eventual intertextualidade. Com efeito, será de salientar que os episódios de necromancia

${ }^{18}$ Ver Lesky 1995, 754; Hollis 2009; Montes Cala 1987. Agradecemos ao peer reviewer anónimo que nos sugeriu este exemplo, o qual nos parece da maior pertinência para o estudo que aqui apresentamos. As afinidades com a Hécale de Calímaco estão, sobretudo, ao nível do tema da hospitalidade, não tanto do da necromancia, evidentemente.

${ }^{19}$ Lesky 1995, 755. 
referidos nos casos de Homero, de Ésquilo e de Heródoto são associados a personagens ou situações de certo modo negativas, o que está de acordo com a situação da consulta necromântica do Saul bíblico. O mesmo não se passa com o exemplo de Calímaco, mais próximo do Saul joséfico. Mais estranha fica assim a ausência de comentários negativos à actividade em si mesma por parte de Josefo, o que se poderá explicar por uma necessidade e manutenção de neutralidade do acto em si mesmo, dada a sua frequente presença em textos greco-latinos anteriores e coevos de Josefo, mas dado sobretudo o gosto helenístico pelo tema.

As mesmas características podem ser associadas a textos do tempo de Josefo ou pouco anteriores a ele. Desde logo, Ovídio parece recuperar o tema tratado por Calímaco na Hécale na versão que apresenta de Báucis e Filémon. Com efeito, o tema de base desse episódio não andava distante da cena de hospitalidade no poema alexandrino e, por essa razão, do episódio bíblico depois tratado por Josefo (Ov. Met. 8.631-724) ${ }^{20}$. Mas neste poeta romano há, segundo nos parece, um outro episódio que não só confirma o gosto helenístico-romano pelo tema da velhinha hospitaleira e generosa, como poderá ter também influenciado Josefo. Desta vez, a história vem tratada não nas Metamorfoses, mas sim nos Fastos. Trata-se também de uma etiologia para uma festa, agora romana. Trata-se da referência a Ana de Bovila, identificada com a antiga figura e culto de Ana Perena, e apresentada por Ovídio como uma velha pobre mas industriosa, que em tempos de carestia, designadamente durante a secessão do Monte Sagrado, teria confeccionado e distribuído pão pela plebe (Ov. Fast. 3.661-674). O tratamento do tema parece radicar em Calímaco e, apesar de Ovídio não referir que Ana tivesse recebido fosse quem fosse na sua casa, há entre ela e Hécale tópicos comuns como a velhice da personagem, o altruísmo e a generosidade ${ }^{21}$ que podemos ler também na versão joséfica da vidente de En-Dor. A história de Ovídio, tal como a de Calímaco, é etiológica, frisando-se a sua função memorialística através de festas e cultos instituídos. Evidentemente, esse aspecto está igualmente ausente da narrativa e personagens joséficas, até porque a base textual do historiador judeu não tinha essa perspectiva. Mas o encómio que lhe é feito no livro VI das Antiguidades vai, de certo modo, ao encontro do espírito que lemos nos textos de Calímaco e de Ovídio.

Já especificamente relacionado com o tema da necromancia ou da evocação dos mortos, na Eneida, o aparecimento do fantasma de Creúsa a Eneias desempenha um papel importante na economia do poema ao profetizar sobre o destino do herói (2.764-799)22. Mas já Cícero acusava Vatínio de evocar as almas de mortos e de ter o hábito de sacrificar entranhas de rapazes aos deuses Manes

\footnotetext{
${ }^{20}$ Sobre eventuais influências de Ovídio em Josefo, ver Gossmann 1989.

${ }^{21}$ Harrison 1993.

${ }^{22} \mathrm{Na}$ comédia Mostellaria de Plauto, cujo enredo gira em torno precisamente de um fantasma, o tema da aparição tinha já um protagonismo assinalável.
} 
(Vat. 14). Também Tácito refere um jovem que, no tempo de Tibério, tentava trazer os mortos do mundo infernal através de artes mágicas (Ann. 2.28).

Igualmente assinalável entre todos esses textos e episódios é sem dúvida a Farsália de Lucano. Na epopeia do sobrinho de Séneca, encontramos uma das mais patéticas e macabras cenas da poesia latina: a nekyomanteia. Trata-se do momento em que, no livro VI, Sexto Pompeio decide consultar um soldado caído em batalha com o objectivo de saber o resultado final do confronto bélico (6.413-830). Como foi já notado por diversos autores, este episódio, justamente um dos mais célebres da obra de Lucano, «emula a famosa descida aos Infernos de Eneias no livro VI do poema virgiliano.» ${ }^{23}$ Com efeito, a localização do episódio no poema não é casual, sendo por certo eco da centralidade que o poeta pretendia dar à cena. Por outro lado, o soldado que a feiticeira Ericto faz ascender dos infernos «proporciona um quadro dos Infernos que inverte até aos mais ínfimos pormenores o Inferno pintado pela Eneida.» ${ }^{24}$ Além disso, a escolha de Sexto Pompeio para destinatário da profecia que anuncia o desaire da facção pompeiana também não é circunstancial, pois tal como Vergílio relaciona a glória de Roma como a gens Iulia, também Lucano associa a gens Pompeia ao declínio. Sexto Pompeio é assim nesta leitura um anti-Eneias ${ }^{25}$.

O papel desta cena no poema de Lucano é particularmente significativo, dado que na epopeia do período neroniano há uma considerável anulação dos elementos divinos que se revelavam essenciais na tradição épica, de que Vergílio é reflexo privilegiado. Assim, no poema de Lucano predomina um tom racionalista que se revela na apresentação das causas da guerra civil em Roma, por exemplo, ou na explicação das tempestades, que não se devem à ira dos deuses, mas a razões meteorológicas e naturais (cf. 5.504-677) ${ }^{26}$. Esse aparato divino é assim substituído por elementos sobrenaturais, que de forma alguma se revelam incompatíveis com a tentativa de racionalizar a mensagem poética. Até porque, não raramente, esses elementos estão associados aos aspectos negativos do enredo. Note-se, por exemplo, como as profecias da Farsália revelam não as glórias de Roma mas os desaires que a aguardam ${ }^{27}$.

Assim, o «maravilhoso sobrenatural» do poema de Lucano manifesta-se em sonhos, visões, profecias e práticas mágicas, entre as quais se inclui a grande cena da necromancia, protagonizada por Sexto Pompeio e Ericto, a feiticeira da Tessália. A composição da Farsália é por certo anterior à das Antiguidades Judaicas, pelo que, dificilmente poderemos estabelecer uma relação inter-textual entre o poema de Lucano e a historiografia de Josefo, no sentido de aquele poder

\footnotetext{
${ }^{23}$ Citroni 2006, 786.

${ }^{24}$ Citroni 2006, 786.

${ }^{25}$ Citroni 2006, 786.

${ }^{26}$ Holgado Redondo 1984, 44-46.

${ }^{27}$ Citroni 2006, 785.
} 
ter sido inspirado no autor judeu. Mas não deixa de ser pertinente a coincidência do tópico em ambos os textos: um grande general consulta uma necromante com o objectivo de conhecer antecipadamente o desfecho de uma batalha. E em ambos os casos a resposta é negativa e contrária aos desejos do consultante. Em ambos os casos, também, o medium é uma mulher.

Naturalmente, podemos evocar o facto de o tema em Josefo assentar num texto matricial, o primeiro Livro de Samuel, que o historiador helenístico desenvolve consideravelmente. Com base nesta premissa, poderíamos equacionar a possibilidade de Lucano ter usado o tópico bíblico para compor o seu poema, o que não seria de todo impossível, uma vez que os textos bíblicos eram, na ocasião, conhecidos em ambiente greco-latino por difusão da versão dos Setenta ${ }^{28}$. A confirmação ou não desta hipótese é um trabalho que ainda poderá e deverá ser feito. De facto, as afinidades temáticas são muitas. Mas esse trabalho fica para outra ocasião. Entretanto, fica assinalada a comunhão temática e estrutural de ambos os episódios nas suas versões lucana e joséfica. Parece-nos evidente, portanto, que quem conhecesse ambos os textos não deixaria de os relacionar um com o outro ${ }^{29}$, não obstante o facto de a Ericto de Lucano ser uma figura muito mais desenvolvida e bem caracterizada, quer ao nível físico quer ao nível das acções - de que se destacam os actos mágicos -, do que a mulher de En-Dor joséfica, retratada de uma forma bem mais simples e lacónica. Há no entanto um aspecto que podemos destacar: o facto de a feiticeira tessália ser apresentada de uma forma bem mais lúgubre e sinistra do que a necromante bíblica, referida de forma inédita por Josefo como «mulherzinha» (quase «pobre mulher» ou "pequena mulher», gynaion), num claro contraste com o modelo em que assenta.

A caracterização dramática e ao mesmo tempo sombria e medonha de Ericto corresponde, aliás, a mais um gosto da época. Com efeito, nas tragédias de Séneca, que era tio de Lucano, a aparição de espectros e fantasmas é comum, dando corpo ao gosto pelo macabro e aos efeitos medonhos e horripilantes ${ }^{30}$. $\mathrm{Na}$ tragédia Édipo, por exemplo, o fantasma de Laio é evocado como instrumento essencial à revelação do mistério da sua própria morte (vv. 619-658), e em Tiestes (vv. 1-100) aparece o espectro de Tântalo enquanto catalisador das desgraças da casa dos Pelópidas. Na Octavia, obra todavia de um autor desconhecido mas atribuída por alguns a Séneca, o fantasma de Agripina também aparece em cena (vv. 593-646) $)^{31}$.

${ }^{28}$ E.g. Rodrigues 2007, 393-413.

${ }^{29}$ Há no entanto que referir a possibilidade de o episódio de Lucano ter reminiscências de As Rãs de Aristófanes. Sobre esta questão, Collison-Morley 1912, 41; ver ainda Felton 1998; Ogden 2009.

${ }^{30}$ Citroni 2006, 756.

${ }^{31} \mathrm{O}$ tema aparece ainda na Tebaida de Estácio e em Púnica de Sílio Itálico. Quanto a estudos 
Os exemplos poderiam multiplicar-se. Outro texto um pouco posterior a Josefo, a Vida de Címon atribuída a Plutarco, inclui um episódio no qual se narra que Pausânias, o general espartano, teria matado uma jovem bizantina chamada Cleonice por engano. Segundo Plutarco, o fantasma de Cleonice passou a aparecer a Pausânias com regularidade. Em sequência deste acontecimento, Pausânias decidiu recorrer ao oráculo dos mortos em Heracleia e consultar o espírito de Cleonice, que lhe profetizou que os seus males terminariam em breve, desde que ele estivesse em Esparta (Cim. 6). Trata-se, portanto, de mais uma cena necromântica ${ }^{32}$.

A carta sobre os fantasmas escrita por Plínio-o-Moço ao seu amigo Licínio Sura já no século II d.C. é também representativa do gosto por estes temas na época de Josefo. A pergunta que o autor latino coloca logo no início da alegada missiva é sintomática da discussão filosófica e racional que o assunto suscitaria entre as elites intelectuais da época. Com efeito, escreve Plínio: «Gostaria muito de saber se acreditas que os fantasmas existem e se têm forma própria, assim como algum tipo de vontade, ou se, pelo contrário, são sombras vazias e irreais que assumem formas por efeito do nosso próprio medo.» (Ep. 7.27.1). Plínio inclui na epístola uma série de exemplos de narrativas cujo objectivo seria o de atestar a existência de fantasmas, tendo estes, na sua maioria, capacidades prognósticas. Assim acontece com a figura da mulher que aparece a Cúrcio Rufo, com o caso da casa assombrada de Atenas sintomaticamente protagonizado por um filósofo ou com os exemplos do liberto e do escravo do próprio Plínio. Mas é sintomático que o autor não dê uma resposta assertiva à pergunta que coloca ao amigo, deixando o assunto à consideração dos seus destinatários e fazendo crer que o tema era tópico de discussão na sociedade da época sem que fosse totalmente desacreditado inclusive pelas elites sociais e intelectuais. Este contexto deverá explicar também as opções de Josefo na narração da consulta de Saul em En-Dor.

Um dos exemplos referidos na carta de Plínio é muito semelhante à narrativa atribuída a Luciano de Samósata, O Mentiroso ou O Incrédulo. Neste texto do século II d.C., refere-se uma casa assombrada, de onde um filósofo pitagórico de nome Arignoto teria feito sair um espírito, que tinha a capacidade de se metamorfosear. Segundo Luciano, Arignoto teria recorrido a conhecimentos mágicos, assumidamente radicados na cultura egípcia (30-31). Este é apenas um dos textos já posteriores a Josefo que recuperam a temática em análise. Não se trata propriamente de um acto de necromancia, pois não há nem invocação do morto nem profecia ou prognose do futuro, mas o fantasma não deixa de ser o tema central.

sobre esses casos, ver e.g. Reitz 1982 e Parkes 2013.

${ }^{32}$ Histórias de fantasmas ou de mortos que voltam para vaticinar aparecem também nos textos de Plínio-o-Velho, Nat. 7.52, 178; 30.1.16; 30.5. 
Com efeito, no que diz respeito a cenas necromânticas, são sobretudo três os textos, gregos e latinos, já posteriores a Josefo que as referem, confirmando a manutenção do gosto pela temática. Trata-se de O burro de ouro de Apuleio, da Vida de Apolónio de Tíana de Filóstrato e de As Etiópicas de Heliodoro. Como facilmente se percebe, o tema da necromancia parece, neste período, ter passado da poesia e da historiografia, em que estava instalado pelo menos desde os Poemas Homéricos e os Trágicos, para o romance, o que é o mesmo que dizer que passou para a narrativa ficcional, no final do período helenístico. Este factor parece ser sintomático de uma significativa alteração da mentalidade, na qual as histórias de fantasmas e de magia a eles associadas, como é o caso das narrativas com cenas de necromancia, passaram a figurar na galeria da ficção.

No romance de Apuleio, refere-se um adivinho egípcio, de nome Zatclas, que teria a ciência de trazer dos infernos a alma de um defunto. Para o efeito, a personagem coloca ervas sobre a boca e o coração de um falecido e, virado para oriente, invoca o sol na sequência do que o morto ressuscita, regressando do Hades (2.28-30). O objectivo desta necromancia é conhecer os pormenores da morte do retornado. Os espectadores ficam a saber que o homem morreu na sequência de «malas-artes» da esposa, tendo sido vítima de uma bebida envenenada. Mas ficam também a conhecer as acções de velhas feiticeiras, que teriam a capacidade de invocar os mortos, chamando-os pelo nome, ao ponto de «articulações entravadas e gélidos membros começarem a ensaiar morosos esforços para obedecer aos comandos da sua arte mágica.» (2.30).

$\mathrm{Na}$ narrativa de Filóstrato, biografia novelesca de um mago pitagórico chamado Apolónio, este invoca o espírito de Aquiles, recorrendo a uma oração que é comparada às fórmulas utilizadas pelos Indianos (4.16). $\mathrm{O}$ fantasma de Aquiles fala sobre a necessidade de manter os rituais fúnebres entre os Gregos, avisando acerca das contrapartidas de não o fazerem, mas responde também a curiosidades sobre a Guerra de Tróia. Trata-se, portanto, de uma cena necromântica que, no essencial, segue os tópicos estipulados desde os primeiros textos.

A última sequência pertence ao romance de Heliodoro. No livro VI, a heroína do romance assiste escondida a um ritual necromântico levado a cabo por uma feiticeira. Trata-se da mãe de um soldado morto que evoca a alma do filho, com ritos mágicos operados sobre o cadáver, uma cena «conhecida dos Egípcios», como nota o autor (6.14.1-5). O ritual, efectuado ao luar, é descrito com algum pormenor no texto de Heliodoro. A velha mãe coloca perguntas ao espectro do filho, às quais ele vai respondendo. Uma das perguntas tem que ver com a necessidade de saber se outro dos seus filhos regressará ou não são e salvo a casa. O filho morto, parecendo ter saído das profundezas da terra ou de uma caverna, começa por anuir apenas com a cabeça, mas acaba por falar, acusando a mãe de agir com recurso a sortilégios e de o forçar a fazer aquilo que ele considera ímpio. Em consequência disso, o defunto profetiza sobre o final infeliz do irmão e sobre a morte cruel da própria mãe (6.14.5-6; 15.1-3). Com 
estas palavras, Heliodoro rotula de forma negativa a prática necromântica, o que, todavia, não anula a percepção de que se trataria de um tema do agrado das audiências de então ${ }^{33}$.

A crença de que era possível evocar as almas dos mortos através de fórmulas mágicas e de com isso entrar em contacto com eles com o objectivo de obter informações privilegiadas sobre o passado, o presente ou o futuro parece ter sido universal na Antiguidade. Por consequência, também a consulta de mortos deverá ter sido bastante comum. Na Grécia, Platão refere-se a esse processo nas Leis (10.909b) e, em Roma, é Cícero quem dá conta da importância de tais actos no tratado sobre a adivinhação (Div. 1.56). Isso mostra que o tema era actual e interessante para Gregos e Romanos, pelo que, quando Josefo parafraseia em grego o capítulo 28 do Livro de Samuel, ele está a recontar um episódio com o qual se estabelecia um significativo diálogo intercultural, do maior interesse para os Judeus do século I.

Não deixa de ser curiosa, porém, a forma como o historiador helenístico reformula o episódio de En-Dor. É um facto que ele não adultera o final da sequência, integrando nela os principais tópicos tratados no texto bíblico, designadamente a decisão do rei em recorrer a uma actividade que ele próprio havia interditado do território em obediência às normas javeístas, a resistência do medium em aceder ao pedido, a evocação do profeta morto, a revelação do futuro e a hospitalidade da mulher. Mas Josefo acrescenta um encómio com o qual pretende elogiar a atitude da anfitriã de Saul, mitigando os eventuais aspectos negativos que adviriam da actividade a que ela se dedicava. Com efeito, parte dessa negatividade fica pendente sobre o próprio rei, como confirmam o suicídio e a morte dos filhos na batalha que não tardará a acontecer. Desse encómio faz parte, claro, o elogio da hospitalidade que faz da mulher de En-Dor um paradigma de xenia.

Será ainda de notar que a forma como Josefo se refere ao medium permite aproximá-lo das figuras greco-romanas da pitonisa ou da sibila, as quais não tinham necessariamente uma conotação negativa. Note-se como a descrição joséfica da mulher é omissa relativamente às técnicas ou métodos de invocar o morto e de trazê-lo de volta ao contacto com os vivos. Lucano, Apuleio e Heliodoro, por exemplo, são particularmente ricos nessas descrições. Josefo opta pelo silêncio. Talvez essa escolha se relacione com o facto de, na tradição bíblica, a magia e a feitiçaria serem fortemente condenadas (ver Le 19,26; Dt 18,9-14). Agindo deste modo, Josefo poderia agradar a duas audiências: ao omitir pormenores relativos a sortilégios e práticas mágicas que seriam de pouco agrado para o seu público judaico, o historiador neutralizava o tema convergindo com os interesses desse público; mas, por outro lado, não deixava

\footnotetext{
${ }^{33}$ Sobre este episódio, ver Pinheiro 1991.
} 
de dar importância e amplificar o episódio, de modo a ir ao encontro do gosto helenístico do seu tempo e de uma audiência helenizada. Isto, não obstante, a maioria das feiticeiras descritas na literatura greco-latina serem personagens negativas e não positivas, como o encómio do historiador sugere para a mulher de En-Dor. Mas talvez esse encómio tenha sido precisamente a forma de amplificar o episódio e de lhe conferir uma importância maior do que a que ele tinha no texto hebraico original. Além disso, o elogio da mulher permitia salientar a característica feminina do medium, o que não era assunto displicente em contexto greco-romano. Como notou D. Ogden, nas fontes mais antigas, os media que interagiram com os defuntos eram sobretudo homens. No período helenístico, eles tornaram-se essencialmente mulheres, qual forma de os minorar em termos sociais e religiosos ${ }^{34}$. Originalmente, o medium da história de Saul era já uma mulher. O seu encómio permitira frisar esse aspecto, independentemente da conotação que ele tivesse entre Gregos e Romanos. O importante seria integrar a cena da vida de Saul nesse contexto e ambiente cultural ${ }^{35}$.

Como é evidente, este conjunto de características encontrava eco significativo numa audiência greco-romana. Tal como acontece, aliás, com todo o episódio. Como demonstrámos, não são poucas as cenas ou episódios literários, desde os Poemas Homéricos antes de Josefo, aos romances greco-latinos posteriores ao historiador, passando pela literatura sua coeva que permitem um enquadramento e um melhor entendimento do valor da cena da necromancia em En-Dor, no conjunto global da obra joséfica. Mais a mais, a associação deste tipo de práticas a correntes culturais orientais, como é frequentemente perceptível nos textos greco-romanos - especificamente ao Egipto, mas também à Pérsia e à Babilónia - contribuiria para um entendimento e uma recepção ainda mais eficaz do episódio entre os leitores/auditores de Josefo.

\footnotetext{
${ }^{34}$ Ogden 2001, 95-96.

35 Sobre o contexto do tema em geral, Bremmer 2015.
} 


\section{Bibliografia:}

Bremmer, J. 2015. "Ancient Necromancy: Fact or Fiction?» in K. Bielawski ed., Mantic Perspectives: Oracles, Prophecy and Performance, Gardzienice/ Lublin/Warszawa, Osrodek Praktyk Teatralnych «Gardzienice», , 119141.

Citroni, M. et al. 2006. Literatura de Roma Antiga, Lisboa, Fundação Calouste Gulbenkian.

Collison-Morley, L. 1912. Greek and Roman Ghost Stories, Oxford, B. H. Blackwell.

Dodds, E. R. 1988. Os Gregos e o Irracional, Lisboa, Gradiva.

Edelman, D. V. 1991. King Saul in the Historiography of Judah, Sheffield, Academic Press.

Feldman, L. H. 1982. «Josephus' Portrait of Saul», HUCA 53, 45-99.

Felton, D. 1998. Haunted Greece and Rome; Ghost Stories from Classical Antiquity, Austin, University of Texas Press.

Gordon, R. P. 1986. I E II Samuel: A Commentary, Grand Rapids, Mich., Zondervan.

Gossmann, H.-C. 1989. «Die Möglichkeit der literarischen Abhängigkeit des Josephus von Ovid: Dargestellt am Beispiel der Sintfluterzählung», Zeitschrift für Religions- und Geistesgeschichte 41/1, 83-86.

Harrison, S. J. 1993. «A Roman Hecale: Ovid, Fasti 3.661-74», CQ 43/2, 455457.

Holgado Redondo, A. 1984. Lucano. Farsalia, Madrid, Editorial Gredos.

Hollis, A. S. 22009. Callimachus Hecale, Oxford, Oxford University Press.

Jones, G. H. 2001. «1 and 2 Samuel» in J. Barton, J. Muddiman, eds., The Oxford Bible Commentary, Oxford, University Press.

Lesky, A. 1995. História da Literatura Grega, Lisboa, Fundação Calouste Gulbenkian.

Montes Cala, J. G. 1987. Calimaco. Hécale, Cadiz, Universidad de Cadiz. Servicio de Publicaciones.

Ogden, D. 2001. Greek and Roman Necromancy, Princeton/Oxford, Princeton University Press.

Ogden, D. 2009. Magic, Witchcraft and Ghosts in the Greek and Roman Worlds: a Sourcebook, Oxford, Oxford University Press.

Parkes, R. 2013. «Chthonic Ingredients and Thematic Concerns: the Shaping of the Necromancy in the Thebaid» in A. Augustakis ed., Religion and Ritual in Flavian Epic, Oxford, Oxford University Press, 165-180. 
Pinheiro, M. F. 1991. «Fonctions du surnaturel dans les Éthiopiques d'Héliodore», BAGB 4, 359-381.

Reitz, C. 1982. Die Nekyia in den Punica des Silius Italicus, Frankfurt-am-Main/ Bern, Peter Lang, .

Rodrigues, N. S. 1996-1997. «Saul Rei: personagem trágica na historiografia de Israel», Cadmo 6/7, 89122.

Rodrigues, N. S. 2007. Iudaei in Vrbe. Os Judeus em Roma do tempo de Pompeio ao tempo dos Flávios, Lisboa, Fundação Calouste Gulbenkian/Fundação para a Ciência e a Tecnologia, .

Rodrigues, N. S. 2000. O Rei Saul segundo Flávio Josefo, Lisboa, Edições Colibri.

Silva, M. F. S., Soares, C. L. 2007. Heródoto. Histórias, Livro V, Lisboa, Edições 70, . 
(Página deixada propositadamente em branco) 


\title{
O SAGRADO CORAÇÃO: \\ IDENTIDADE E MAGIA NO ANTIGO EGIPTO (The sacred heart: identity and magic in Ancient Egypt)
}

\author{
Rogério Sousa \\ Centro de Estudos Clássicos e Humanísticos da Universidade de Coimbra \\ (solar.benu@gmail.com)
}

\begin{abstract}
Resumo - O amuleto do coração é um dos objectos apotropaicos mais frequentemente encontrados nos enterramentos egípcios. Neste artigo apresentamos as ideias, símbolos e conceitos sobre o coração que se manifestam na cultura material com o intuito de proporcionar instrumentos mágicos capazes de atingir determinados objectivos rituais. Iremos focar a nossa análise nos símbolos e na iconografia do coração, tomando-os como a expressão material das antigas representações sobre a mente e a consciência, bem como o papel que desempenhavam nos rituais mágicos, quer estes se aplicassem à vida terrena ou ao Além.
\end{abstract}

Palavras-Chave: amuleto do coração, cultura material funerária egípcia, ritual

Aвstract - The heart amulet is one of the apotropaic objects most frequently found in Egyptian burials. In this article, we present the ideas, symbols and concepts about the heart that manifest themselves in the material culture in order to provide magical instruments capable of achieving certain ritual objectives. We will focus our analysis on the symbols and the iconography of the heart, taking them as the material expression of the old representations on the mind and consciousness, as well as the role they played in the magical rituals, whether these applied to earthly life or to the Beyond .

KEY words: heart amulet, Egyptian funerary material culture, ritual

O estudo das representações do coração nas fontes literárias egípcias tem demonstrado a forte associação desta noção com o conceito de maat, a ordem cósmica ${ }^{1}$. Jan Assmann, em particular, traçou os principais estádios de evolução da noção de coração, demonstrando como esta evoluiu das representações deste órgão como sede da vida e da sabedoria para uma visão mais transcendente do coração entendido como o templo interior onde o deus supremo se revela intimamente a cada indivíduo. No contexto dos textos sapienciais e religiosos, o coração desempenha um papel crucial como guia, encerrando em si o segredo para o sucesso e a felicidade ${ }^{2}$.

Deste modo, o discurso sobre o coração no antigo Egipto tem uma história e uma cronologia próprias e detecta-se no contexto das autobiografias, textos

\footnotetext{
${ }^{1}$ Estudo desenvolvido no âmbito do projeto UID/ELT/00196/2013, financiado pela FCT - Fundação para a Ciência e Tecnologia.

${ }^{2}$ Assmann, 1984:12.
} 
sapienciais e hinos religiosos. A evolução traçada por Jan Assmann na sua “Teoria do Coração" é um fenómeno tipicamente derivado do contexto da teologia explícita, isto é, dos textos que problematizam a unidade de deus, a teodiceia e a especulação sobre a ordem cósmica.

No nosso estudo procurámos traçar a caracterização do coração a partir das fontes emanadas da cultura material egípcia. A focagem da nossa análise em objectos mágicos e rituais - amuletos do coração e suas representações - levounos a traçar um retrato distinto, mas ainda assim complementar, da noção de coração traçada a partir das fontes literárias. Ao investigar as representações do coração nas fontes materiais detecta-se uma "teoria implícita do coração": embora não expressa de forma explícita, como o fazem as fontes literárias, os objectos e representações mágicas encriptam em símbolos as representações mágicas associadas ao poder do coração, o qual se espera activar no contexto específico de certos contextos rituais.

A caracterização do coração proveniente por estas fontes é mágica e constelativa por natureza, isto é, as ideias e os símbolos sobre o coração emanam de um contexto mítico, onde elas se tornam objecto de uma acção ritual desempenhada por um deus tendo em vista alcançar um resultado mágico bem determinado.

Neste contexto, quando se procura apurar o significado do amuleto do coração, devemos em primeiro lugar ter em conta o carácter hieroglífico da arte egípcia. Alguns artefactos reproduzem hieróglifos em três dimensões, pelo que o amuleto do coração deve ser visto desde logo como a materialização do signo ib (F 34 da lista de Gardiner) que significa justamente "coração", "mente" ou "consciência".

$\mathrm{Na}$ maior parte dos objectos inventariados, o coração é representado como um vaso sagrado equipado com duas pequenas projecções laterais simbolizando o seu poder para assegurar a integração cósmica (Fig. 2). O coração é, portanto, usado como um símbolo da consciência e do poder revitalizador da sabedoria, mais do que um símbolo do órgão cardíaco no sentido anatómico do termo ${ }^{3}$.

Embora este significado esteja sempre subjacente, o inventário dos objectos e representações do coração revela variações formais que introduzem interpretações distintas sobre o poder mágico do coração.

\section{O sagrado coração de Hórus}

Um dos aspectos mais marcantes da magia é o seu carácter performativo. As acções envolvidas no ritual têm uma economia própria e requerem um equipamento eficaz capaz de potenciar a prossecução do objectivo final. Nas suas diversas materializações, a magia egípcia converge para um objectivo último que

\footnotetext{
${ }^{3}$ Sousa, 2011.
} 
é o de "curar" o mundo dos efeitos destrutivos causados pela isefet, o princípio contrário à maat, que consiste no esvaziamento da ordem cósmica, traduzindose na doença, na morte e no caos.

A luta para fazer regressar o mundo à sua plenitude original, é mitologicamente expressa no combate de Hórus e Set ${ }^{4}$. Set, o assassino de Osíris, personifica o princípio da morte, do isolamento e da desintegração, enquanto Hórus, o vingador do seu pai Osíris, é o agente da vida, o garante da conectividade, coesão e unidade.

No plano mágico, o coração é usado como símbolo de união e conectividade que garante o poder de vida que se quer potencial através do ritual. Nesta qualidade, a representação do coração como elemento conectivo enraíza-se no ciclo mitológico de Hórus, o qual fundamenta a ordem cósmica.

As fontes arqueológicas indicam que o amuleto do coração tenha precisamente como origem este núcleo mitológico e que os primeiros destes artefactos se destinassem a um uso exclusivamente real. Neste contexto, o amuleto do coração era usado pelo faraó como símbolo do coração solar do deus Hórus, assinalando o centro do cosmos onde o mundo é recriado numa unidade essencial. Amuletos deste tipo representam o coração equipado com um disco solar (Fig. 1) assinalando o nascer do sol. Esta imagem poderosa ilustra a vitória de Hórus sobre Set e a subsequente iluminação do seu coração, de onde a maat emana para o mundo. Este tipo de objecto era provavelmente usado como símbolo da iluminação do faraó, ou seja, da identificação do seu coração/ consciência com o de Hórus, o Príncipe cósmico ${ }^{5}$.

Coevo deste tipo de uso do amuleto do coração é um outro tipo de objectos dotados de uma cartela real. Normalmente feitos em ouro, estes amuletos parecem ter sido usados por altos funcionários reais como uma condecoração real que assinalava o apreço do faraó pelos seus serviços. Esta condecoração elevava o funcionário ao restrito círculo dos amigos íntimos do faraó e era vista com um símbolo da sua lealdade. A condecoração do coração assinalava assim o papel do funcionário como aliado do faraó no seu combate contra Set.

As duas categorias de objectos eram usadas na vida terrena com um forte significado político. Contudo, o prestígio destes amuletos levou inevitavelmente a que eles fossem também usados no contexto funerário, de modo a exaltar o mérito do defunto. $\mathrm{O}$ elevado prestígio social inerente a estes objectos limitaram grandemente a sua expressão na cultura material, permanecendo um privilégio restrito a um escasso número de indivíduos. Como veremos na próxima rubrica este hábito acabou por levar à criação de amuletos do coração com uma especificidade funerária.

\footnotetext{
${ }^{4}$ Hornung, 1986:158.

${ }^{5}$ Sousa, 2011.
} 


\section{O Sagrado Coração de Osíris}

A mumificação tinha como objectivo não só preservar o cadáver mas também operar, através de manipulações mágicas, uma transformação decisiva para alcançar a imortalidade: criar uma identificação entre o cadáver mumificado e o corpo sagrado de Osíris. Do ponto de vista mitológico, estas operações eram feitas sobre o cadáver, animadas por uma forte carga amorosa, à imagem dos cuidados que Ísis e Néftis haviam dispensado a Osíris.

$O$ passo seguinte na reanimação do defunto era assegurado por Hórus e Thot, que desempenhavam um papel essencial na afirmação da identidade e do estatuto social do defunto. Longe de constituir um fenómeno integrado na ordem natural das coisas, a morte era, na mentalidade egípcia, uma aberração, um atentado à dignidade do indivíduo. Por isso, do ponto de vista mitológico, ela era evocada sob a forma de um crime perpetrado por Set, o deus que personificava os poderes letais do deserto e do próprio ego, como a avidez, a inveja e a cupidez.

No umbral do Além, o defunto tinha de ser proclamado como um deus osirificado, ou seja, um deus identificado plenamente com a bondade e a virtude de Osíris. Esta "mumificação moral" era assegurada através da pesagem do coração, operação que tinha lugar diante do trono de Osíris e perante a assembleia divina do Além e onde se examinava o coração do defunto, não no sentido literal, mas no sentido que lhe conhecemos na literatura e na iconografia, como sede da consciência do indivíduo. Se o coração fosse tão leve como a pluma de maat, que simbolizava a verdade e a justiça, o defunto seria aclamado como um deus e flanqueava os horizontes da imortalidade.

É neste enquadramento mitológico que foram criados os amuletos do coração, especificamente concebidos para uma utilização funerária. Tal como os seus antecessores, estes amuletos obedeciam a uma ética distintiva. De certo modo, continuavam a ser atribuídos ao defunto como uma condecoração, uma distinção real, desta feita concedida pelo soberano do Além, Osíris. Esta condecoração dotava o defunto com um objecto que evocava o coração de Osíris, que Set havia dilacerado, mas que o amor de Ísis havia resgatado. O coração de Osíris evocava o poder da virtude e da sabedoria para resgatar o indivíduo da morte (Fig. 3).

Com esta nova interpretação, rapidamente o amuleto do coração se tornou num dos objectos mais desejados para equipar a múmia, sobretudo a partir do Período Ramséssida (1292-1069 a.C.) ${ }^{6}$. Tipicamente estes objectos são esculpidos em pedras escuras (tratam-se afinal evocativas do coração morto de Osíris) e apresentam por vezes versão abreviadas do Capítulo 30 do Livro dos Mortos, o qual procurava assegurar um resultado favorável na pesagem do coração. O papel

\footnotetext{
${ }^{6}$ Niwinski, 2006: 245-264.
} 
mágico deste objecto fazia-se sobre o próprio coração da múmia: os amuletos, de grandes dimensões, eram colocados sobre o peito, evocando o coração de Osíris e o seu poder para assegurar a ressurreição do defunto.

O sucesso deste tipo de artefactos devia-se assim ao seu poder de materializar umas das mais intensas expectativas geradas ao longo da vida: a de corresponder às exigências do tribunal do Além e de encerrar afinal a manifestação quintessencial da consciência, no estado osiríaco de bondade pura, o único que assegurava ao defunto a aspiração de viver eternamente (Fig. 5).

\section{O Sagrado CORAÇão de Nut}

Uma outra categoria de amuletos do coração foi criada, sobretudo a partir da Época Baixa (664-332 a.C.), para ser usada tanto no Além como na vida terrena.

No âmbito funerário, estes amuletos eram representados no contexto de uma peregrinação que levava o defunto a percorrer os locais sagrados do Egipto e o integrava no séquito da barca solar na sua viagem pelo mundo inferior.

Existe uma vasta panóplia de representações pictóricas que ilustram diversas etapas desta viagem. Uma grande parte destas figurações representa o defunto equipado com o amuleto do coração. Neste contexto, o amuleto assegurava que o defunto era um bem-aventurado e funcionava como um salvo-conduto para enfrentar as perigosas etapas da viagem no Além, proporcionando-lhe protecção contra os demónios (Fig. 6) 7 .

Equipado com o amuleto do coração, o defunto penetrava nas regiões nocturnas mais secretas que o deus sol atravessava no seu percurso pelo mundo inferior rumo à sua própria regeneração8.

O objectivo final desta viagem era o renascimento, o qual se manifestava sob a forma do sol nascente que emergia do horizonte, plenamente vivificado. Este renascimento contudo só era possível através de um retorno ao ventre da grande deusa cósmica.

A deusa que presidia a este ciclo de representações era Nut, a deusa celeste que acolhia o defunto no seu ventre9.

Contudo, a possibilidade de sofrer um renascimento solar era um privilégio concedido apenas aos eleitos que haviam triunfado, graças à sua sabedoria e bondade, sobre Set. O renascimento solar era, portanto, um summum bonum: apenas os eleitos poderiam subtrair-se à aç̧ão do tempo e encetar uma viagem literalmente à origem do mundo para aí ser rejuvenescidos e recriados. Uma tal gestação tinha ligar no ventre da mãe cósmica, onde o defunto se dissolvia nas

\footnotetext{
${ }^{7}$ Piankoff, Rambova, 1955: P1. 77.

${ }^{8}$ Piankoff, 1954: P1. 86.

9.Assmann, 2003: 253.
} 
águas purificadoras do Nun ser novamente reintegrado num novo ciclo solar ${ }^{10}$. Este núcleo de crenças enraizava-se em prerrogativas reais ancestrais e pode ser detectada desde logo nos Textos das Pirâmides:

Sê puro! A tua mãe Nut é a Grande Protectora. Ela purifica-te, ela protege-te ${ }^{11}$.

Simbolizada no próprio sarcófago ou ataúde que envolvia a múmia, a deusa envolvia o defunto e alimentava-o com o seu próprio coração, palavras e magia. Esta regeneração era seguida de um renascimento do defunto sob a forma do deus Khepri, o deus do sol nascente (Fig. 7). O triunfo da vida sobre a morte era então plenamente alcançado.

Com um imaginário tão impactante como este em pano de fundo, é fácil de compreender a grande difusão que os amuletos do coração tiveram se associaram a este núcleo de crenças. Uma vez interpretado à luz dos mitos que associavam a mãe divina com a criança solar, o amuleto do coração foi investido com um novo significado, tornando-se no símbolo da protecção dispensada por Nut, a grande dadora de vida e de sabedoria. Este imaginário tornou-se muito importante no Egipto da Época Baixa e até mesmo da Época Greco-Romana (332-641 a.C.), traduzindo-se na criação de novas estruturas arquitectónicas como os mammisi, ou templos do nascimento. Integrado nestas inovações, o amuleto do coração passou a ser representado como um santuário, um mammisi em miniatura, no interior do qual se propiciava o rejuvenescimento do indivíduo ou a gestação do seu ser quintessencial (Fig. 4). Desta forma, o amuleto deixou de ter um uso exclusivamente funerário e passou a ser usado como proteç̧ão para a vida quotidiana. Tal utilização não inviabilizava o uso funerário do amuleto passando a ser integrado em grande número no mesmo enterramento e sem qualquer relação com a posição do coração na múmia. A sua função apotropaica tinha agora uma função curativa e protectora que não se restringia especificamente ao coração, mas sim ao poder da deusa para garantir o renascimento solar do defunto.

\section{Conclusão}

Um dos aspectos mais interessantes a destacar na leitura dos vários significados detectados nos símbolos associados ao amuleto do coração é o significado elitista e fortemente associado a uma ética distintiva ao uso deste objecto. A origem real do objecto explica a sua raridade em períodos mais recuados e só a partir do reinado de Tutmés III, a sua utilização parece ter extravasado o círculo da família real, para se estender aos funcionários leais

\footnotetext{
${ }^{10}$ Spelleers, 1938: 37-67.

${ }^{11}$ Faulkner, 1969:150.
} 
ao faraó. Utilizado como condecoração, o amuleto do coração foi usado para assinalar uma elite muito diferenciada que se impunha graças à sua lealdade ao faraó. O objecto era assim utilizado numa estratégia para cimentar alianças entre o faraó e os seus altos funcionários, pelo que o prestígio associado ao objecto era bastante significativo. A origem deste prestígio radica-se no alcance e dimensão do seu poder mágico que era o de identificar o coração do seu possuidor com o poder instaurador de vida do próprio coração Hórus, o Príncipe da criação.

Devido à matriz fortemente elitista da cultura funerária egípcia, o prestígio político associado a este objecto acabou por ser usado no âmbito funerário com um carácter comemorativo, usando o triunfo conquistado em vida como um «argumento de peso» para apresentar no tribunal do Além.

Estas conotações acabaram por se repercutir na criação de uma condecoração funerária, usada no tribunal de Osíris. A matriz simbólica do objecto assim criado associava-se agora ao imaginário de Osíris e o poder mágico a ele associado foi de tal forma intenso que o amuleto rapidamente passou a ter um peso substancial na cultura material.

O desenvolvimento das crenças funerárias solares acabou por tornar manifesta uma leitura que até aí havia estado em segundo plano. $\mathrm{O}$ amuleto do coração foi reconhecido como a evocação do vaso sagrado, o símbolo da mãe cósmica e das suas águas regeneradoras que propiciavam a Verdade (maat) e a Vida (ankh). A «democratização» das crenças funerárias que se registou a partir da Época Baixa levou a uma rápida difusão deste amuleto que, em virtude do imaginário solar subjacente, conheceu uma popularidade sem precedentes, tornando-se num símbolo de protecção por excelência, eficaz tanto na vida terrena como na vida do Além.

No seu conjunto, é interessante constatar que, apesar das flutuações registadas na semântica mágica do amuleto do coração, as suas variações correspondem a uma valorização diferencial de um significado em particular em relação a um espectro de significações que se encontram potencialmente associados a este símbolo. A evolução aqui esboçada não reflecte portanto uma evolução do conceito do coração em si mesmo, no que toca às suas conotações mitológicas, mas sim a uma evolução das práticas no sentido de canalizar um ou outro aspecto que, num determinado momento, se considera mais importante para garantir a eficácia ritual. 


\section{BiBLIOGRAPHY}

Assmann, J. (1984), The Search for God in Ancient Egypt, Ithaca, London.

Assmann, J. (2003), Mort et au-delà dans l'Égypte ancienne, Monaco.

Assmann, J. (1993), "Zur Geschichte des Herzens im alten Ägypten” in Assmann (ed.) Die Erfindung des inneren Menschen: Studien zur reliogiösen Anthropologie, Gütersloch: 81-113

Faulkner, R. (1969), The Ancient Egyptian Pyramid Texts, Oxford.

Hornung, E. (1986), Les Dieux de l'Égypte:l'Un et le Multiple, Paris.

Hornung, E. (1999), The Ancient Egyptian Books of the Afterlife, Ithaca, London.

Frankfort, H. (1933), The Cenotaph of Seti I, London.

Piankoff, A. (1930), Le «Coeur» dans les Textes Égyptiens depuis l'Ancien jusqú à la fin du Nouvel Empire, Paris.

Piankoff, A. (1954), Tomb of Ramses VI, New York.

Piankoff, A.; Rambova, N. (1957), Mythological Papyri, New York.

Niwinski, A. (2006), "The Book of the Dead on the Coffins of the 21st Dynasty" in H. Backes, I. Munro, S. Stor (eds.), Totenbuch-Forschungen. CITY: 245264.

Niwinski, A. (1989), Studies on the Illustrated Theban Funerary Papyri, Fribourg.

Spelleers, L., "La résurrection et la toilette du mort selon les Textes des Pyramides", RdE 3 (1938), 37-67.

Sousa, R. (2011), The Heart of Wisdom: Studies on the Heart Amulet in Ancient Egypt, Oxford.

Sousa, R. (2010), "Animal and Human Headed Heart Amulets: Symbolism and Meaning" in Boletin de la Societé Egyptologique de Genéve 28. Genéve: $129-138$

Sousa, R. (2010), "Symbolism and Meaning of the Cornice Heart Amulets". In Chronique d’Égypte 85. Brussels: 81-91

Sousa, R. (2009) "Symbolism and Meaning of Pendulum Heart Amulets" in Göttinger Miszellen 221. Göttingen: 69-79

Sousa, R. (2007), "The meaning of the heart amulets in Egyptian Art" in Journal of the American Research Center in Egypt 43. Cairo: 59-70 


\title{
DEISIDAIMONIA Y TECHNAI EN LOS DIÁLOGOS DE PLATÓN (Deisidaimonia and Technai in Plato's Dialogues)
}

\author{
Víctor Hugo Méndez Aguirre \\ Universidad Nacional Autónoma de México \\ (mendezaguirre@prodigy.net.mx)
}

\begin{abstract}
Aвstracto - El propósito del presente texto consiste en el postular de la existencia de una "deisidación intelectual" en los diálogos de Platón que se enciende en lo que variantes de magia y adivinación son considerados por el autor de los diálogos. $\mathrm{Me}$ parece que tal oxímoron es el resultado de la interpretación filosófica tanto de la religión griega arcaica y clásica como el demonio en la vida y el pensamiento de Sócrates. Palabra-Clave: diálogos de Platon; religión; vida y pensamiento; Sócrates
\end{abstract}

Abstract - The purpose of the present text is to postulate the existence of an "intellectualistic deisidaimonia" in the dialogues of Plato that is that certain variants of magic and divination are considered technai by the author of the dialogues. It seems to me that such an oxymoron is the result of the philosophical interpretation of both classical and archaic Greek religion as well as of the devil in the life and thought of Socrates

Keyword: Platon dialogues; religion; life and thought; Socrates.

En primer lugar, planteo el problema de la oposición entre superstición y racionalidad en Occidente y ofrezco el estado de la cuestión de los últimos años en lo relativo a los estudios clásicos. En segundo lugar, como prerrequisito para entender la deisidaimonia, me aboco a la caracterización de los demonios en el politeísmo griego. A continuación, señalo que para los contemporáneos de Esquilo la mántica era considerada una de las technai.

Por último, planteo que la magia y la mántica son technai frecuentemente soslayadas en los diálogos de Platón. Este filósofo no se conforma con las versiones populares de las prácticas religiosas de su tiempo, por el contrario, es un severo crítico de muchas de ellas y de la literatura que las avala. Sin embargo, se preocupa particularmente por determinar su estatus epistemológico.

\section{Planteamiento del problema y estado de la cuestión: SUPERSTICIÓN O RACIONALIDAD}

"Superstición" es definida por la Real Academia de la Lengua Española como "creencia extraña a la fe religiosa y contraria a la razón" (RAE, 1992: 1362). En diferentes periodos, han sido contrapuesta tanto a la religión como a la ciencia, entre sus detractores más furibundas se han contado algunas autoridades religiosas, ciertos filósofos y no han faltado los científicos, entre los que han destacado desde los mismos orígenes de su arte los médicos. 
En los últimos siglos, la tensión entre superstición y racionalidad puede constatarse tanto en el Renacimiento como en la Ilustración y, particularmente, alrededor del positivismo decimonónico. Los positivistas suelen juzgar tratar despectivamente todo lo que no sea estrictamente "ciencia".

En 1628, el Tratado de las supersticiones de Pedro Ciruelo distinguía cuatro variantes principales de ésta, a saber, la nigromancia, la adivinación, el ensalmo y la hechicería (Ciruelo, 1986: 32). A decir de Ciruelo, los "malos ángeles" o los "diablos" son causantes y cómplices de tales desviaciones (Ciruelo, 1986: 31). Para santo Tomás, en el siglo XIII, las principales formas del pecado de la superstición son "idolatry, magic, divination, vain observation and finally, maleficium (sorcery/witchcraft)" (Paiva, 2002: 37),

En el ámbito de algunos Estudios Clásicos del último lustro se sigue hablando en términos de la presunta oposición entre superstición y magia por una parte, y religión y racionalidad por la otra. En este mismo 2015, según María Emilia Cairo, la oposición religio / superstitio puede ser encontrada en obras como De natura deorum y De divinatione en relación al término divinatio (Cairo, 2015: 20). En el 2014, Barceló y Hernández comentan la forma en la que Darío fue nombrado rey merced a que su cabalgadura relinchó en el momento oportuno al tiempo que un relámpago estremeció un cielo despejado. "Desde el punto de vista griego, este estrafalario modo de proceder para asignar el trono imperial aqueménida, caracterizado por la superstición y el engaño, no dejaba de ser un espectáculo extraño y bárbaro [...]" (Barceló y Hernández, 2014: 231).

No todos los clasicistas comparten la visión positivista de la superstición, la adivinación y la magia. Desde principios del siglo veinte escuelas como los "ritualistas de Cambridge" han contribuido a alcanzar una visión de las religiones clásicas cada vez más compleja. Los avances de la arqueología y la antropología han ayudado a comprender mejor el pasado y su imaginario social. Sucintamente, existe un debate sobre el papel desempeñado por la superstición, la adivinación y la magia en la antigüedad.

Es verdad que Platón censura la religión homérica-hesiódica imperantes en su época, los cultos soteriológicos emergentes en aquel entonces y, empleando una categoría de corte weberiano, la "religión popular" de sus contemporáneos. Sin embargo, el propósito del presente texto es hacer hincapié en que superstición, adivinación y magia no sólo eran parte de la religión de la Grecia clásica, sino que incluso tienen cabida en los diálogos de Platón. Por una parte, la deisidaimonia es parte esencial del método socrático. Por otra parte, Platón, célebre por su férrea oposición a ciertas variantes de magia a las que incluso trata de erradicar, regañadientes acepta que el daimon en general resulta ininteligible sin la magia y la adivinación. Éstas, cuando menos sus buenas variantes, no sólo no son irracionales sino que forman parte de las technai griegas. 


\section{LA SUPERSTICIÓN EN LENGUA GRIEGA}

Las palabras griegas que suelen ser traducidas por superstición son deisidaimonia y theiasmos. En su libro Inventing Superstition. From the Hippocratics to the Christians Martin dedica un apartado inicial al término "deisidaimonia"; "deisis" es "miedo" y "daimon" "demonio" o "divinidad indeterminada". "Temer a lo divino" puede ser interpretado de diferentes maneras. Como bien observa Martin, se registra un problema de definición que impide una traducción simple y llana de "deisidaimonia" por superstición tal y como éste término es entendido en ambientes "positivistas". En Grecia clásica su sentido oscilaba entre religión, como ahora se dice que una persona piadosa es aquella que "tiene temor de Dios”, y superstición (Martin, 2004: 10-20).

En resumidas cuentas, superstición y deisidaimonia no son sinónimos completamente exactos aunque ambas palabras se encuentran relacionadas con la magia, la adivinación y los demonios. La modernidad puede suponer las creencias en estos como irracionales; el Renacimiento y la Edad Media los considera malos; pero tales concepciones no proceden del politeísmo griego. Resulta imposible entender cabalmente la deisidaimonia sin reflexionar previamente en el politeísmo griego y sin tomar nota de que el daimon griego es una divinidad que no se puede identificar con el demonio del monoteísmo occidental.

\section{LOS DEMONIOS EN LA RELIGIÓN HOMÉRICA-HESIÓDICA}

Las divinidades en las obras de Homero y Hesíodo son de varios tipos, pero destacan principalmente, sin ánimos de ser exhaustivos, tres categorías, esto es, el dios, "theos", el demonio, "daimon" y el ángel, "ángelos".

La divinidad griega, a diferencia de lo que ocurre en el planteamiento creacionista y monoteísta, no es "eterna"; mucho menos es todopoderosa, ni siquiera es omnipresente.

En cuanto a la temporalidad, a excepción de las entidades primordiales como la pareja de Océano y Tetis en Homero o el Caos Hesiódico, el Dios griego nace, y desde el primer momento de su alumbramiento se dedica a conquistar el honor que le corresponderá, el cual es directamente proporcional a su fuerza y astucia. Una vez llegado a la madurez que le corresponde, lo que sí reivindica una deidad helena para sí misma es una juventud continua, clave de su felicidad. E1 Dios griego no es eterno; pero sí inmortal.

Los dioses son tanto los inmortales como los bienaventurados, makares, por antonomasia, y esto los distingue de los afligidos mortales. ¿Cómo pasan sus días los bienaventurados inmortales? En el banquete en el que ingieren néctar y ambrosía. Aunque estrictamente los dioses griegos son inmortales y no requieren para sobrevivir de la ingesta de estas substancias, el carecer de ellas disminuye la plenitud de su existencia. 
El néctar es rojo y, de manera análoga a lo que ocurre con la ambrosía, aromático. Ambas substancias pueden mantener el vigor de un mortal o impedir temporalmente la corrupción de un cadáver. Así son los dioses. ¿Cómo son los demonios?

Uno de los grandes temas de los estudiosos de la religión griega radica en discernir las diferencias, si las hay, entre ellos, particularmente entre dioses y demonios.

Giovanni Reale es uno de los estudiosos contemporáneos que se ha abocado particularmente al estudio del "daimon" en Grecia clásica. Este autor postula: "La diferencia entre dios y demonio, como han señalado recientemente los más agudos intérpretes de la religión pagana, consiste en esto: un dios manifiesta la totalidad del mundo, es decir, la totalidad del ser, en la dimensión que le es propia, el demonio, en cambio, tiene una potencia circunscrita a un ámbito específico" (Reale, 2004: 180).

Para evitar confusiones entre los demonios helenos y aquellos procedentes de otras tradiciones se ha buscado acuñar un término que los singularice, "demon" por ejemplo. Sea como fuere, lo importante es retener que el "demonio" heleno no es un ente esencialmente malo; pero el "ángel” griego tampoco es bueno por definición.

Los ángeles homéricos son divinidades que fungen como mensajeros; comunican a los dioses entre sí mismos, a éstos con los mortales y a distintos niveles de lo real. En la obra de Homero destacan dos ángeles: Iris y Hermes.

Las etimologías de los teónimos griegos no siempre generan consensos entre los especialistas; pero excepcionalmente hay cierto acuerdo de que el nombre de esta divinidad alude tanto al arcoiris -intermedio entre el cielo y la tierra- como al iris del ojo -frontera entre la exterioridad y la interioridad del animal-. Iris funge como mensajera de los dioses fundamentalmente en la Iliada, mientras que Hermes incide mayormente en la Odisea, si bien no deja de tener presencia significativa en la Ilíada.

Hermes desempeña labores de mensajería entre los dioses y los inmortales e inmortales. Y así como su colega Iris conecta niveles de realidad diversos - cielo y tierra o adentro y afuera-, Hermes conecta a los que dejan la vida con el Hades. En su función de psicopompo conduce las almas de los muertos a su destino final.

Hermes, el ángel por antonomasia, es uno de los doce dioses griegos. Quizá sea el más humilde de los Olímpicos; pero no deja de ser uno de ellos. Así pues, los ángeles griegos son un subconjunto de los dioses que se caracterizan por su función subordinada dentro del panteón, esto es, transmitir mensajes. Y su labor de conectar al todo consigo mismo también los acerca a los demonios. De hecho, Luis Muñoz Delgado, en su Léxico de magia y religión en los papiros mágicos griegos, afirma que ocasionalmente un ángelos puede ser un theos o un daimon; en ese sentido esta división, aunque útil y procedente de los mismos Homero y Hesíodo, no puede considerarse infranqueable (Muñoz y Rodríguez, 2001: 3). 
Los dioses, demonios y ángeles jugaban con la historia; pero no sólo en la epopeya homérica. Incluso los historiadores, Heródoto más que Tucídides, así lo pensaban (Oost, 1975: 186-196). Las personas comunes y corrientes también podían verse beneficiadas o perjudicadas por ellos en sus existencias anónimas. Es un hecho incontrovertible que "[...] the majority of the ancient believers were deisidaimones in the literal sense of the world" (Riess, 1903: 435). La religion griega arcaica y clásica se aboco a encontrar mecanismos de comunicación entre las deidades y las personas.

\section{La adivinación como techNe en Grecia Clásica}

La palabra techne suele ser interpretada anacrónicamente, restringiéndola a "arte" o "técnica". Siendo raíz de ambas para los antiguos griegos incluía algunos otros sentidos. La mántica constituye parte esencial de la religión y la política de aquellas épocas y latitudes. "Pero lo que caracteriza a la adivinación antigua es el hecho de que era parte integrante del mundo de la religión, de la que incluso constituía una rama importante" (Bloch, 2014: 8). Esta afirmación es avalada por diversas fuentes, tanto literarias como por objetos procedentes de la cultura material, en particular vasos griegos.

En primer lugar, "techne" y "mantis" son términos que aparecen varias veces en la Odisea. En el Himno homérico a Apolo la divinidad epónima decide establecer su oráculo, centro gravitacional de la mantike.

Telfusa, esplêndido templo aqui pretendo erigir, um oráculo para os homens, que sem cessar aqui virão me ofertar perfeitas hecatombes -tanto os que habitam o Peloponeso feraz, quanto os que habitam a Europa e as ilhas equóreas - para sondar o oráculo: a todo meu aviso infalível irei proclamar, vaticinando no templo opulento (b. AP. 247-253)

\section{Candido comenta al Respecto de este pasaje:}

O grego acreditava que o conhecimento prévio das ações divinas facilitava as intervenções humanas visando minimizar os resultados fatais. Participavam da crença de que os deuses concordavam, por vezes, em comunicar aos homens os seus desígnios através do domínio da techné, do saber-usar a mantike. No Hino Homérico a Apolo, o jovem deus se predispõe a ceder e ensinar aos homens como usar a mantike para conhecer os desígnios de Zeus (v. 247-293) no qual o mantis tornara-se o contato intermediário entre os homens e os deuses. Os especialistas em mantis eram os sacerdotes e sacerdotisas que detinham a capacidade de exercer diferentes domínios na techné da mantike, a saber: - cledonomancia - produzida pela linguagem verbal, presságio. -ornithoscopia - interpretação das atitudes das aves. -hieroscopia - leituras das entranhas dos animais. -empyromancia - observação de como a vítima sacrificial é consumida pelo fogo na pira (Candido, 2015: 67-68). 
La tragedia es otra de las fuentes imprescindibles para cualquier intento de aproximación a la Atenas del siglo $\mathrm{V}$ a. C. Sófocles enfatiza la importancia del mantis a quien frecuentemente pertenece a una estirpe distinguida de adivinos.

Sófocles, en sus tragedias Anfiarao, Alcmeón, Erifila y Epígonos, alude a uno de los mantis más famosos de la antigüedad: Anfiarao. Lamentablemente, sólo se han preservado algunos versos de estas obras. García Gual señala que "Anfiarao es el más ilustre descendiente de una estirpe de adivinos: la del gran Melampo, quien con sus dotes de purificador y profeta logró curar de su locura a las hijas del rey Preto de Argos, y obtuvo como pago a su curación las dos terceras partes del reino" (García, 2014: 31). Y añade que "resulta excepcional que reúna el oficio de rey y el saber del profeta o adivino, heredado sin duda de su abuelo Melampo" (García, 2014: 41). Los grandes trágicos no dejan lugar a dudas de que la mántica era considerada una techne en la Atenas clásica. Esquilo escribe que "todas las artes para los mortales provienen de Prometeo” (A. Pr. 506). El Titán se jacta en este contexto de que "también las muchas formas de mántica organicé" (A. Pr. 484485). Es una época de technai y los trágicos no permanecen inmunes ante ellas.

Así, en Prometeo encadenado, Prometeo no sólo obsequia a los hombres el don del fuego sino también la habilidad para seguir las estaciones del año con ayuda de las estrellas, la aritmética, la escritura y la domesticación de animales (442-471); por otro lado, detalla prolijamente la técnica de interpretar la voluntad de los dioses que le enseñó a la humanidad (484-500) y que se halla a medio camino entre la medicina y la metalurgia [...]" (Scodel, 2014: 112).

La literatura por sí misma sería suficiente para fundamentar la afirmación de que en Grecia arcaica y clásica la mántica fue considerada una techne. Sin embargo, objetos de la cultura material helena frecuentemente complementan tal información. Un ejemplo privilegiado de tal complementariedad es el Himno homérico a Deméter y el vaso intitulado "Retorno de Persefone".

Como es bien sabido, Atenas inundó de vasos cerámicos la cuenca del Mediterráneo. Gracias a sus finas decoraciones es posible acceder a través de fuentes directas a un conocimiento invaluable de la cultura griega en general y de su religión en particular. En palabras de Candido:

A partir das imagens do vaso, objeto de nossa analise, podemos analisar como era realizado o poder da mantica/mantike assim como os procedimentos ritualísticos e mágicos atribuídos as sacerdotisas da deusa Hécate. A questão se relaciona ao conceito de politeísmo da religião grega e do xenikoi theoi cuja pratica passou a fazer parte da vida cotidiana do homem grego em meados do $V$ século. $O$ grego detém a noção da fragilidade do ser humano e detém a crença que a trajetória da vida na terra depende dos desígnios divinos. Pierre Bonnechere considera relevante o lugar de fala da mantike, adivinhação como resposta oracular visando explicitar ações especificas do passado, agir de forma eficaz no presente e visualizar os procedimento do futuro (Homero, Iliada, I:69-70), ações relacionadas 
a vida do solicitante. $\mathrm{O}$ autor acrescenta que, num mundo ao qual o menor erro de interpretação pode ser fatal, o homem grego dependia das adivinhações realizadas pelas sacerdotisas para indicar a melhor opção diante da dúvida, visando tornar eficaz a decisão diante do caminho desconhecido (P. Bonnechere, 2010, p.145). Oráculos, adivinhos, com as suas profecias, e as sacerdotisas detém um lugar de fala primordial junto aos gregos, pois é através deles que os canais de contato com o divino são estabelecidos. Ratificam o contato através da indicação de oferendas, libações e preces precisas endereçadas aos deuses e assim a mantis busca trazer os desígnios determinados pelas divindades que controlam as ações humanas (Candido, 2015: 66-67).

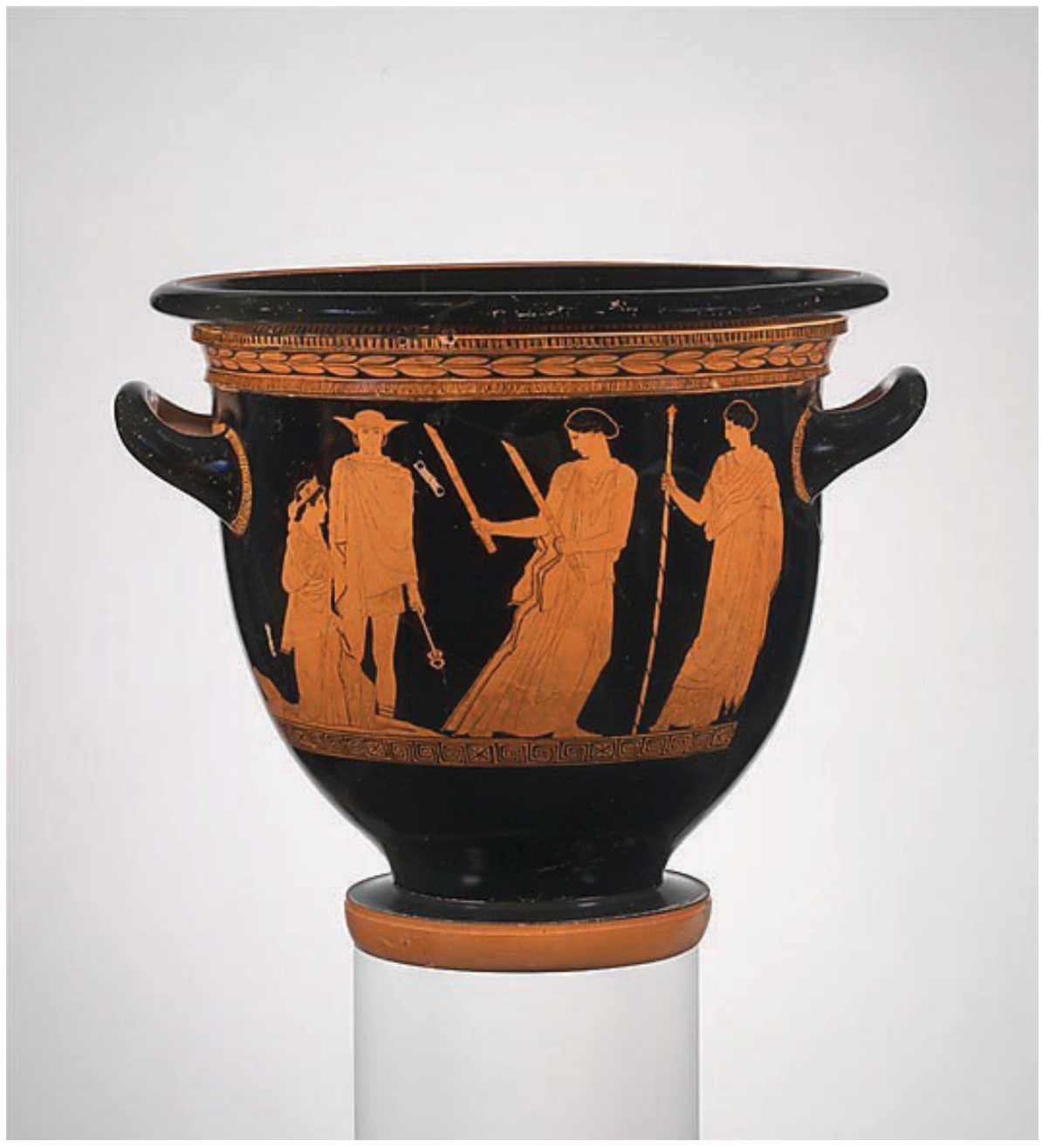

Terracotta bell-krater Attributed to the Persephone Painter.

The Metropolitan Museum of Art. Accession Number: 28.57.23. <www.metmuseum.org>. 
Con su análisis del vaso intitulado "Retorno de Persefone", Candido aporta una visión integral de la mántica que complementa lo que se sabe de ella a partir de las fuentes homéricas canónicamente privilegiadas sobre cualquier otro tipo de documentación de dicha época:

Consideramos que a deusa Hécate reverenciada por Medeia no V sec. A.C., embora diferente da divindade reverenciada por Hesíodo, também tinha um corpo de sacerdotisas, porém eram mulheres estrangeiras que dominavam o conhecimento das ervas e os filtros amorosos, ação que as qualificava de pharmakides, usavam de encantamentos mágicos/epodai e do saber-fazer os katadesmoi para efetivar vinganças, transpor obstáculos e prejudicar os inimigos (como Frineia de Thespis, Nino, Theoris de Lemnos). Algumas sacerdotisas detinham o conhecimento especifico da necromancia, ou seja, evocação da alma e manipulação do corpo do morto em meio as sepulturas visando atender as determinações e anseios dos solicitantes e usuários da magia dos katadesmoi. A outra evocação aos mortos configura-se como uma techné praticada exclusivamente pelos homens como nos aponta Homero ao narrar as instruções ofertadas pela sacerdotisa Circe ao herói Odisseu, na tragédia Os Persas de Esquilo e o drama satírico Alcestes de Eurípides (Ma.R.Candido, 2006,p.191). Os poetas deixam transparecer que essa especificidade de saber mágico era realizada exclusivamente pelos homens, identificada como techné do psychagogos e da katabasis. Empédocles de Agrakas nos fornece indícios de que foi iniciado no ritual da mantike como nos aponta as suas experiências na obra Purificações (Candido, 2015: 69-70).

En las atinadas palabras de Brickhouse y Smith, "the recognition of divination as a techne may be found elsewhere in Greek literature" (Brickhouse y Smith, 1993: 49). Y tal arte fue practicado por varones, por mujeres, por familias y por filósofos. De hecho, a pesar de que no se presta suficiente atención al respecto, el mantis es una figura esencial en los diálogos de Platón.

\section{Magia y mántica en Platón technal frecuentemente soslayadas}

Las preocupaciones platónicas con respecto a las technai en general son bien conocidas. Diotima instruye al filósofo ágrafo sobre algunas de las diversas funciones desempeñadas en el cosmos por los daimones.

Por interpretar y conducir hasta los dioses las cosas de los hombres y hasta los hombres las de los dioses, de los dioses las súplicas y los sacrificios, de los dioses los mandatos y el trueque de los sacrificios, hace, cual intermediario de ambos, de complemento, y de esta manera el todo mismo ha quedado unido consigo mismo una vez más. A través de Él fluyen el arte adivinatoria y las técnicas de los sacerdotes, tanto las concernientes a los sacrificios, iniciaciones y encantamientos como el vaticinio íntegro y la magia; que Dios no se mezcla con los hombres, mas por medio del Amor tienen lugar todos los tratos y comunicaciones entre 
dioses y hombres dormidos o despiertos. Y será varón demoniaco el que en tales cosas sea sabio, mas el que lo sea en otras cosas, manuales o técnicas, no pasará de menesteral (P1. Smp. 202 e).

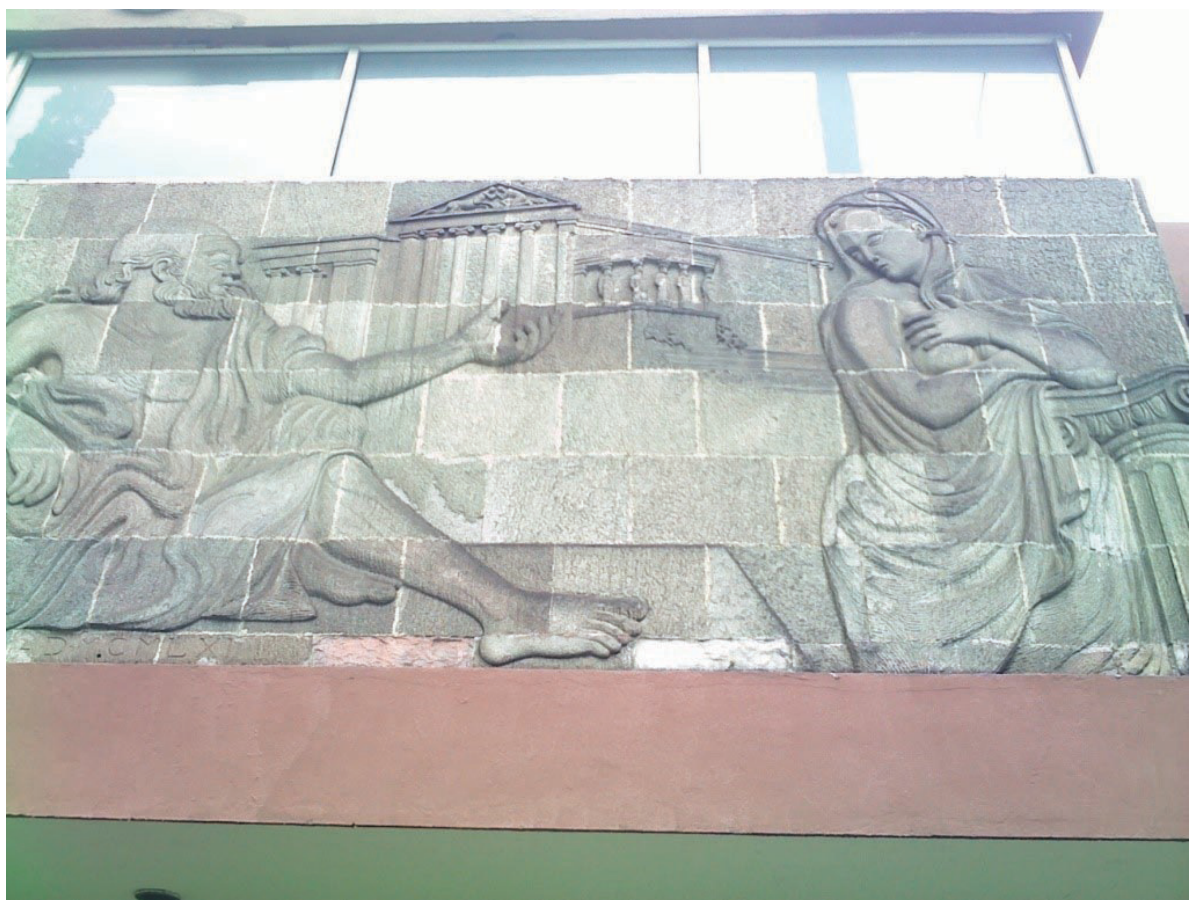

Sócrates y Diotima. Universidad Autónoma de Nuevo León. Monterrey, México.

De acuerdo con lo expuesto por Diotima a través de los demonios se encuentran comunicados dioses y humanos; "they experience the communicative or hermeneutical aspect of divinity when the daimonion relays to them divine orders, precepts and commands" (Evans, 2006: 12). Pero no sólo en su juventud y madurez Platón se preocupó con los demonios y la mántica; también en los diálogos de senectud encontramos la afirmación contundente de que la adivinación es un arte.

E1 Politico es la parte intermedia, y aparentemente final, de una trilogía inconclusa que pretendía pergeñar los perfiles del sofista, el político y el filósofo. El tema de la techne nunca es abandonado por el autor de los diálogos y aquí vuelve a relucir. En esta obra Sócrates cede su rol preeminente a un extranjero cuyo interés gravita precisamente en la política en su carácter de ciencia "directora” (Pl. Pol. 290 c-d) y en su análisis se aboca al estudio de otras artes de algún modo relacionadas. El extranjero que protagoniza esta obra inquiere al joven Sócrates "Confundiremos el arte del rey con el del intérprete, el del cómitre, el del adivino, el del heraldo, y con muchas otras artes que con estas guardan 
relación, las cuales poseen, todas sin excepción, la misión específica de dictar órdenes?" (Pl. Pol. $260 \mathrm{~d}-\mathrm{e})$.

Sucintamente, la mántica es una de las "mediumistic technai", como han sido denominadas por Brickhouse y Smith (1993: 46). Sin embargo, no deja de ser una techne, y en tal sentido no resulta completamente inútil para la filosofía clásica.

\section{A manera de Conclusión}

La deisidaimonia, la magia y la mántica forman parte de la religión de la Grecia arcaica y clásica. En esta época surge lo que ha sido denominado a partir de Varrón "teología natural", esto es, las concepciones de los filósofos acerca de cómo deberían ser las divinidades de acuerdo como lo dicta la razón. La Ilustración sin lugar a dudas también fomentó cierta adeisidaimonia, como lo hará nuevamente la del siglo XVIII o el desencantamiento del mundo barruntado por Weber. Sin embargo, en esta tensión destaca el hecho de que la mántica, asociada indisolublemente a la deisidaimonia y la magia, es considerada en aquel entonces como una de las technai.

En el caso de Platón, este es un autor que se manifiesta en contra de buena parte de lo escrito tanto por Homero y Hesíodo como de la "religión popular" de su época. Sin embargo, el demonio de Sócrates es protagonista indirecto de la mayoría de sus diálogos y Diotima lo obliga a reconocer que de los demonios se derivan tanto la magia como la mántica. La teoría platónica de las technai retoma, aunque sean versiones depuradas al gusto de Platón, ciertas magia y adivinación. ¿O qué quedaría de la filosofía de Platón sin el demonio de Sócrates y su deisidaimonia intelectualista?

Si lo hasta ahora expuesto no está del todo equivocado, el oxímoron socrático deisidaimonia intelectualista constituye un capítulo insoslayable de la historia de la superstición en Occidente. 


\section{Documentação Textual}

Esquilo. (2013), Prometeo encadenado. México.

Homero (2004), O bino homérico a Apolo. Edição Bilingue, Introdução, Tradução, Comentários e Notas Luiz Alberto Machado Cabral. Campinas.

Platón. (1944), Banquete. México.

Platón. (1994) El politico, Critón, Menón, Madrid.

Platón. (2013) Ion, Madrid.

\section{Bibliografia}

Bloch, R. (2014, 2a ed.), La adivinación en la Antigüedad. México.

Blyth, D. (2014), "Political Technê: Plato and the Poets", Polis 31: 313-351.

Barceló, P. y Hernández, D. (2014), Historia del pensamiento politico griego. Teoría $y$ praxis, Madrid.

Brickhouse, T. y Smith, N. (1993), “He Mantike Techne': Statesman 260e1 and 290c4-6", Polis 12: 37-51.

Cairo, M. (2015), "El empleo del término divinatio en De natura deorum y De divinatione. Su lugar en la oposición religio/superstitio", in C. Fernández, G. Zecchin y J. Tobías (eds.), Séptimo Coloquio Internacional: [Una] nueva visión de la cultura griega antigua en el comienzo del tercer milenio perspectivas y desafios. Programa y resúmenes, La Plata, 20.

Candido, M. R. (2015), "A iniciação da mulher grega como sacerdotisa de Hécate a partir da imagem do vaso intitulado "Retorno de Persefone" in V. Méndez y M. P. Irigoyen (eds.), Mujeres en Grecia y Roma y su trascendencia: dioses, heroinas y esposas. México, 57-74.

Ciruelo, P. (1986, 2a ed.), Tratado de las supersticiones. Puebla.

Evans, N. (2006), "Diotima and Demeter as Mystagogues in Plato's Symposium", Hypatia 21.2: pp. 1-27. Disponible en internet: http://www.jstor.org/ stable/3810989. Consulta 6 de octubre de 2015.

García, C. (2014), La venganza de Alcmeón. Un mito olvidado. Madrid.

García, M. (2015), “La mitología clásica hoy”, in G. Ramírez y A. Vargas (eds.), La ritualidad de la palabra, México, 99-116.

Martin, D. B. (2004), Inventing Superstition. From the Hippocratics to the Christians. Cambridge/London.

Muñoz, L. Y Rodríguez, J. (2001), Léxico de magia y religión en los papiros mágicos griegos. Diccionario Griego Español Anejo V, Madrid.

Oost, S. (1975), “Thucydides and the Irrational: Sundry Passages”, CPh 70.3: 186-196. 
Paiva, J. (2002), “The Persecution of Popular Superstition in $17^{\text {th }}$ and $18^{\text {th }}$ Century Portugal", in F. Diez (ed.), Miedo y religión. Madrid, 37-49.

Reale, G. (2004), Eros, demonio mediador. El juego de las máscaras en el Banquete de Platón. Barcelona.

Rae. (1992, 21ª ed.), Diccionario de la Lengua Española. Madrid.

Riess, E. (1903), "Studies in Superstition”, AJPh 24.4: 423-440.

(1895), “On ancient Superstition”, ТАPhA 26: 40-55.

Scodel, R. (2014), La tragedia griega. Una introducción. México. 


\title{
ENCHANTED WINE IN THE ODYSSEY \\ J. C. B. Petropoulos
}

\author{
Harvard University \\ (yiannis@chs.harvard.edu)
}

\begin{abstract}
It is by now a commonplace that magic in the Graeco-Roman world is not a late phenomenon, introduced in the Hellenistic period from Egypt or the Near to certain classes or groups such as hetairai or other marginals. Quite the contrary, magic reaches back to the 'world or worlds of Homer', to archaic Greek societies and still earlier, and can be inferred from a number of practices and especially formulations already attested in the epics. ${ }^{1}$ The Odyssey abounds in instances of magic such as Kirke's evil potion, which instantaneously and turns men into grunting pigs. ${ }^{2}$ In the Iliad magic is infrequent or at least harder to spot at first blush. "Nothing must be allowed to disturb the delicately constructed image of high perfection", as Alan Griffiths states, echoing the consensus about the Iliad's suppression of magic and monsters and other 'messy' subjects. ${ }^{3}$ In this article I will be concerned mainly with the description in Odyssey 9 of the special wine, the "divine drink" (205, theion poton) that incapacitated the cannibal Polyphemos.
\end{abstract}

KeY-words: Homer; Odyssey; Iliad; magic; wine

Abstrait - À l'heure actuelle, il est banal que la magie dans le monde gréco-romain ne soit pas un phénomène tardif, introduit dans la période hellénistique d'Egypte ou du Near à certaines classes ou groupes tels que les hetairai ou d'autres marginaux. Bien au contraire, la magie remonte au «monde ou aux mondes d'Homère», aux sociétés grecques archaïques et encore plus tôt, et peut être déduite d'un certain nombre de pratiques et surtout de formulations déjà attestées dans les épopées. L'Odyssée abonde dans des cas de magie tels que la potion maléfique de Kirke, qui instantanément et rend les hommes en porcs grognants. Dans la magie de l'Iliade, il est peu fréquent ou au moins plus difficile à repérer au premier rougissement. "Rien ne doit permettre de perturber l'image délicatement construite de la haute perfection", comme l'affirme Alan Griffiths, faisant écho au consensus sur la suppression par la Iliade de la magie et des monstres et d'autres sujets «désordonnés». Dans cet article, je me préoccuperai principalement de la description dans Odyssée 9 du vin spécial, la "boisson divine" (205, theion poton) qui a invalidé le cannibale Polyphemos.

Mots-clés: Homère; Odyssée; Iliade; la magie; du vin

The description occurs in Odysseus' narrative of his adventure in the Land of the Cyclopes. After the fall of Troy Odysseus sailed with his twelve ships to Ismaros, the inhabitants of which, the Kikones, had been allies of the Trojans

\footnotetext{
${ }^{1}$ See, e.g., Petropoulos (1988), 215-22; Faraone \& Obbink (1991); Gordon (1999), 159275; Luck (2006); n2 immed. below.

${ }^{2}$ On magic objects in Homer: de Romilly (1984), 74-91.

${ }^{3}$ Griffiths (1995), 87.
} 
(Iliad 2. 846, 17. 73). He and his men captured and then plundered this city on the coast of Thrace (9. $39 \mathrm{ff}$.). This is the next-to last traceable location on the map of the hero's sea adventures; after the attack on the city the flotilla sailed on to Cape Malea and the island of Kythera and thereafter entered an uncharted fairy world, which takes up books 9-12. At Ismaros Maron, Apollo's priest, gave the hero-probably under duress-- an extraordinary wine:

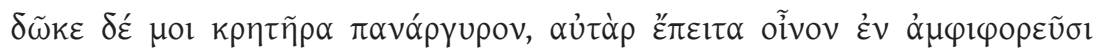

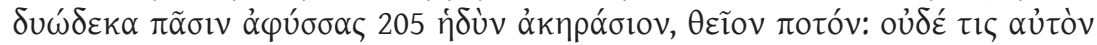

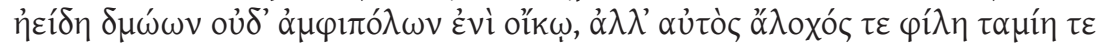

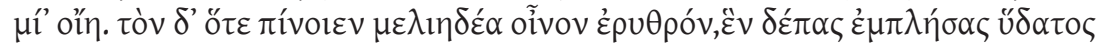

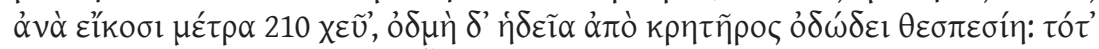

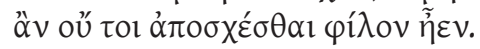

"and he gave me a mixing-bowl all of silver; and besides these, wine, wherewith he filled twelve jars in all, [205] wine sweet and unmixed, a drink divine. Not one of his slaves nor of the maids in his halls knew thereof, but himself and his dear wife, and one house-dame only. And as often as they drank that honey-sweet red wine he would fill one cup and pour it into twenty measures of water, [210] and a smell would rise from the mixing-bowl marvellously sweet; then verily would one not choose to hold back. With this wine I filled and took with me a great skin..."4 Odyssey 9. 203-11 (trans. S. Butler).

The lines are a veritable advertisement of the wine that will prove Odysseus' secret weapon. The drink was already a well-kept secret known only to Maron, his wife, and his maidservant (tamie). Its exceptional, supernatural character is conveyed in terms reminiscent of 'apophatic' language. This negative idiom is often used in Greek and Latin literature to evoke the antitheses and reversals associated with unimaginable, otherworldly beings (such as monsters), objects, and places. 'Apophasis' also suits descriptions of magic, because this activity deals in negations and contortions of normality. Lines 205-6 in the passage above bring out the wine's esoteric exclusiveness ("Not one of his slaves nor of the maids in his halls knew thereof, but himself and his dear wife, and one house-dame only"). The drink is akerasios (205), an adjective with a privative alpha prefix literally meaning 'unmixed, undiluted' but also 'pure' almost in a religious sense (confirmed subsequently when Cyclops, despite his professed unconcern for the gods, praises it as an ambroisal distillation [9. 359]). Line 211, "Then verily would one not choose to hold back" (aposkhesthai) i.e. 'abstain', is a negative way of conjuring the irresistible, indescribable aroma of the drink.

\footnotetext{
${ }^{4}$ All texts and translations of Homer are taken from Perseus online.

${ }^{5}$ Petropoulos (forthcoming).
} 
The whiff of the wine gripped or held one; the description may be playing on the term katekhein, which admittedly later became standard in magic texts. The alliteration of $\delta$ in lines 205-6 and 210 is noteworthy; see below.

The mini-story of the wine reaches something of a climax ("a divine drink") in line 205 ("drew off/ sweet, pure, a divine drink")—a run-on line - and properly culminates with thespesie tellingly at the beginning of 211, another enjambed line ("would rise/ marvellous [ly]"). The passage stresses the wine's sublime (cf. thespesie) bouquet and potency; both qualities will prove instrumental to the blinding of the Cyclops, who drank Maron's wine neat, and captivated by its ambrosial and nectarean flavour gladly drank not one but three (a formulaic number in narratives) cups, lost his wits as it were, and fell asleep in no time:

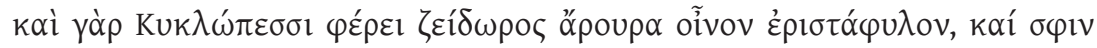

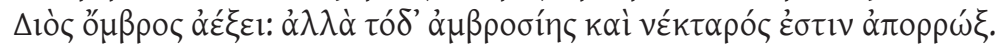

'For among the Cyclopes the earth, the giver of grain, bears the rich clusters of wine, and the rain of Zeus gives them increase; but this is a streamlet of ambrosia and nectar." Odyssey 9. 357-9 (trans. S. Butler).

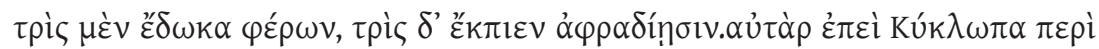

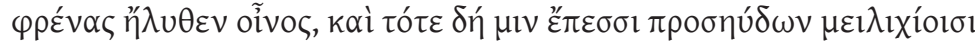

"Thrice I brought and gave it him, and thrice he drained it in his folly. But when the wine had stolen about the wits of the Cyclops, then I spoke to him with gentle words."

Odyssey 9. 361-3 (trans. S. Butler).

The fact that the wine, which was served each time in a human-size cup, put the ogre to sleep suggests its disproportionate strength: three cups sufficed to tranquilise a giant as tall as a mountain crag (see 9. 191-2). Might we call the drink 'magical'?

Magic tampers with the natural and social order in varying degrees. But how first to define 'magic' as perceived by the ancient Greeks themselves? This requires us to view matters from the inside; whereas we can merely do so from the outside. ${ }^{6}$ Robert Fowler has done precisely this. After surveying the staggering bibliography of magic and the manifold debate about the term's definition he concludes that magic is a subset of the religious or sacred; that it "does not in essence differ from religion; it differs only in the degree of social approval it enjoys, or does not enjoy... ${ }^{7}$ Magic is activity meant to achieve the goals of prevailing religion in ways

\footnotetext{
${ }^{6} \mathrm{I}$ am here invoking the anthropological distinction between 'emic'/ indigenous and 'etic'/ universal models of explanation; see Petropoulos (2008)a, 137.

${ }^{7}$ Fowler (2000), 341.
} 
disapproved by that religion." ${ }^{8}$ One among many of the discredited modi operandi of Greek magic is the following: the practitioner mobilised, manipulated or even occasionally coerced the demons of the dead or certain (usually underworld) gods, and he or she did this in an automatic, mechanical fashion, customarily without any element of kharis — of mutuality. ${ }^{9}$ The earliest binding spells (katadesmoi) attested in the Greek world, which date from the late $6^{\text {th }}$ century BC, accordingly operate by ritually consigning the victim to an underworld deity. As Fritz Graf notes, "The scope of the ritual...is clear: the texts remove an individual (or sometimes a group of individuals) from the care of the Olympian deities into the realm of the underwordly powers, moving them to a status that is close but not identical with being dead: like the dead, they will not be able to speak or walk" and generally be themselves. ${ }^{10}$ The infernal dead, when appeased (by libations or other means) might also be induced to carry out constructive actions, which thus verge on 'white magic'; cf. Aeschylus Choephoroi 94-5.11 The Olympian deities, too, might be prevailed upon to bring out 'magical' results, as in Sappho's prayer to Aphrodite (fr. $1[\mathrm{LP}])^{12}$ and in the 'Nestor's cup incantation' (on which anon).

A good way of approaching the role of Odysseus' Ismarian wine is to consider Helen's and Kirke's employment of wine and pharmaka. Kirke's potion is a notorious concoction of wine and other ingredients. It is a chthonian posset; laced with "harmful pharmaka" (236) and activated by certain actions, this drink-cum-meal is straightforwardly magical: ${ }^{13}$

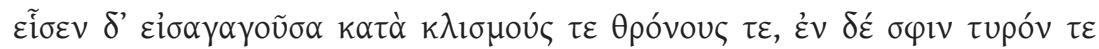

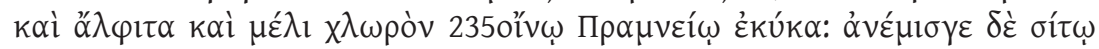

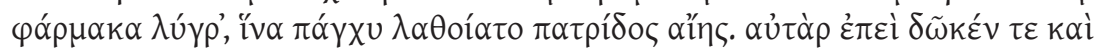

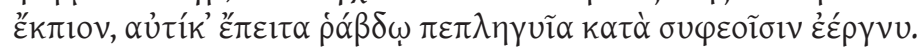

"She brought them in and made them sit on chairs and seats, and made for them a potion of cheese and barley meal and yellow honey [235] with Pramnian wine; but in the food she mixed baneful drugs, that they might utterly forget their native land. Now when she had given them the potion, and they had drunk it off, then she presently smote them with her wand, and penned them in the sties." Odyssey 10. 233-8 (trans. S. Butler).

Although these lines seem to be describing three successive stages- the men imbibe the potion, forget Ithaca, and mirabile visu, become swine as soon as

\footnotetext{
${ }^{8}$ Fowler op. cit., 343 (my emphasis).

${ }^{9}$ Petropoulos (2008)a, 3-4.

${ }^{10}$ Graf (2008), 16.

${ }^{11}$ Johnston (1999), esp. 29,46.

${ }^{12}$ See Petropoulos (1993), 43-56.

${ }^{13}$ E.g., Marinatos (2008), esp. 12-13.
} 
she whacks them with her wand-in reality the poet intends a single, sweeping magical operation with lightning-bolt effect. ${ }^{14}$ Consider now Helen's drink in 4. 219-33:

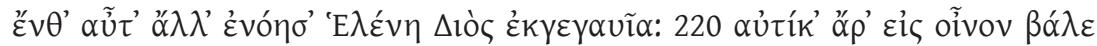

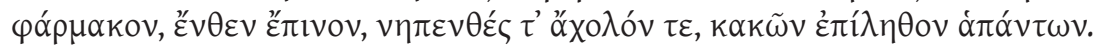

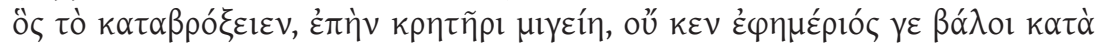

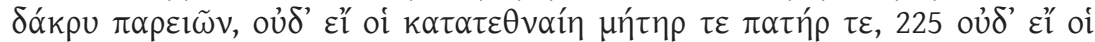

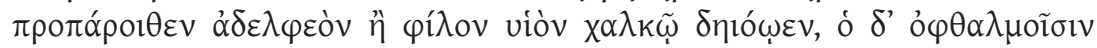

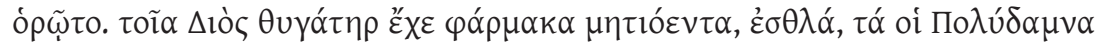

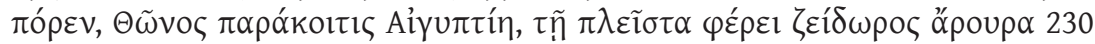

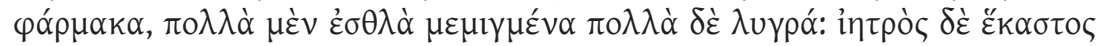

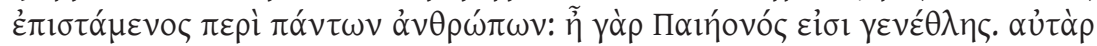

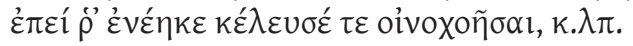

Then Helen, daughter of Zeus, took other counsel. [220] Straightway she cast into the wine of which they were drinking a drug to quiet all pain and strife, and bring forgetfulness of every ill. Who so should drink this down, when it is mingled in the bowl, would not in the course of that day let a tear fall down over his cheeks, [225] no, not though his mother and father should lie there dead, or though before his face men should slay with the sword his brother or dear son, and his own eyes beheld it. Such cunning drugs had the daughter of Zeus, drugs of healing, which Polydamna, the wife of Thon, had given her, a woman of Egypt, for there the earth, the giver of grain, bears greatest store [230] of drugs, many that are healing when mixed, and many that are baneful; there every man is a physician, wise above human kind; for they are of the race of Paeeon. Now when she had cast in the drug, and had bidden pour forth the wine, etc. Odyssey 4. 219-33 (trans. S. Butler).

The setting is the feast which Menelaos offered Telemachos and Peisitratos in 4. 60ff. in his palace at Sparta. Helen joined the men a little later, in lines $120 \mathrm{ff}$; the conversation turned to Odysseus and soon all four interlocutors were moved to tearful lamentation (4. 183-9). The queen's use of wine and "cunning drugs,/salutary ones" (227-8, pharmaka metioenta/ esthla) brings about results less spectacular than those of Kirke's concoction. Helen's potion, a mixture of wine and an exotic herb, is capable of altering her victims' inner state for only a day, whilst Kirke's strange porridge only affects them on the outside, leaving their human minds (nous) - though not their memory- intact (10. 240). The Spartan queen's recipe may at first appear to be rather an instance of a psychotropic

${ }^{14}$ Heubeck \& Hoekstra (1989), 57 ad 234-43 suggests this in noting that "the transformation proceeds from 237" and the touch of the wand is part of it. This view is borne out by the theory and practice of magic on which see $\mathrm{n} 19$ below. 
remedy than outright sorcery. Her drug possesses the hoary respectability of Egyptian pharmacology. ${ }^{15}$ The poet-narrator explains that the drug came from Egypt, a country whose inhabitants were knowledgeable healers (ietros) dispensing therapeutic (esthla) and deleterious (lugra) drugs alike. ${ }^{16}$

Lines 227-8, "Such cunning drugs (pharmaka metioenta) had the daughter of Zeus,/salutary drugs (esthla)" aligns Helen with another famous daughter of Zeus, Athena, and the deployment of her 'good' drug with the craftiness and skill (metis) commonly associated with Zeus and in particular Athena. ${ }^{17}$ Helen's status a Zeus' daughter is stated twice, in the beginning of the account (219) and midway, in the Egyptian digression (227). The formula used of Helen at 4.219 (Dios ekgegauia) is also applied to Athena in Odyssey 6.229 where the goddess is said to miraculously make Odysseus taller and stronger (6. 229-30). Given her unique status and the provenance of her medicine cabinet, Helen's wonder-work comes as no surprise. Yet how truly estblon is a drug that once belonged to an expert by the name of Polydamna ('Multiple subduer') and that erases the human emotions of pity and terror, even if for a day? ${ }^{18}$ Helen's operation, executed with the same automatic impulsiveness of a sorceress (cf. the telling adverb autikal 'at once' at 4.220 and 10.237-8, used of Circe), ${ }^{19}$ blurs into the realm of double-edged fantasy, conveyed through negation: nepenthes t' akbolon te, the first two in the string of three compound epithets in line 221, are privative whilst the third, epilethon, is also negative in meaning. The triple anaphora of negatives (ou, oud' oud') in 223-5 brings out the otherworldly effect of the drug. Nepenthes anaesthetises the memory of those who drink it to the radical point of dehumanising them. In being targeted at their memory (or rather their 'sense of priorities') her drink is comparable with the fruit of the lotos (another ambiguously 'good' substance, see 9. 94-7) and Kirke's mélange, both of which make Odysseus' men forget Ithaka (10. 236). ${ }^{20}$ Helen administers her drug moreover in secret and in the setting of xenie - as a perverse continuation thereof.

One might be further inclined to assign her preparation to the ambiguous area of magic especially if one considers that the syntax of Odyssey 4. 222-6 (an indefinite construction with hos) can be correlated to that of many magical

${ }^{15} \mathrm{Cf}$. Herodotus 2.84 on Egyptian medicine and commentators ad Odyssey $4.220 \mathrm{ff}$.

${ }^{16}$ The genealogy of a remedy, including presumably the transmission of the necessary skill to

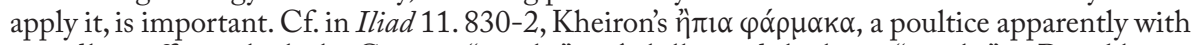
a curdling effect, which the Centaur "taught" to Achilles and the latter "taught" to Patroklos.

${ }^{17}$ Detienne \& Vernant (1991), passim connect metis with magic tricks and the use of philtres.

${ }^{18}$ For the latter consideration see Gordon op. cit., 244-5.

${ }^{19}$ Fairy tale creatures can generally be robot-like; but in the case at least of Kirke impulsiveness may answer to the instant effect of her magic; cf. the automatism of 'Nestor's cup potion' below.

20 On magic and 'forgetfulness': Petropoulos (1988), 218-21; id. (1993), 50. Also Plato

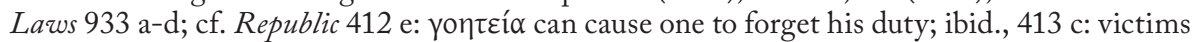

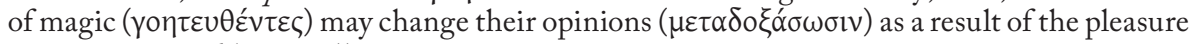
or terror inspired by a spell. 
incantations that feature an indefinite conditional clause with hos/hos tis followed by a minatory apodosis. The indefinite construction in the Helen passage is retrospective; that in magical conditions, prospective. Thus the description of the 'enchanting' song of the Sirens in Odyssey 12. $41-4$ (cf. 40, 44, thelgousin) seems to be modelled on conditional incantations: hos tis + subjunctive is the indefinite condition; the dire effect is expressed in apodosis with a primary tense (in this case the generalising present). The earliest non-literary example of an indefinite conditional clause in magic is the 'Nestor's cup inscription' (Ischia, late $8^{\text {th }}$ century $\mathrm{BC}$ ) —an aphrodisiac spell. ${ }^{21}$

Here is Nestor's incantation:

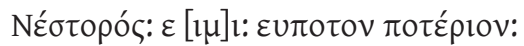

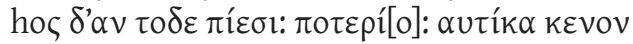

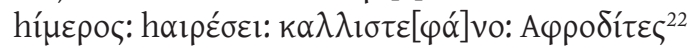

I am Nestor's drinking-cup that is good to drink from.

Whoever drinks from THIS drinking-cup, at once him

Will the desire for/of Aphrodite of the beautiful garland seize.

The reference to Nestor, unless he is the namesake of the actual owner of the cup, is puzzling. Perhaps in the epichoric myth of the region of the Bay of Naples the hero possessed a magic cup; perhaps a myth connected therewith provided the exemplum or 'persuasive analogy' for the incantation. ${ }^{23}$ What seems pretty likely is that whoever drank wine from the cup compelled Aphrodite and Dionysos to arouse instantly his (the drinker's) libido; ${ }^{24}$ hence the text preserves either a magic malediction (on the assumption that erotic desire is necessarily accursed) ${ }^{25}$ or (more probable in my view) a bracingly benevolent aphrodisiac charm. ${ }^{26}$ Either way, because it presupposed drinking in a specific cup, the incantation may have been associated with a potion (made of wine and other

${ }^{21}$ For "if A, then B" formulations in magic from the archaic period on, see Petropoulos (1993), 45; for such formulations in oaths and proprietary curses, see Faraone (1996), 80-2 and below.

${ }^{22}$ Meiggs \& Lewis (1988), no. 1 = CEG 454; further edns cited in Faraone (1996), 77-8n1.

${ }^{23}$ Petropoulos (2008)b, 44-5 (with biblio.).

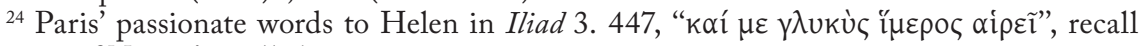
lines 2-3 of Nestor's spell above.

${ }^{25}$ Faraone (1996), 82.

${ }^{26}$ Henrichs (2003), 46-7. After all, desire (bimeros) can be sweet; see n24 above. Though the transition from the first person in verse 1 to the third person in the remaining two verses and the emphatic demonstrative $\tau o \delta \varepsilon$ (in the genetive) have worried some scholars (see Faraone op. cit., 96) colloquial usage admits the mutual reference of 'I' to 'this-here', as Bakker (2010), esp.153-7 demonstrates: cf. his exx. 8-11. 
ingredients such as pharmaka). ${ }^{27}$

The grammatical mood of indefiniteness in the assertions about Helen's drug suggests that Odyssey 4. $222 \mathrm{ff}$. evokes an act of magic; it is a subtle, redeeming touch that the drug will only provide relief for twenty-four hours, for magic is less suitable to Sparta than the preposterous world of Kirke. If in fact the narrator has deliberately admitted magical formulation, he has done so for a combination of two reasons. He is exploiting the common ground between a 'wonder drug' (ordinarily abetted by prayer) and a magical pharmakon. In Homer medicine was theurgic; it had a stake in fostering confusion between the physical/mental ('objective') and the fabulous ('magical') effects of a remedy. ${ }^{28}$ The narrator is at the same time showing forth the psychotropic effects of wine; the narrative, repeating as it does the word pharmakon/a no less than thrice $(220,227,230)$, is an allegory about the mind and emotion-altering qualities of alcohol. The 'potion' after all is not served by Helen but an oinokhoos (233): on this point Homer keeps up the pretence of sympotic custom.

To return to the question whether Homer understood Maron's wine to be magical or not: if intended as a charm, the drink, despite its origin in the 'real world' of Thracian Ismaros, surely fits the topsy-turvy ambience of the Land of the Cyclopes. The fact that Odysseus, a xenos, becomes a twisted xenistes, proffering the wine as a complement to Cyclops' macabre meals consolidates the climate of inversion and absurdity congenial to magic. ${ }^{29}$ In a small number of modern folk tale variants of the 'Blinding of the Ogre' the hero uses a magic potion that induces sleep in the giant. ${ }^{30}$ Folk tales sometimes introduce magical and other fantastical elements which literary myth leaves unstated but understands. Perhaps this is the case here. Magical language, moreover, is partial to alliteration; ${ }^{31} \mathrm{cf}$. again the alliteration of $\delta$ in the description of Maron's wine (9. 205-6, 210) and, e.g., the

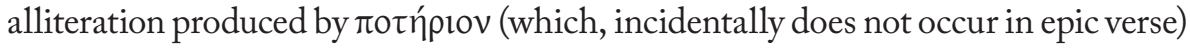

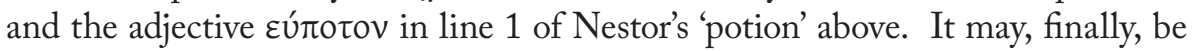
worthwhile to consider again lines 9. 208-11. The lines express an action and state indefinitely recurrent in the past. To an audience familiar with magical language, the lines may have sounded rather like a conditional incantation formula that has been readjusted to the past. In like fashion, as noted, the effects of Helen's potion (4. 222-3) and those of the lotos (9. $94 \mathrm{ff}$.) are expressed in indefinite constructions dependent on historic verbs. Were Nestor's magical spell set in the past in a thirdperson narrative, its effects would have been advertised similarly.

\footnotetext{
${ }^{27}$ Also cf. Faraone op. cit., 104-6.

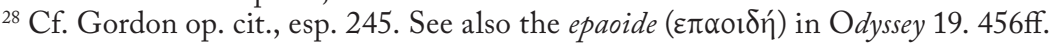

${ }^{29} \mathrm{Cf}$. among the constituents of the ideal feast (dais), bread and wine served by an oinokhoos (Odyssey 9.9-10).

${ }^{30}$ Glenn (1971), 162 with n119.

${ }^{31}$ PetropoulosI (1988), 219.
} 
The arbiters of the question whether Maron's wine was magical were Homer's ancient audiences. I have suggested several details which cumulatively would have made an 'indigenous' auditor perceive the drink not merely as wondrously potent but also magical-as irresistible in fact as the Sirens' enchanting song, which trapped men forever. 


\section{BiBLIOGRAPHY}

Bakker, E. J. (2010), "Pragmatics: Speech and text”, in E. J. Bakker (ed.), A companion to the ancient Greek language, Oxford, 2010, 151-67.

Detienne, M. \& Vernant, J.-P. (1991), Cunning intelligence in Greek culture and society, J. Lloyd (tr.), Chicago.

Faraone, C. \& Obbink, D. (1991) (eds), Magika hiera: Ancient Greek magic and religion, Oxford.

Faraone, C. (1996), "Taking the Nestor's cup inscription seriously: Conditional curses and erotic magic in the earliest Greek hexameters", $C A$ 15: 77-112.

Fowler, R. (2000), “Greek magic, Greek religion”, in R. Buxton (ed.), Oxford readings in Greek religion, Oxford, 317-43.

Glenn, J. (1971), “The Polyphemus folktale and Homer's Kyklopeia”, TAPA 102: 133-81.

Gordon, R. (1999), "Imagining Greek and Roman magic", in B. Ankarloo \& S. Clark (eds), The Athlone history of witchcraft and magic in Europe, ii, London, 159-275.

Graf, F. (2008), “Tapping other powers. Magic in Greek and Roman life”, in A.

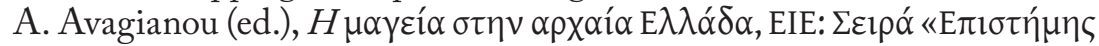
Kolvwvía», Athens, 11-36.

Griffiths, A. (1995), "Non-aristocratic elements in archaic poetry", in A. Powell (ed.), The Greek world, London \& New York, 85-103.

Henrichs, A. (2003), "Writing religion: Inscribed texts, ritual authority, and the religious discourse of the polis", in $\mathrm{H}$. Yunis (ed.), Written texts and the rise of literate culture in ancient Greece, Cambridge, 38-58.

Heubeck, A. \& Hoekstra, A. (1989), A commentary on Homer's Odyssey ii, Books IX-XVI, Oxford.

Johnston, S. I. (1999), Restless dead, Berkeley.

Luck, G. (2006), Arcana mundi: Magic and the occult in the Greek and Roman worlds: A collection of ancient texts, $2^{\text {nd }}$ edn, Baltimore.

Marinatos, N. (2008), "Magic, amulets and Circe", in J.C. B. Petropoulos (ed.), Greek magic: Ancient, medieval and modern, London \& New York, 10-13.

Meiggs, R. \& Lewis, D. (1988) (eds), A selection of Greek historical inscriptions to the end of the fifth century $B C$ (rev. edn), Oxford.

Petropoulos, J.C. B. (1988), “The erotic magicl papyri”, in B. Mandilaras (ed.), Proceedings of the XVIII International Congress of Papyrology, i, Athens, 215-22.

(1993), "Sappho the sorceress-Another look at fr. 1 (LP)", ZPE 97: 43-56. 
(2008)a, "Introduction: Magic in ancient Greece", "Introduction: The theory of magic", in J.C.B. Petropoulos (ed.), Greek magic: Ancient, medieval and modern, London \& New York, 3-5, 137-8.

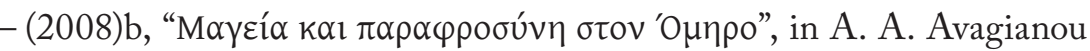

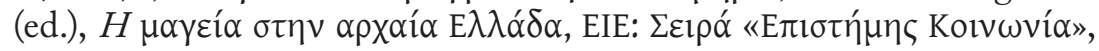
athens, 37-48.

(forthcoming), Residents of the Via Negativa: Homer's Cyclopes and other monsters.

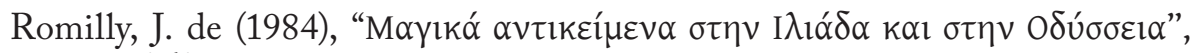

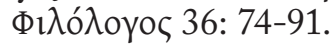


(Página deixada propositadamente em branco) 


\section{INDEX LOCORVM}

$1 \mathrm{Sm} 28$

154

1 Sm 28,3

$1 S m$ 28,3-25

142

142

$1 \mathrm{Sm} 28,7$

143

$1 \mathrm{Sm} 28,8$

$1 \mathrm{Sm} 28,9$

$1 S m$ 28,12-3

$1 S m 28,15$

1 Sm 28,17-8

$1 S m$ 28,21-5

$1 \mathrm{Sm} 31$

Aelianus

Ael. NA 11.31

Aelius Aristides

Aristid. Her. 40.12

Aristid. Or. 21-23

Aristid. Or. 32

Aristid. Or. 33

Aeschines

Aeschin. 1.114

Aeschylus

A. Ch. 94-5

A. Pers. 318

A. Pers. $626-841$

A. $\operatorname{Pr} .442-71$

A. $\operatorname{Pr} \cdot 484-5$

A. Pr. $484-500$
172

142

143

145

143

143

143

143

69

20

74

71

71

123

182

11

A. Pr. 506

172

A. Supp. 685

A. Th. $375-676$

A. Th. passim

$119-128$

Alcaeus

Alc. fr. 142

110

Anthologia Graeca

AP. 6.201

49

AP. 6.276

47

Antipho

Antipho 5.12

123

Apuleius

Apul. Met. 2.28-30 153

Apul. Apol. 26-7

Aristophanes

Ar. Lys. 187-9

122

Aristides Atheniensis

Arist. Ath. Apol. 10.2-3 75

Arist. Ath. Apol. $14.2 \quad 75$

Arist. Ath. Apol. 15.3-8 75

Athenagoras

Athenag. Leg. 24.3-25.1 76

Athenag. Leg. 27.1-2 77

Athenag. Leg. $30.3 \quad 76$

Bacchylides

B. 3.58-62 
Callimachus

Call. Hec. frg. 238-57

147

Call. Hec. frg. 252

148

Carmina Epigraphica Graeca CEG 454

Cicero

Cic. Div. 1.56

154

Cic. Vat. 14

150

Clemens Alexandrinus

Clem. Al. Protr. 58.3

78

Clem. Al. Protr. 115.2

Clem. Al. Strom. 1.21.143

Corp. Herm. 16.2

Defixionum Tabellae

DT 49

61

DT 68

Didache XII apostolorum 2.2

Diegesis

Diodorus Siculus

D.S. 2.52

D.S. $4.51-2$

15

Diogenes Laertius

D.L. Vit. phil. 5.76

D.L. Vit. phil. 8.3

13

Dt 18,10-2

74

Dt 18,11

142

Dt 18,11

145

Dt 18,9-14

154

Eusebius Caesariensis

Eus. Hist. 4.3.2

75

Eus. Contra Hieroc. 2

Ex 22.17

13

74

Firmicus Maternus

Firm. Err. prof. rel. 13.1-2 76

Gn 40.9-19

76

Gn 41.17-32

h. Ap. $247-53$

171

h. Ap. 247-93

171

b. Dia. 19 sq.
Heliodorus

Hld. 6.14.1-5

153

Hld. 6.14.5-6 153

Hld. 15.1-3 153

Hellenistic Epigrams 36 GP

12

Heraclitus

Heraclit. DK 12b F14

11

Herodotus

Hdt. 2.84

184

Hdt. 3.36.1

110

Hdt. 3.50

147

Hdt. 4.13-6

Hdt. 4.95.1

110

Hdt. 5.92

147

Hdt. 6.68

123

Hesiodus

Hes. Th. 60-3

109

Hes. Th. 233-36

111

Iamblichus

Iamb. Myst. 7 4-5

75

Ibycus

Ibyc. frg. 285 PMG

120

Ignatius Antiochenus

Ign. Anth. Ep. ad Eph. $19.3 \quad 75$

Inscriptiones Graecae

$I G$ 4.1.121-2 Est. $1.5 \quad 20$

IG 4.1.121-2 Est. 1.18

IG 4.1.121-2 Est. 2.21

IG 12.8.359 44

IG 14.966

Homero

Il. $1.69-70 \quad 172$

Il. $1.69-72 \quad 108$

Il. 1.74-9 109

Il. $2.846 \quad 180$

Il. 3.447

Il. 9.39 sq. $\quad 180$

Il. 11.830-2 184

Il. 13.630 
Il. 17.73

Il. 17.490

180

Il. 21.112

122

Il. 23.59-101

Od. $1.90-151$

Od. 4

Od. 4.120

Od. 4.183-9

Od. 4.219

Od. 4.219-33

Od. 4.220

Od. 4.220-233

Od. $4.222-6$

Od. $4.227-8$

Od. 4.60 sq.

Od. 6.229-30

Od. 9

Od. 9.9-10

Od. 9.94-7

Od. 9.191-2

Od. 9.203-11

Od. 9.205-211

Od. $9.357-9$

Od. 9.359

Od. $9.361-3$

Od. 10

Od. 10.233-8

Od. $10.237-8$

Od. 10.240

Od. 12

Od. 12.41-4

Od. 19

Od. 19.456sq.

Iohannes Chrysostomus

Iohan. Chrys. Adv. Iud. 8.935100 Iohan. Chrys. Adv. Iud. 8.93599

Iohan. Chrys. Cat. Ilum. 4.6 95

Iohan. Chrys. Hom. in 1Cor. 12,12
Iohan. Chrys. Hom. in Stat. 2.1 96, 98

Iohan. Chrys. Hom. in Stat. 2.1097

Iohan. Chrys. Hom. in Stat. 3.397

Iohan. Chrys. Hom. in Stat. 3.1797

Iohan. Chrys. Hom. in Stat. 7.598

Iohan. Chrys. Hom. in Stat. 1097

Iohan. Chrys. Hom. in Stat. 1397

Iohan. Chrys. Sac. 6.12-3 95

Josephus

J. AJ 3.224-286 145

J. AJ 4.199-301 145

J. $A J 6$

J. AJ 6.327-339 143

J. AJ $6.329 \quad 143,145$

J. AJ 6.331

J. AJ 6.332

J. AJ 6.339

J. AJ 6.340-342 146

Julianus Imperator

Jul. Ep. $60.378 \mathrm{c} \quad 71$

Jul. Or. 136a 71

Justinus

Iustin. Dial. cum Tryph. $7.3 \quad 76$

Iustin. Dial. cum Tryph. $85.3 \quad 76$

Iustin. IApol. $14.1 \quad 74$

Iustin. IIApol. $5.3 \quad 76$

Iustin. IIApol. 6.6

Lycurgus

Lycurg. 20

123

Lucanus

Luc. 5.504-677 150

Luc. 6.413-830 150

Lucianus

Lucianus Pseudol. 30-31 152

Lc. 14,1-6 19

Lv. 19,26 74, 154

Lv. 19,31 74

Lv. 19,31 142, 145 
Lv, 20,6

142,145

Lev. 20,27

142,145

Mc. 7.31-37

19

Mt. 1.20-24

76

Mt. 2.13-14

Mt. 15.29-31

76

19

Minucius Felix

Min. Fel. Oct. 26.8-27.1

Origenes

Origenes Cels. 1.24-5

Origenes Cels. 1.28

Origenes Cels. 1.6

Origenes Cels. 1.68

Origenes Cels. 5.2

Origenes Cels. 5.34

Origenes Cels. 5.37

Origenes Cels. 5.38

Origenes Cels. 5.42

Origenes Cels. 5.45

Origenes Cels. 7.69

Origenes Cels. 8.11

Origenes Cels. 8.20

Origenes Cels. 8.24

Origenes Cels. 8.25-7

Origenes Cels. 8.36

Origenes Cels. 8.37

Origenes Cels. 8.41

Origenes Cels. 8.45

Origenes Cels. 8.47

Origenes Cels. 8.48

Origenes Cels. 8.49

Origenes Cels. 8.58

Origenes Cels. 8.63

Ovidius

Ov. Fast. 3.661-674

Ov. Met. 8.631-724

149

149

Papyri Colonienses

PCol. 1982
Paul. Nol. Carm. 19.98-106

76

Pausanias

Paus. 7.25.10

49

Papyri Graecae Magicae

PGM 1.226-227

73

PGM 4

12

PGM 4.296

136-7

PGM 4.296

137

PGM 4.296-466

136

PGM 4.380

61

PGM 4.395

61

PGM 4.1444-53 72

PGM $4.1456 \quad 62$

PGM 4.1510-20 57

PGM 4.1708-15 73

PGM 4.2565 62

PGM 4.2740-4 63

PGM $4.2939 \quad 58$

PGM 5.447-58 73

PGM $5.486 \quad 72$

PGM 7.985

PGM $7.1025 \quad 62$

PGM $12.306 \quad 62$

PGM $12.307 \quad 63$

PGM $13.237 \quad 63$

PGM 13.618-20 72

PGM 13.633-40 73

PGM $13.847 \quad 62$

PGM $15.19 \quad 61$

PGM 17a 60

PGM 19a 55

PGM $32 \quad 58$

PGM 32a 58

PGM 61.29-30 63

Philochoros

Philoch. FGrH/BNJ 328 F109 12

Philostratos

Philostr. VA 4.16

153

Philostr. VA 2.40 
Pindarus

Pi. P. 4

$11,59,61,65$

Plato

P1. Chrm. $158 \mathrm{~b} \quad 110$

P1. Lg. 9.933a 68

P1. Lg. 9.933a-d 184

P1. Lg. $10.909 \mathrm{~b}$

P1. Plt. 290c-d 175

Pl. R. $412-413$

P1. Smp. 202e 175

P1. Smp. 202-203 92

Plutarchus

Plu. Ant. 58.11

Plu. Cim. $6 \quad 152$

Plu. Thes. $14 \quad 12,148$

Plinius Maior

Plin. Nat. 7.52 .178

152

Plin. Nat. 30.1 .16

152

Plin. Nat. 30.5

152

Plin. Nat. 30.9 13

Plin. Nat. 37. 27

48

Plinius Minor

Plin. Ep. 7.27.1

152

Papyri Oxyrhynchus

POxy. 8.1148

POxy. 8.1149

70

POxy. 9.1213

70

POxy. 11.1382

70

POxy. 12.1484

70

POxy. 31.2592

70

POxy. 43.3094

70

POxy 52.3693

70

POxy. 59.3992

70

POxy 62.4339

70

POxy 66.4540

70

Rufinus Aquileiensis

Ruf. Aquil. Hist. eccl. 2.23

74

Sappho

Sapph. F1 LP $\quad$ 11, 56, 58, 65, 182
Seneca

Sen. Oed. 619-658

151

Sen. Thy. 1-100 151

[Ps.] Sen. Oct 593-646 151

Sl 95,5

80

Supplementum Magicum

$S M 42$ 58

$S M 45.36$

61

SM $45.44 \quad 61$

SM $47.7 \quad 61$

SM $48.7 \quad 61$

SM $49.19 \quad 61$

SM $49.62 \quad 61$

SM $49.77 \quad 61$

Sophron

Sophron Gyn. Fr.4a/4PS-1214 134

Strabo

Str. C589 F16 13

Str. C762 13

Tacitus

Tac. Ann. $2.28 \quad 150$

Tac. Hist. 4.83-4 74

Tatianus

Tatian. Orat. 17.3-4 77

Tatian. Orat. 18.5-6 77

Tatian. Orat. 8.1-9.1 77

Tatian. Orat. 7.4-5 76

Theocritus

Theoc. 2 11, 41, 61-2, 64-5, 124

Theoc. $2.10-15$ 43, 135

Theoc. $2.15 \quad 135$

Theoc. $2.25 \quad 135$

Theoc. 2.30 43, 136

Theoc. $2.45 \quad 136$

Tertullianus

Tert. Barn. ep. $20.1 \quad 75$

Tert. Ad nat. 2.7.14 76

Tert. Ad nat. 2.8.10-17 76 
Tert. Apol. 12.1

Tert. Apol. 22.3

76

Tert. Apol. 22.11

76

Tert. De anim. 46.13-47.1

Tert. De anim. 47.1

78

74

Theophilus Antiochenus

Theoph. Ad Aut. 1.9

Vergilis

Verg. A. 2.764-799

Xenophon

X. An. 2.2.9

122-3 


\section{ÍNDICE DE NOMES PRÓPRIOS}

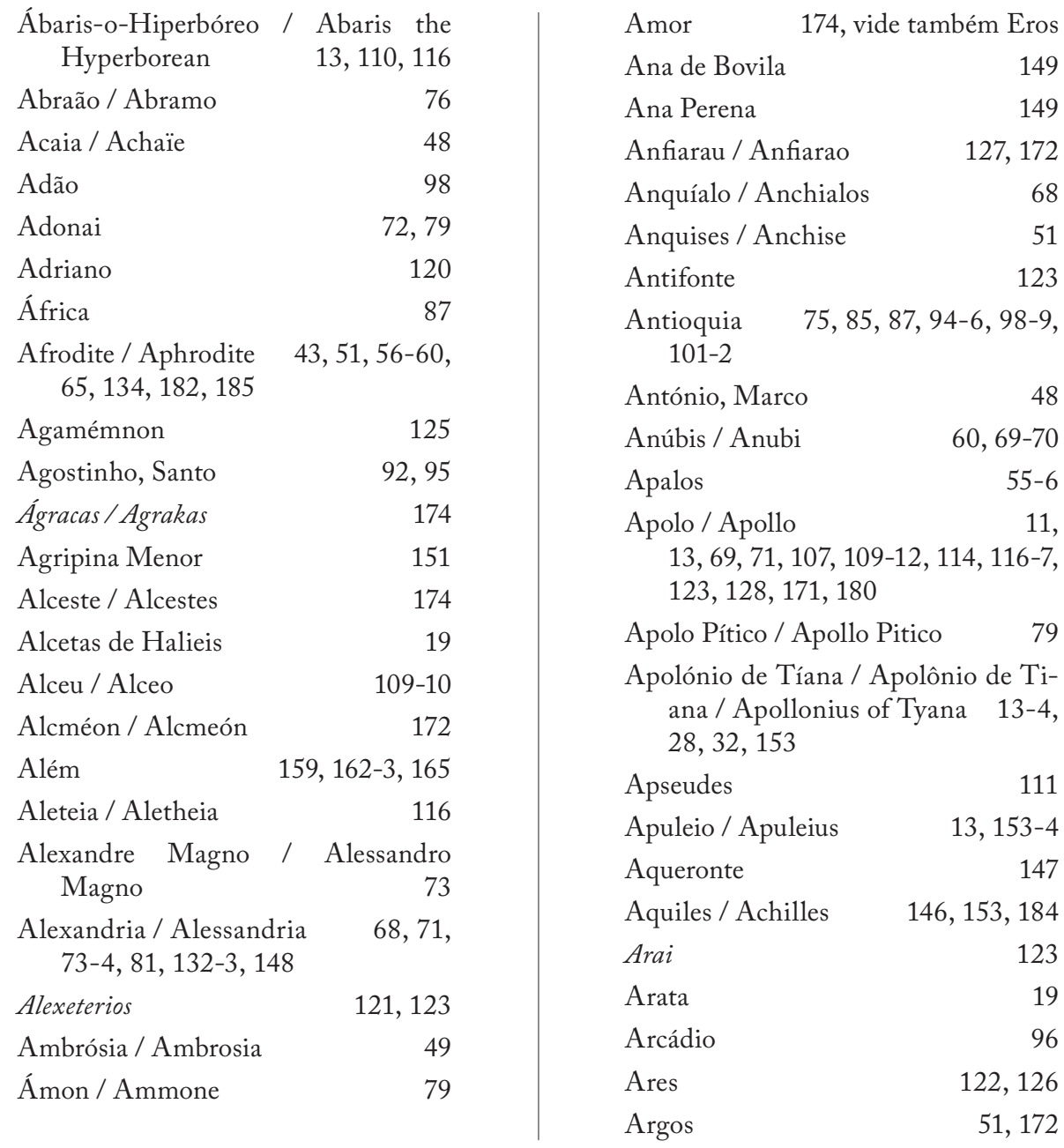


Índice de nomes próprios

$\begin{array}{lr}\text { Ariadne } & 63,136 \\ \text { Arignoto } & 152 \\ \text { Arísteas / Aristeas } & 13,110,116 \\ \text { Aristides } & 20 \\ \text { Aristides-o-Ateniense / } & \text { Aristide di } \\ \quad \text { Atene } & 75 \\ \text { Aristófanes } & 151\end{array}$

26, 29

Artapano

$$
26,29
$$

Ártemis / Artémis / Artemis / Artemisa 15, 41, 43-52, 91, 110 Ártemis Enódia / Artémis Énodia 46 Ártemis Eulóquia / Artémis Eulochia

Ártemis Eupória / Artémis Eupôria 51 Ártemis Limenoscopo / Artémis Liménoskopos $\quad 51$

Ártemis Polo / Artémis Pôlô 43

Ártemis Sodina / Artémis Sôodina 45

Artemísias / Artémisias

Artemision / Artémision 41, 43, 45-6, 48, 50-1

Asclépio / Asclepio 19, 69, 75, 79

Ásia Menor

Astorga 72

Atena / Athena 184

Atena Itónia / Athéna Itonia 46

Atenágoras / Atenagora 76-7

Atenas / Atene 69, 116, 133-4, 137, 152, 172

Ática / Attica

Autólico / Autolycus

Babilónia 155

Baía de Nápoles / Bay of Naples 185

Baquílides 111

Báucis 149

Bíblia / Bible $12-3,146,148$

Bitínia / Bitinia

Boston

British Museum

Bura / Boura 48-9
Buraico / Buraïcus

Calcas / Calcante

108-9

Calcídica / Chalcidique 45

Caldeus / Caldei 75

Calímaco / Callimache / Callimachus $12,50-1,141,147-9$

Calipso / Calypso 42, 135

Cambridge 168

Camiro / Camiros 47, 69

Canopo

Caos

Capaneu 125-6

Capitólio 48

Caracala / Caracalla 71

Cária / Caria 69, 122

Cárias 63

Carmanor-o-Cretense / Karmanor el Cretense 116

Carosa 55-6

Castália / Castalia 109

Celso 77-81

Centauro / Centaur 184

$\mathrm{Ceo} / \mathrm{Ceos}$

Cheol 143-5

Chipre 59,60

Chuném

Cícero 149,154

Ciclopes / Cyclops 11, 179, 181, 186

Cícones / Kikones

Címon 152

Cipriano de Cartago 95

Circe / Kirke 11, 64, 91, 120, 134-6, 174, 179, 182-4, 186

Ciríaco de Ancona / Ciriaco d'Ancona 72

Ciro / Cyrus 122

Ciruelo, Pedro 168

Citeros / Kythera 180

Cítia / Escitia 116, 121

Citno / Kythnos 
Cláudio Eliano

Clazómenas

Clearco / Clearchus

122

Clemente de Alexandria / Clemente Alessandrino 77-8

Cleonice 152

Cleópatra 48

Clitemnestra 125

Cnossos 116

Cocito 128

Comodila / Comodilla 21

Constâncio II 93

Constantino 101

Corinto 147

Cós 132

Creso 112

Creta $69,112,115,117$

Creúsa 134,149

Cristo 75-6, 79-81, 101

Crónida 108

Cúrcio Rufo 152

Dario 147

David 141-2

Dejanira 134, 137

Délfis / Delphis 12, 42, 61-4, 133-7

Delfos 109-11, 123

Delos / Délos / Delo 49, 68-70, 111

Deméter / Démèter

42, 172

Demétrio de Faleros / Demetrio Falereo

Dia

Dice / Dike 111, 115-6, 121, 127

Diktaios

Diodoro da Sicília / Diodore de Sicile / Diodorus Siculus 15,47

Diógenes Laércio / Diogenes Laertius 13

Dionísio Escitobráquion / Dionysius Scytobrachion

Dioniso / Dionysos 107, 110, 117, 185
Diotima

174-6

Dodecaneso / Dodecanneso

69

Édipo

120-1, 127, 151

Éfeso / Éphèse

13,47

Egípcios / Egiziani

75, 153

Egipto / Egito / Egitto / Egypt 11, 73-4, 76, 90, 155, 159, 163, 164, $179,183-4$

Elêutero / Eleuter 108-09

Élio Aristides / Elio Aristide 71, 74

Empédocles / Empedocles 13, 174

En-Dor / Endor 12-3, 141-46, 148-9, 151-2, 154

Eneias

149-50

Enio / Enyo / Enyalios 122

Enódia / Énodia 46

Enódia 46

Epáulia / Épauliè 44

Epeia / Épiè 45

Epígonos 172

Epiménides de Cnosso ou Creta / Epimenides of Cnossus 13, 112, 115-7

Epiro

Ericto 150-1

Erifile / Erifila 172

Erínias

Eros 120, 128, vide também Amor

Escidrótemis / Scidrotemide

74

Esfinge 126-7

Éson

Esparta / Sparta 152, 183, 186

Espírito Santo / Spirito Santo 24, 76, 79, 87

Ésquilo / Esquilo / Eschyle / Aeschylus $11,14,45,111,120,122,125$, $141,147,149,167,172,174,182$

Ésquines 123

Estácio 151

Estobeu / Stobaeus

Estrabão / Strabone / Strabo 13, 69 
Índice de nomes próprios

Estratonice / Stratonica

Harpócrates / Arpocrate

Etéocles / Eteocles 14-5, 119, 121, 123-8

Hebreus

Hécale / Hecale

$12,147-9$

Etéoclo 125

Etiópicas 153

Eufórion

Eulóquia 45

Eunápio / Eunapius

Eupória

Hecalésias

Hecálio

Hécate / Hecate / Ecate 15, 41-8, 50-2, 62-4, 69, 72, 91, 134-6, 172, 174

Hélade

Eurípides

$41,134,174$

Europa

24,171

Eusébio / Eusebius

Falero / Phalerum

Faro

Fedra / Phèdre

42, 137

Feras / Pherai

Festo / Phaistos

Filémon

Filia / Philia

Filisteus

Filócoro

Fílon de Alexandria

Filóstrato / Filostrato / Philostratus $13,32,153$

Flacila

Flaviano

Frígia

Frine / Frineia

Gadira

Galileia

Geia / Gea

Getas / Getae

Graças / Charites

Grécia / Grèce / Grecia 45, 59, 63, 68, 110-1, 154, 168-71, 176

Gregos / Greeks 80, 109-11, 116, 124, $144,147,153-5,171,175,181$

Guilboa

Helena / Helen

$11,182-6$

Hélio / Helios $71,73,124$

Hélio 69-70

Heliodoro 153-4

Hélios Zeus Serápis / Helios Zeus Serapide

Hera / Héra 43,134

Heracleia Pôntica / Eraclea Pontica 72

Heracleia 152

Héracles / Hérakles 48

Heraclito / Heraclitus 11

Heraion / Héraion 48

Hércules / Hercule 19-20, 49

Hermeias 60

Hermes / Hermès / Ermete 50-1, 64, $72,75,170$

Hermíone

Hermotimo de Clazómenas / Hermotimus of Clazomenae

Heródoto / Herodotus 13, 110, 123, 147, 149, 171

Hesíodo 92, 108, 110-1, 169-70, 174, 176

Hiérocles / Hierocles

Hiperbóreo / Hyperborean 13, 110, 114, 116

Hipólito / Hippolyte 41-2

Hipomedonte / Hippomedon 15, 125-6

Hipona

Hades / Hadès / Aides 43, 71, 133, $135,137,144-5,153,170$

Hispânia Tarraconense / Hispania Tarraconensis 
Homero / Homer $\quad 11,92,122,149$, 169-70, 174, 176, 179, 186

Hórus / Horus

$15,160-2,165$

Iao

Íbico 120

Idade Média / Edad Media 169

Ilitia / Eileithyia

Iluminismo / Ilustración 168, 176

Inácio de Antioquia / Ignazio di Antiochia

75

Indianos 153

Infernos / Enfers 43, 150

Inuentio Crucis 101

Iolco / Iolcus 15

Iris / Iris 170

Isaac / Isacco 76

Isidoro

Ísis / Iside $68-70,162$

Ísmaros / Ismaros $179,180,186$

Ísquia / Ischia 185

Israel $19,141-3,145-6$

Ítaca / Ithaca 182,184

Itónia 46

Iulia, gens 150

Jacob / Giacobbe 76

Jasão / Jason $11,59-60,134$

Javé / Iavé / Jahvé $92,120,142-3$

Jesus de Nazaré / Gesù di Nazareth 19, 21-4, 26-9, 32, 75-6, 79-80, 90, 94

João Crisóstomo / John Chrysostom $14,85,87,94-102$

João, São

Jorge da Capadócia / Giorgio di Cappadocia

José [do Egipto] / Giuseppe $\quad 76$

José, São / Giuseppe, san 76

Josefo, Flávio / Josephus, Flavius 12$3,26,29,31,141,143-6,148-55$

Judeus / Giudei 72, 75, 79, 99-100, 102,154
Juliano-o-Apóstata / Giuliano, l'apostata 71

Justiça

Justino / Giustino 26, 76

Justino Mártir / Giustino Martire 74-5

Khepri 164

Labdácidas 128

Lacedónia / Lacedônia 19

Laio $120-1,123,127-8,151$

Lázaro 21

Lebena 69

Lemnos 174

Léptis Magna / Leptis Magna 68-9

Lesbos / Lesbo

Leto / Létô $46,49,51,110$

Levante das Estátuas 96-8

Lex Cornelia de Sicariis et Veneficis 93

Licínio Sura 152

Licomedes / Lycomedeides 47

Licurgo 123

Limenoscopo

Lisístrata / Lysistrata

Lívia 48

Livro dos Mortos 162

Lucano $141,150-1,154$

Luciano de Samósata 25, 152

Málea, cabo / Malea, cape 180

Manes 149

Mar de Mármara 116

Mar Mediterrâneo $32,90,172$

Mar Negro 116

Maratona 147

Marcelino, São

Marcos, São 22,27

Máron / Maron 11, 180-1, 186

Mateus, São

Medeia / Medea 11, 15, 59-60, 64, 91, $134-5,137,174$

Megareu 126 
Índice de nomes próprios

Melampo 172

Melicerta / Melicherta $\quad 72$

Meligenetor $\quad 72$

Melissa 147

Meliúco / Meliouchos 72

Menelau / Menelaos 183

Meras / Moiras 137

Mercúrio / Mercurio $\quad 70$

Messénia / Messene 20

Metanira / Métaneire 42

Micenas 116

Minos 111

Minúcio Félix / Minucio Felice 76-7

Mitilene 109

Mitra / Mithra / Mitras 71-2

Mitreu / Mitreo

Mnemósine / Mnemosyne 108, 115, 120

Mnesarco

Moisés / Mosé $\quad$ 21, 72, 79, 90, 99

Monte Sagrado

Muníquia / Mounychia

Musas / Mousas / Mousai 108, 111, $115,119,120$

Nápoles / Naples 185

Néftis 162

Nemertes 111

Nereu / Nereo 111

Nesso 134

Nestor $\quad 11,182,184-6$

Nino 174

Níobe / Niobè 46

Novo Mundo 87

Numénio / Numenio $\quad 68,71$

Nun 164

Nut 163-4

Oceano / Océano 169

Octávia 151

Odisseu / Odysseus 11, 134, 174, 179, 182, 183-4, 186, vide também
Ulisses / Ulysses

Ogre

11,186

Olimpo

$59,71,109$

Orfeu / Orpheus

13

Orígenes / Origene / Origen 14, 67-8, $71,73-4,77-81$

Osíris 161-3, 165

Ovídio 141,149

Oxirrinco / Ossirinco 70

Pã / Pan 42

Palestina 26

Panemério / Panemerios 69

Papeu / Papeo 79

Páris / Paris 185

Paro / Paros 47,50

Partenopeu 125-6

Pasisseno 68

Pátroclo / Patroklos 146, 184

Paulo, São 100

Pausânias, general 152

Pausânias, periegeta $\quad 48$

Pedro, São 21

Pélias / Pelias 15

Pelópidas 151

Peloponeso 171

Penélope 120

Pentateuco 74

Péon / Paeeon 183

Pérgamo / Pergame 43

Periandro 147

Perimede 64

Persas / Persians 122, 147,174

Perséfone / Persefone / Persephone 64, 91, 172-4, vide também Prosérpina

Pérsia

Persuasão 59-60

Piéria / Pieria 108

Píndaro / Pindar 11, 60-1, 65

Pireu / Pirée 
Pisítrato / Peisitratos

Pitágoras / Pythagoras

13,110

Pítia / Pitia / Pythia / Pitonisa13, 114, 123

Pítico

Píton 116

Platão / Platón / Plato 14, 25, 92 , $110,113,154,167-8,174-6$

Plateias

Plauto 149

Plínio-o-Moço 152

Plínio-o-Velho / Pliny, the Elder 13, 90

Plutão

Plutarco

Polidamna 183-4

Polifemo / Polyphemus

Polinices / Polynices 14, 119, 121-3, 127-8

Polo

Pompeio, Sexto 150

Ponto 73-4, 81, 111

Porfírio 92

Posídon / Poseidon 20

Preto 172

Proconeso / Proconnesus 13

Prometeu / Prometeo 172

Prosérpina / Proserpina 91, vide também Perséfone

Ptolemeu / Tolomeu / Ptolemy 14, 67-8, 73-4, 81

Ptolemeu I Sóter / Tolomeu I Soter 73

Ptolemeu II Filadelfo / Ptolemy II Philadelphus 12,148

Quadrato 75

Quintanila de Somoza / Quintanilla de Somoza

Quíron / Kheiron 184

Reino de Deus 27

Renascimento / Renacimiento 168-9
Roma $21,69,71-2,150,154$

Romanos 154-5

Rufino de Aquileia / Rufino di Aquileia

74

Sabaot / Sabaoth 79

Safo / Sappho $11,56-9,65,182$

Salomão 99

Salvador / Salvatore 79

Samo / Samos 47, 110

Samuel $141-5,148,151,154$

Satanás 92, 95, 98

Saul 141-3, 145-6, 149, 152, 154-5

Selene / Sélénè 15, 43, 64

Séneca 150-1

Septuaginta / Setenta / Septuagint $12,148,151$

Serapeu / Serapeo

Serápis / Serapide / Sarapis 14, 67-74, $76,79,81$

Sereias / Sirens

185, 187

Set

161-3

Sicília 20, 132

Sileno / Silène 50

Sílio Itálico 151

Simeão, São / Simeone, san

Simeta / Simaitha / Simaetha 11-2, $15,42,61-4,131,133-7$

Siracusa / Syracuse 131-4

Síria

Sócrates / Socrates 14, 25-6, 167, 175-6

Sodina 45

Sofia 60

Sófocles 172

Sófron de Siracusa 133-5

Sosípatra de Éfeso / Sosipatra of Ephesus

Sóter 70-3

Sula / Sila

Surião / Surione 70 
Índice de nomes próprios

\begin{tabular}{|c|c|}
\hline Taciano / Taziano & $76-7$ \\
\hline Tácito / Tacito & 73,150 \\
\hline Tântalo & 151 \\
\hline Taso / Thasos & $15,41,43-50$ \\
\hline $\begin{array}{c}\text { Tebas / Thebes } \\
126-8\end{array}$ & $14,119-21,123-4$ \\
\hline Telémaco / Telem & chos \\
\hline \multicolumn{2}{|c|}{ Telfusa } \\
\hline Teló & \\
\hline $\begin{array}{l}\text { Teócrito / Théocr } \\
2,15,42,61,\end{array}$ & $\begin{array}{l}\text { / Theocritus } 11 \\
3,65,124,131-5\end{array}$ \\
\hline
\end{tabular}

Teodora 63

Teodósio 96

Teófilo / Teofilo 74

Teonila 56

Teóris / Theoris 174

Terra 121,123

Terror 122

Tertuliano / Tertulliano 74-8

Teseu / Theseus 12, 63, 136, 147-8

Tesmofórion / Thesmophorion 43

Téspis / Thespis 174

Tessália 150

Téstilis / Thestylis 12, 43, 61-2, 64

Tétis / Tetis 169

Tibério 150

Tideu / Tydeus $15,124-5$

Tiestes 151

Tifeu 126

Tífon / Typhon 15

Tigeró 60

Tirésias 146

Titã / Titán 172

Tomás, São 168

Ton / Thon 183

Tot / Thot 162

Trácia / Tracia / Thrace 13, 116, 180

Trívia

Trofónio / Trophonius
Troia / Troya / Troy 109, 153, 179

Troianos / Trojans 179

Tucídides 171

Tutmés III 164

Ulisses / Ulysse 42, 146, vide também Odisseu / Odysseus

Ursas / Ourses $\quad 51$

Valério Apro / Valerius Aper $\quad 20$

Varrão / Varrón 176

Vatínio 149

Verdade 165

Vergílio / Virgílio $\quad 150$

Vida 165

Weber, Max 176

Xenofonte / Xenophon 122-3

Zalmóxis / Zalmoxis 13, 110

Zatclas 153

Zen 79

Zeus $15,51,69-74,79,108-11,120$, $123-6,148,171,181,183-4$

Zeus Alexeterios

121,123

Zeus Diktaios

115

Zeus Hecálio 148

Zeus Hélio / Zeus Helios 69-70

Zeus Hélio Mitra Serápis / Zeus Helios Mithra Serapide

72

Zeus Hélio Serápis / Zeus Helios Serapide 70

Zeus Iao Adonai 72

Zeus Panemério / Zeus Panemerios

Zeus Protector 121

Zeus Serápis / Zeus Serapide / Zeus Sarapis 70-3

Zeus Sóter Serápis / Zeus Soter Serapide 70, 72

Zoroastro / Zoroaster 13, 90 


\section{Volumes publicados na Coleção Humanitas Supplementum}

1. Francisco Oliveira, Cláudia Teixeira e Paula Barata Dias: Espaços e Paisagens. Antiguidade Clássica e Heranças Contemporâneas. Vol. 1 - Linguas e Literaturas. Grécia e Roma (Coimbra, Classica Digitalia/CECH, 2009).

2. Francisco Oliveira, Cláudia Teixeira e Paula Barata Dias: Espaços e Paisagens. Antiguidade Clássica e Heranças Contemporâneas. Vol. 2 - Linguas e Literaturas. Idade Média. Renascimento. Recep̧̧ão (Coimbra, Classica Digitalia/CECH, 2009).

3. Francisco Oliveira, Jorge de Oliveira e Manuel Patrício: Espaços e Paisagens. Antiguidade Clássica e Heranças Contemporâneas. Vol. 3 - História, Arqueologia e Arte (Coimbra, Classica Digitalia/CECH, 2010).

4. Maria Helena da Rocha Pereira, José Ribeiro Ferreira e Francisco Oliveira (Coords.): Horácio e a sua perenidade (Coimbra, Classica Digitalia/CECH, 2009).

5. José Luís Lopes Brandão: Máscaras dos Césares. Teatro e moralidade nas Vidas suetonianas (Coimbra, Classica Digitalia/CECH, 2009).

6. José Ribeiro Ferreira, Delfim Leão, Manuel Tröster and Paula Barata Dias (eds): Symposion and Philanthropia in Plutarch (Coimbra, Classica Digitalia/ $\mathrm{CECH}, 2009)$.

7. Gabriele Cornelli (Org.): Representaçôes da Cidade Antiga. Categorias históricas e discursos filosóficos (Coimbra, Classica Digitalia/CECH/Grupo Archai, 2010).

8. Maria Cristina de Sousa Pimentel e Nuno Simões Rodrigues (Coords.): Sociedade, poder e cultura no tempo de Ovídio (Coimbra, Classica Digitalia/ $\mathrm{CECH} / \mathrm{CEC} / \mathrm{CH}, 2010)$.

9. Françoise Frazier et Delfim F. Leão (eds.): Tychè et pronoia. La marche du monde selon Plutarque (Coimbra, Classica Digitalia/CECH, École Doctorale 395, ArScAn-THEMAM, 2010).

10. Juan Carlos Iglesias-Zoido, El legado de Tucidides en la cultura occidental (Coimbra, Classica Digitalia/CECH, ARENGA, 2011).

11. Gabriele Cornelli, O pitagorismo como categoria bistoriográfica (Coimbra, Classica Digitalia/CECH, 2011).

12. Frederico Lourenço, The Lyric Metres of Euripidean Drama (Coimbra, Classica Digitalia/CECH, 2011).

13. José Augusto Ramos, Maria Cristina de Sousa Pimentel, Maria do Céu Fialho, Nuno Simões Rodrigues (coords.), Paulo de Tarso: Grego e Romano, Judeu e Cristão (Coimbra, Classica Digitalia/CECH, 2012).

14. Carmen Soares \& Paula Barata Dias (coords.), Contributos para a bistória da alimentação na antiguidade (Coimbra, Classica Digitalia/CECH, 2012).

15. Carlos A. Martins de Jesus, Claudio Castro Filho \& José Ribeiro Ferreira 
(coords.), Hipólito e Fedra - nos caminhos de um mito (Coimbra, Classica Digitalia/CECH, 2012).

16. José Ribeiro Ferreira, Delfim F. Leão, \& Carlos A. Martins de Jesus (eds.): Nomos, Kosmos E Dike in Plutarch (Coimbra, Classica Digitalia/CECH, 2012).

17. José Augusto Ramos \& Nuno Simões Rodrigues (coords.), Mnemosyne kai Sophia (Coimbra, Classica Digitalia/CECH, 2012).

18. Ana Maria Guedes Ferreira, O homem de Estado ateniense em Plutarco: o caso dos Alcmeónidas (Coimbra, Classica Digitalia/CECH, 2012).

19. Aurora López, Andrés Pociña \& Maria de Fátima Silva, De ayer a hoy: influencias clásicas en la literatura (Coimbra, Classica Digitalia/CECH, 2012).

20. Cristina Pimentel, José Luís Brandão \& Paolo Fedeli (coords.), O poeta e a cidade no mundo romano (Coimbra, Classica Digitalia/CECH, 2012).

21. Francisco Oliveira, José Luís Brandão, Vasco Gil Mantas \& Rosa Sanz Serrano (coords.), A queda de Roma e o alvorecer da Europa (Coimbra, Imprensa da Universidade de Coimbra, Classica Digitalia/CECH, 2012).

22. Luísa de Nazaré Ferreira, Mobilidade poética na Grécia antiga: uma leitura da obra de Simónides (Coimbra, Imprensa da Universidade de Coimbra, Classica Digitalia/CECH, 2013).

23. Fábio Cerqueira, Ana Teresa Gonçalves, Edalaura Medeiros \& JoséLuís Brandão, Saberes e poderes no mundo antigo. Vol. I - Dos saberes (Coimbra, Imprensa da Universidade de Coimbra, Classica Digitalia, 2013). 282 p.

24. Fábio Cerqueira, Ana Teresa Gonçalves, Edalaura Medeiros \& Delfim Leão, Saberes e poderes no mundo antigo. Vol. II - Dos poderes (Coimbra, Imprensa da Universidade de Coimbra, Classica Digitalia, 2013). 336 p.

25. Joaquim J. S. Pinheiro, Tempo e espaço da paideia nas Vidas de Plutarco (Coimbra, Imprensa da Universidade de Coimbra, Classica Digitalia, 2013). 458 p.

26. Delfim Leão, Gabriele Cornelli \& Miriam C. Peixoto (coords.), Dos Homens e suas Ideias: Estudos sobre as Vidas de Diógenes Laércio (Coimbra, Imprensa da Universidade de Coimbra, Classica Digitalia, 2013).

27. Italo Pantani, Margarida Miranda \& Henrique Manso (coords.), Aires Barbosa na Cosmópolis Renascentista (Coimbra, Classica Digitalia/CECH, 2013).

28. Francisco Oliveira, Maria de Fátima Silva, Tereza Virgínia Ribeiro Barbosa (coords.), Violência e transgressão: uma trajetória da Humanidade (Coimbra e São Paulo, IUC e Annablume, 2014).

29. Priscilla Gontijo Leite, Ética e retórica forense: asebeia e hybris na caracterização dos adversários em Demóstenes (Coimbra e São Paulo, Imprensa da Universidade de Coimbra e Annablume, 2014).

30. André Carneiro, Lugares, tempos e pessoas. Povoamento rural romano no Alto 
Alentejo. - Volume I (Coimbra, Imprensa da Universidade de Coimbra, Classica Digitalia, 2014).

31. André Carneiro, Lugares, tempos e pessoas. Povoamento rural romano no Alto Alentejo. - Volume II (Coimbra, Imprensa da Universidade de Coimbra, Classica Digitalia, 2014).

32. Pilar Gómez Cardó, Delfim F. Leão, Maria Aparecida de Oliveira Silva (coords.), Plutarco entre mundos: visóes de Esparta, Atenas e Roma (Coimbra e São Paulo, Imprensa da Universidade de Coimbra e Annablume, 2014).

33. Carlos Alcalde Martín, Luísa de Nazaré Ferreira (coords.), O sábio e a imagem. Estudos sobre Plutarco e a arte (Coimbra e São Paulo,Imprensa da Universidade de Coimbra e Annablume, 2014).

34. Ana Iriarte, Luísa de Nazaré Ferreira (coords.), Idades e género na literatura e na arte da Grécia antiga (Coimbra e São Paulo, Imprensa da Universidade de Coimbra e Annablume, 2015).

35. Ana Maria César Pompeu, Francisco Edi de Oliveira Sousa (orgs.), Grécia e Roma no Universo de Augusto (Coimbra e São Paulo, Imprensa da Universidade de Coimbra e Annablume, 2015).

36. Carmen Soares, Francesc Casadesús Bordoy \& Maria do Céu Fialho (coords.), Redes Culturais nos Primórdios da Europa - 2400 Anos da Fundação da Academia de Platão (Coimbra e São Paulo, Imprensa da Universidade de Coimbra e Annablume, 2016).

37. Claudio Castro Filho, "Eu mesma matei meu filho": poéticas do trágico em Eurípides, Goethe e García Lorca (Coimbra e São Paulo, Imprensa da Universidade de Coimbra e Annablume, 2016).

38. Carmen Soares, Maria do Céu Fialho \& Thomas Figueira (coords.), Pólis/ Cosmópolis: Identidades Globais \& Locais (Coimbra e São Paulo, Imprensa da Universidade de Coimbra e Annablume, 2016).

39. Maria de Fátima Sousa e Silva, Maria do Céu Grácio Zambujo Fialho \& José Luís Lopes Brandão (coords.), O Livro do Tempo: Escritas e reescritas. Teatro Greco-Latino e sua recepção I (Coimbra e São Paulo, Imprensa da Universidade de Coimbra e Annablume, 2016).

40. Maria de Fátima Sousa e Silva, Maria do Céu Grácio Zambujo Fialho \& José Luís Lopes Brandão (coords.), O Livro do Tempo: Escritas e reescritas. Teatro Greco-Latino e sua recep̧ão II (Coimbra e São Paulo, Imprensa da Universidade de Coimbra e Annablume, 2016).

41. Gabriele Cornelli, Maria do Céu Fialho \& Delfim Leão (coords.), Cosmópolis: mobilidades culturais às origens do pensamento antigo (Coimbra e São Paulo, Imprensa da Universidade de Coimbra e Annablume, 2016).

42. Nair de Nazaré Castro Soares, Cláudia Teixeira (coords.), Legado clássico no Renascimento e sua recę̧ão: contributos para a renovação do espaço cultural europeu. (Coimbra e São Paulo, Imprensa da Universidade de Coimbra e Annablume, 2016). 
43. Françoise Frazier \& Olivier Guerrier (coords.), Plutarque. Éditions, Traductions, Paratextes (Coimbra e São Paulo, Imprensa da Universidade de Coimbra e Annablume, 2017).

44. Cláudia Teixeira \& André Carneiro (coords.), Arqueologia da transição: entre o mundo romano e a Idade Média. (Coimbra e São Paulo, Imprensa da Universidade de Coimbra e Annablume, 2017).

45. Aldo Rubén Pricco \& Stella Maris Moro (coords.), Pervivencia del mundo clásico en la literatura: tradición y relecturas. (Coimbra e São Paulo, Imprensa da Universidade de Coimbra eAnnablume, 2017).

46. Cláudia Cravo \& Susana Marques (coords.), O Ensino das Linguas Clássicas: reflexóes e experiências didáticas. (Coimbra e São Paulo, Imprensa da Universidade de Coimbra e Annablume, 2017).

47. Breno Battistin Sebastiani, Fracasso e verdade na recep̧ão de Polibio e Tucídides (Coimbra e São Paulo, Imprensa da Universidade de Coimbra e Annablume 2017).

48. Christian Werner, Memórias da Guerra de Troia: a performance do passado épico na Odisseia de Homero. (Coimbra e São Paulo, Imprensa da Universidade de Coimbra e Annablume, 2018).

49. Paola Bellomi, Claudio Castro Filho, Elisa Sartor (eds.), Desplazamientos de la tradición clásica en las culturas hispánicas. (Coimbra e São Paulo, Imprensa da Universidade de Coimbra eAnnablume, 2018).

50. V.M. Ramón Palerm, G. Sopeña Genzor, A.C. Vicente Sánchez (eds.), Irreligiosidad y Literatura en la Atenas Clásica. (Coimbra e São Paulo, Imprensa da Universidade de Coimbra e Annablume, 2018).

51. Luiz César de Sá Júnior, Escrever para não morrer: retórica da imortalidade no epistolário de Damião de Góis. (Coimbra e São Paulo, Imprensa da Universidade de Coimbra e Annablume, 2018).

52. José Luís Brandão \& Paula Barata Dias (coords.), O Melhor é a Água: da Antiguidade Clássica aos Nossos Dias. (Coimbra e São Paulo, Imprensa da Universidade de Coimbra e Annablume, 2018).

53. Tereza Virgínia Ribeiro Barbosa, Matheus Trevizam, Júlia Batista Castilho de Avellar, Tempestades clássicas: dos Antigos à Era dos Descobrimentos. (Coimbra e São Paulo, Imprensa da Universidade de Coimbra e Annablume, 2018).

54. Lorena Jiménez Justicia \& Alberto J. Quiroga Puertas (eds.), Ianus. Innovación docente y reelaboraciones del legado clásico (Coimbra e São Paulo, Imprensa da Universidade de Coimbra e Annablume, 2018). 157 p.

55. Carmen Soares, José Luís Brandão \& Pedro C. Carvalho (coords.), História Antiga: Relaçôes Interdisciplinares. Fontes, Artes, Filosofia, Política, Religião e Receşão (Coimbra, Imprensa da Universidade de Coimbra, 2018). 421 p.

56. Carmen Soares, José Luís Brandão \& Pedro C. Carvalho (coords.), História Antiga: Relaçôes Interdisciplinares. Paisagens Urbanas, Rurais E̋ Sociais (Coimbra, Imprensa da Universidade de Coimbra, 2018). 463 p. 
57. Isabella Tardin Cardoso, Marcos Martinho (eds.), Cícero: obra e recep̧̧ão (Coimbra, Imprensa da Universidade de Coimbra, 2019). 239 p.

58. Delfim Leão, José Augusto Ramos, Nuno Simões Rodrigues (coords.), Arqueologias de Império (Coimbra, Imprensa da Universidade de Coimbra, 2018). $381 \mathrm{p}$.

59. Breno Battistin Sebastiani, Fernando Rodrigues Jr., Bárbara da Costa Silva (coords.), Problemas de Historiografia Helenistica (Coimbra, Imprensa da Universidade de Coimbra, 2019).

60. Dámaris Romero-González, Israel Muñoz-Gallarte, Gabriel Laguna-Mariscal (eds.), Visitors from beyond the Grave: Ghosts in World Literature (Coimbra, Imprensa da Universidade de Coimbra, 2019).

61. Delfim Leão \& Olivier Guerrier (eds.), Figures de sages, figures de philosophes dans l'cuvre de Plutarque (Coimbra, Imprensa da Universidade de Coimbra, 2019).

62. Maria de Fátima Silva, Maria das G. Moraes Augusto \& Maria C. Z. Fialho (eds.), Casas, património, civilização. Nomos versus Physis no pensamento grego (Coimbra, Imprensa da Universidade de Coimbra, 2019). 386 p.

63. A. Carneiro; N. Christie \& P. Diarte-Blasco (eds.), Urban Transformations in the Late Antique West: Materials, Agents, and Models (Coimbra, Imprensa da Universidade de Coimbra, 2020). 380 p.

64. Juan Carlos Iglesias-Zoido (ed.), Conciones ex historicis excerptae. Nuevos estudios sobre las antologias de discursos historiográficos (Coimbra, Imprensa da Universidade de Coimbra, 2020). 254 p.

65. Claudia Beltrão \& Federico Santangelo (coords.), Estátuas na religião romana (Coimbra, Imprensa da Universidade de Coimbra, 2020). 206 p.

66. Fernando Rodrigues Junior, Breno Battistin Sebastiani \& Bárbara da Costa e Silva (coords.), A Poética Calimaquiana e sua Influência na Poesia Epigramática (Coimbra, Imprensa da Universidade de Coimbra, 2021). 226 p.

67. José Ruivo \&Virgílio Hipólito Correia (eds.), Conimbriga Diripitur. Aspetos das ocupações tardias de uma antiga cidade romana (Coimbra, Imprensa da Universidade de Coimbra, 2021). 430 p.

68. Maria do Céu Fialho, Maria Regina Candido, Nuno Simões Rodrigues (Coords.), Magia e Superstição no Mediterrâneo Antigo (Coimbra, Imprensa da Universidade de Coimbra, 2021). 210 p. 
(Página deixada propositadamente em branco) 
Este volume nos permitiu reunir especialistas brasileiros, espanhóis, franceses, gregos, italianos e portugueses que pesquisam sobre Magia e Superstição no Mediterrâneo Antigo. O tema circulou em torno da relação entre magia, religião e superstição em diferentes sociedades antigas e com uma acentuada bibliografia atualizada, que nos leva a refletir sobre a relação entre os homens e os deuses e as suas diferentes manifestações mágico-religiosas. 
OBRA PUBLICADA

COM A COORDENAÇÃO

CIENTÍFICA

ECH $=$

$\begin{array}{lll}1 & 2\end{array}$

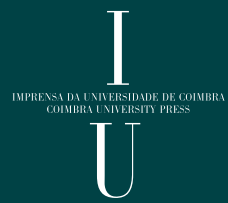

